PROGRAMA DE DOCTORADO EN INGENIERÍA TERMODINÁMICA DE FLUIDOS

TESIS DOCTORAL:

\title{
EXPERIMENTAL DETERMINATION AND MODELING OF PHYSICAL PROPERTIES AND PHASE EQUILIBRIA IN MIXTURES OF CELLULOSE DISSOLVING IONIC LIQUIDS WITH SELECTED CO-SOLVENTS
}

Presentada por Laura de Pablo Nisa para optar al grado de Doctor/a por la Universidad de Valladolid

Dirigida por:

Má Dolores Bermejo Roda 



\title{
UNIVERSIDAD DE VALLADOLID
}

\author{
ESCUELA DE DOCTORADO
}

\section{Secretaría}

La presente tesis doctoral queda registrada en el folio № del correspondiente Libro de Registro con el №

Valladolid, a de de 2018

Fdo. El encargado del Registro 



\section{María Dolores Bermejo Roda}

Investigadora Ramón y Cajal del Departamento de Ingeniería Química

y Tecnología del Medio Ambiente

Universidad de Valladolid

\section{CERTIFICA QUE:}

LAURA DE PABLO NISA ha realizado bajo su dirección el trabajo "EXPERIMENTAL DETERMINATION AND MODELING OF PHYSICAL PROPERTIES AND PHASE EQUILIBRIA IN MIXTURES OF CELLULOSE DISSOLVING IONIC LIQUIDS WITH SELECTED COSOLVENTS", en el Departamento de Ingeniería Química y Tecnología del Medio Ambiente de la Escuela de Ingenierías Industriales de la Universidad de Valladolid. Considerando que dicho trabajo reúne los requisitos para ser presentado como Tesis Doctoral expresan su conformidad con dicha presentación.

Valladolid a de de 2018.

Fdo. María Dolores Bermejo Roda 

Reunido el tribunal que ha juzgado la tesis doctoral "EXPERIMENTAL DETERMINATION AND MODELING OF PHYSICAL PROPERTIES AND PHASE EQUILIBRIA IN MIXTURES OF CELLULOSE DISSOLVING IONIC LIQUIDS WITH SELECTED COSOLVENTS" presentada por Laura de Pablo Nisa y en cumplimiento con lo establecido por el Real Decreto 861/2010 (BOE 28.01.2011) ha acordado conceder por la calificación de

Valladolid, a de de 2018 

A Evilasio y Balbina A Laura y Vane A Jorge

"Las teorías van y vienen, pero los datos fundamentales siempre son los mismos."

Mary Leakey - antropóloga británica 



\section{Abstract, introduction and objectives}

Cellulose is a natural, abundant, renewable and environmental friendly resource from which it is possible to obtain multiple of different substances with a high added value, as sugars, ethanol, lactic acid or aromatics. Increasing the use of cellulose as a raw matter can mean a reduction of the use of fossil fuels. Nevertheless, due to its structure, cellulose is not soluble in water soluble nor in other conventional solvents, therefore it is difficult to process. Thus, finding an environmentally friendly solvent for cellulose is a very important step in order to use this material.

In the last years the interest in ionic liquids as cellulose solvents has increased. The number of articles published in the field of ionic liquids have increased exponentially, see Figure 1, this means that more than 64000 papers were published in the current decade. In addition, more than 70 patents have been published in the biomaterials processing topic since 2005 . ${ }^{1}$ Ionic liquids are composed entirely by ions and they are thermally and chemically stable, with an extremely low vapor pressure, which makes them to be considered as "green" solvents. Its complex structure makes them difficult to crystalize, and therefore, their melting point are extremely low. But maybe their most interested property, they present a high solvation power for organic, inorganic and polymeric substances, among them cellulose and other natural polymers.

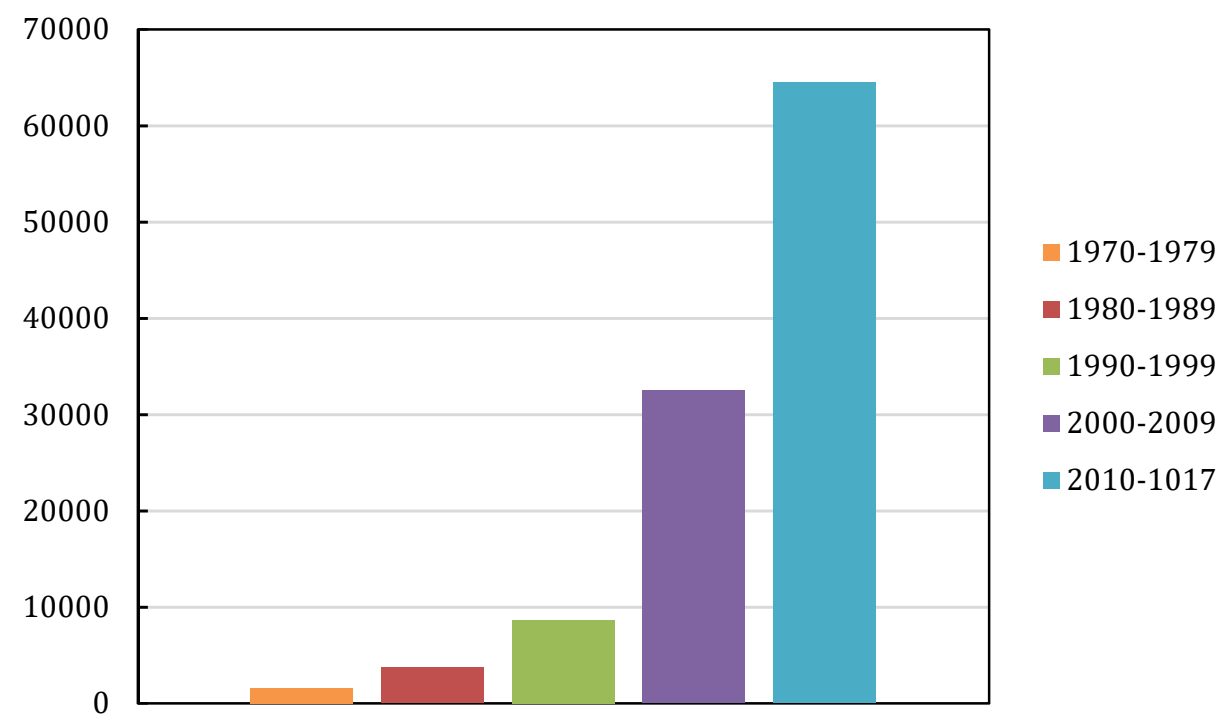

Figure 1. Number of papers published in the topic of ionic liquids. Source: Web of Science. Nevertheless, the ionic liquids present two main challenges to be used as common cellulose solvent, their high viscosity, especially when cellulose is dissolved into them and their high hydroscopicity, (this is a major problem if it is considered that water acts as an antisolvent 
of cellulose dissolved in ionic liquids). The first problem can be solved using co-solvents that allow decrease the viscosity of the mixture, and at the same time do not cause cellulose precipitation, being the most common dimethylsulfoxide (DMSO). The second problem can be solvent by an appropriate handle of the ionic liquids to reduce their water content, nevertheless a completely dry ionic liquid, especially in an environmental environment can be an unrealistic goal.

Among the millions of ionic liquids possible, it has been proved that imidazolium chloride and imidazolium dialkylphosphate based ionic liquids, among others, present a high cellulose solubility. However, the lack of experimental physical properties of these ionic liquids can be a drawback in the development of new processes, included that of cellulose processing. Density, viscosity and equilibrium solubility are fundamental properties used in the industry to design pipes, valves and other equipment, from laboratory scale to the industrial scale.

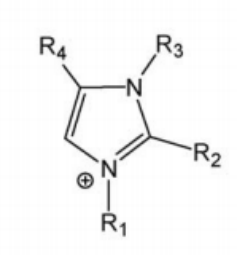

imidazolium

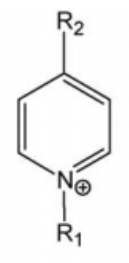

pyridinium

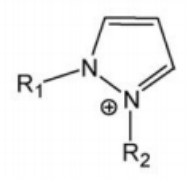

pyrazolium

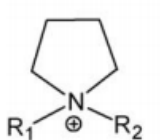

pyrrolidinium

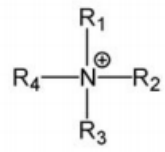

ammonium

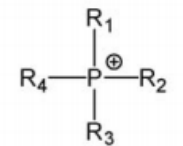

phosphonium

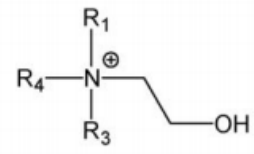

cholinium
$\mathrm{Cl}^{-}, \mathrm{Br}^{*}, \mathrm{I}^{-}$

$\mathrm{Al}_{2} \mathrm{Cl}_{7}^{-}, \mathrm{Al}_{3} \mathrm{Cl}_{10}-$

$\mathrm{Sb}_{2} \mathrm{~F}_{11}{ }^{-}, \mathrm{Fe}_{2} \mathrm{Cl}_{7}^{-}, \mathrm{Zn}_{2} \mathrm{Cl}_{5}^{-}, \mathrm{Zn}_{3} \mathrm{Cl}_{7}^{-}$

$\mathrm{CuCl}_{2}^{-}, \mathrm{SnCl}_{2}{ }^{-}$

$\mathrm{NO}_{3}{ }^{-}, \mathrm{PO}_{4}{ }^{3-}, \mathrm{HSO}_{4}^{-}, \mathrm{SO}_{4}{ }^{2-}$

$\mathrm{CF}_{3} \mathrm{SO}_{3}{ }^{\circ}, \mathrm{ROSO}_{3}{ }^{\circ}, \mathrm{CF}_{3} \mathrm{CO}_{2}{ }^{\circ}, \mathrm{C}_{6} \mathrm{H}_{5} \mathrm{SO}_{3}{ }^{*}$

$\mathrm{PF}_{6}^{-}, \mathrm{SbF}_{6}, \mathrm{BF}_{4}^{-}$,

$\left(\mathrm{CF}_{3} \mathrm{SO}_{2}\right)_{2} \mathrm{~N}^{-}, \mathrm{N}(\mathrm{CN})_{2}{ }^{-},\left(\mathrm{CF}_{3} \mathrm{SO}_{2}\right)_{3} \mathrm{C}^{-}$

$\mathrm{BR}_{4}{ }^{-}, \mathrm{RCB}_{11} \mathrm{H}_{11}$

Figure 2. Main cations and anions of the ionic liquids. ${ }^{2}$

What it is more, as there are at least dozens of possible ionic liquids of each family, many of them never synthetized, measuring all the necessary properties of all of them is an impossible task. In Figure 2 can be seen the most common cations and anions used in the literature. To solve this problem, correlations and specially those based on group contribution methods are promising tools for the prediction of the properties of the mixtures of different ionic liquids with different substances. The ability to predict the behavior of the mixtures can help the scientific to design appropriately a process, which involves these substances.

\section{Objectives}

To help to solve these problems, the objective of this thesis is the thermodynamic characterization (density, viscosity and phase equilibrium) of binary mixtures of cellulose 
dissolving ionic liquids with its most commonly used substances presented in cellulose processing (DMSO, water) and the modelization of these properties as well as their phase behavior. As representative ionic liquids for this study a member of the imidazolium chloride, and a member of the imidazolium alkylphosphate ionic liquids were selected, in particular 1-allyl-3-methylimidazolium chloride [Amim][Cl] and 1-ethyl-3methylimidazolium diethylphosphate $\left[\right.$ EtMeIm] $\left[\mathrm{Et}_{2} \mathrm{PO}_{4}\right]$. As co-solvents DMSO was selected as the more representative co-solvent and water since it is always present in working with ionic liquids, especially is this work involves manipulating natural substances as cellulose. Also, $\mathrm{CO}_{2}$ was proposed as novel co-solvent. It can dissolve in high amounts in ionic liquids decreasing both viscosity and melting point, it is not an anti-solvent for cellulose, at least in the ILs selected for this work, it is easy to separate from ILs by simply decreasing the pressure and in addition is a cheap, abundant solvent without environmental limitations.

In order to achieve this objective, the main goals are as follow.

1 Experimental determination and correlation of densities and viscosities of [Amim] [Cl] and $[$ EtMeIm] $]\left[\mathrm{Et}_{2} \mathrm{PO}_{4}\right]$ with co-solvents as water and DMSO.

2 To adapt the Group Contribution Equation of State to perform equilibrium calculation with ionic liquids of the family imidazolium alkylphosphates.

3 Determination of equilibrium of $\mathrm{CO}_{2}+\left[\right.$ EtMeIm] $\left[\mathrm{Et}_{2} \mathrm{PO}_{4}\right]$ at different temperatures.

\section{Summary and organization of the work}

This work is divided into 3 parts.

In the first part a brief literature state of the art is presented (Chapter 1) regarding the most recent advances in the field of IL as solvents for cellulose.

In part II, the realization of objective 1 , density and viscosity of determination and correlation is presented. It comprises 3 chapters:

- Chapter 2, where the measurement of density and viscosity of mixtures of $[\mathrm{Amim}][\mathrm{Cl}]+\mathrm{DMSO}$ at atmospheric pressure is performed

- Chapter 3, where the determination of density of mixtures of [Amim][Cl] + DMSO at pressures up to $35 \mathrm{MPa}$ is presented

- Chapter 4, where the measurement of density and viscosity of [EtMeIm] $\left[\mathrm{Et}_{2} \mathrm{PO}_{4}\right]+$ $\mathrm{H}_{2} \mathrm{O}$ / DMSO at atmospheric pressure is shown

In the third part, comprised by chapter 5 and 6 , the second and third objective of this thesis is achieved regarding the equilibrium between IL's and selected compounds 
- In Chapter 5 parameterization of two new groups for the group contribution equation of state of Skold Jorgensen as well as the parameterization of the binary parameters with the main and most common groups, accomplishing in this way objective 2 .

- In Chapter 6, data of chemical equilibrium, in particular, the solubility of $\mathrm{CO}_{2}$ in the ionic liquid $\mathrm{CO}_{2}+\left[\right.$ EtMeIm] $\left[\mathrm{Et}_{2} \mathrm{PO}_{4}\right]$ at high pressure and different temperatures was presented, and experimental data along with literature data is correlated with the group contribution equation of state according to objective 2 and 3.

The experimental work of this thesis was performed in the premises of the research group TERMOCAL, a metrological and calibration laboratory, and High Pressure Processes Group (HPP) both in the University of Valladolid, in the frame of the project VA295U14 “Determinación de Propiedades Termofísicas y Equilibrio de Mezclas $\mathrm{CO}_{2}+$ Líquido Iónico para el Desarrollo de Nuevas Tecnologías Limpias de Procesado de Biomasa con Fines Energéticos", funded by the Junta de Castilla y León. TERMOCAL laboratory is a specialist in the measurement of fundamental physical properties such as density, viscosity and binary equilibrium.

The modeling with GC-EoS was performed under the supervision of Dr. Selva Pereda in PLAPIQUI, Universidad Nacional del Sur-CONICET. The stay in this institution was funded through the Erasmus Mundus Eurica PhD student grant. 


\section{Contents}

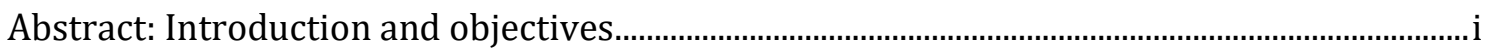

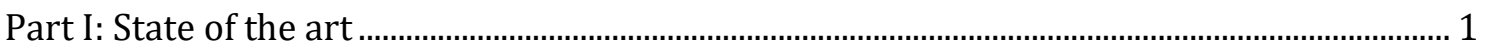

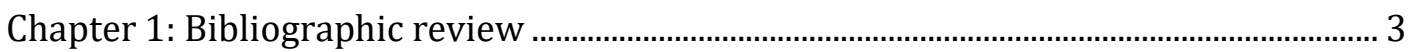

Part II: Density and viscosity measurements............................................................................. 15

Chapter 2: Determination of density, viscosity and vapor pressures of mixtures of dimethyl sulfoxide + 1-allyl-3-methylimidazolium chloride at atmospheric pressure .17

Chapter 3: Determination of density and excess molar volume of dimethyl sulfoxide + 1-allyl-3-methylimidazolium chloride mixtures at high pressure 45

Chapter 4: Determination of density and viscosity of binary mixtures of water and dimethylsulfoxide with 1-ethyl-3-methylimidazolium diethylphosphate

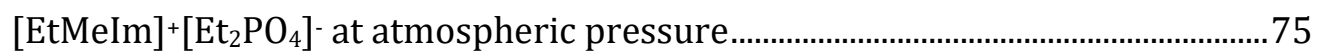

Part III: Phase equilibrium of selected cellulose dissolving Ionic Liquids. 103

Chapter 5: GC-EoS extension to model phosphate imidazolium ionic liquids . 105

Chapter 6: Determination of the solubility of $\mathrm{CO}_{2}$ in selected cellulose dissolving ILs at high pressure and modeling with the GC-EoS. 123

Conclusions 145

Resumen 149

About the author 167 



\section{Part I: State of the art}





\section{Chapter 1: Bibliographic review}





\section{Introduction}

Lignocellulose is the most abundant biomaterial in the Earth. It can be found in the vegetable cell walls. It is composed by cellulose (35-50\%), hemicellulose (20-35\%) and lignin (5-25\%). The mayor difficulty of the cost-effective use of the lignocellulose is the lack of technology developed for its conversion in biofuels or high-value chemicals. ${ }^{1}$ In 1934, it was discovered that it was possible to dissolve cellulose in some molten organic salts. ${ }^{2}$ In 2002, it was discovered that some ionic liquids can dissolve cellulose. ${ }^{2}$ This provides new opportunities for the processing cellulose and other biopolymers as lignin ${ }^{3}$ or chitin. ${ }^{4}$

Dissolution of cellulose with ionic liquids can be industrially attractive for many reasons: 1

- Good solubility (5-20\% in mass) depending on the ionic liquid and the conditions

- Good properties in the cellulose recovering

- Low toxicities

- Good stability of the cellulose-ionic liquid mixtures.

The mayor issue for the solubilization of cellulose is the inter- and intra- hydrogen bonding between the cellulose chains. These bonds help the formation of crystalline organized networks which gives protection against hydrolysis. For the production of glucose from cellulose it is necessary to apply a hydrolysis process using acids or enzymes to break these bonds into glucose molecules. Usually, acid hydrolysis of cellulose is performed with excess of acid. ${ }^{5}$ All the solutions able to dissolve cellulose have in common a high polarity.

The best ionic liquids to dissolve cellulose are the ones able to break the hydrogen bonds present in the cellulose, such as those with chloride, carboxilates (acetate, formate, propionate, lactate), dialkylphosphates, dialkyl- and trialkylphosphonates and amino acids anions. All these ionic liquids form strong interactions with the hydrogen bond of the cellulose molecules and have a high hydrogen bond basicity. The substances with high hydrogen bond (HB) basicity (ability to form hydrogen bonds) weaken the inter- and intramolecular hydrogen bonds of the cellulose that leads into its dissolution. The empirical Kamlet-Taft model is one of the most frequent used for the prediction of the cellulose solubility in IL. ${ }^{1}$ The HB basicity can be quantified with three parameters following the Kamlet-Taft model: hydrogen-bonding acidity $(\alpha)$, hydrogen-bonding basicity $(\beta)$ and dipolarity/polarizability $\left(\pi^{*}\right)$. These parameters are measured by the UV- 
Vis spectra of dyes in the IL. The HB basicity is mainly dependent on the anion and a high value $(\beta>0.8)$ is necessary in order to dissolve cellulose and weak the hydrogen bonding of the cellulose chains. It has been suggested than the difference between the $\alpha$ and $\beta$ can also be used to determine if a IL will be able to dissolve cellulose or not 1

However, there are some exceptions, $[\mathrm{BuMeIm}]+\left[\mathrm{MeSO}_{4}\right]-$ and $[\mathrm{BuMeIm}]+\left[\mathrm{Me}_{2} \mathrm{PO}_{3} \mathrm{Se}\right]-$ have a comparable $\beta$ to other cellulose dissolving IL but they do not dissolve cellulose. This indicates that there are other effects that determine cellulose solubility such as the anion size and geometry. In addition, it has been reported that high values of $\beta$ are related to a low IL stability. ${ }^{1}$

The cations also play a role in the dissolution of cellulose, and the best are: alkylmethylimidazolium, alkyl-methylpyridine with allyl, ethyl or butyl side chains. The alkyl chains with an even carbon number works better and double bounds reduces the viscosity. ${ }^{6}$

The dissolved cellulose can be modified or regenerated (adding water, acetone, ethanol... etc). The regenerated cellulose is essentially amorphous and porous and it is more susceptible to chemical or enzymatic process degradation 5,7,8 which can lead to the production of sugars effectively.

The conversion of cellulose into glucose and therefore, bioethanol or 5hydroxymethylfurfural, which is a high-value compound, can lead a significant change in the carbon dioxide emissions and reduce the greenhouse effect. ${ }^{7}$

The ionic liquid can be a suitable media for hydrogenations, hydroformilations, isomerizations, dimerizations, etc. In general, they are an excellent media for biocatalyzed reactions, particularly for the homogeneous catalyzed reactions, which can reach a higher selectivity. In this type of reaction, the separation of the products would be easy due to the negligible vapor pressure of the IL. The ability to dissolve many compounds polar and no polar made them a potential reaction media for traditionally multi-phase reactions (and therefore, mass-transfer limited). ${ }^{9}$

In order to design a process involving ionic liquids on industrial scale it is necessary to determine accurately a wide range of physical properties including density, viscosity, heat capacity, phase equilibria, etc. ${ }^{10}$

Despite the numerous articles published in the last years, additional data is required to fully understand the properties and possible applications of the IL, and to increase and optimize the actual processes involving these substances. Because their relatively new 
discovery there is a lack of experimental data for example phase behavior, solubility, heat capacities, viscosities, densities, thermal conductivity and electrical conductivity.

The present challenges for the ionic liquids come though the cost, lack of physical properties and corrosion and toxicity test. To be competitive, ionic liquid needs to reduce its cost per gram dramatically. ${ }^{9}$ The mayor barrier for the adopting of IL in the process is the cost of the IL per se, because the capital equipment of the technology is the same as used in other processes.

The properties of mixtures cellulose and ionic liquid have been studied in the literature. Gericke et al. ${ }^{11}$ studied the rheological properties of cellulose/ionic liquid mixtures and concluded that viscosity increases with cellulose concentration and molecular weight of the biopolymer. A higher viscosity of these mixtures are attributed to the stronger interactions between the anion, the cation and the cellulose. Sescousse et al. ${ }^{12}$ studied the variation of the viscosity in ionic liquid mixtures as a function of polymer concentration and temperature and found two regions, a "dilute" one when the concentration of cellulose is lower than $2 \%$ in mass and the viscosity has a linear dependence on the cellulose concentration, and a "semidilute" region where applies an exponential tendency.

\subsection{Chlorides}

The imidazolium chloride ionic liquids are the one of the most powerful solvents for cellulose. The small size of the chloride ion and its strong electronegativity makes them excellent solvents for cellulose. However, this group have some drawbacks, like the high melting points (between $399.4 \mathrm{~K}$ and $325.1 \mathrm{~K}$ ), high viscosity and high hygroscopicity. IL with big alkyl chains (5-10 carbons) suffer for metastable states below its melting point and present a high viscosity. ${ }^{5}$ In general, an increase in the number of carbon in the side chain result in a decrease in the viscosity of the IL, but side chains larger than 7 carbons results in an increase in the viscosity due to the attractive van der Waals interactions start outweighing the symmetry effect. 13 The IL [Amim][Cl]. has a very low glass-transition temperature compared to the rest of imidazolium chloride based ILs due to the allyl group, which have demonstrated to decrease the viscosity in the ILs when is situated in the side chain in the cation. ${ }^{5}$ This IL has a great cellulose solubility with imidazolium-based core, being able to dissolve up to $25 \%(\mathrm{w} / \mathrm{w}) .{ }^{14}$

To decrease the melting point of this family some studies has been published, Lopes et al. was able to decrease the melting points, specifically [Amim] [Cl] was the more influenced of the presence of $\mathrm{CO}_{2}$ between the imidazolium based IL studied. ${ }^{15}$ The hydrogen bond basicity is not the only parameter that can determine the cellulose solubility since 
viscosity can also affect negatively the velocity and temperature of solubilization. ${ }^{5}$ In Table 1 can be observed some of the most common imidazolium chloride ionic liquids used in the literature.

Table 1. Some of the most common imidazolium chloride ionic liquids

\begin{tabular}{|c|c|c|}
\hline Structure & Name & Abbreviation \\
\hline$\left\langle{ }_{\mathrm{CH}_{3}}^{N^{+} \mathrm{CH}_{3}} \mathrm{Cl}^{-}\right.$ & $\begin{array}{l}\text { 1-Ethyl-3- } \\
\text { methylimidazolium } \\
\text { chloride }\end{array}$ & {$[$ EtMeIm] $[\mathrm{Cl}]$} \\
\hline $\mathrm{CH}_{3}$ & $\begin{array}{l}\text { 1-Butyl-3- } \\
\text { methylimidazolium } \\
\text { chloride }\end{array}$ & {$[$ BuMeIm] $][\mathrm{Cl}]$} \\
\hline${ }_{=\mathrm{CH}_{2}}^{\mathrm{CH}_{3}} \mathrm{Cl}^{-}$ & $\begin{array}{l}\text { 1-Allyl-3- } \\
\text { methylimidazolium } \\
\text { chloride }\end{array}$ & $\begin{array}{l}{[\text { AllMeIm }][\mathrm{Cl}] \text { or }} \\
{[\text { Amim }][\mathrm{Cl}]}\end{array}$ \\
\hline $\begin{array}{ll}\mathrm{CH}_{3} \\
\mathrm{CH}_{\mathrm{N}}^{\mathrm{N}^{+}} \mathrm{Cl}^{-} \\
\mathrm{C}^{\prime} \mathrm{CH}_{2}\left(\mathrm{CH}_{2}\right)_{4} \mathrm{CH}_{3}\end{array}$ & $\begin{array}{l}\text { 1-Hexyl-3- } \\
\text { methylimidazolium } \\
\text { chloride }\end{array}$ & {$[\mathrm{HeMeIm}][\mathrm{Cl}]$} \\
\hline 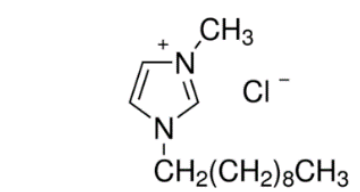 & $\begin{array}{l}\text { 1-Decyl-3- } \\
\text { methylimidazolium } \\
\text { chloride }\end{array}$ & {$[\mathrm{DeMeIm}][\mathrm{Cl}]$} \\
\hline
\end{tabular}

The chloride anions are determining for the success of this family in the cellulose dissolution. Chloride can eliminate the inter- and intramolecular hydrogen bonds among the cellulose, and the formation of hydrogen bonds between the anions of the IL and the hydroxyl groups of the cellulose.

The presence of impurities of chlorine (common in this family) affect negatively the viscosity. ${ }^{16}$ 


\subsection{Di-alkylphosphates}

Ionic liquids based on imidazolium dialkylphosphate have better cellulose dissolution properties than the pyrrolidinium dialkylphosphate ionic liquid, 17 and a good thermal stability and low viscosity. This can be a halogen-free alternative solvent for the dissolution of cellulose. Also, they are effective dissolving cellulose at lower temperatures than the chloride salts, however they have a lower thermal stability. ${ }^{5}$ In Table 2 are presented some of the most common imidazolium dialkylphosphates ionic liquids used in the literature.

Table 2. Some of the most common imidazolium dialkylphosphate ionic liquids.

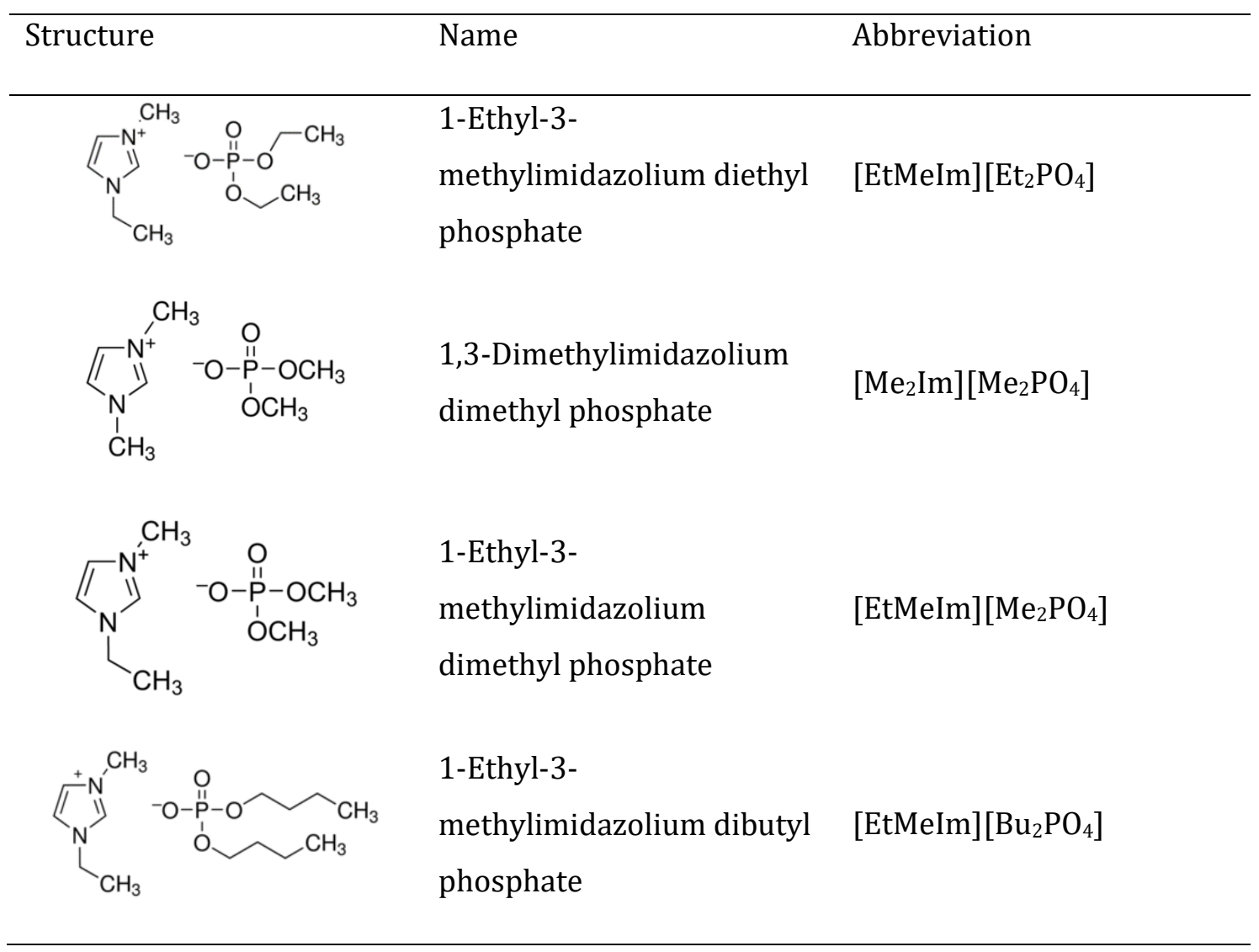

This family of IL has been object of several researches to measure the cellulose dissolution properties and other fundamental physical properties as density, viscosity, equilibrium, etc. Vitz et al. studied the dissolution properties of some of IL from this family and concluded that $[\mathrm{EtMeIm}]\left[\mathrm{Et}_{2} \mathrm{PO}_{4}\right]$ is the most suitable for cellulose dissolution because a very low degradation of the dissolved cellulose was observed. In addition, lower melting points and lower hydroscopicity was also observed in comparison with other IL with chloride od acetate counter anion. 18 


\subsection{Use of co-solvents and anti-solvents}

Due to the high viscosity of the IL efforts have been made to find suitable co-solvents for the cellulose - IL's mixtures. For example, an addition of a small amount of DMSO in the mixtures were found to decrease the viscosity with no noticeable effects in the cellulose solubility. However, an excess of the co-solvent ratio can make a precipitation irreversible. ${ }^{19}$ DMSO lacks the ability to act as hydrogen bonding acceptor so the IL' anion preserve the ability to coordinate with the hydroxyl groups of the cellulose. ${ }^{20}$ the reduction of the viscosity can lead in a reduction of the dissolution time and therefore reduce process cost. ${ }^{21}$ Other substances has been reported to decrease the viscosity of cellulose/IL's solutions as $\mathrm{N}, \mathrm{N}$-dimethylacetamide (DMA) or N, N-dimethylformamide (DMF) ${ }^{22}$ or pyridine. ${ }^{23}$

Also, it has been studied the effect of other substances in the IL's, and their possible application as anti-solvent. For example, the solubility of cellulose decreases with the presence of other compounds able to compete in forming hydrogen bonds with the ionic liquids. This is the reason why the precipitation takes place when other dipolar solvents as water, ethanol or acetone are present in the mixture. These compounds behavior like an anti-solvent. 6,8,14 It is believed that water interacts with the anion forming strong hydrogen bonds that compete with the cellulose hydroxyl groups and prevent the anion interact with cellulose. ${ }^{1}$ Other possible reason is that the competitive hydrogen bonding is formed in the cellulose with the same result. ${ }^{14}$ When water is added to the solution at approximately 0.5 in mole fraction ( $1 \%$ in mass) the cellulose becomes insoluble in the IL. 14 Water can come from the air or from the biomass. ${ }^{1}$ Swatloski et al. ${ }^{14}$ studied the morphology of the regenerated cellulose and concluded that it can vary depending on the how the contact between the IL solution and the anti-solvent is performed. The morphologies these authors achieved were powder, monoliths, fibers, rods and films, which can be extremely useful for industry purposes.

\section{Ionic liquids and carbon dioxide}

The ionic liquids have a higher solubility of carbon dioxide than the conventional solvents. The $\mathrm{CO}_{2}$ is absorbed and fill the empty places between the molecules. The anions and cations reorganize to leave some room to the $\mathrm{CO}_{2}$ molecules and form relatively rigid networks. ${ }^{7}$

Therefore, the solubilization of carbon dioxide produces a big negative excess volume. The solubility of carbon dioxide depends on the cation and the anion, being the anion the one most influent. 7 The carbon atom of the $\mathrm{CO}_{2}$ has a significant positive charge, which interacts preferably with the negative charge atoms of the anion. ${ }^{24}$ The free volume and 
the intermolecular and intramolecular interactions are determining for the $\mathrm{CO}_{2}$ solubility in the ionic liquids. ${ }^{24}$

The supercritical $\mathrm{CO}_{2}$ is soluble in ionic liquid, however, the ionic liquid is not soluble in supercritical $\mathrm{CO}_{2}$. This means that it is possible to use the $\mathrm{CO}_{2}$ to remove completely solvents or other reaction products from the ionic liquids. ${ }^{25}$ In general, $\mathrm{CO}_{2}$ cannot be used as an antisolvent because the volume of the ionic liquids does not change with the addition of $\mathrm{CO}_{2}$, even at high concentrations of $\mathrm{CO}_{2}$, and this change in the volume is directly related with the solvent strength of the mixture $\mathrm{IL}+\mathrm{CO}_{2}$. This can be explained due to the strong electrostatic interactions between the anion and the cation. ${ }^{24}$ However, $\mathrm{CO}_{2}$ have demonstrated to act as an antisolvent to recover inorganic salts in organic / IL mixtures. ${ }^{26}$ Acetate based IL react with $\mathrm{CO}_{2}$ forming zwitterionic imidazolium carboxylate that sequesters the acetate anions from the system IL-biopolymer and results in a precipitation of the last, so $\mathrm{CO}_{2}$ can also act as an antisolvent for dissolved chitin or cellulose in determined IL's. ${ }^{27-29}$

Other important application of the dissolution of the carbon dioxide is the reduction of the viscosity and melting points of the ionic liquid. ${ }^{30,31}$ This can be very useful for reducing the viscosity of cellulose - ionic liquid mixtures, as for example, the acetylation reaction of cellulose in $[\mathrm{Amim}][\mathrm{Cl}]$, the cellulose acetate was faster and the quality of the product was higher due to the presence of $\mathrm{sc}-\mathrm{CO}_{2}$ and the consequent viscosity reduction. ${ }^{32}$ 


\section{References}

(1) Brandt, A.; Gräsvik, J.; Halletta, J. P.; Welton, T. Green Chem. 2013, 15, 550-583.

(2) Tim Liebert. Cellulose Solvents: For Analysis, Shaping and Chemical Modification; 2010; Vol. 1033.

(3) Mukherjee, A.; Mandal, T.; Ganguly, A.; Chatterjee, P. K. ChemBioEng Rev. 2016, 3 (2), 86-96.

(4) Jaworska, M. M.; Gorak, A. Mater. Lett. 2016, 164, 341-343.

(5) Ohno, H.; Fukaya, Y. Chem. Lett. 2009, 38 (1), 2-7.

(6) Jimenez de la Parra, C.; Navarrete, A.; Bermejo, M. D.; Cocero, M. J. Recent Pat. Eng 2012, 6 (3), 159-182.

(7) Zhang, Y.; Chan, J. Y. G. Energy Environ. Sci. 2010, 3 (4), 408-417.

(8) Zhu, S.; Wu, Y.; Chen, Q.; Yu, Z.; Wang, C.; Jin, S.; Ding, Y.; Wu, G. Green Chem. 2006, 8 (4), 325.

(9) Brennecke, J. F.; Maginn, E. J. AIChE J. 2001, 47 (11), 2384-2389.

(10) Domańska, U.; Mazurowska, L. Fluid Phase Equilib. 2004, 221 (1-2), 73-82.

(11) Gericke, M.; Schlufter, K.; Liebert, T.; Heinze, T.; Budtova, T. Biomacromolecules 2009, 10 (Mc), 1188-1194.

(12) Sescousse, R.; Le, K. A.; Ries, M. E.; Budtova, T. J. Phys. Chem. B 2010, 114 (21), 72227228.

(13) Pinkert, A.; Marsh, K. N.; Pang, S.; Staiger, M. P. Chem. Rev. 2009, 109 (12), 67126728.

(14) Swatloski, R. P.; Spear, S. K.; Holbrey, J. D.; Rogers, R. D. J. Am. Chem. Soc. 2002, 124, 4974-4975.

(15) Lopes, J. M.; Sánchez, F. A.; Reartes, S. B. R.; Bermejo, M. D.; Martín, Á.; Cocero, M. J. J. Supercrit. Fluids 2016, 107, 590-604.

(16) Seddon, K. R.; Stark, A.; Torres, M.-J. Pure Appl. Chem. 2000, 72 (12), 2275-2287.

(17) Lall-Ramnarine, S. I.; Thomas, M. F.; Jalees, M.; Payen, F.; Boursiquot, S.; Ramati, S.; Ewko, D.; Zmich, N. V.; Wishart, J. F. Phosphorus, Sulfur Silicon Relat. Elem. 2015, 190 (5-6), 891-895. 
(18) Vitz, J.; Erdmenger, T.; Haensch, C.; Schubert, U. S. Green Chem. 2009, 11 (3), 417.

(19) Fort, D. a.; Remsing, R. C.; Swatloski, R. P.; Moyna, P.; Moyna, G.; Rogers, R. D. Green Chem. 2007, 9 (1), 63.

(20) Gericke, M.; Liebert, T.; Seoud, O. A. El; Heinze, T. Macromol. Mater. Eng. 2011, 296 (6), 483-493.

(21) Andanson, J.-M.; Bordes, E.; Devémy, J.; Leroux, F.; Pádua, A. a. H.; Gomes, M. F. C. Green Chem. 2014, 16 (5), 2528.

(22) Gale, E.; Wirawan, R. H.; Silveira, R. L.; Pereira, C. S.; Johns, M. A.; Skaf, M. S.; Scott, J. L. ACS Sustain. Chem. Eng. 2016, 4 (11), 6200-6207.

(23) Evlampieva, N. P.; Vitz, J.; Schubert, U. S.; Ryumtsev, E. I. Russ. J. Appl. Chem. 2009, 82 (4), 666-672.

(24) Mejía, I.; Stanley, K.; Canales, R.; Brennecke, J. F. J. Chem. Eng. Data 2013, 58 (9), 2642-2653.

(25) Blanchard, L. A.; Brennecke, J. F. Ind. Eng. Chem. Res. 2001, 40 (1), 287-292.

(26) Saurer, E. M.; Aki, S. N. V. K.; Brennecke, J. F. Green Chem. 2006, 8 (2), 141.

(27) Barber, P. S.; Griggs, C. S.; Gurau, G.; Liu, Z.; Li, S.; Li, Z.; Lu, X.; Zhang, S.; Rogers, R. D. Angew. Chemie Int. Ed. 2013, 52 (47), 12350-12353.

(28) Liu, Z.; Sun, X.; Hao, M.; Huang, C.; Xue, Z.; Mu, T. Carbohydr. Polym. 2015, 117, 5462.

(29) Gurau, G.; Rodríguez, H.; Kelley, S. P.; Janiczek, P.; Kalb, R. S.; Rogers, R. D. Angew. Chemie - Int. Ed. 2011, 50 (50), 12024-12026.

(30) Tomida, D.; Kenmochi, S.; Qiao, K.; Bao, Q.; Yokoyama, C. Fluid Phase Equilib. 2011, 307 (2), 185-189.

(31) Ahosseini, A.; Ortega, E.; Sensenich, B.; Scurto, A. M. Fluid Phase Equilib. 2009, 286 (1), 72-78.

(32) Lopes, J. M.; Bermejo, M. D.; Pérez, E.; Martín, Á.; Segovia Puras, J. J.; Cocero, M. J. J. Supercrit. Fluids 2017, No. September, 1-7. 


\section{Part II: Density and viscosity}

measurements 


\title{
Chapter 2: Determination of density, viscosity and vapor pressures of mixtures of dimethyl sulfoxide +1 - allyl-3-methylimidazolium chloride at atmospheric pressure
}

\begin{abstract}
In this work, densities, viscosities and vapor pressures of dimethyl sulfoxide (DMSO) + 1allyl-3-methylimidazolium chloride $(\mathrm{AmimCl})$ mixtures have been experimentally determined. Densities and viscosities were measured at temperatures $\mathrm{T}=[293.15,373.15]$ $\mathrm{K}$ and molar fractions of dimethyl sulfoxide $\mathrm{X}_{\mathrm{DMSO}}=0,0.05,0.1,0.15,0.25,0.5,0.75,0.9$ and 1 at atmospheric pressure with a Stabinger densimeter-viscosimeter. Viscosities and densities were found to decrease with increasing temperature and DMSO concentrations. Correlation of viscosity was made as a function of temperature and concentration with two modifications of the Seddon and Grunberg-Nissan equation, one with an average relative deviation of $6.8 \%$ and the second one of $16.3 \%$. Vapor pressures of the mixtures were measured at $\mathrm{T}=[353.1,433.1] \mathrm{K}$. and were correlated with Non-Random-Two-Liquid (NRTL) model, obtaining ARD\% between 5 and $12 \%$.
\end{abstract}

Keywords: ionic liquid, viscosity, vapor pressure, correlation.

This Chapter has been accepted for publication in "Pablo Nisa, L.; Segovia, J. J.; Martín, Á.; Martín, M. C.; Bermejo, M. D. Determination of density, viscosity and vapor pressures of mixtures of dimethyl sulfoxide +1 -allyl-3-methylimidazolium chloride at atmospheric pressure. J. Chem Thermodynamics" 


\section{Introduction}

Ionic liquids (ILs) are ionic substances liquids at room or near-room temperature. They have a practically negligible vapor pressure. They also present high solvation power for different kinds of substances and it is possible to adjust their properties by choosing the ions and its substituents. ${ }^{1}$ Due to their low vapor pressure they are considered as "green" solvents and they have been proposed as replacement of the conventional organic solvents with high volatility. ${ }^{2}$ In the last years they have attracted a lot of attention as no derivatizing solvents for cellulose. ${ }^{3}$ In special, the ionic liquid 1-allyl-3-methylimidazolium chloride (AmimCl) has attracted a lot of attention in the last years due to its ability to dissolve cellulose and its relatively low viscosity and melting point. 4,5

The most important disadvantage of using ILs as solvents of cellulose is their high viscosity. In addition, the viscosity of the ILs increase dramatically when cellulose is added. 3,6 Therefore, ionic liquids for cellulose processing are frequently used in combination with cosolvents, 7,8 as it is well known that molecular solvents are able to decrease the viscosity of ionic liquids. ${ }^{9}$ Some solvents as dimethyl sulfoxide (DMSO) are frequently used in applications of cellulose processing with ILs because it is a swelling agent of the cellulose, 4 it decreases the friction between monomers ${ }^{10}$ and it does not reduce cellulose solubility. ${ }^{11}$ Andanson et al. ${ }^{8}$ studied the effect of DMSO in the mixtures of DMSO + IL and concluded that the DMSO does not affect the ionic liquid - glucose interactions.

Some fundamental physical properties of mixtures of imidazolium chloride based ionic liquids with co-solvents have been measured by different authors in recent years. Density, viscosity, refractive index and conductivity of mixtures $\mathrm{H}_{2} \mathrm{O}+\mathrm{AmimCl}$ at $298.15 \mathrm{~K}$ were measured by $\mathrm{Wu}$ et al. ${ }^{12}$. Sescousse et al. ${ }^{13}$ measured the viscosity of mixtures cellulose + 1-butyl-3-methylimidazolium chloride (BmimCl) at different temperatures. Calvar et al. ${ }^{14}$ measured densities, refractive indices, speeds of sound and isentropic compressibility of the ternary mixture ethanol + water $+\mathrm{BmimCl}$. In addition, for binary mixtures of $\mathrm{BmimCl}$ with ethanol or water, the said properties were also determined at $298.15 \mathrm{~K}$ and atmospheric pressure. Lopes et al. ${ }^{15}$ studied the reduction in the viscosity of the ionic liquid AmimCl caused by dissolution of $\mathrm{CO}_{2}$. Jiménez et al. ${ }^{16}$ measured densities and viscosities of aqueous mixtures of AmimCl and they found negative excess molar volumes of the mixtures and correlated the viscosities of the mixtures. However, to the best of our knowledge there are no experimental data of viscosities or vapor pressures of mixtures DMSO + AmimCl. 
Some authors have studied the influence of the ionic liquids in the vapor pressure of organic compounds and water. It has been found that in general ionic liquids reduce the vapor pressure of mixtures IL + organic compounds and IL + water, presenting a negative deviation from the Raoult's law that is attributed to the interactions and affinity between the molecules. 17,18 This has been observed among others by Zhao et al., ${ }^{17}$ who measured and adjusted vapor pressures of a variety of alkylimidazolium dialkylphosphates based ionic liquids, Jiang et al. ${ }^{18}$ measured vapor pressures of systems containing water, alcohols + 1-ethyl-3-ethylimidazolium diethylphosphate $\left(\mathrm{Et}_{2} \mathrm{ImEt}_{2} \mathrm{PO}_{4}\right)$. Han et al. ${ }^{19}$ studied the vapor pressure of mixtures containing 1-ethyl-3-methylimidazoliun tetrafluoroborate $\left(\mathrm{EmimBF}_{4}\right)$ using benzene, thiophene, toluene and water as solutes. However, some authors reported positive deviations of the Raoult's Law, such as in the systems containing bis(trifluoromethyl-sulfonyl) imide $\left(\mathrm{TF}_{2} \mathrm{~N}\right), \mathrm{PF}_{6}$ and $\mathrm{BF}_{4}$ anions. ${ }^{20-22}$

In this work viscosity and densities of mixtures of DMSO $+\mathrm{AmimCl}$ were measured at atmospheric pressure at various conditions of temperature and concentration and correlated. Vapor pressures of the mixtures were also experimentally determined and correlated with the Non-Random Two Liquids (NRTL) Model. 


\section{Experimental}

\subsection{Materials}

The DMSO used in the experiments was provided by Sigma- Aldrich and has a purity of $98 \%$ with a humidity of $200 \mathrm{ppm}$. The ionic liquid 1-allyl-3-methylimidazolium chloride was purchased from Iolitec (assay (NMR) $=98 \%$; 1-Allyl-3-methylimidazolium (IC) $=99.9 \%$; Chloride (IC) $=99.9 \%$; 1 -Methylimidazole (IC) $<1 \%$ and Water $(\mathrm{KF})=0.2467 \%$ in mass fraction). The ionic liquid was further dried by applying a high level of vacuum while using a magnet stirring at temperature of $86^{\circ} \mathrm{C}$ for two days, and the final humidity was below $0.14 \%$ in mass fraction, determined by a Karl - Fischer Coulometric titration using Mettler Toledo C20 KF. The compound data are summarized in the sample table in Table 1.

Table 1. Materials and purification methods.

\begin{tabular}{lcllll}
\hline Chemical name & Source & $\begin{array}{l}\text { Initial mass } \\
\text { fraction } \\
\text { purity }\end{array}$ & $\begin{array}{l}\text { Purification } \\
\text { method }\end{array}$ & $\begin{array}{l}\text { Final mass } \\
\text { fraction } \\
\text { purity }\end{array}$ & $\begin{array}{l}\text { Analysis } \\
\text { method }\end{array}$ \\
\hline $\begin{array}{l}\text { 1-allyl-3- } \\
\text { methylimidazolium } \\
\text { chloride }\end{array}$ & Iolitec & 0.98 & $\begin{array}{l}\text { Vacuum } \\
\text { treatment }\end{array}$ & $0.9986 a$ & $\mathrm{KFa}$ \\
$\begin{array}{l}\text { dimethyl sulfoxide } \\
\text { aigma }\end{array}$ & $\begin{array}{l}0.98 \text { (mole } \\
\text { basis) }\end{array}$ & - & $\begin{array}{l}0.98 \text { (mole } \\
\text { basis) }\end{array}$ & - \\
\hline
\end{tabular}

a: Based on water impurity only

b: Karl - Fischer Coulometric titration

\subsection{Measurements with Stabinger viscometer}

The mixtures were prepared gravimetrically by using a high precision balance (Sartorius Basic BA 310P, precision $=0.001 \mathrm{~g}$ ) inside an inert gas chamber. The water concentration of the mixtures was determined with Karl - Fischer Coulometric titration using Mettler Toledo C20 KF before the experiments, and immediately equipment was charged. Thus, a proper handling was used to avoid as much as possible the absorption of water of the mixtures, as both IL and DMSO are hygroscopic compounds, some water was effectively absorbed being the final concentration of the samples those shown in table 2. Molar fractions are defined by the amount of the component in mol divided by the total amount in mol of all components in the mixture. For the composition shown in this table water was the only impurity taken into account. 
Table 2. Composition of the mixtures DMSO + AmimCl measured in this work

\begin{tabular}{cl}
\hline$x_{\text {DMSO }} / \mathrm{mol} / \mathrm{mol}$ & $x_{\text {water }} / \mathrm{mol} / \mathrm{mol}$ \\
\hline 0 & 0.059 \\
0.048 & 0.042 \\
0.091 & 0.047 \\
0.14 & 0.048 \\
0.241 & 0.049 \\
0.482 & 0.031 \\
0.729 & 0.023 \\
0.893 & 0.008 \\
0.999 & 0.001
\end{tabular}

Uncertainty $(\mathrm{k}=2)$ of the molar fraction is $0.001 \mathrm{~mol} / \mathrm{mol}$

To determine densities and viscosities at atmospheric pressure, a Stabinger viscometer (SVM 3000 model) was used. The Stabinger viscometer consists of two rotating concentric tubes. It works based on the principle of Couette that states that the viscosity is proportional to the torque difference between the rotating cylinders. The Stabinger viscometer can simultaneously measure the density because it has a vibrating tube densimeter integrated into its structure. Both density and viscosity cells are filled in one cycle, and the measurements are carried out simultaneously. With this apparatus the measurements can be done from 233.15 to $373.15 \mathrm{~K}$ in a viscosity range from $0.2 \mathrm{mPa} \cdot \mathrm{s}$ to $20,000 \mathrm{mPa} \cdot \mathrm{s}$ and in a density range from $0.65 \mathrm{~g} \cdot \mathrm{cm}^{-3}$ to $2 \mathrm{~g}^{\cdot} \mathrm{cm}^{-3}$. The uncertainty of the temperature is $0.22 \mathrm{~K}(\mathrm{k}$ $=2$, level of confidence 95.45\%) from (278.15 to 343.15) K. Apparatus performs five measurements automatically with a relative uncertainty of the viscosity $2.0 \%(\mathrm{k}=2)$, and the expanded uncertainty of the density is $0.00052 \mathrm{~g}^{\cdot \mathrm{cm}^{-3}}(\mathrm{k}=2$, level of confidence $95.45 \%)$.

The uncertainty of the Stabinger viscometer was calculated following the law of propagation of uncertainty described in JCGM 100: 2008 23. The results are summarized in Table 3 and Table 4. 
Table 3. Uncertainty budget of density for Stabinger Viscometer. Values calculated for $x_{\mathrm{DMSO}}$ $=0.091,313.15 \mathrm{~K}$ and $\rho=1.1378 \mathrm{~g} \cdot \mathrm{cm}^{-3}$

\begin{tabular}{cccccc}
\hline Uncertainty & & Units & Estimate & Divisor & $\mathrm{u}(x)$ \\
& & & & & \\
\hline \multirow{3}{*}{$\mathrm{u}(T)$} & Calibration & & 0.020 & 1 & \\
& Resolution & $\mathrm{K}$ & 0.001 & $2 \sqrt{3}$ & 0.1 \\
& Repeatability & & 0.005 & 1 & \\
\hline \multirow{3}{*}{$\mathrm{u}(\rho)$} & Calibration & & 0.0005 & 2 & \\
& Resolution & $\mathrm{g} \cdot \mathrm{cm}^{-3}$ & 0.0001 & $2 \sqrt{3}$ & $3 \mathrm{E}-04$ \\
\hline $\mathrm{U}(\rho)$ & Repeatability & & 0.0001 & 2 & \\
\hline $\mathrm{U}(\rho)$ & & $\mathrm{g} \cdot \mathrm{cm}^{-3}$ & & $\mathrm{k}=2$ & $5 \mathrm{E}-04$ \\
\hline
\end{tabular}

Mixtures were carefully introduced in the viscometer in order to avoid bubbles. The viscosity and the density were measured from $293.15 \mathrm{~K}$ to $373.15 \mathrm{~K}$ with a temperature step of $10 \mathrm{~K}$. After the measurement of each mixture the viscometer was first cleaned with water, then with hexane and finally with air. To ensure that the Stabinger was clean after this process, the properties of pure water were measured after the cleaning step and if the obtained values were close to the theoretical values obtained from Refprop, 24 it was considered that the equipment was clean.

Table 4. Uncertainty budget of viscosity for the Stabinger viscometer. Values calculated for $x_{\text {DMSO }}=0.091,323.15 \mathrm{~K}$ and $\mu=130 \mathrm{mPa} \cdot \mathrm{s}$

\begin{tabular}{cccccc}
\hline Uncertainty & & Units & Estimate & Divisor & $\mathrm{u}(x)$ \\
& & & & & \\
\hline \multirow{3}{*}{$\mathrm{u}(T)$} & Calibration & & 0.020 & 1 & \\
& Resolution & $\mathrm{K}$ & 0.001 & $2 \sqrt{3}$ & 0.1 \\
& Repeatability & & 0.005 & 1 & \\
\hline \multirow{2}{*}{$\mathrm{u}(\mu)$} & Calibration & & 1.3 & 1 & 1 \\
& Resolution & $\mathrm{mPa} \cdot \mathrm{s}$ & 0.0001 & $2 \sqrt{3}$ & \\
\hline $\mathrm{U}(\mu)$ & Repeatability & & 0.13 & 1 & 3 \\
\hline $\mathrm{U}(\mu)$ & & $\mathrm{mPa} \cdot \mathrm{s}$ & & $\mathrm{k}=2$ & $2 \mathrm{E}-02$ \\
\hline
\end{tabular}




\subsection{Equipment and procedure for vapor pressure measurements}

The equipment used for the measurements of the vapor pressure consisted of a stainless steel cell of $20 \mathrm{~mL}$ of internal volume homogenized by magnetic stirrer. The inner pressure of the cell was determined by an absolute pressure gauge GE DPI 104, with an expanded uncertainty of $0.1 \%(\mathrm{k}=2)$, the final uncertainty was calculated taking into account the repeatability, the pressure gauge uncertainty and other error sources, the final expanded uncertainty of the vapor pressure measurements is $9 \%(\mathrm{k}=2)$. The temperature inside of the cell was determined by a Pt100 with an uncertainty of $\pm 0.1 \mathrm{~K}$ for $\mathrm{T}<433.15 \mathrm{~K}$, and a thermocouple with an uncertainty of $\pm 2 \mathrm{~K}$ for $\mathrm{T}>433.15 \mathrm{~K}$. The temperature inside the cell was fixed by a clamp electric heater controlled by a PID regulator connected to the temperature sensor. The cell was also connected to a vacuum pump through a valve.

The experimental procedure consists of the following steps:

1) The cell was loaded with an approximate volume of $10 \mathrm{~mL}$ of mixture. The ionic liquid previously dried as explained in section 2.1 (5.9\% mol water) was stored in a flask inside of a desiccator under vacuum. Then it was loaded in the cell and mixed with DMSO of a nitrogen chamber, closed and all the connections were checked.

With a vacuum pump, vacuum was made until the pressure was lower than 0.01 bar. The electric resistance was connected and the temperature was raised to $333.15 \mathrm{~K}$. After a period of at least $60 \mathrm{~min}$ at $333.15 \mathrm{~K}$, (the vapor pressure of DMSO at $333.15 \mathrm{~K}$ is $0.007 \mathrm{bar}$ ) vacuum was made again until a pressure lower than 0.01 bar. The purpose of this step was to remove absorbed air or volatiles components that may be present in the IL and could distort the measurements. It was considered that the composition of the sample was not influenced by this step due to the low vapor pressure of DMSO at this temperature that causes a negligible loss of DMSO by evaporation. As the cell was not opened again in this point the final water content until this last step could not be experimentally determined, but it can be estimated from the initial water concentration of DMSO and IL

2) The temperature was fixed for the first vapor pressure measurement. Once the equilibrium was reached, that is, when pressure and temperature were constant, the value of these properties was registered, and then the temperature was increased until the next value. 


\section{Experimental results}

\subsection{Densities of DMSO + AmimCl}

Densities are presented in table 5. In literature several melting temperatures were reports for the AmimCl. 5,25,26 In a previous work of the group it was determined to be $324.95 \mathrm{~K}$ by DSC (Differential Scanning Calorimetry) using AmimCl of the same supplier and nominal purity. ${ }^{26}$ Below this temperature the $\mathrm{AmimCl}$ is presented as a liquid, as happens frequently with most ionic liquids that can be liquid at temperatures much below the melting point. 27 Data at higher concentrations of IL and at lower temperatures were not measured to prevent blockage of the equipment due to possible solidification of the IL.

Table 5. Densities of the binary mixture DMSO + AmimCl.

\begin{tabular}{cccccccccc}
\hline $\begin{array}{c}\text { Atmospheric } \\
\text { pressure / }\end{array}$ & 0.934 & 0.931 & 0.928 & 0.928 & 0.929 & 0.931 & 0.930 & 0.935 & 0.934 \\
bar & & & & & & & & & \\
$X_{\mathrm{H} 20}$ & 0.059 & 0.042 & 0.047 & 0.048 & 0.049 & 0.031 & 0.023 & 0.008 & 0.001 \\
$x_{\mathrm{DMSO}}$ & 0.000 & 0.048 & 0.091 & 0.140 & 0.241 & 0.482 & 0.728 & 0.893 & 0.999 \\
$T / \mathrm{K}$ & & & & & $\rho / \mathrm{g} \cdot \mathrm{cm}^{-3}$ & & & & \\
\hline 293.15 & & & 1.1500 & 1.1496 & 1.1482 & 1.1436 & 1.1302 & 1.1169 & 1.1012 \\
303.15 & & & 1.1439 & 1.1434 & 1.1420 & 1.1367 & 1.1223 & 1.1080 & 1.0912 \\
313.15 & & 1.1382 & 1.1378 & 1.1373 & 1.1357 & 1.1297 & 1.1143 & 1.0990 & 1.0811 \\
323.15 & 1.1327 & 1.1324 & 1.1319 & 1.1313 & 1.1292 & 1.1229 & 1.1062 & 1.0900 & 1.0711 \\
333.15 & 1.1271 & 1.1267 & 1.1261 & 1.1254 & 1.1231 & 1.1161 & 1.0981 & 1.0810 & 1.0612 \\
343.15 & 1.1215 & 1.1210 & 1.1203 & 1.1195 & 1.1172 & 1.1093 & 1.0901 & 1.0720 & 1.0513 \\
353.15 & 1.1160 & 1.1154 & 1.1146 & 1.1136 & 1.1112 & 1.1026 & 1.0824 & 1.0631 & 1.0411 \\
363.15 & 1.1105 & 1.1099 & 1.1089 & 1.1079 & 1.1052 & 1.0960 & 1.0745 & 1.0543 & 1.0313 \\
373.15 & 1.1052 & 1.1045 & 1.1034 & 1.1024 & 1.0993 & 1.0894 & 1.0668 & 1.0455 & 1.0214 \\
\hline
\end{tabular}

The expanded uncertainty $(\mathrm{k}=2)$ of the density is $5.210^{-4} \mathrm{~g}^{\cdot \mathrm{cm}^{-3}}$. Expanded uncertainty in the temperature is $0.22 \mathrm{~K}$. Expanded uncertainty of the molar fraction is $0.001 \mathrm{~mol} / \mathrm{mol}$. Expanded uncertainty of the atmospheric pressure is 0.001 bar. 


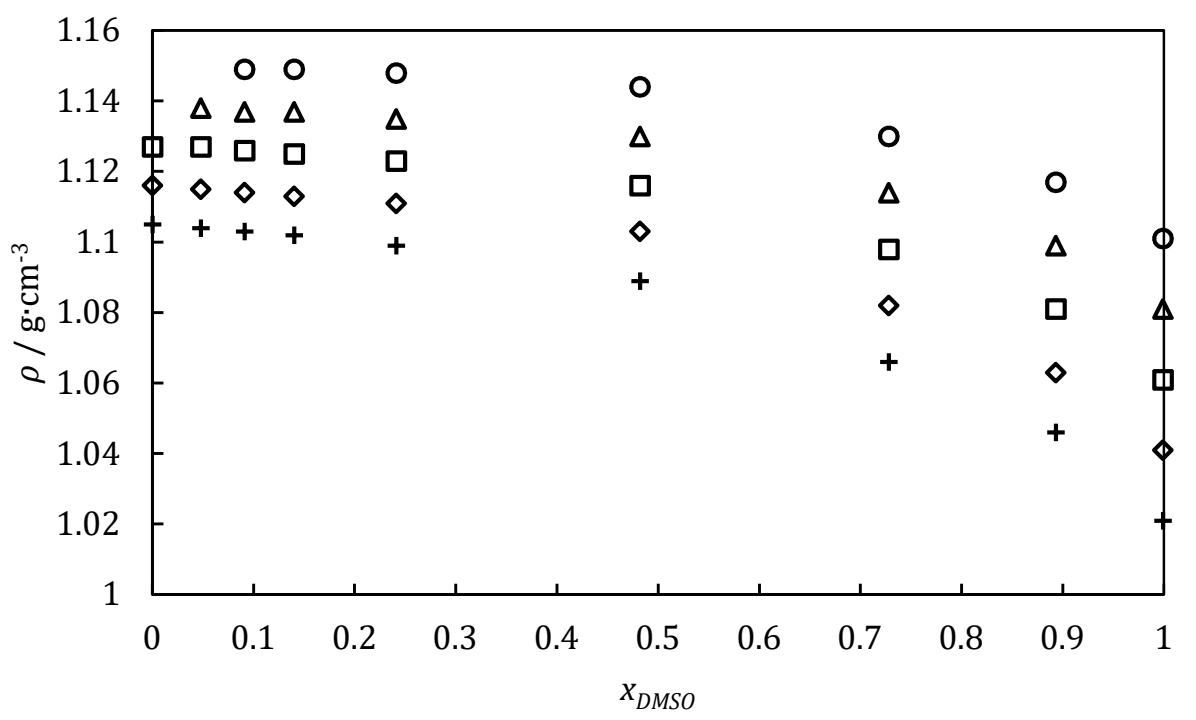

Figure 1. Densities of binary mixtures of DMSO + AmimCl at atmospheric pressure $293.15 \mathrm{~K}$ $(\bigcirc)$; $313.15 \mathrm{~K}(\triangle)$; $333.15 \mathrm{~K}(\square)$; $353.15 \mathrm{~K}(\diamond)$ and $373.15 \mathrm{~K}(+)$.

As it is shown in Figure 1, density of the mixtures decreases when increasing the temperature and the molar fraction of DMSO, presenting a nonlinear convex trend. Literature data regarding the density of imidazolium-based ionic liquid and molecular solvents as water or alcohols presents a similar trend. ${ }^{28-30}$ The influence of the temperature is slightly bigger at high concentrations of DMSO.

Table 6 shows that the densities were inconsistent with those determined by Jiménez et al. 16 for the "pure" IL ( $x_{\text {water }}=0.045$ similar to our $x_{\text {water }}=0.059$ ). The discrepancy between the measures may be caused by different amount of impurities in the ionic liquids. The measurements were performed by the same equipment and in both articles the ionic liquid were provided by Iolitec. 
Table 6. Comparison between densities measured in this work and reported by Jiménez et al. 16

\begin{tabular}{cccc}
\hline & Density, this work & Density, Jiménez et al. ${ }^{16}$ & \\
$T / \mathrm{K}$ & $X_{\text {water }}=0.059$ & $X_{\text {water }}=0.045$ & $\frac{|\Delta \rho|}{\rho} \cdot 100$ a \\
& $\mathrm{g} \mathrm{cm}^{-3}$ & 1.1310 & \\
\hline 323.15 & 1.1327 & 1.1254 & 0.15 \\
333.15 & 1.1271 & 1.1199 & 0.15 \\
343.15 & 1.1215 & 1.1144 & 0.14 \\
353.15 & 1.1160 & 1.1088 & 0.14 \\
363.15 & 1.1105 & 1.1036 & 0.15 \\
373.15 & 1.1052 & 0.15 \\
\hline
\end{tabular}

a) $\frac{|\Delta \rho|}{\rho} \cdot 100=\mid \rho_{-}($Jimenez et al. $)-\rho_{-}($This work $) \mid / \rho_{-}($Jimenez et al. $) \cdot 100$

The Table 6 compares the relative deviations of density of the ionic liquid at atmospheric pressure and different temperatures between our experimental data and Jiménez et al. 16 data. The difference can be explained by the imidazolium or chloride impurities in the ionic liquid.

Comparison of the DMSO density with literature data ${ }^{31-38}$ is presented in Figure 3. It can be observed that our data are consistent with the data reported by others authors. Even though, in general there is important dispersion among the data of different authors. Most literature data are presenting deviation lower than $0.1 \%$ and in many cases within the experimental uncertainty of our data. A few data $[31,36,38]$ present higher deviation but in all cases lower than $0.3 \%$. 


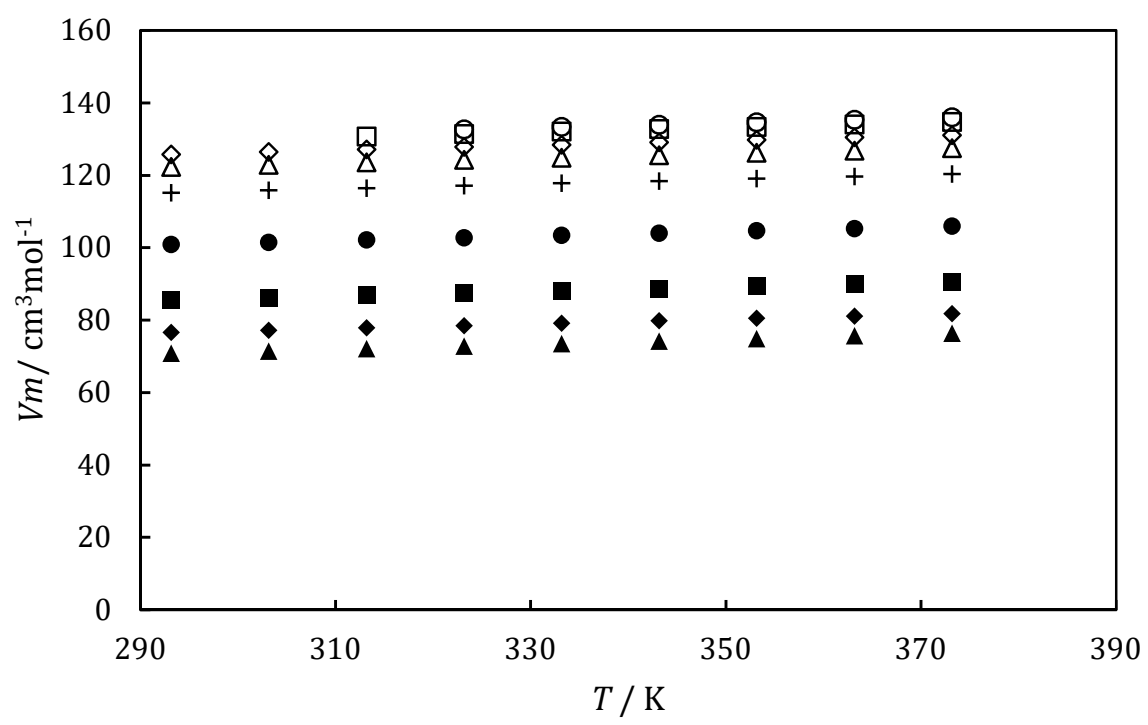

Figure 2. Molar volumes of the mixtures at $x_{\mathrm{DMSO}}=0.000(\bigcirc) ; 0.048(\square) ; 0.091(\diamond)$; $0.140(\triangle) ; 0.241(+) ; 0.482(\bullet) ; 0.728(\square) ; 0.893(\diamond) ; 0.999(\Delta)$.

In Figure 2 can be seen the linear tendency with the temperature in the molar volume of the mixtures at different molar fraction of DMSO.

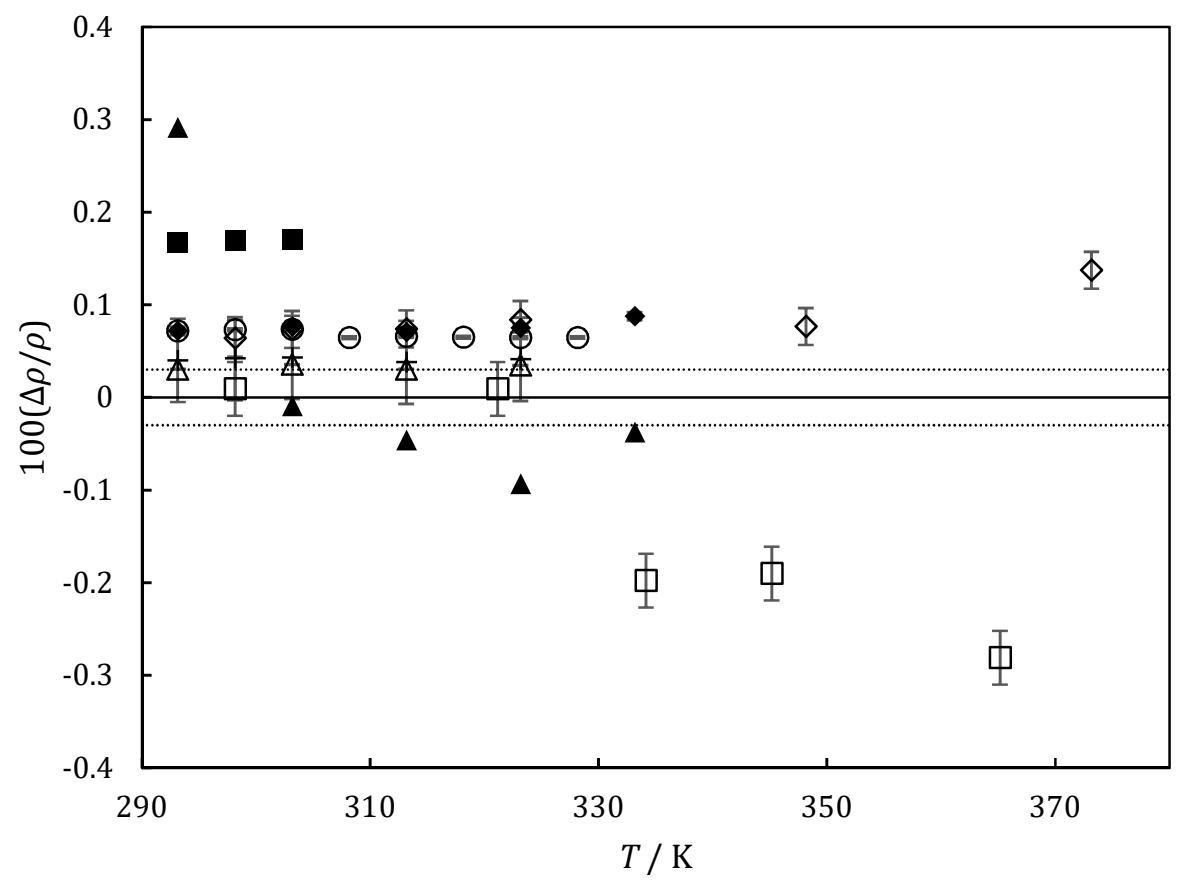

Figure 3. Relative deviations for DMSO density against the temperature between the experimental density data of this work and those reported by: Campbell ${ }^{31}(\square)$; Casteel et al. ${ }^{32}(\diamond)$; Wang et al. ${ }^{33}(\triangle)$; Ivanov et al. ${ }^{34}(\bigcirc)$; Iulian et al. ${ }^{35}(+)$; Krakoviak et al. ${ }^{36}(\mathbf{\square})$; Zarei et al. ${ }^{37}(\bullet)$ and Clever et al. ${ }^{38}(\boldsymbol{\Delta})$ (uncertainty not reported). 


\subsection{Viscosity of mixtures DMSO + AmimCl}

Results of viscosity of mixtures DMSO + AmimCl at atmospheric pressure and different temperatures and DMSO concentrations are presented in Table 7.

Table 7. Viscosities of the binary mixtures DMSO + AmimCl.

\begin{tabular}{ccccccccccc}
\hline $\begin{array}{c}\text { Atmospheric } \\
\text { Pressure / bar }\end{array}$ & 0.934 & 0.931 & 0.928 & 0.928 & 0.929 & 0.931 & 0.930 & 0.935 & 0.934 \\
$X_{\mathrm{H} 20}$ & 0.059 & 0.042 & 0.047 & 0.048 & 0.049 & 0.031 & 0.023 & 0.008 & 0.001 \\
$X_{\text {DMSO }}$ & 0 & 0.048 & 0.091 & 0.14 & 0.241 & 0.482 & 0.729 & 0.893 & 0.999 \\
\hline$T / \mathrm{K}$ & & & \multicolumn{7}{c}{$\mu / \mathrm{mPa} \mathrm{s}$} \\
293.15 & & & 1330 & 1070 & 557 & 133 & 16.3 & 5.33 & 2.26 \\
303.15 & & & 529 & 439 & 250 & 70.4 & 11.1 & 4.06 & 1.85 \\
313.15 & & 388 & 247 & 209 & 128 & 41.7 & 8.04 & 3.21 & 1.56 \\
323.15 & 212 & 195 & 130 & 112 & 75.7 & 26.7 & 6.08 & 2.60 & 1.33 \\
333.15 & 115 & 107 & 75.5 & 66.1 & 46.1 & 18.3 & 4.76 & 2.16 & 1.16 \\
343.15 & 68.7 & 64.0 & 47.4 & 42.1 & 30.3 & 13.1 & 3.83 & 1.83 & 1.02 \\
353.15 & 44.0 & 41.3 & 31.6 & 28.4 & 21.0 & 9.85 & 3.16 & 1.57 & 0.905 \\
363.15 & 30.0 & 28.2 & 22.3 & 20.2 & 15.3 & 7.64 & 2.66 & 1.36 & 0.815 \\
373.15 & 21.4 & 20.3 & 16.2 & 15.0 & 11.6 & 6.10 & 2.28 & 1.20 & 0.741 \\
\hline
\end{tabular}

The expanded uncertainty of the viscosity is $2.0 \%$. Expanded uncertainty $(\mathrm{k}=2)$ in the temperature is $0.22 \mathrm{~K}$. Uncertainty of the molar fraction is $0.001 \mathrm{~mol} / \mathrm{mol}$. Expanded uncertainty of the atmospheric pressure is 0.001 bar.

From Figure 4 it can be observed that the viscosity decreases with the temperature and with DMSO concentration. It has an exponential behavior in all temperatures. At lower temperatures the influence of the DMSO concentration increases considerably.

Comparing the viscosities of pure AmimCl measured by Jiménez et al. ${ }^{16}$ with our data in the Table 8, the results of Jiménez et al. are slightly lower, with a maximum difference of $8.6 \%$ at $323 \mathrm{~K}$ and a minimum difference of $3.6 \%$ at $373 \mathrm{~K}$. This can be explained by the lower water content of water in the samples prepared in the work of Jiménez et al, and the strong influence of the co-solvent concentration in viscosity. ${ }^{16}$ 


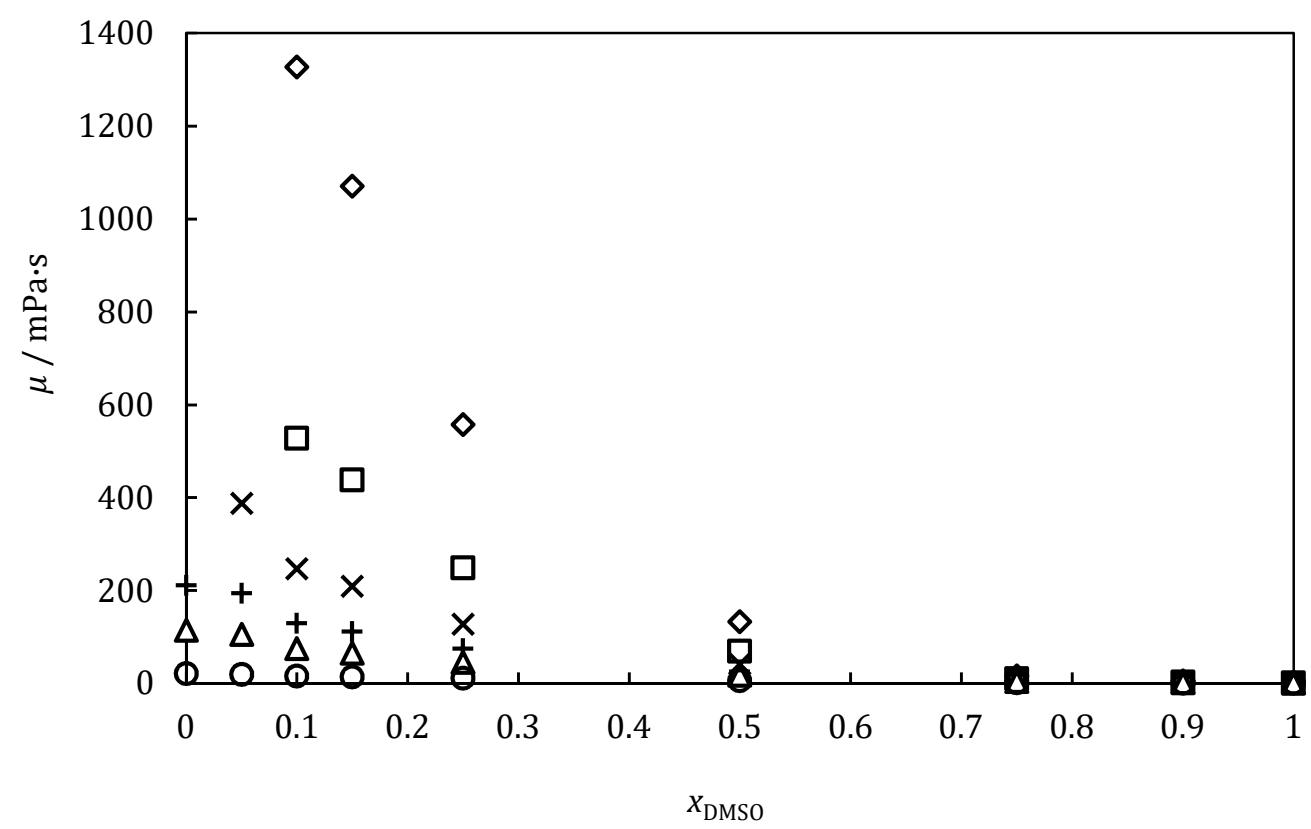

Figure 4. Viscosities of binary mixtures DMSO + AmimCl at atmospheric pressure and 293.15 K $(\diamond)$; 303.15 K ( $\square)$; 313.15 K (×); 323.15 K (+); 333.15 K $(\triangle)$ and 373.15 K $(\bigcirc)$.

Table 8. Comparison between viscosities measured in this work and results reported by Jiménez et al. ${ }^{16}$ corrected for $x_{\text {water }}=0.059$. The water concentration in this work was $x_{\text {water }}$ $=0.059$.

\begin{tabular}{cccc}
\hline$T / \mathrm{K}$ & $\begin{array}{c}\text { Viscosity, this work } \\
\mathrm{mPa} \mathrm{s}\end{array}$ & $\begin{array}{c}\text { Corrected viscosity, Jiménez et al. }{ }^{16} \\
\text { mPa s }\end{array}$ & $\frac{|\Delta \mu|}{\mu} \cdot 100 \mathrm{~b}$ \\
\hline 323.15 & 212 & 221 & 4.07 \\
333.15 & 115 & 119 & 3.36 \\
343.15 & 68.7 & 70.5 & 2.55 \\
353.15 & 44.4 & 44.9 & 1.11 \\
363.15 & 30.0 & 30.4 & 1.32 \\
373.15 & 21.4 & 21.7 & 1.38 \\
\hline b) $\frac{|\Delta \mu|}{\mu} \cdot 100=\mid \mu_{-}($Jimenez et al. $)-\mu_{-}\left(\right.$This work) $\mid / \mu_{-}($Jimenez et al. $) \cdot 100$
\end{tabular}




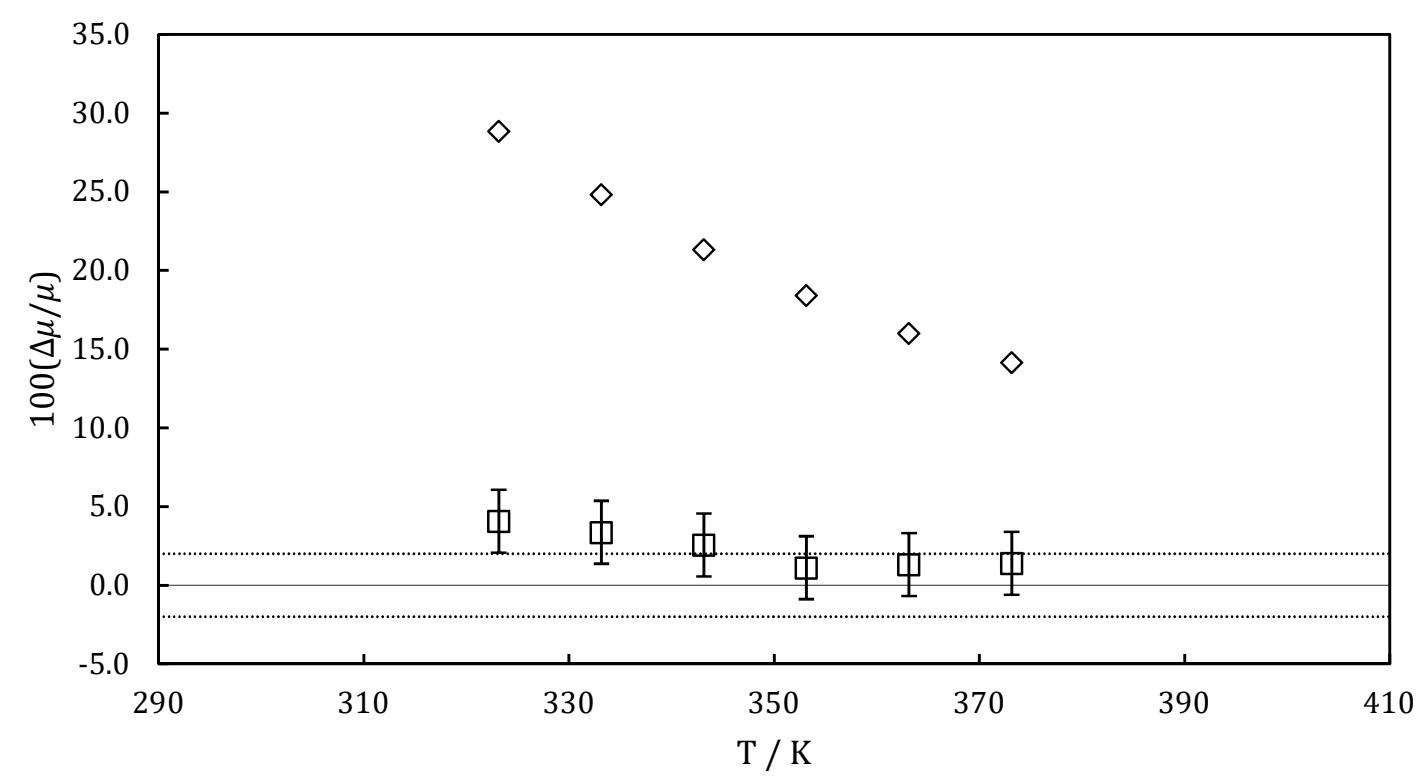

Figure 5. Relative deviations for viscosity of pure AmimCl against the temperature between the experimental viscosity data of this work and those reported by Jiménez et al. ${ }^{16}(\square)$ and Hiraga et al. ${ }^{39}(\diamond)$ (estimated $x_{\mathrm{H} 20}=0.01$ ). Dotted lines represent uncertainty of our data.

Figure 5 shows the relative deviations of viscosity of $\mathrm{AmimCl}$ at atmospheric pressure and different temperatures between our data and other data from literature 16,39. Important differences with the data of Hiraga et al. ${ }^{39}$ can be observed, but differences can be explained due to the impurities (1-Methylimidazole) present in the ionic liquid and / or presence of water in our samples.

Figure 6 shows the relative deviations of viscosity of DMSO at atmospheric pressure and different temperatures between our data and other data from literature. 32,40-47 In general, some scattering is found between our data and literature data, with data within or slightly outside the uncertainty limit. Only a few literature data present important deviation at temperatures above $320 \mathrm{~K}$. Reported data by Kapadi et al. ${ }^{47}$ shows a good agreement with this work. Discrepancies can be due to different content of impurities in the samples. DMSO is hygroscopic, so the water content can be different between the authors. In the literature, only Govinda et al. ${ }^{43}$ measured the water content in their samples, which was kept below $70 \mathrm{ppm}$. 


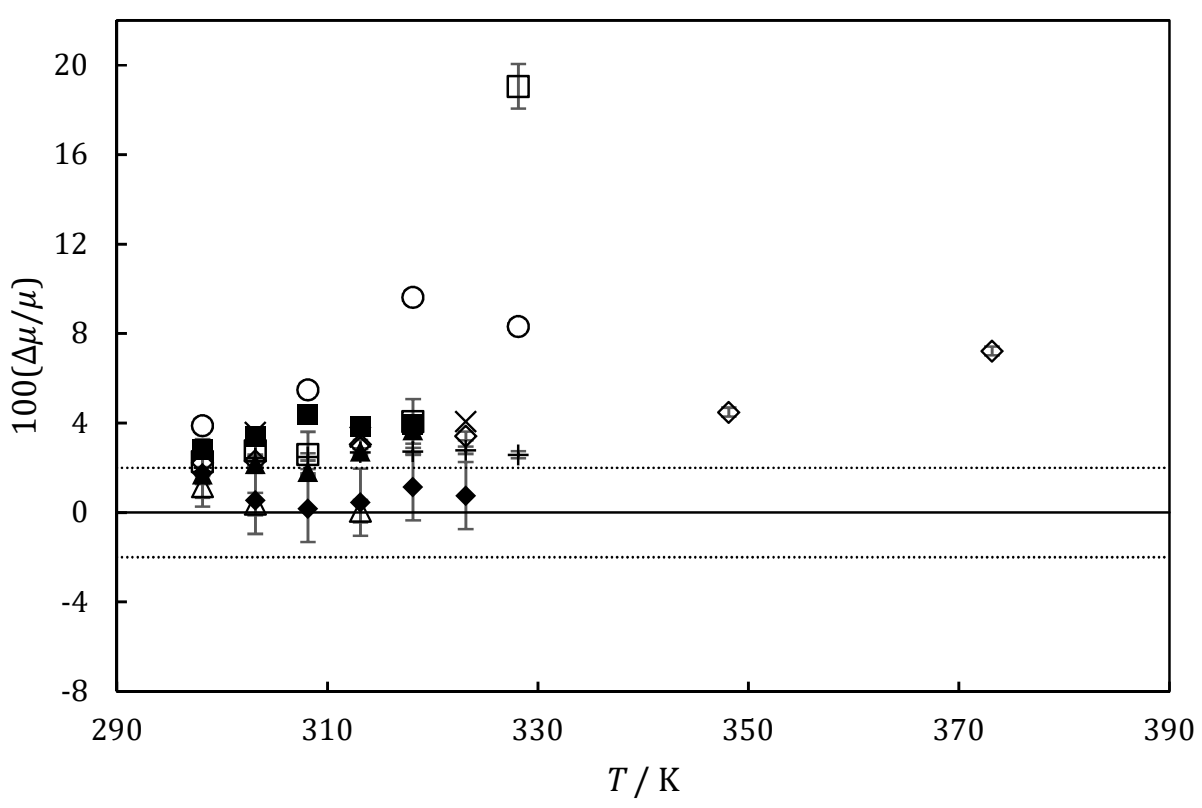

Figure 6. Relative deviation for viscosity of pure DMSO against the temperature between the experimental viscosity data of this work and those reported by: Casteel et al. ${ }^{32}(\diamond)$; Ciocirlan et al. ${ }^{40}(\triangle)$; Yang et al. ${ }^{41}(\times)$ (uncertainty not reported); Govinda et al. ${ }^{42}(\square)$; Gokavl et al. ${ }^{43}(\bigcirc)$ (uncertainty not reported); Saleh et al. ${ }^{44}(+)$; Ali et al. ${ }^{45}(\boldsymbol{\square})$ (uncertainty not reported); Zhao et al. ${ }^{46}(\bullet)$ and Kapadi et al. ${ }^{47}(\mathbf{A})$.

\subsection{Viscosity correlation}

The viscosity was correlated as a function of temperature and concentration with two viscosity correlations previously used by our research group to describe viscosities of mixtures of imidazolium ionic liquids with molecular solvents. 15,16

Equation ( 1 ) modified from the correlation of Grunberg and Nissan, was used to correlate data with DMSO molar fractions in all the concentration range as a function of temperature. Due to the big influence of water in viscosity, the concentration of water of each sample was also considered in the correlation. The parameters for the pure IL, E, A and B, were taken from the original work of Jiménez et al. with the same IL ${ }^{16}$. Parameters F, D and C used for describing the interaction water-AmimCl water were also taken from the work of Jimenez et al. ${ }^{16}$. The parameters $\mathrm{G}, \mathrm{H}$ and I, corresponding to the interactions with DMSO, were adjusted in this work by minimization of the average relative deviation (ARD \%) defined in eq. ( 2 ). An ARD of $6.8 \%$ was obtained with a maximum deviation of $30.7 \%$ at $373.15 \mathrm{~K}$ and $x_{\mathrm{DMSO}}=0$, which represents a good description of the system. The parameters obtained are 
reported in Table 9. Experimental data is compared with predictions from the correlation (Eq. 1) in Figure 7, in logarithmic scale. A good correlation of the data is observed.

$$
\begin{gathered}
\ln \mu=x_{I L}\left(\frac{E}{T^{2}}+\frac{A}{T}+B\right)+x_{D M S O} \ln \mu_{D M S O}+x_{H_{2} O} \ln \mu_{H_{2} O}+\frac{x_{I L} x_{H_{2} O}}{x_{I L}+F}(C+D T) \\
+\frac{x_{I L} x_{D M S O}}{x_{I L}+G}(H+I T) \\
A R D \%=\frac{\sum\left(\frac{\left|\mu_{\text {exp }}-\mu_{\text {calc }}\right|}{\mu_{\text {exp }}}\right)}{n} \cdot 100
\end{gathered}
$$

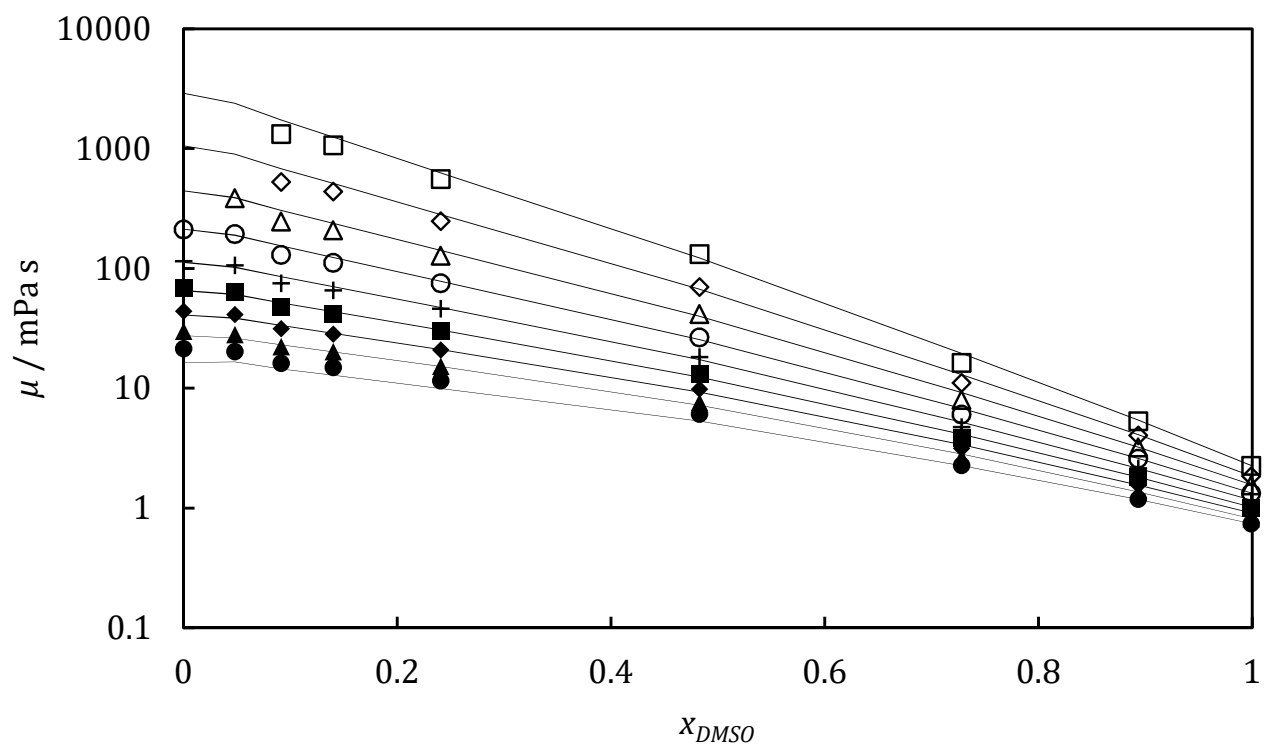

Figure 7. Correlation of experimental viscosity for the binary mixtures DMSO $+\mathrm{AmimCl}$ at $293.15 \mathrm{~K}(\square)$; $303.15 \mathrm{~K}(\diamond)$; $313.15 \mathrm{~K}(\triangle)$; $323.15 \mathrm{~K}(\bigcirc)$; $333.15 \mathrm{~K}(+)$; $343.15 \mathrm{~K}(\mathbf{\square})$; 353.15 K $(\diamond)$; $363.15 \mathrm{~K}(\boldsymbol{\Delta})$ and $373.15 \mathrm{~K}(\bullet)$. The points represent the experimental data, and lines represent the data calculated with equation (1) 
Table 9. Fitted parameters for the correlation of viscosity of the mixtures DMSO $+\mathrm{AmimCl}$ with equation ( 1 ) for all concentration range.

\begin{tabular}{|c|c|}
\hline A & $-1.51 \mathrm{E}+04$ \\
B & $1.76 \mathrm{E}+01$ \\
C & $-8.72+05$ \\
D & $-4.25 \mathrm{E}+07$ \\
$\mathrm{E}$ & $3.64 \mathrm{E}+06$ \\
$\mathrm{~F}$ & $5.02 \mathrm{E}+07$ \\
$\mathrm{G}$ & $9.01 \mathrm{E}+07$ \\
$\mathrm{H}$ & $3.00 \mathrm{E}+05$ \\
$\mathrm{I}$ & $-8.49 \mathrm{E}+06$ \\
\%ARD & $6.8 \%$ \\
\%Max & $30.7 \%$ \\
\hline
\end{tabular}

Equation ( 3 ) is also a modification of Grunberg and Nissan correlation, it is used to correlate the viscosity with DMSO molar fractions lower than 0.25 , where the viscosity presents a liner behavior with the impurity molar fraction. Parameters F, C and D were adjusted for the DMSO by minimization of the average relative deviation (ARD \%) in the same way defined in eq. ( 2 ). An ARD\% of $16.3 \%$ was obtained with a maximum deviation of $45.2 \%$ at $293.15 \mathrm{~K}$ and $x_{\mathrm{DMSO}}=0.091$, which represent a good description of the system. Parameters E, A and B were taken from Jiménez et al. ${ }^{16}, \mathrm{C}$ and D parameters are adjusted and shown in Table 10. Correlation prediction and experimental data are compared in Figure 6. It can be observed how the predictions are not valid for concentrations higher than $x_{\text {DMSO }}=0.15$, as shown in Figure 8.

$$
\mu=\exp \left(\frac{E}{T^{2}}+\frac{A}{T}+B\right) \cdot \exp \left(\frac{x_{\mathrm{H}_{2} \mathrm{O}}}{C+D T}\right) \cdot \exp \left(\frac{x_{D M S O}}{F+G T}\right)
$$




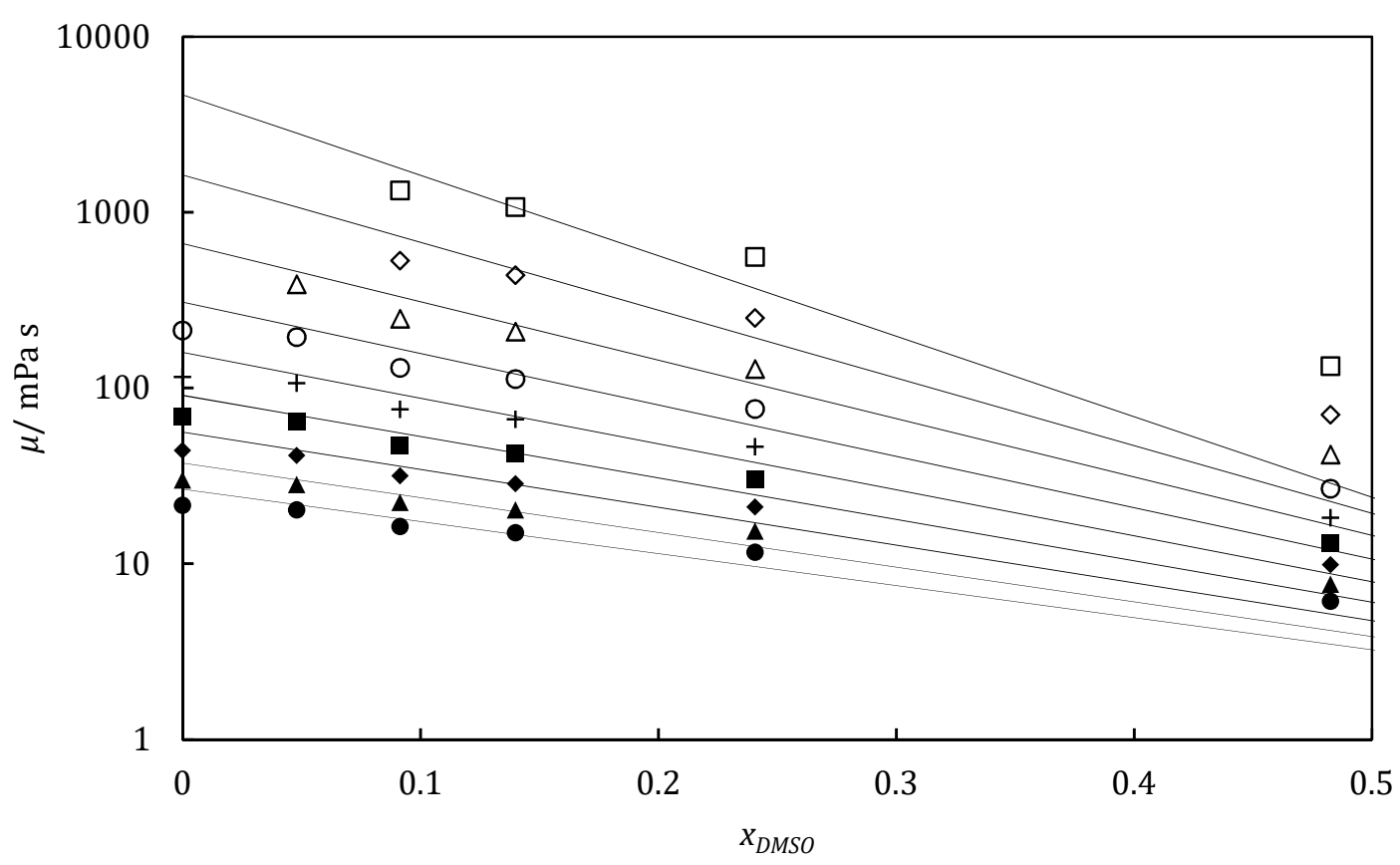

Figure 8. Correlation of experimental viscosity for the binary mixtures DMSO $+\mathrm{AmimCl}$ at $293.15 \mathrm{~K}(\square)$; $303.15 \mathrm{~K}(\diamond)$; $313.15 \mathrm{~K}(\triangle)$; $323.15 \mathrm{~K}(\bigcirc)$; $333.15 \mathrm{~K}(+)$; $343.15 \mathrm{~K}(\mathbf{\square})$; $353.15 \mathrm{~K}(\diamond)$; $363.15 \mathrm{~K}(\boldsymbol{\Delta})$ and $373.15 \mathrm{~K}(\bullet)$. The points represent the experimental data, and straight lines represent the data calculated with equation ( 3 )

Table 10. Fitted parameters for the correlation of viscosity of the mixtures DMSO + AmimCl with equation ( 3 ). Valid for co-solvent concentration lower than 0.15 .

\begin{tabular}{|c|c|}
\hline$A$ & $-1.51 \mathrm{E}+04$ \\
$B$ & $1.76 \mathrm{E}+01$ \\
$C$ & $-1.51 \mathrm{E}+05$ \\
$D$ & $4.16 \mathrm{E}+02$ \\
$E$ & $3.64 \mathrm{E}+06$ \\
$F$ & $4.30 \mathrm{E}-01$ \\
$G$ & $-1.79 \mathrm{E}-03$ \\
$\% A R D$ & $16.3 \%$ \\
$\% M a x$ & $45.2 \%$ \\
\hline
\end{tabular}




\subsection{Vapor pressure measurements}

The experimentally determined vapor pressures of mixtures DMSO + AmimCl are listed in Table 11.

Table 11. Vapor pressures of mixtures DMSO + AmimCl at various temperatures.

\begin{tabular}{|c|c|c|c|c|c|c|c|c|c|c|}
\hline$T / \mathrm{K}$ & & 353.1 & 363.1 & 373.1 & 383.1 & 393.1 & 403.1 & 413.1 & 423.1 & 433.1 \\
\hline $\begin{array}{c}X_{\mathrm{DMSO}} \\
\mathrm{mol} / \mathrm{mol}\end{array}$ & $\begin{array}{c}X_{\mathrm{H} 20} \\
\mathrm{~mol} / \mathrm{mol}\end{array}$ & & & & & $P$ / bar & & & & \\
\hline 1.000 & & 0.020 & 0.032 & 0.050 & 0.076 & 0.112 & 0.160 & 0.227 & 0.316 & 0.432 \\
\hline 0.973 & & 0.018 & 0.028 & 0.045 & 0.068 & 0.100 & 0.147 & 0.210 & 0.296 & 0.411 \\
\hline 0.947 & & 0.017 & 0.026 & 0.041 & 0.065 & 0.096 & 0.142 & 0.205 & 0.292 & 0.408 \\
\hline 0.896 & & 0.015 & 0.024 & 0.039 & 0.063 & 0.092 & 0.138 & 0.201 & 0.288 & 0.405 \\
\hline 0.822 & & 0.013 & 0.021 & 0.035 & 0.051 & 0.085 & 0.128 & 0.190 & 0.276 & 0.394 \\
\hline 0.753 & & 0.012 & 0.019 & 0.032 & 0.051 & 0.080 & 0.122 & 0.182 & 0.266 & 0.383 \\
\hline 0.664 & & 0.011 & 0.018 & 0.029 & 0.047 & 0.074 & 0.113 & 0.169 & 0.248 & 0.358 \\
\hline 0.580 & & 0.011 & 0.017 & 0.027 & 0.045 & 0.072 & 0.110 & 0.164 & 0.242 & 0.350 \\
\hline 0.452 & & 0.010 & 0.015 & 0.026 & 0.041 & 0.066 & 0.100 & 0.151 & 0.222 & 0.322 \\
\hline 0.357 & & 0.008 & 0.013 & 0.022 & 0.035 & 0.055 & 0.084 & 0.126 & 0.185 & 0.268 \\
\hline 0.344 & & 0.008 & 0.013 & 0.021 & 0.035 & 0.054 & 0.082 & 0.122 & 0.180 & 0.259 \\
\hline 0.194 & & 0.007 & 0.012 & 0.019 & 0.030 & 0.046 & 0.069 & 0.102 & 0.147 & 0.210 \\
\hline 0.167 & & 0.006 & 0.010 & 0.016 & 0.026 & 0.042 & 0.065 & 0.098 & 0.145 & 0.211 \\
\hline 0.150 & & 0.005 & 0.009 & 0.015 & 0.024 & 0.038 & 0.059 & 0.090 & 0.133 & 0.195 \\
\hline 0.088 & $0.011^{*}$ & 0.005 & 0.008 & 0.013 & 0.020 & 0.033 & 0.051 & 0.076 & 0.113 & 0.164 \\
\hline
\end{tabular}

Expanded uncertainty of the DMSO molar fraction is $0.001(\mathrm{k}=2)$. The expanded uncertainty of the pressure is $9 \%(\mathrm{k}=2)$. The uncertainty of the temperature is $\pm 0.1 \mathrm{~K}$ for $\mathrm{T}<433.15 \mathrm{~K}(\mathrm{k}=2)$ The uncertainty of the temperature is $\pm 2 \mathrm{~K}$ for $\mathrm{T} \geq 433.15 \mathrm{~K}(\mathrm{k}=2)$.

* In this point the estimated contribution of the water to the vapor pressure is higher than the uncertainty of the pressure, so the expanded uncertainty at this point is increased to $13 \%$. Composition was estimated from the water content of the pure compounds.

Vapor pressure data of the mixture DMSO + AmimCl at different temperatures are presented in Figure 9. 


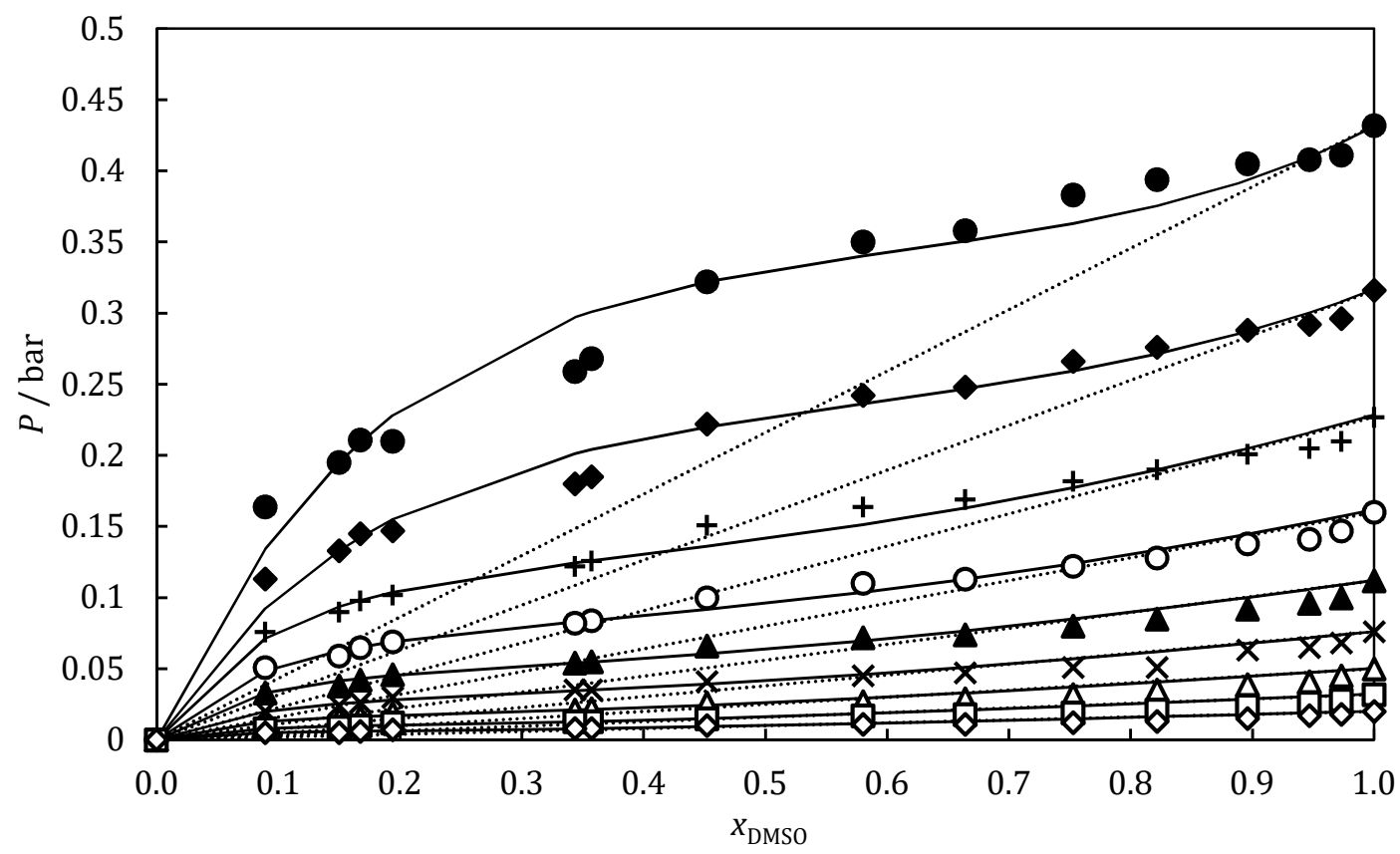

Figure 9. Experimental vapor pressures of mixtures of DMSO + $\mathrm{AmimCl}$ at $433.15 \mathrm{~K}(\bullet)$;

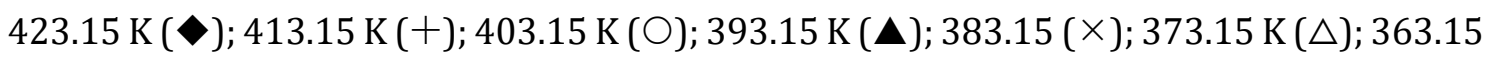
$\mathrm{K}(\square) ; 353.15 \mathrm{~K}(\diamond)$. Symbols represent the experimental data, solid lines represent NRTL calculations and dotted lines represent Raoult's Law prediction.

It is observed that the uncertainties achieved in the pressure are higher than the uncertainties achieved by other authors ${ }^{48}\left( \pm 10^{-4}\right.$ bar $)$ and ${ }^{18,49}\left( \pm 4 \cdot 10^{-4} \mathrm{kPa}\right)$. The vapor pressure present positive deviations from the Raoult's Law at low concentrations of DMSO and thus, high concentrations of ionic liquid, while at low concentrations of ionic liquid the data presents a very slight negative deviation of the Raoult law, presenting a good approximation to it as expected. This behavior suggests unfavorable interactions between the DMSO and the ionic liquid. A positive deviation from the Raoult's Law was also observed by Nebig et al. ${ }^{50}$ and Kato et al. ${ }^{51}$ that measured vapor pressure of a variety of alkyl imidazolium bis(trifluoromethylsulfonyl)imide IL with some alkanes, alkenes, aromatics and alcohols. Zhao et al. ${ }^{52}$ measure the vapor pressures of binary systems containing water, methanol or propanol plus some imidazolium dialkylphosphate family ionic liquids. The authors found a negative deviation of the Raoult's law, but with different extends depending on the different affinity between the different solvents. Similar results were found by Huo et al., ${ }^{22}$ they studied the vapor pressure of imidazolium [ $\left.\mathrm{BF}_{4}-\right]$ and $\left[\mathrm{PF}_{6}-\right]$ with organic solvents, and found a that the vapor pressure of the solvents reduces when these ionic liquids are added until below the Raoult's Law due to the complex interactions between the aromatic compounds and the ionic liquids. Carvalho et al. ${ }^{53}$ studied the system composed by 1-alky-3-methylimidazolium chloride family of ionic liquids plus water or ethanol. They 
found negative deviations of the Raoult's law that suggest favorable interactions between these components and the ionic liquid.

In order to test our measurements the vapor pressures of the pure DMSO were compared to that of literature. ${ }^{54-57}$ Results are reported in Figure 10 showing some scattering between the data reported by different authors in the literature. Despite the scattering, data reported in this work is in agreement with the authors due to the high uncertainty of our data. Some of the discrepancies can be explained due to the possible presence of impurities as water, only Tochigi et al. 56 and Zhang et al. 57 report purities in the DMSO, being $99.9 \%$ mass fraction for both authors.

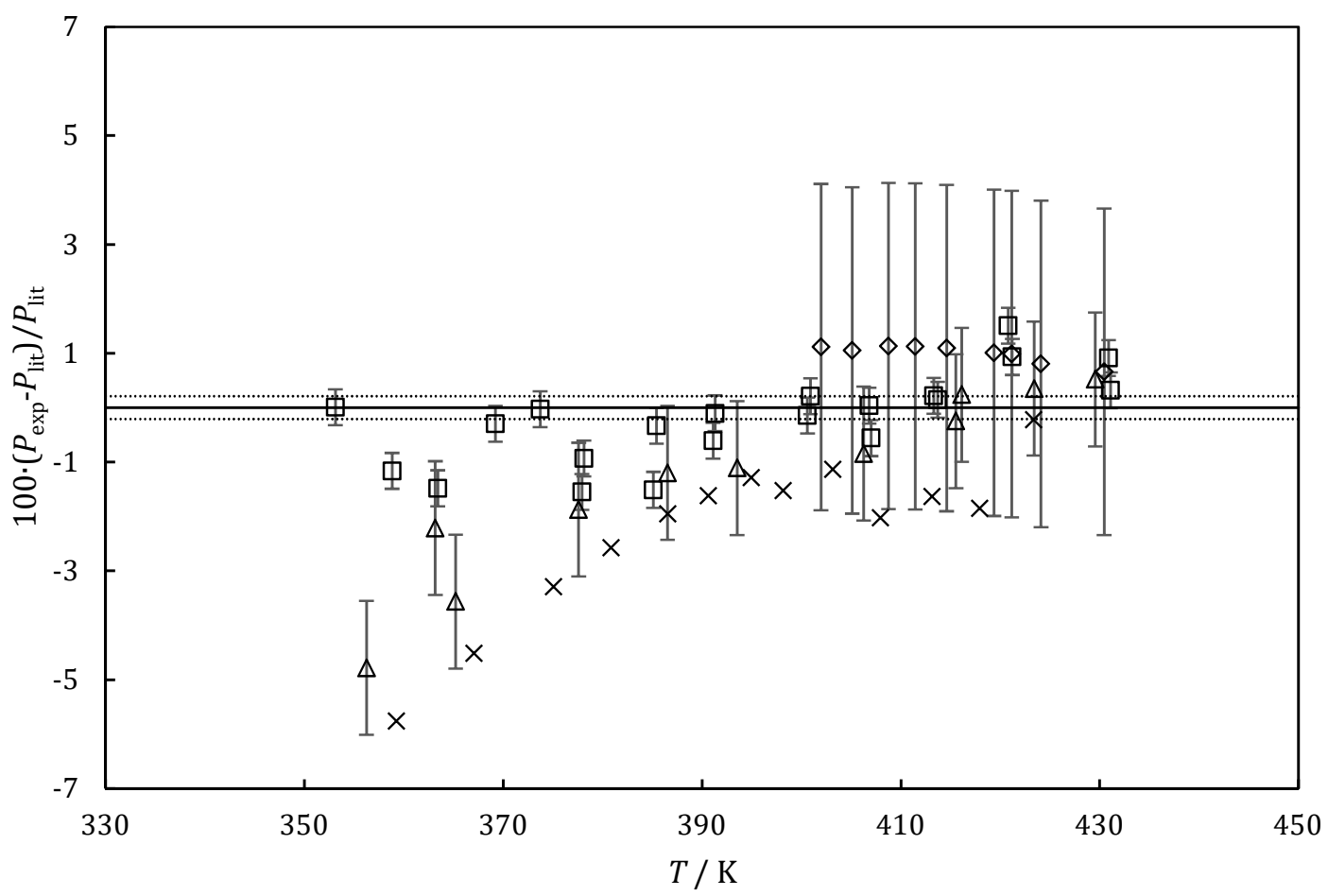

Figure 10. Relative deviation (\%) of the experimental data of DMSO vapor pressure from the literature as a function of the temperature: Jakli et al. ${ }^{54}(\square)$; Nishimura et al. ${ }^{55}(\times)$ (data uncertainty not reported); Tochigi et al. ${ }^{56}(\triangle)$ and Zhang et al. $57(\diamond)$. Interpolation of our data was used in order to calculate the relative deviation of the literature data.

The data were correlated with the Non-Random-Two-Liquids (NRTL) Model. This model correlates the activity coefficients $\gamma_{i}$ with $x_{i}$.

The equations for a binary mixture are presented in eq. 4 and 5: 


$$
\begin{aligned}
& \left\{\begin{array}{l}
\ln \gamma_{1}=x_{2}^{2}\left[\tau_{21}\left(\frac{G_{21}}{x_{1}+x_{2} G_{21}}\right)^{2}+\frac{\tau_{12} G_{12}}{\left(x_{2}+x_{1} G_{12}\right)^{2}}\right] \\
\ln \gamma_{2}=x_{1}^{2}\left[\tau_{12}\left(\frac{G_{12}}{x_{2}+x_{1} G_{12}}\right)^{2}+\frac{\tau_{21} G_{21}}{\left(x_{1}+x_{2} G_{21}\right)^{2}}\right]
\end{array}\right. \\
& \left\{\begin{array}{l}
\ln G_{12}=-\alpha_{12} \tau_{12} \\
\ln G_{21}=-\alpha_{21} \tau_{21}
\end{array}\right.
\end{aligned}
$$

Correlated parameters are presented in Table 12.

Table 12. Correlated parameters of the NRTL Model for the vapor pressure of DMSO+IL mixtures

\begin{tabular}{c|ccccccccc}
\hline$T / \mathrm{K}$ & 353.1 & 363.1 & 373.1 & 383.1 & 393.1 & 403.1 & 413.1 & 423.1 & 433.1 \\
\hline$\alpha_{12}=\alpha_{21}$ & 0.30 & 0.30 & 0.30 & 0.30 & 0.30 & 0.30 & 0.30 & 0.30 & 0.30 \\
$\tau_{12}$ & 3.12 & 3.04 & 2.82 & 2.41 & 2.36 & 2.07 & 1.85 & 0.85 & 0.71 \\
$\tau_{21}$ & -0.92 & -0.89 & -0.78 & -0.58 & -0.45 & -0.26 & -0.07 & 0.83 & 1.20 \\
ARD\% & 11.82 & 11.93 & 9.87 & 7.16 & 5.67 & 4.05 & 3.69 & 4.03 & 4.75 \\
\hline
\end{tabular}

The vapor pressures calculated with the NRTL model are represented in Figure 9. Symbols represent the experimental data and the solid line represents the NRTL values. The ARD\% reduces when the temperature rises, however, at $433.15 \mathrm{~K}$, the uncertainty of the temperature increases therefore the ARD\% increases as well.

The parameters $\tau$ are function of temperature as follows:

$$
\begin{gathered}
\tau_{12}=a_{12}+\frac{b_{12}}{T /(K)} \\
\tau_{21}=a_{21}+\frac{b_{21}}{T /(K)}
\end{gathered}
$$

The parameters were fitted and are presented in Table 13:

Table 13. Parameters for equations ( 6 ) and ( 7 ).

\begin{tabular}{|l|l|}
\hline$a_{12}$ & -9.7592 \\
$b_{12}$ & 4656.6 \\
$a_{21}$ & 9.5976 \\
$b_{21}$ & -3840.3 \\
\hline
\end{tabular}




\section{Conclusions}

Density, viscosity, and vapor pressure of DMSO + AmimCl were experimentally determined. Densities and viscosities were measured at temperatures $\mathrm{T}=[293.15,373.15] \mathrm{K}$ and $x_{\mathrm{DMSO}}$ $=0,0.050 .1,0.15,0.25,0.5,0.75,0.9$ and pure DMSO at atmospheric pressure with a Stabinger viscosimeter. The mixtures behave as expected in literature.

The density and the viscosity decrease with increasing temperature and DMSO concentrations. Correlation of viscosity was made as a function of temperature and concentration with two equations. The first one has an average relative deviation (ARD\%) $=6.8 \%$ and $\% \operatorname{Max}=30.7 \%$, The second one has an $\mathrm{ARD} \%=16.3 \%$ and $\% \operatorname{Max}=45.2 \%$.

Vapor pressures of the mixtures were measured at $\mathrm{T}=[353.1,433.1] \mathrm{K}$. Positive deviations were observed at low DMSO concentrations while at high concentration the behavior approximates the Raoult's Law. The measurements were correlated with Non-RandomTwo-Liquid (NRTL) model, obtaining ARD\% between 5 and 12\%. Therefore, a good fitting for the viscosities and vapor pressures correlation was achieved.

\section{List of symbols}

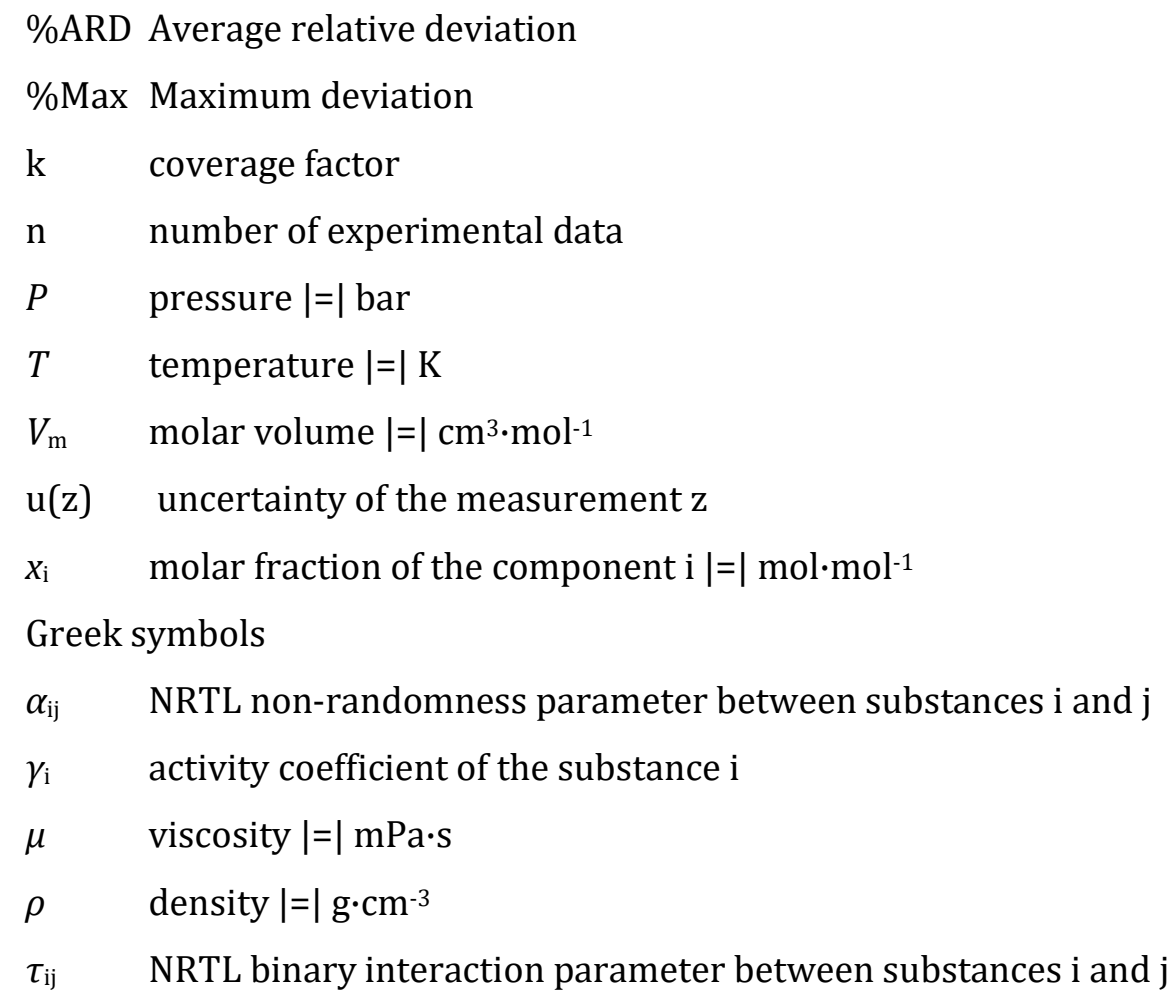




\section{Acknowledgements}

Authors thank the Junta de Castilla y León for funding through the project VA295U14 and to the Spanish Ministry of Economy and Competitiveness (MINECO) for the project ENE2014-53459-R. MDB thanks the MINECO for the Ramón y Cajal research fellowship (RYC-2013-13976).

\section{References:}

(1) Marsh, K. N.; Boxall, J. A.; Lichtenthaler, R. Fluid Phase Equilib. 2004, 219 (1), 93-98.

(2) Brennecke, J. F.; Maginn, E. J. AIChE J. 2001, 47 (11), 2384-2389.

(3) Vitz, J.; Erdmenger, T.; Schubert, U. S. Cellul. Solvents Anal. Shap. Chem. Modif. 2010, 299-317.

(4) Cuissinat, C.; Navard, P.; Heinze, T. Carbohydr. Polym. 2008, 72 (4), 590-596.

(5) Zhang, H.; Wu, J.; Zhang, J.; He, J. Macromolecules 2005, 38 (20), 8272-8277.

(6) Gericke, M.; Liebert, T.; Seoud, O. A. El; Heinze, T. Macromol. Mater. Eng. 2011, 296 (6), 483-493.

(7) Jan, R.; Rather, G. M.; Bhat, M. A. J. Solution Chem. 2014, 43 (4), 685-695.

(8) Andanson, J.-M.; Bordes, E.; Devémy, J.; Leroux, F.; Pádua, A. a. H.; Gomes, M. F. C. Green Chem. 2014, 16 (5), 2528.

(9) Seddon, K. R.; Stark, A.; Torres, M.-J. Pure Appl. Chem. 2000, 72 (12), 2275-2287.

(10) Lv, Y.; Wu, J.; Zhang, J. J.; Niu, Y.; Liu, C. Y.; He, J.; Zhang, J. J. Polymer (Guildf). 2012, 53 (12), 2524-2531.

(11) Wang, X.; Li, H.; Cao, Y.; Tang, Q. Bioresour. Technol. 2011, 102 (17), 7959-7965.

(12) Wu, D.; Wu, B.; Zhang, Y. M.; Wang, H. P. J. Chem. Eng. Data 2010, 55 (2), 621-624.

(13) Sescousse, R.; Le, K. A.; Ries, M. E.; Budtova, T. J. Phys. Chem. B 2010, 114 (21), 72227228.

(14) Calvar, N.; González, B.; Domínguez, A.; Tojo, J. J. Solution Chem. 2006, 35, 1217-1225.

(15) Lopes, J. M.; Kareth, S.; Bermejo, M. D.; Martín, Á.; Weidner, E.; Cocero, M. J. J. Supercrit. Fluids 2016, 111, 91-96.

(16) Jiménez de la Parra, C.; Zambrano, J. R.; Bermejo, M. D.; Martín, Á.; Segovia, J. J.; Cocero, M. J. J. Chem. Thermodyn. 2015, 91, 8-16. 
(17) Zhao, J.; Li, C.; Wang, Z. J. Chem. Eng. Data 2006, 51, 1755-1760.

(18) Jiang, X.; Wang, J.; Li, C.; Wang, L.; Wang, Z. J. Chem. Thermodyn. 2007, 39, 841-846.

(19) Han, J.; Lei, Z.; Dai, C.; Li, J. J. Chem. Eng. Data 2016, 61 (3), 1117-1124.

(20) Kato, R.; Gmehling, J. J. Chem. Thermodyn. 2005, 37 (6), 603-619.

(21) Verevkin, S. P.; Safarov, J.; Bich, E.; Hassel, E.; Heintz, A. Fluid Phase Equilib. 2005, 236 (1-2), 222-228.

(22) Huo, Y.; Xia, S.; Yi, S.; Ma, P. Fluid Phase Equilib. 2009, 276 (1), 46-52.

(23) Joint Committee for Guides in Metrology. Int. Organ. Stand. 2008.

(24) Lemmon, E. W.; Span, R. J. Chem. Eng. Data 2006, 51, 785-850.

(25) Melo, C. I.; Rodrigues, A. I.; Bogel-Łukasik, R.; Bogel-Łukasik, E. J. Phys. Chem. A 2012, $116,1765-1773$.

(26) Lopes, J. M.; Sánchez, F. A.; Reartes, S. B. R.; Bermejo, M. D.; Martín, Á.; Cocero, M. J. J. Supercrit. Fluids 2016, 107, 590-604.

(27) Galiński, M.; Lewandowski, A.; Stępniak, I. Electrochim. Acta 2006, 51 (26), 55675580 .

(28) Gómez, E.; González, B.; Domínguez, a; Tojo, E.; Tojo, J. J. Chem. Eng. Data 2006, 51, 696-701.

(29) Qian, W.; Xu, Y.; Zhu, H.; Yu, C. J. Chem. Thermodyn. 2012, 49 (67), 87-94.

(30) Sastry, N. V.; Vaghela, N. M.; Macwan, P. M. J. Mol. Liq. 2013, 180, 12-18.

(31) Campbell, A. N. Can. J. Chem. 1979, 57, 705-707.

(32) Casteel, J. F.; Sears, P. G. J. Chem. Eng. Data 1974, 19 (3), 196-200.

(33) Wang, X.; Yang, F.; Gao, Y.; Liu, Z. J. Chem. Thermodyn. 2013, 57, 145-151.

(34) Ivanov, E. V.; Lebedeva, E. Y.; Abrosimov, V. K.; Ivanova, N. G. J. Solution Chem. 2012, 41 (8), 1311-1313.

(35) Iulian, O.; Ciocirlan, O. J. Chem. Eng. Data 2012, 57 (10), 2640-2646.

(36) Krakowiak, J.; Bobicz, D.; Grzybkowski, W. J. Mol. Liq. 2000, 88 (2-3), 197-207.

(37) Zarei, H. A.; Shahvarpour, S. 2008, No. 1, 1660-1668.

(38) Clever, H. L.; Snead, C. C. J. Phys. Chem. 1963, 67 (4), 918-920.

(39) Hiraga, Y.; Kato, A.; Sato, Y.; Aida, T. M.; Watanabe, M.; Smith, R. L. Sep. Purif. Technol. 2015, 155, 139-148. 
(40) Ciocirlan, O.; Iulian, O. J. Chem. Eng. Data 2012, 57 (11), 3142-3148.

(41) Yang, C.; Wei, G.; Li, Y. J. Chem. Eng. Data 2008, 53 (5), 1211-1215.

(42) Govinda, V.; Attri, P.; Venkatesu, P.; Venkateswarlu, P. Fluid Phase Equilib. 2011, 304 (1-2), 35-43.

(43) Gokavl, G. S.; Raju, J. R.; Aminabhavi, T. M.; Balundgi, R. H.; Muddapur, M. V. J. Chem. Eng. Data 1986, 31 (1), 15-18.

(44) Saleh, M. A.; Ahmed, O.; Ahmed, M. S. J. Mol. Liq. 2004, 115 (1), 41-47.

(45) Ali, A.; Nain, A. K.; Chand, D.; Ahmad, R. J. Chinese Chem. Soc. 2006, No. 53, 531-543.

(46) Zhao, T.; Zhang, J.; Guo, B.; Zhang, F.; Sha, F.; Xie, X.; Wei, X. J. Mol. Liq. 2015, 207 (July), 315-322.

(47) Kapadi, U. R.; Chavan, S. K.; Yemul, O. S. J. Chem. Eng. Data 1997, 42 (96), 548-550.

(48) Calvar, N.; Domínguez, Á.; Macedo, E. A. J. Chem. Thermodyn. 2013, 66, 137-143.

(49) Shen, C.; Li, X. M.; Lu, Y. Z.; Li, C. X. J. Chem. Thermodyn. 2011, 43 (11), 1748-1753.

(50) Nebig, S.; Bölts, R.; Gmehling, J. Fluid Phase Equilib. 2007, 258 (2), 168-178.

(51) Kato, R.; Krummen, M.; Gmehling, J. Fluid Phase Equilib. 2004, 224 (1), 47-54.

(52) Zhao, J.; Jiang, X.-C.; Li, C.-X.; Wang, Z.-H. Fluid Phase Equilib. 2006, 247 (1-2), 190198.

(53) Carvalho, P. J.; Khan, I.; Morais, A.; Granjo, J. F. O.; Oliveira, N. M. C.; Santos, L. M. N. B. F.; Coutinho, J. A. P. Fluid Phase Equilib. 2013, 354, 156-165.

(54) Jakli, G.; Alexander Van Hook, W. J. Chem. Thermodyn. 1972, 4 (6), 857-864.

(55) Nishimura, M.; Nakayama, M.; Yano, T. 1972, No. 3, 223-226.

(56) Tochigi, K.; Akimoto, K.; Ochi, K.; Liu, F.; Kawase, Y. J. Chem. Eng. Data 1999, 44 (3), 588-590.

(57) Zhang, Z.; Lv, M.; Huang, D.; Jia, P.; Sun, D.; Li, W. J. Chem. Eng. Data 2013, 58 (12), 3364-3369. 
Chapter 2 


\title{
Chapter 3: Determination of density and excess molar volume of dimethyl sulfoxide + 1-allyl-3- methylimidazolium chloride mixtures at high pressure *
}

\begin{abstract}
In this work, densities of dimethyl sulfoxide + 1-allyl-3-methylimidazolium chloride mixtures have been experimentally determined with a vibrating tube densimeter. Densities were measured at temperatures between 293.15 and $373.15 \mathrm{~K}$ and molar fractions of dimethyl sulfoxide $\mathrm{X}_{\mathrm{DMSO}}=0,0.05,0.1,0.15,0.25,0.5,0.75,0.9$ and 1 at pressures in the range $\mathrm{P}=[0.1,35] \mathrm{MPa}$. It was found that density increases with ionic liquid concentration and with pressure and decrease with temperature. Excess molar volumes were calculated resulting in negative values with a maximum of non-ideality at DMSO concentration of $\mathrm{X}_{\mathrm{DMSO}}$ $=0.5$. The excess molar values were less negative at high pressures. At $T=330 \mathrm{~K}$ a maximum in the excess molar values was observed at several concentrations. Density was correlated as a function of temperature, pressure and concentration with an average relative deviation of $0.12 \%$.
\end{abstract}

Keywords: ionic liquid, 1-ally-3-methylimidazolium Chloride, dimethyl sulfoxide, density, excess molar volume, correlation.

*This Chapter is published as "Pablo Nisa, L.; Segovia, J. J.; Martín, Á.; Martín, M. C.; Bermejo, M. D. Determination of Density and Excess Molar Volume of Dimethyl Sulfoxide + 1-Allyl-3Methylimidazolium Chloride Mixtures at High Pressure. J. Supercrit. Fluids 2017, 130, 7683." 


\section{Introduction:}

Currently, and due to the strong need of environmentally benign technologies, the possibilities of using so-called ionic liquids (ILs) are being explored. These substances are characterized by being composed only by ions whose size are irregular and large enough to prevent the formation of a solid net. Thus, they are liquid at room temperatures. Therefore, ILs can be defined as salts in liquid phase ${ }^{1}$. Their most notable property is its negligible vapor pressure ${ }^{2}$ and high solvation power for multitude of components, both organic and inorganic. These properties make them attractive for their use as an alternative to traditional and highly volatile organic solvents. By combining different anions and cations, millions of ionic liquids can be synthetized and their properties can be tuned by simply changing, cations, anions or the length of the alkyl chain substituents. ${ }^{1}$ Among them, imidazolium based ionic liquids with acetate, chloride or alkylphosphate anions stand out for their capacity of dissolving cellulose and other natural polymers. ${ }^{3}$

Cellulose is the most abundant organic substance on earth and its processing can lead to obtain high added-value substances. 4 Most conventional processes for cellulose transformation are based on the use of highly pollutant solvents or extreme operational conditions. 5 Thus, the development of process for cellulose transformation using ionic liquids has attracted a lot of attention in the last years. ${ }^{6-12}$ One of the main inconvenient for the development of cellulose processing in ionic liquid is the high viscosity of ILs, ${ }^{13}$ especially in the case of those with chloride anion. In addition, the dissolution of cellulose in ILs causes the viscosity of the mixture to increase significantly. ${ }^{5,14}$ As a consequence, ionic liquids are often used in combination with co-solvents in order to reduce the viscosity and enhance the transport properties, 15 because it is well known that molecular solvents decrease the viscosity of alkyl-imidazolium ionic liquids while other impurities as chloride increase it. 16,17 In the case of cellulose processing it is important that the co-solvent chosen do not cause the precipitation of cellulose thus, dimethyl formamide or most frequently dimethyl sulfoxide (DMSO) are used. ${ }^{18-20}$ Thus, it is important to know the physical properties of these mixtures at different operational conditions.

In literature, it is possible to find several published works where the density and viscosity of several imidazolium chloride based ionic liquids are determined along with co-solvents or impurities. For example, Lv and coworkers, ${ }^{14}$ measured the effect of the DMSO in the viscosity of the ionic liquid + cellulose mixtures and concluded that the addition of DMSO in cellulose/AmimCl or cellulose/BmimCl decreases dramatically the viscosity of them. 
Densities, excess volume, viscosities and other thermodynamics properties of aqueous mixtures of alkyl-imidazolium chloride based IL's has also been studied among others by Sastry et al., ${ }^{21}$ Tariq et al., ${ }^{22}$ Liu et al., ${ }^{23}$ Sing \& Kumar ${ }^{24}$ and Gomez et al. 25 Properties of aqueous mixtures of AmimCl by Xu et al., ${ }^{26} \mathrm{Wu}$ et al., ${ }^{27}$ and Jimenez and co-workers. ${ }^{28}$ Kumar et al., ${ }^{29}$ proceed to measure the density of mixtures ethylene glycol + alkylimidazolium chloride ionic liquids at atmospheric pressure. Lopes et al. ${ }^{30}$ measured the density and viscosity of mixtures $\mathrm{CO}_{2} / \mathrm{AmimCl}$ and correlated the viscosity with a modified equation from Seddon et al. ${ }^{16}$ In general, it is observed that density decreases with temperature and with co-solvent concentration.

Some other authors have studied the influence of the pressure on the density. For example, Tomé et al. have studied the change of the density of pure imidazolium based Ionic Liquids with the pressure, and correlated this data with the Tait equation, ${ }^{31}$ Machida et al. also measured the density of L-Lactate-containing Ionic Liquids up to $200 \mathrm{MPa}, 32$ and Safarov et al. determined the density and viscosity of pure 1-butyl-3-methylimidazolium acetate [Bmim][Ac] up to $140 \mathrm{MPa} .{ }^{33}$ Gardas et al. ${ }^{34}$ measured the density of imidazolium-based Ionic Liquids and then correlated it with the Tait equation. All of them found that the density of ionic liquids increased with pressure. There is also a number of works presenting densities of different organic liquids + different organic solvents under pressure, 35-38 observing also that the density of the mixture increases with pressure.

In the literature, examples of both positive and negative excess molar volumes in co-solvent + ionic liquid mixtures can be found. In ${ }^{39}$ Bahadur et al. studied the excess molar volume in mixtures of ionic liquid and water, and they concluded that excess molar volumes are the result of two competitive effects, a positive effect caused by the reduction of self-association between molecules due to the influence of the hydrogen bonds or Van der Waals interactions, and a negative effect that could be a result of a better packing caused of polar interactions between molecules. In mixtures of co-solvents with imidazolium chloride or acetate ionic liquids it is reported that excess molar volume is decreasing with increasing co-solvent concentration until reaching a minimum for molar fractions of around 0.6-0.7. 25,28 Sandhya et al. studied the influence of the temperature and alcohol's length on the excess volume, and they found that when the temperature and the alcohol chain length increases, the mixture becomes less ideal, and the point where the excess molar volume is maximum moves to higher compositions. ${ }^{40}$ On the other hand, Makhtarani et al. measured the behavior of binary mixtures of pyridinium based ionic liquid plus water, and they found that the mixtures have positive excess molar volume, and it is less ideal when the 
temperature increases. ${ }^{41}$ To the best of our knowledge, there are no experimental data of densities and excess molar volume of mixtures DMSO + AmimCl.

In this work the density of mixtures of DMSO $+\mathrm{AmimCl}$ at various conditions of temperature, pressure and concentration are presented. Excess molar volumes were calculated using the experimental density data. Density was correlated as a function of temperature, pressure and composition.

\section{Experimental}

\subsection{Materials}

For the calibration, pure water and vacuum were used. Density of toluene was measured in order to check the calibration. Both compounds, water and toluene were supplied by Sigma Aldrich with purities of $100 \%$ and $99.8 \%$ respectively. The DMSO has a purity of $99.9 \%$ and was supplied by Sigma - Aldrich with a humidity of $\approx 200$ ppm. The 1-allyl-3methylimidazolium chloride supplied by Iolitec (assay (NMR) $=98 \%$; 1-Allyl-3methylimidazolium (IC)= 99.9\%; Chloride (IC)=99.9\%; 1 -Methylimidazole (IC) $<1 \%$ and Water $(\mathrm{KF})=0.2467 \%)$. The ionic liquid was further dried by applying a level of vacuum of $10^{-2}$ mbar while stirred at temperature of $86^{\circ} \mathrm{C}$. Good results of humidity were obtained after this procedure as it is shown in Table 1. In addition, the ionic liquid was carefully handled in order to avoid absorption of water from the air, as it is explained below.

Table 1. Water content in mixtures DMSO + AmimCl

\begin{tabular}{ll}
\hline$X_{\text {DMSO }} / \mathrm{mol} / \mathrm{mol}$ & $X_{\text {water }} / \mathrm{mol} / \mathrm{mol}$ \\
\hline 0.000 & 0.013 \\
0.048 & 0.015 \\
0.098 & 0.016 \\
0.147 & 0.014 \\
0.248 & 0.006 \\
0.495 & 0.011 \\
0.729 & 0.021 \\
0.893 & 0.008 \\
0.999 & 0.001
\end{tabular}

Uncertainty of the molar fraction is $0.001 \mathrm{~mol} / \mathrm{mol}$ 


\subsection{Description of the equipment}

The mixtures were prepared gravimetrically by using a high precision balance (Sartorius Basic BA 310P, precision $=0.001 \mathrm{~g}$ ) under nitrogen atmosphere, in which the humidity is kept below 30\%. The water content of IL, DMSO and of their mixtures was measured with Karl - Fischer Coulometric titration using Mettler Toledo C20 KF, taking at least three measurements per sample.

Densities of these mixtures at various temperatures and pressures, from atmospheric pressure to $35 \mathrm{MPa}$, were performed in a vibrating tube densimeter (VTD) model Anton Paar DMA 514, connected to a frequency meter Anton Paar DMA 60. A schematic diagram of the equipment is shown in Figure 1. The basis of a vibrating tube densimeter is that the resonance frequency of a body immersed in a fluid depends on the density. The vibrating tube viscometer is a simple device consisting mainly of a thin " $U$ " tube filled with the liquid which density we want to determine. The tube is surrounded by mineral oil bath, Julabo $\mathrm{F}$ 25, whose purpose is merely to keep constant its temperature. A Pt100 thermometer is placed in the curved part of the " $U$ " (where the resonance frequency is precisely measured) and a temperature controller, Julabo HE, integrated in the above mentioned thermal bath keeps the temperature constant. The Pt100 thermometer has an uncertainty of $\pm 0.05 \mathrm{~K}$ and the frequency meter has an uncertainty of $\pm 7.510^{-3} \mu \mathrm{s}$. The pressure is measured with a digital manometer GE Drunk DPI 104 and controlled by a manually operated piston. The manometer has an uncertainty of \pm 0.02 bar. To calibrate is necessary to measure the response of the equipment in two different conditions, firstly with the tube under vacuum and secondly with a fluid of known density, which in this case, high purity distilled water was chosen. It is important that the conditions of pressure and temperature of these calibrations are the same that the final intended measuring conditions. Previous to the measurement of the mixtures DMSO + AmimCl, toluene density was measured in order to compare with the available data on Refprop. ${ }^{42}$ The equipment was previously described in literature. 43,44 


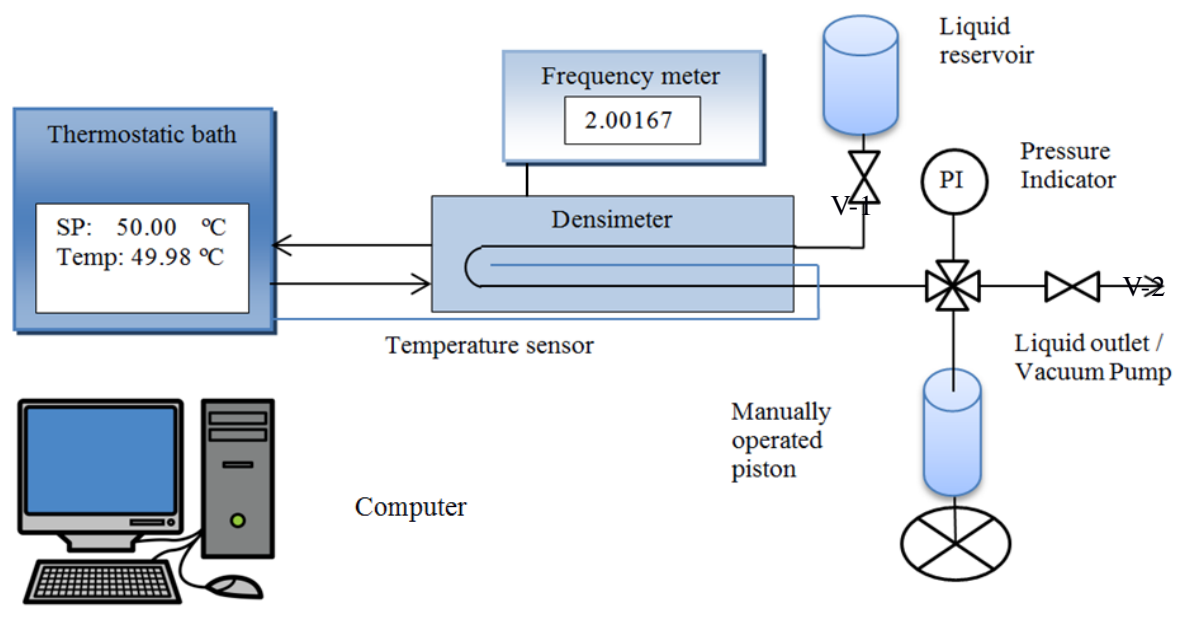

Figure 1: Installation scheme.

\subsection{Densimeter loading and measuring procedures}

Ionic liquids are in general very hygroscopic, so they must be handled with extreme care in order to avoid their humidification. Thus to charge the mixture in the densimeter the following procedure was used: first of all, a vacuum pump is connected to the pipe, and then, when the pressure inside is lower than $10^{-2} \mathrm{mPa}$ the pump is stopped and the valve $\mathrm{V}-2$ is closed. Secondly, a funnel filled with the mixture is connected to the pipe. In the next step, the valve $\mathrm{V}-1$ is opened and the mixture enters and fills the equipment. It is important to avoid that air bubbles entering in the pipe because they can modify the density measurements.

While working with the highly viscous mixture, during the filling step, the bath temperature is set to $80^{\circ} \mathrm{C}$ so the mixture can flow easily through the pipe. Finally, all valves are closed, so the mixture keeps insulated from water.

After the mixture is introduced inside the equipment, the bath temperature is set to the first temperature, and then the densities of the mixture at the specified temperature in all range of pressures are measured. The density is measured 3 times for each point and 10 times at atmospheric pressure, the final value is an average of all the measurements. Finally, the next temperature is set up in the bath and the process is repeated. 


\section{Evaluation of the uncertainty}

In this work the calibration method for the vibrating tube densimeter developed Lagourette et al. 45 and modified by Comuñas et al. ${ }^{44}$ was used. In this method, the density of one fluid depends on the oscillation period as is described in the equation (1):

$$
\rho(T, P)=A(T) \tau^{2}(T, P)-B(T, P)
$$

With two sets of data, for (vacuum and high purity water) it is possible to determine the calibration constants " $A$ " and " $B$ " that are the characteristic parameters of the apparatus, for every operational condition. In this work, vacuum and high purity water were used as reference fluids.

Table 2. Uncertainty budget for the vibrating tube densimeter. Values calculated for density of $x_{\text {DMSO }}=0.247, P=1 \mathrm{MPa}$ and $T=333.15 \mathrm{~K}$.

\begin{tabular}{|c|c|c|c|c|c|}
\hline Uncertainty & & Units & Estimate & Divisor & $\begin{array}{l}\mathrm{u}(x) / \\
\mathrm{kg} / \mathrm{m} 3\end{array}$ \\
\hline $\mathrm{u}(\rho$ ref $)$ & $\begin{array}{c}\text { Reference } \\
\text { Material }\end{array}$ & $\mathrm{kg} / \mathrm{m}^{3}$ & 0.1 & 2 & 0.058 \\
\hline $\mathrm{u}(T)$ & $\begin{array}{c}\text { Calibration } \\
\text { Resolution } \\
\text { Repeatability }\end{array}$ & $\mathrm{K}$ & $\begin{array}{l}0.050 \\
0.010 \\
0.005\end{array}$ & $\begin{array}{c}2 \\
2 \sqrt{3} \\
1\end{array}$ & 0.0257 \\
\hline $\mathrm{u}(P)$ & $\begin{array}{c}\text { Calibration } \\
\text { Resolution } \\
\text { Repeatability }\end{array}$ & $\mathrm{MPa}$ & $\begin{array}{l}0.02 \\
0.01 \\
0.01\end{array}$ & $\begin{array}{c}2 \\
2 \sqrt{3} \\
1\end{array}$ & 0.014 \\
\hline $\mathrm{u}(\tau$ water $)$ & $\begin{array}{c}\text { Repeatability } \\
\text { Resolution }\end{array}$ & $\mu \mathrm{s}$ & $\begin{array}{l}2.32 \mathrm{E}-06 \\
1.00 \mathrm{E}-06\end{array}$ & $\begin{array}{c}1 \\
2 \sqrt{3}\end{array}$ & $2.34 \mathrm{E}-06$ \\
\hline $\mathrm{u}(\tau$ void $)$ & $\begin{array}{c}\text { Repeatability } \\
\text { Resolution }\end{array}$ & $\mu \mathrm{s}$ & $\begin{array}{l}1.77 \mathrm{E}-06 \\
1.00 \mathrm{E}-06\end{array}$ & $\begin{array}{c}1 \\
2 \sqrt{3}\end{array}$ & $1.79 \mathrm{E}-06$ \\
\hline $\mathrm{u}(\mathrm{A}(T))$ & & $\mathrm{kg} \mathrm{m}^{-3} \mu \mathrm{s}^{2}$ & & & 0.1 \\
\hline $\mathrm{u}(\mathrm{B}(T, P))$ & & $\mathrm{kg} \mathrm{m}^{-3}$ & & & 0.5 \\
\hline $\mathrm{U}(\mathrm{A}(T))$ & & $\mathrm{kg} \mathrm{m}^{-3} \mu \mathrm{s}^{2}$ & & $\mathrm{k}=2$ & 0.3 \\
\hline $\mathrm{U}(\mathrm{B}(T, P))$ & & $\mathrm{kg} \mathrm{m}^{-3}$ & & $\mathrm{k}=2$ & 1.0 \\
\hline $\mathrm{u}(\rho)$ & & $\mathrm{kg} \mathrm{m}^{-3}$ & & & 0.7 \\
\hline $\mathrm{U}(\rho)$ & & $\mathrm{kg} \mathrm{m}^{-3}$ & & $\mathrm{k}=2$ & 1.5 \\
\hline$\overline{\mathrm{U}_{\mathrm{r}}(\rho)}$ & & $\mathrm{kg} \mathrm{m}^{-3} / \mathrm{kg} \mathrm{m}^{-3}$ & & $\mathrm{k}=2$ & $1.3 \mathrm{E}-03$ \\
\hline
\end{tabular}


Equations of uncertainty of the vibrating tube densimeter can be calculated from 43 following the law of propagation of uncertainty described in JCGM 100: 2008. 46

The uncertainty achieved has the same order of magnitude as that obtained by others authors using the same or similar equipment. ${ }^{43}$

Finally, the density of toluene measured with the densimeter is compared to data from Refprop ${ }^{42}$ resulting in a proper fit with the experimental data. 


\section{Experimental results}

\subsection{Densities of DMSO + AmimCl.}

Densities at different DMSO molar fractions as a function of pressure and temperature are presented in tables from Table 3 to Table 11. Density measurements are plotted versus pressures and temperatures in Figure 2. It is observed that density increases linearly with pressure and decrease with temperature. The same behavior is observed for all the concentrations studied.

Table 3. Densities of pure DMSO, $x_{\mathrm{H} 20}=0.001$.

$\rho / \mathrm{kg} \mathrm{m}^{-3}$

\begin{tabular}{c|lllll}
\hline \multicolumn{1}{c}{$P$ / bar } & & & & \\
\multicolumn{1}{c}{293.15} & 313.15 & 333.15 & 353.15 & 373.15 \\
\hline 1 & 1098.5 & 1078.9 & 1061.0 & 1040.6 & 1019.9 \\
5 & 1099.8 & 1079.2 & 1061.2 & 1041.1 & 1020.4 \\
10 & 1100.1 & 1079.6 & 1061.6 & 1041.1 & 1020.7 \\
20 & 1100.7 & 1080.1 & 1061.9 & 1041.9 & 1021.5 \\
30 & 1101.3 & 1080.7 & 1062.5 & 1042.6 & 1022.5 \\
40 & 1101.8 & 1081.1 & 1063.1 & 1043.2 & 1023.2 \\
60 & 1102.8 & 1082.9 & 1064.3 & 1044.7 & 1024.5 \\
80 & 1103.9 & 1083.5 & 1065.5 & 1046.1 & 1026.0 \\
100 & 1105.0 & 1084.7 & 1066.8 & 1047.5 & 1027.6 \\
150 & 1106.1 & 1087.6 & 1069.9 & 1051.0 & 1031.4 \\
200 & 1109.0 & 1090.7 & 1073.0 & 1054.4 & 1035.0 \\
250 & 1111.1 & 1093.2 & 1076.0 & 1057.3 & 1038.6 \\
300 & 1113.6 & 1095.8 & 1078.9 & 1060.5 & 1042.2 \\
350 & 1116.1 & 1098.5 & 1081.7 & 1063.6 & 1045.6 \\
\hline
\end{tabular}

Expanded uncertainty of the density $\mathrm{U}(\rho)=1.5 \mathrm{~kg} \mathrm{~m}^{-3}$, expanded uncertainty of the temperature $\mathrm{U}(T)=0.05 \mathrm{~K}$, expanded uncertainty of the pressure $\mathrm{U}(P)=0.03$ bar, expanded uncertainty of the composition $\mathrm{U}(x)=0.001$ with $\mathrm{k}=2$. 
Table 4. Densities of mixture DMSO $+\mathrm{AmimCl}, x_{\mathrm{DMSO}}=0.893, x_{\mathrm{H} 20}=0.008$.

\begin{tabular}{c|lllll}
\multicolumn{5}{c}{$\rho / \mathrm{kg} \mathrm{m}^{-3}$} \\
\hline$P$ / bar & 293.15 & 313.15 & 333.15 & 353.15 & 373.15 \\
\hline 1 & 1115.3 & 1097.1 & 1081.0 & 1062.6 & 1044.5 \\
5 & 1115.4 & 1097.3 & 1081.2 & 1063.1 & 1045.0 \\
10 & 1115.8 & 1097.6 & 1081.4 & 1063.2 & 1046.0 \\
20 & 1116.2 & 1098.2 & 1082.0 & 1063.7 & 1045.7 \\
30 & 1116.6 & 1098.6 & 1082.5 & 1064.3 & 1046.4 \\
40 & 1117.1 & 1099.1 & 1083.1 & 1064.9 & 1047.1 \\
60 & 1118.3 & 1100.3 & 1084.2 & 1066.2 & 1048.3 \\
80 & 1119.0 & 1101.2 & 1085.2 & 1067.4 & 1049.5 \\
100 & 1119.9 & 1102.3 & 1086.5 & 1068.6 & 1050.8 \\
150 & 1122.2 & 1104.8 & 1089.1 & 1071.4 & 1054.2 \\
200 & 1124.8 & 1107.2 & 1091.7 & 1074.3 & 1057.2 \\
250 & 1126.7 & 1109.7 & 1094.3 & 1077.4 & 1060.3 \\
300 & 1128.7 & 1112.0 & 1096.8 & 1080.0 & 1063.2 \\
350 & 1130.9 & 1114.3 & 1099.3 & 1082.6 & 1066.3 \\
\hline
\end{tabular}

Expanded uncertainty of the density $\mathrm{U}(\rho)=1.5 \mathrm{~kg} \mathrm{~m}^{-3}$, expanded uncertainty of the temperature $\mathrm{U}(T)=0.05 \mathrm{~K}$, expanded uncertainty of the pressure $\mathrm{U}(P)=0.03$ bar, expanded uncertainty of the composition $\mathrm{U}(x)=0.001$ with $\mathrm{k}=2$. 
Table 5. Densities of mixture DMSO + AmimCl, $x_{\mathrm{DMSO}}=0.729, x_{\mathrm{H} 20}=0.021$.

\begin{tabular}{c|ccccc}
\multicolumn{5}{c}{$\rho / \mathrm{kg} \mathrm{m}^{-3}$} \\
\hline \multicolumn{7}{c}{$P$ / bar } & 293.15 & 313.15 & 333.15 & 353.15 & 373.15 \\
\hline 1 & 1129.0 & 1113.3 & 1097.8 & 1081.5 & 1065.3 \\
5 & 1129.2 & 1113.5 & 1097.9 & 1082.0 & 1065.7 \\
10 & 1129.3 & 1113.7 & 1098.0 & 1082.0 & 1066.0 \\
20 & 1129.8 & 1114.2 & 1098.8 & 1082.5 & 1066.5 \\
30 & 1130.0 & 1114.7 & 1099.0 & 1083.0 & 1067.1 \\
40 & 1130.4 & 1115.1 & 1099.6 & 1083.4 & 1067.7 \\
60 & 1131.2 & 1115.9 & 1100.4 & 1084.6 & 1068.6 \\
80 & 1132.0 & 1116.8 & 1101.2 & 1085.6 & 1069.7 \\
100 & 1132.8 & 1117.7 & 1102.3 & 1086.5 & 1070.6 \\
150 & 1134.8 & 1119.9 & 1104.5 & 1089.0 & 1073.2 \\
200 & 1137.1 & 1122.0 & 1106.7 & 1091.4 & 1075.8 \\
250 & 1138.7 & 1124.2 & 1109.1 & 1093.7 & 1078.4 \\
300 & 1141.4 & 1126.2 & 1111.2 & 1096.3 & 1080.9 \\
350 & 1143.3 & 1128.2 & 1113.3 & 1098.4 & 1083.6 \\
\hline
\end{tabular}

Expanded uncertainty of the density $\mathrm{U}(\rho)=1.5 \mathrm{~kg} \mathrm{~m}^{-3}$, expanded uncertainty of the temperature $\mathrm{U}(T)=0.05 \mathrm{~K}$, expanded uncertainty of the pressure $\mathrm{U}(P)=0.03 \mathrm{bar}$, expanded uncertainty of the composition $\mathrm{U}(x)=0.001$ with $\mathrm{k}=2$. 
Table 6. Densities of mixture DMSO + AmimCl, $x_{\mathrm{DMSO}}=0.496, x_{\mathrm{H} 20}=0.011$.

\begin{tabular}{c|ccccc}
\multicolumn{5}{c}{$\rho / \mathrm{kg} \mathrm{m}^{-3}$} \\
\hline$P /$ bar & 293.15 & 313.15 & 333.15 & 353.15 & 373.15 \\
\hline 1 & 1144.9 & 1128.8 & 1116.1 & 1101.9 & 1088.2 \\
5 & 1145.1 & 1129.0 & 1116.3 & 1102.7 & 1088.7 \\
10 & 1145.3 & 1129.1 & 1116.5 & 1102.8 & 1088.9 \\
20 & 1145.7 & 1129.5 & 1116.7 & 1102.8 & 1090.1 \\
30 & 1146.0 & 1129.7 & 1116.8 & 1103.2 & 1089.9 \\
40 & 1146.3 & 1130.0 & 1117.2 & 1103.9 & 1090.0 \\
60 & 1147.1 & 1130.9 & 1117.9 & 1104.3 & 1090.8 \\
80 & 1147.8 & 1131.6 & 1119.5 & 1105.0 & 1091.6 \\
100 & 1148.5 & 1132.2 & 1119.6 & 1105.7 & 1092.5 \\
150 & 1150.2 & 1134.1 & 1121.6 & 1107.9 & 1094.6 \\
200 & 1152.3 & 1136.2 & 1123.1 & 1109.7 & 1096.6 \\
250 & 1153.6 & 1138.0 & 1125.4 & 1111.7 & 1099.0 \\
300 & 1155.2 & 1139.6 & 1126.7 & 1113.5 & 1100.7 \\
350 & 1156.9 & 1142.6 & 1128.4 & 1115.4 & 1103.1 \\
\hline
\end{tabular}

Expanded uncertainty of the density $\mathrm{U}(\rho)=1.5 \mathrm{~kg} \mathrm{~m}^{-3}$, expanded uncertainty of the temperature $\mathrm{U}(T)=0.05 \mathrm{~K}$, expanded uncertainty of the pressure $\mathrm{U}(P)=0.03$ bar, expanded uncertainty of the composition $\mathrm{U}(x)=0.001$ with $\mathrm{k}=2$. 
Table 7. Densities of mixture DMSO + AmimCl, $x_{\mathrm{DMSO}}=0.248, x_{\mathrm{H} 20}=0.006$.

$\rho / \mathrm{kg} \mathrm{m}^{-3}$

\begin{tabular}{c|lllll}
\hline \multicolumn{2}{c}{$P /$ bar } & & & \multicolumn{1}{l}{$T / \mathrm{K}$} & \\
\multicolumn{1}{c}{293.15} & 313.15 & 333.15 & 353.15 & 373.15 \\
\hline 1 & 1150.4 & 1137.9 & 1124.4 & 1112.9 & 1100.9 \\
5 & 1150.5 & 1137.9 & 1124.5 & 1113.3 & 1101.3 \\
10 & 1150.7 & 1138.1 & 1124.5 & 1113.3 & 1101.5 \\
20 & 1151.2 & 1138.4 & 1124.9 & 1113.5 & 1101.7 \\
30 & 1151.4 & 1138.6 & 1125.2 & 1113.8 & 1102.2 \\
40 & 1151.7 & 1138.9 & 1125.5 & 1114.1 & 1102.5 \\
60 & 1152.4 & 1139.4 & 1126.0 & 1114.6 & 1103.0 \\
80 & 1153.0 & 1140.0 & 1126.6 & 1115.4 & 1103.6 \\
100 & 1153.5 & 1140.4 & 1127.5 & 1116.2 & 1104.3 \\
150 & 1155.1 & 1142.1 & 1129.0 & 1117.9 & 1106.0 \\
200 & 1157.0 & 1143.5 & 1130.6 & 1119.7 & 1108.7 \\
250 & 1158.1 & 1145.0 & 1132.6 & 1121.4 & 1110.0 \\
300 & 1159.8 & 1146.6 & 1134.1 & 1123.3 & 1111.7 \\
350 & 1161.1 & 1147.9 & 1135.7 & 1124.7 & 1114.5 \\
\hline
\end{tabular}

Expanded uncertainty of the density $\mathrm{U}(\rho)=1.5 \mathrm{~kg} \mathrm{~m}^{-3}$, expanded uncertainty of the temperature $\mathrm{U}(T)=0.05 \mathrm{~K}$, expanded uncertainty of the pressure $\mathrm{U}(P)=0.03$ bar, expanded uncertainty of the composition $\mathrm{U}(x)=0.001$ with $\mathrm{k}=2$. 
Table 8. Densities of mixture DMSO + AmimCl, $x_{\mathrm{DMSO}}=0.147, x_{\mathrm{H} 20}=0.014$.

$\rho / \mathrm{kg} \mathrm{m}^{-3}$

\begin{tabular}{c|lllll}
\hline \multicolumn{2}{c}{$P /$ bar } & & & & \\
\multicolumn{1}{c}{293.15} & 313.15 & 333.15 & 353.15 & 373.15 \\
\hline 1 & 1150.1 & 1138.8 & 1125.3 & 1113.3 & 1101.7 \\
5 & 1150.3 & 1138.9 & 1125.4 & 1113.9 & 1102.1 \\
10 & 1150.4 & 1139.2 & 1125.6 & 1113.8 & 1102.3 \\
20 & 1150.8 & 1139.5 & 1126.0 & 1114.1 & 1102.6 \\
30 & 1151.0 & 1139.7 & 1126.4 & 1114.3 & 1103.1 \\
40 & 1151.3 & 1140.0 & 1126.7 & 1114.7 & 1103.5 \\
60 & 1152.1 & 1140.8 & 1127.2 & 1115.6 & 1104.0 \\
80 & 1152.5 & 1141.4 & 1127.8 & 1116.6 & 1104.7 \\
100 & 1153.1 & 1142.0 & 1128.6 & 1117.3 & 1105.3 \\
150 & 1154.6 & 1143.5 & 1130.2 & 1118.9 & 1106.9 \\
200 & 1156.5 & 1145.0 & 1131.7 & 1120.5 & 1108.7 \\
250 & 1157.6 & 1146.6 & 1133.6 & 1122.0 & 1110.4 \\
300 & 1159.0 & 1148.1 & 1135.0 & 1123.6 & 1112.1 \\
350 & 1160.4 & 1149.6 & 1136.5 & 1125.2 & 1114.0 \\
\hline
\end{tabular}

Expanded uncertainty of the density $\mathrm{U}(\rho)=1.5 \mathrm{~kg} \mathrm{~m}^{-3}$, expanded uncertainty of the temperature $\mathrm{U}(T)=0.05 \mathrm{~K}$, expanded uncertainty of the pressure $\mathrm{U}(P)=0.03$ bar, expanded uncertainty of the composition $\mathrm{U}(x)=0.001$ with $\mathrm{k}=2$. 
Table 9. Densities of mixtures DMSO $+\mathrm{AmimCl}, x_{\mathrm{DMSO}}=0.098, x_{\mathrm{H} 20}=0.016$.

$\rho / \mathrm{kg} \mathrm{m}^{-3}$

\begin{tabular}{c|lllll}
\hline \multicolumn{1}{c}{$P$ / bar } & & & \multicolumn{1}{l}{$T / \mathrm{K}$} & & \\
\multicolumn{1}{c}{293.15} & 313.15 & 333.15 & 353.15 & 373.15 \\
\hline 1 & 1148.1 & 1136.2 & 1126.7 & 1114.8 & 1103.2 \\
5 & 1148.2 & 1136.3 & 1127.0 & 1115.2 & 1103.4 \\
10 & 1148.4 & 1136.7 & 1126.9 & 1115.0 & 1103.4 \\
20 & 1148.7 & 1136.9 & 1127.2 & 1115.2 & 1103.6 \\
30 & 1148.9 & 1137.1 & 1127.6 & 1115.6 & 1104.0 \\
40 & 1149.1 & 1137.4 & 1128.1 & 1115.9 & 1104.3 \\
60 & 1149.8 & 1138.1 & 1128.6 & 1116.5 & 1104.9 \\
80 & 1150.4 & 1138.6 & 1129.0 & 1117.3 & 1105.7 \\
100 & 1150.9 & 1139.3 & 1129.8 & 1117.9 & 1106.3 \\
150 & 1152.6 & 1140.8 & 1131.4 & 1119.9 & 1108.0 \\
200 & 1154.5 & 1142.4 & 1133.0 & 1121.4 & 1109.6 \\
250 & 1155.5 & 1143.9 & 1134.5 & 1122.8 & 1111.6 \\
300 & 1156.9 & 1145.4 & 1136.2 & 1124.5 & 1113.1 \\
350 & 1158.3 & 1146.6 & 1137.6 & 1126.0 & 1115.3 \\
\hline
\end{tabular}

Expanded uncertainty of the density $\mathrm{U}(\rho)=1.5 \mathrm{~kg} \mathrm{~m}^{-3}$, expanded uncertainty of the temperature $\mathrm{U}(T)=0.05 \mathrm{~K}$, expanded uncertainty of the pressure $\mathrm{U}(P)=0.03$ bar, expanded uncertainty of the composition $\mathrm{U}(x)=0.001$ with $\mathrm{k}=2$. 
Table 10. Densities of mixtures DMSO + AmimCl, $x_{\mathrm{DMSO}}=0.048, x_{\mathrm{H} 20}=0.015$.

$\rho / \mathrm{kg} \mathrm{m}^{-3}$

\begin{tabular}{|c|c|c|c|c|c|}
\hline \multirow{2}{*}{$P /$ bar } & \multicolumn{5}{|c|}{$T / \mathrm{K}$} \\
\hline & 293.15 & 313.15 & 333.15 & 353.15 & 373.15 \\
\hline 1 & 1149.3 & 1138.2 & 1128.2 & 1115.5 & 1104.2 \\
\hline 5 & 1149.8 & 1138.3 & 1128.3 & 1116.3 & 1104.7 \\
\hline 10 & 1149.9 & 1138.5 & 1128.6 & 1116.2 & 1104.8 \\
\hline 20 & 1150.0 & 1139.0 & 1128.5 & 1116.2 & 1104.8 \\
\hline 30 & 1150.2 & 1139.4 & 1128.9 & 1116.4 & 1105.5 \\
\hline 40 & 1150.5 & 1139.3 & 1129.2 & 1116.8 & 1105.8 \\
\hline 60 & 1151.1 & 1140.0 & 1129.5 & 1117.6 & 1106.0 \\
\hline 80 & 1151.7 & 1140.5 & 1129.9 & 1118.3 & 1106.9 \\
\hline 100 & 1152.3 & 1141.1 & 1130.6 & 1119.0 & 1107.4 \\
\hline 150 & 1153.7 & 1142.7 & 1132.1 & 1120.4 & 1109.3 \\
\hline 200 & 1155.6 & 1144.1 & 1133.7 & 1122.2 & 1110.2 \\
\hline 250 & 1156.6 & 1145.7 & 1135.4 & 1123.7 & 1112.6 \\
\hline 300 & 1158.1 & 1147.0 & 1136.7 & 1125.6 & 1114.4 \\
\hline 350 & 1159.3 & 1148.6 & 1138.2 & 1126.9 & 1116.1 \\
\hline
\end{tabular}

Expanded uncertainty of the density $\mathrm{U}(\rho)=1.5 \mathrm{~kg} \mathrm{~m}^{-3}$, expanded uncertainty of the temperature $\mathrm{U}(T)=0.05 \mathrm{~K}$, expanded uncertainty of the pressure $\mathrm{U}(P)=0.03$ bar, expanded uncertainty of the composition $\mathrm{U}(x)=0.001$ with $\mathrm{k}=2$. 
Table 11. Densities of pure AmimCl. $x_{\mathrm{H} 20}=0.013$.

$\rho / \mathrm{kg} \mathrm{m}^{-3}$

\begin{tabular}{|c|c|c|c|c|c|}
\hline \multirow{2}{*}{$P /$ bar } & \multicolumn{5}{|c|}{$T / \mathrm{K}$} \\
\hline & 293.15 & 313.15 & 333.15 & 353.15 & 373.15 \\
\hline 1 & 1149.9 & 1139.0 & 1129.4 & 1117.3 & 1106.0 \\
\hline 5 & 1150.0 & 1139.1 & 1129.4 & 1117.8 & 1106.4 \\
\hline 10 & 1150.2 & 1139.4 & 1129.5 & 1117.5 & 1106.5 \\
\hline 20 & 1150.5 & 1139.6 & 1129.8 & 1117.7 & 1106.7 \\
\hline 30 & 1150.7 & 1139.8 & 1130.0 & 1118.2 & 1107.3 \\
\hline 40 & 1151.0 & 1140.2 & 1130.4 & 1118.2 & 1107.4 \\
\hline 60 & 1151.6 & 1140.8 & 1131.1 & 1118.9 & 1107.9 \\
\hline 80 & 1152.2 & 1141.4 & 1131.5 & 1119.5 & 1108.6 \\
\hline 100 & 1152.8 & 1142.2 & 1132.1 & 1120.3 & 1109.4 \\
\hline 150 & 1154.1 & 1143.6 & 1133.7 & 1121.9 & 1110.8 \\
\hline 200 & 1155.9 & 1145.0 & 1135.1 & 1123.5 & 1112.6 \\
\hline 250 & 1157.0 & 1146.7 & 1136.7 & 1124.9 & 1114.2 \\
\hline 300 & 1158.3 & 1148.0 & 1138.2 & 1126.8 & 1116.1 \\
\hline 350 & 1159.7 & 1149.5 & 1139.7 & 1127.9 & 1117.7 \\
\hline
\end{tabular}

Expanded uncertainty of the density $\mathrm{U}(\rho)=1.5 \mathrm{~kg} \mathrm{~m}^{-3}$, expanded uncertainty of the temperature $\mathrm{U}(T)=0.05 \mathrm{~K}$, expanded uncertainty of the pressure $\mathrm{U}(P)=0.03$ bar, expanded uncertainty of the composition $\mathrm{U}(x)=0.001$ with $\mathrm{k}=2$. 
In Figure 2 the density of mixtures is represented as a function of pressure and temperature at various concentrations of DMSO. The density decreases with the temperature and increases with the pressure.

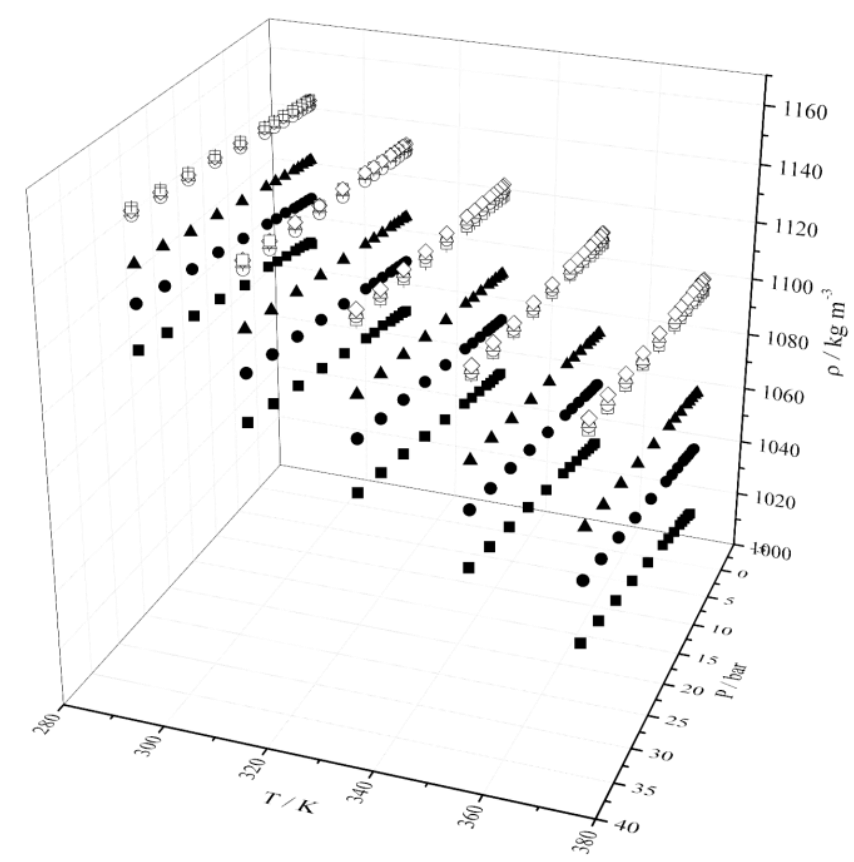

Figure 2. Graphical representation of the density of the mixtures of DMSO + AmimCl at $x_{\mathrm{DMSO}}$ $=0.999(\square) ; 0.893(\bullet) ; 0.729(\Delta) ; 0.495(\diamond) ; 0.247(+) ; 0.147(\square) ; 0.098(\bigcirc) ; 0.048(\triangle)$; $0.000(\diamond)$.

In Table 12 a comparison between the densities of the ionic liquid AmimCl obtained in this work by the VTD and the data from Jiménez et al. ${ }^{28}$ obtained using a Stabinger viscosimeterdensimeter at atmospheric pressure is presented. Both set of data are consistent. 
Table 12. Comparison between densities of the AmimCl measured in this work and from Jiménez et al. 28

\begin{tabular}{ccc}
\hline Temp. & $\begin{array}{c}\text { Density, Jiménez et al. 28 } \\
x_{\text {water }}=0.045 .\end{array}$ & $\begin{array}{c}\text { Density, this work } \\
x_{\text {water }}=0.013 \\
\mathrm{~K}\end{array}$ \\
$\mathrm{~g} \mathrm{~cm}^{-3}$ & $\mathrm{~g} \mathrm{~cm}^{-3}$ \\
\hline 323.15 & 1.131 & \\
333.15 & 1.125 & 1.129 \\
343.15 & 1.119 & \\
353.15 & 1.114 & 1.117 \\
363.15 & 1.108 & 1.106 \\
373.15 & 1.103 & \\
\hline
\end{tabular}

In Figure 3, densities measured at 0.1, 6 and 35 MPa are plotted versus DMSO composition and temperature. It is observed that the density is decreasing with DMSO molar function and with temperature. Small scattering in the data at concentrations between 0.05 and 0.25 are observed and were attributed to the different water content of the samples used.

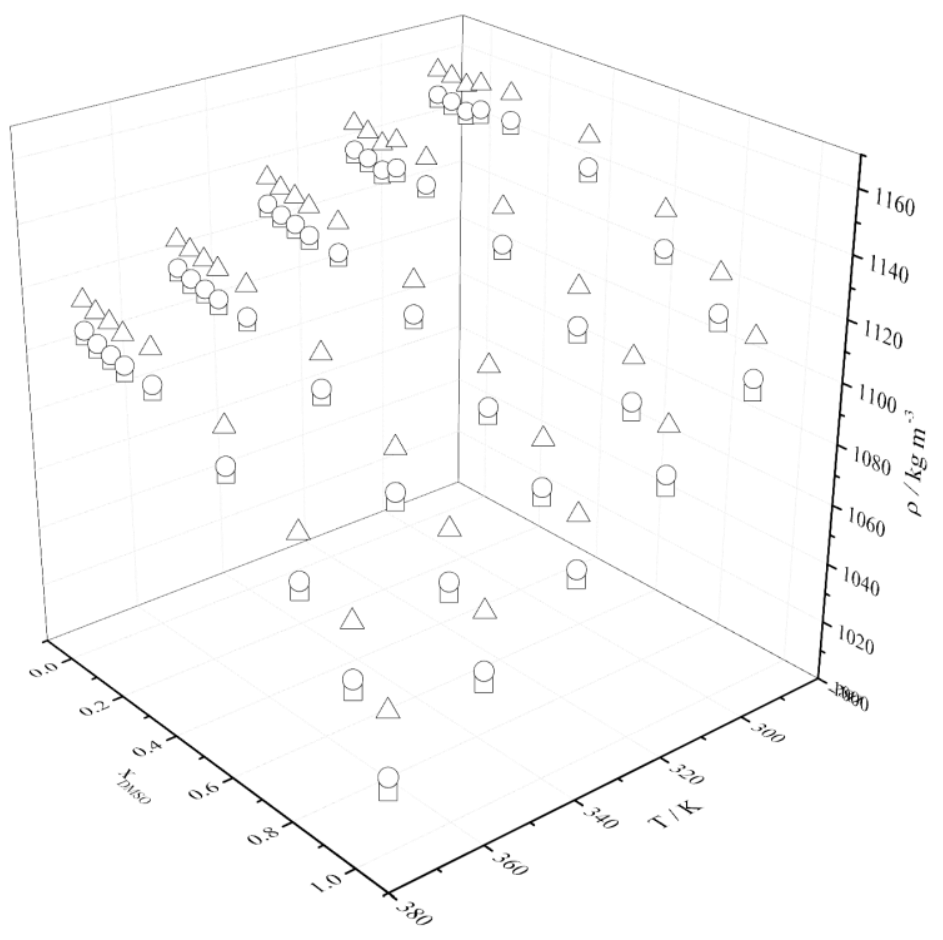

Figure 3. Density of mixtures at $0.1 \mathrm{MPa}(\square) ; 6 \mathrm{MPa}(\bigcirc)$ and $35 \mathrm{MPa}(\triangle)$.

Figure 3 shows that the density also presents a linear trend with the temperature. 


\subsection{Excess molar volume}

Molar volumes were calculated considering the difference between the experimental and the theoretical value, using equation (2) the contribution of the water in the mixtures was taken into account.

$$
\begin{gathered}
V_{m}^{E}=V_{m}-V_{m}^{i d}=\frac{x_{I L} M_{I L}+x_{D M S O} M_{D M S O}+x_{\mathrm{H}_{2} \mathrm{O}} M_{\mathrm{H}_{2} \mathrm{O}}}{\rho^{\text {exp }}}-\left(x_{I L} \frac{M_{I L}}{\rho_{I L}^{\text {pure }}}+x_{D M S O} \frac{M_{D M S O}}{\rho_{D M S O}^{\text {pure }}}+\right. \\
\left.x_{\mathrm{H}_{2} \mathrm{O}} \frac{M_{\mathrm{H}_{2} \mathrm{O}}}{\rho_{\mathrm{H}_{2} \mathrm{O} \mathrm{O}}^{\text {pure }}}\right)
\end{gathered}
$$

Where $M_{I L}, M_{H 2 O}$ and $M_{D M S O}$ are the molar weights of the components, and $V_{m}$ is the experimental molar volume and $V_{m^{i d}}$ is the ideal molar volume both in $\mathrm{cm}^{3} \mathrm{~mol}^{-1}$. Water density data were taken from Refprop. ${ }^{42}$ Density of DMSO was measured in this work. In the case of the IL the experimental density was assumed pure to obtain the rest of the points.

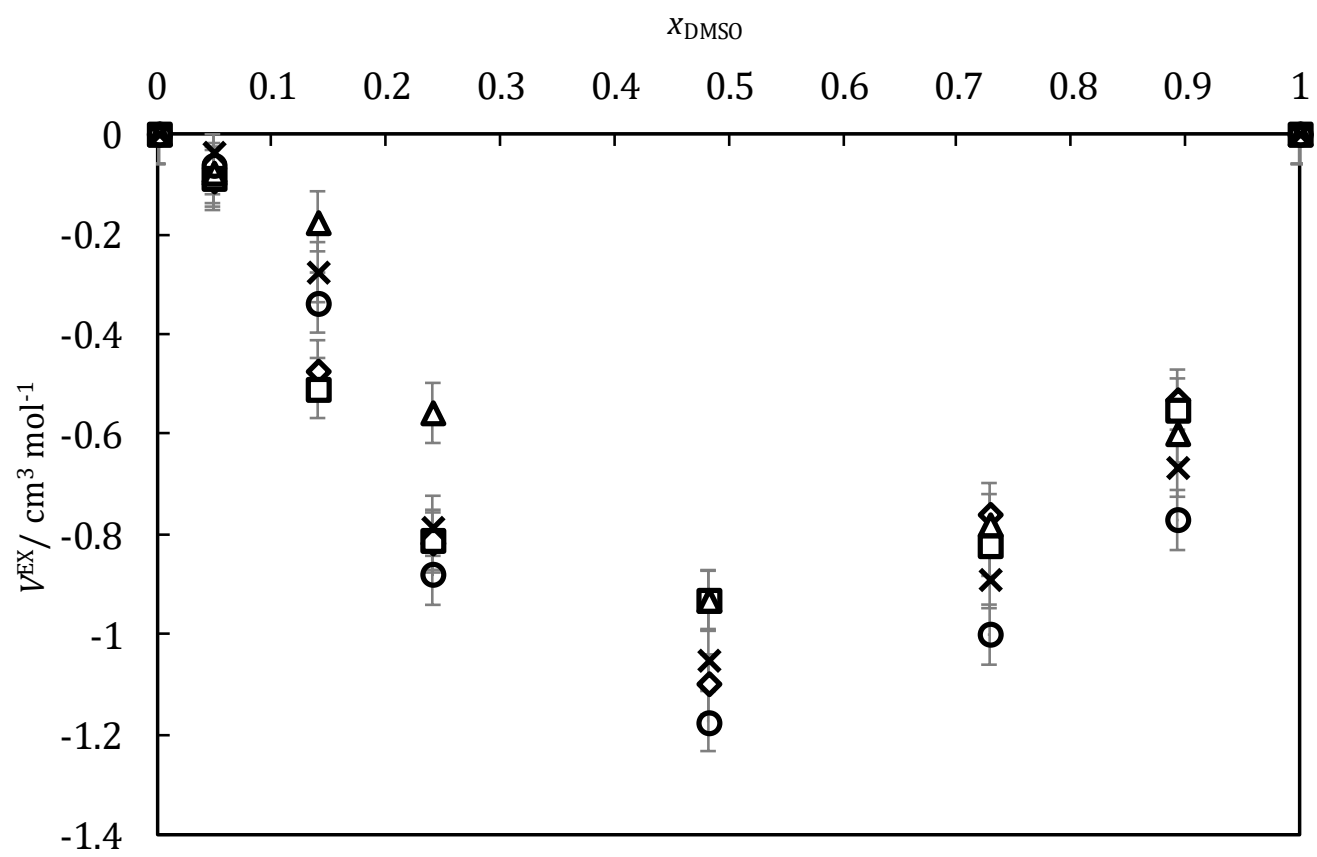

Figure 4. Excess molar volume $\left(V^{\mathrm{Ex}}\right)$ in mixtures $\mathrm{DMSO}+\mathrm{AmimCl}$ at $0.1 \mathrm{MPa}$ and $293.15 \mathrm{~K}$ $(\diamond) ; 313.15 \mathrm{~K}(\square) ; 333.15 \mathrm{~K}(\triangle)$; $353.15 \mathrm{~K}(\times)$ and $373.15 \mathrm{~K}(\bigcirc)$. 
Excess molar volumes at atmospheric pressures are plotted versus DMSO concentrations at various molar fractions in Figure 4. It is observed that excess molar volume has a minimum around 0.5 molar fraction. It is well known that the mixtures of other molecular solvents with chloride based ILs such as water + Imidazolium chloride ILs have a significant negative excess molar volume and present a minimum around the concentration of $0.5-0.7$ molar fraction of water. $25,28,47,48$

In the case of DMSO + AmimCl this curve is more negative compared to the same ionic liquid mixed with water. ${ }^{28}$ The negative excess molar volume is due to the effect of packaging between molecules of DMSO and ionic liquid. The co-solvent molecules introduce in the "free" volume available between the ionic liquid structure without expanding it, it the case of DMSO compared with water, the DMSO can introduce more effectively into the ionic liquid structure without decreasing the interactions between the ionic liquid and the DMSO.

a) $x_{\text {DMSO }}=0.241$

$T / \mathrm{K}$

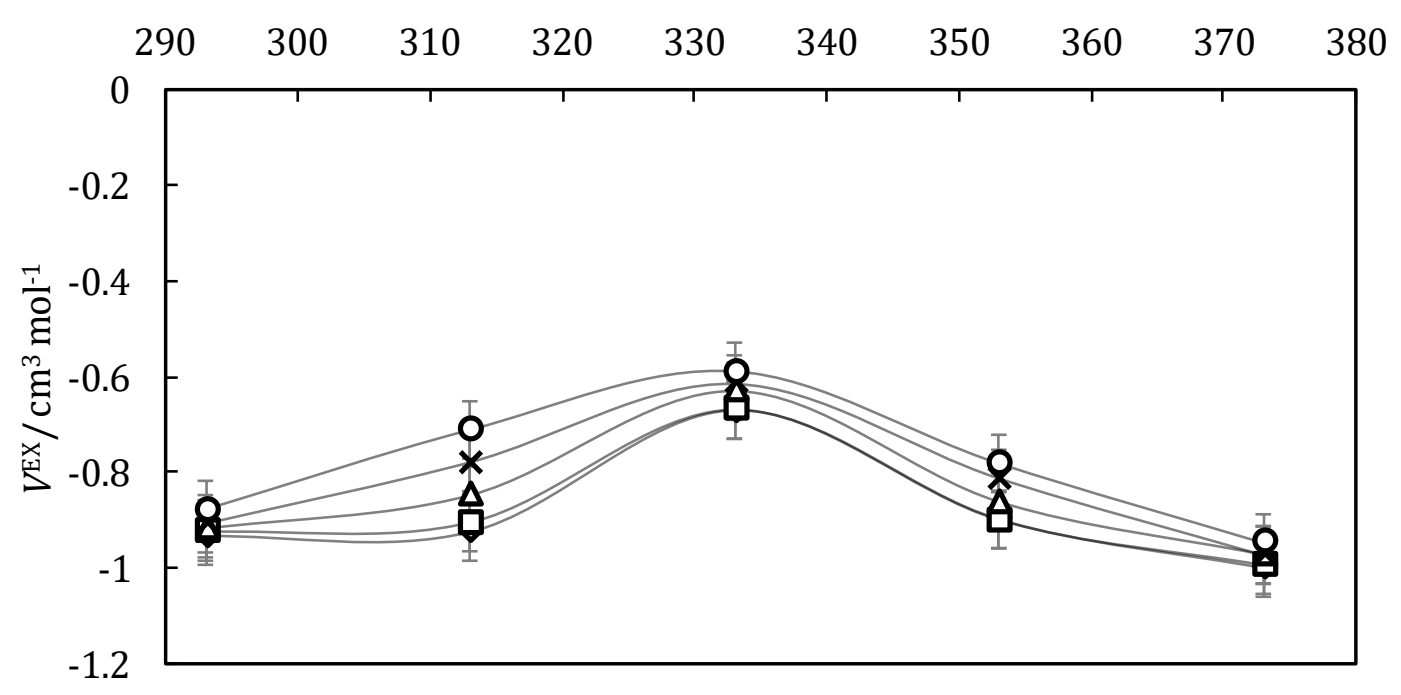


b) $X_{\text {DMSO }}=0.140$

$$
T / \mathrm{K}
$$

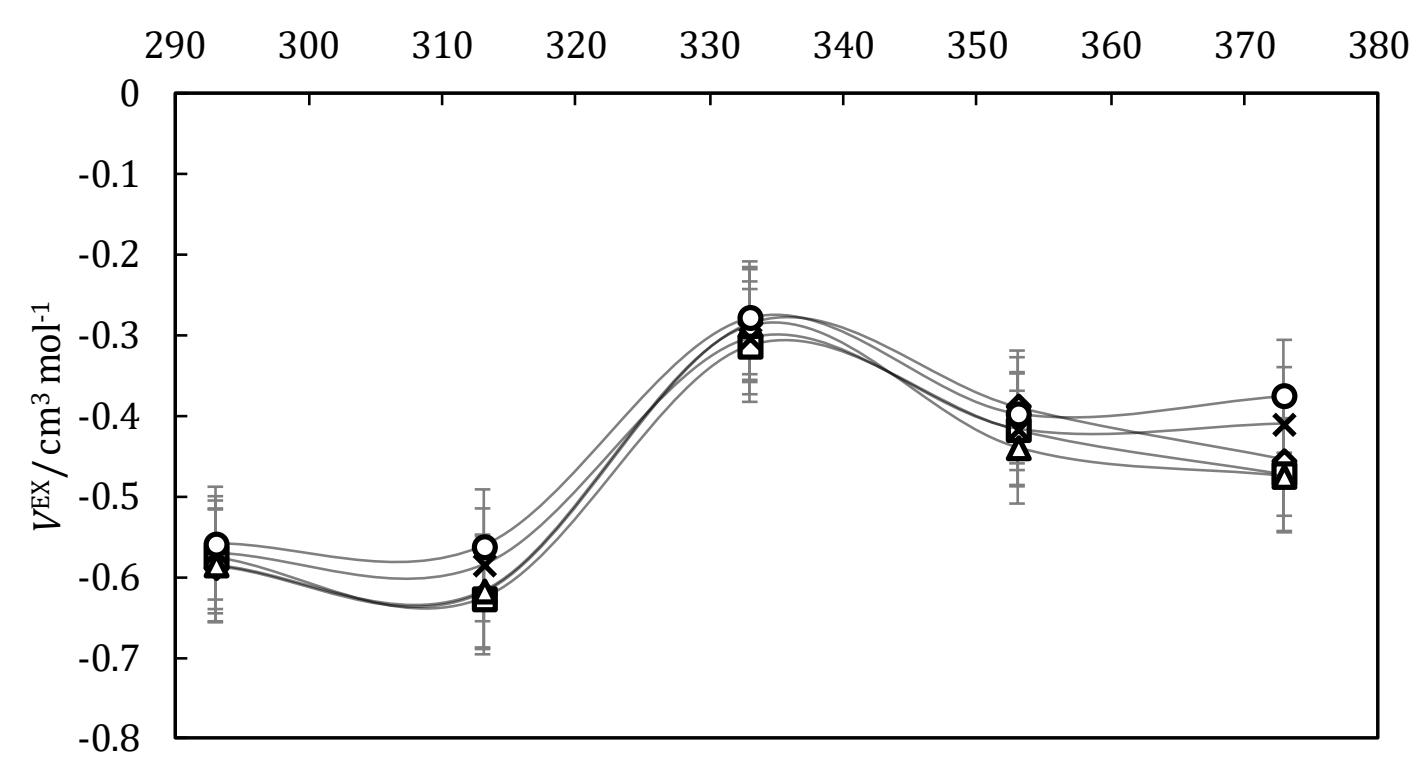

Figure 5. Influence of temperature on the excess molar volume in the mixture for a) $x_{\mathrm{DMSO}}=$ 0.241 and b) $x_{\text {DMSO }}=0.14$ at $0.1 \mathrm{MPa}(\diamond) ; 2 \mathrm{MPa}(\square) ; 6 \mathrm{MPa}(\triangle) ; 20 \mathrm{MPa}(\times)$ and $35 \mathrm{MPa}$ (O). The lines are drawn as a guide to the data.

In Figure 5 the excess molar volumes of the mixtures with molar fractions of 0.241 and 0.140 of DMSO are represented as a function of temperature at various pressures. As it can be seen from Figure 5, the excess molar volume presents a maximum when it approximates to $333.15 \mathrm{~K}$, temperature near the melting point of the IL (324 $\mathrm{K}$ according to Lopes et al. ${ }^{49}$ ). This behavior was found in more concentrations as is shown in Figure 6, being more pronounced at concentrations from 0.048 to 0.482 . To the best or our knowledge, this behavior has not been described by others authors before.

A hypothesis for this behavior is that there are two contributions in the excess volume, at lower temperatures the molecules are closer and the interactions are stronger, and at higher temperatures there is more free volume "available" and the molecules can accommodate there. And therefore, at $333.15 \mathrm{~K}$, in the middle of the temperature range the two contributions have a minor effect.

Therefore, these data reflect a behavior that can be useful in the correlation of an equation of state in order to describe as accurate as possible this system. 


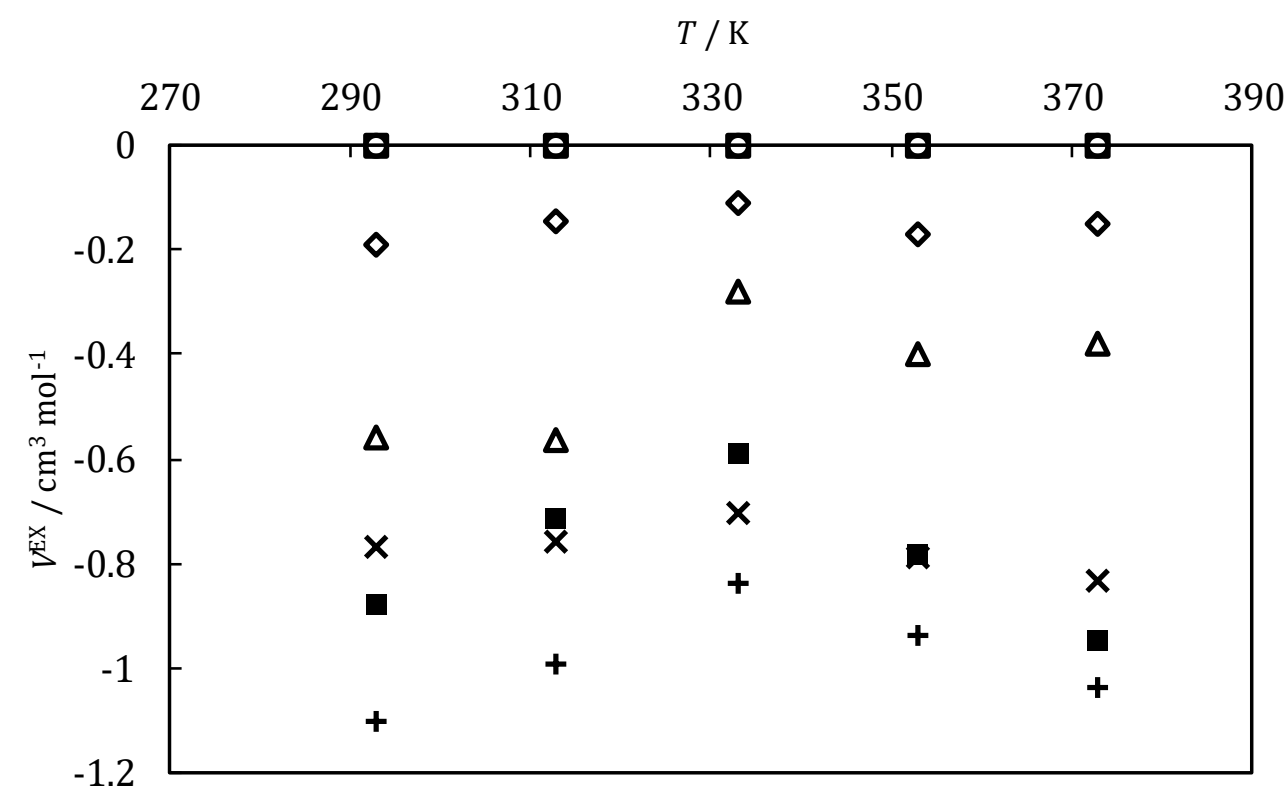

Figure 6. Excess molar volume at $35 \mathrm{MPa}$ at $x_{\mathrm{DMSO}}=0.999(0) ; 0.728(\times) ; 0.482(+) ; 0.241$ $(\square) ; 0.140(\triangle) ; 0.048(\diamond) ; 0.000(\square)$.

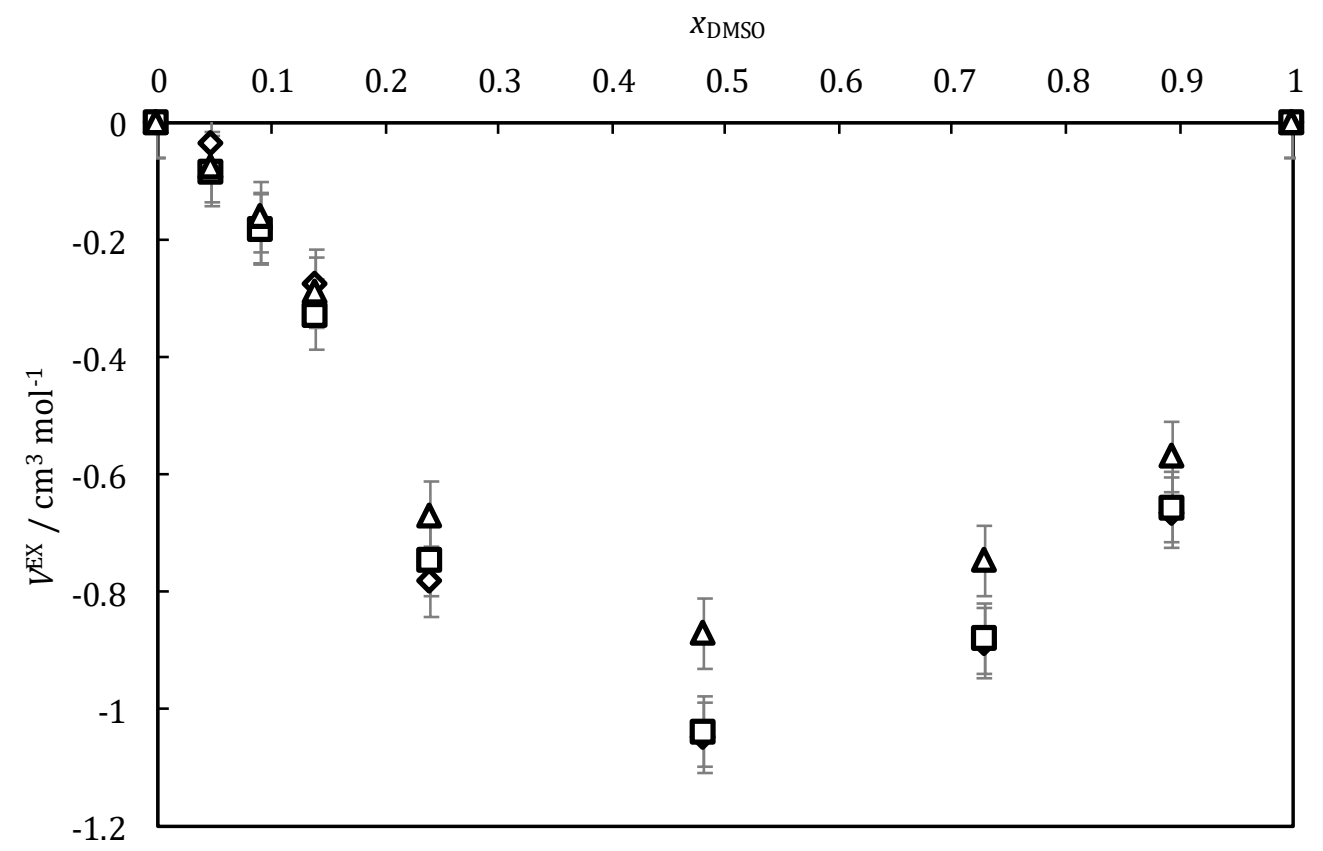

Figure 7. Excess molar volume in mixtures DMSO + AmimCl at $333.15 \mathrm{~K}$ and $0.1 \mathrm{MPa}(\diamond) ; 6$ $\operatorname{MPa}(\square)$ and $35 \mathrm{MPa}(\triangle)$. 
In Figure 7 excess molar volume was plotted versus DMSO molar fraction. In general, the pressure has a small influence on the excess volume, that decreases slightly with the pressure, being the slight molar volumes more negatives at lower pressures.

\subsection{Density correlation of mixtures DMSO + AmimCl}

The data were adjusted to an empirical correlation as a function of the temperature, the pressure and the composition.

Where:

$$
\begin{gathered}
\rho=A+B \cdot P+C \cdot T \\
A=A_{1} \cdot x_{D M S O}+A_{2} \\
B=B_{1} \cdot x_{D M S O}^{2}+B_{2} \cdot x_{D M S O}+B_{3} \\
C=C_{1} \cdot x_{D M S O}^{2}+C_{2} \cdot x_{D M S O}+C_{3} \\
A R D \%=\frac{\sum\left(\frac{\left|\rho_{\text {exp }}-\rho_{\text {calc }}\right|}{\rho_{\text {exp }}}\right)}{n} \cdot 100
\end{gathered}
$$

The correlated parameters are shown in Table 13.

Table 13. Correlated parameters of the equation ( 3 )

\begin{tabular}{ll}
\hline $\mathrm{A}_{1}$ & 63.87 \\
$\mathrm{~A}_{2}$ & 1311.39 \\
$\mathrm{~B}_{1}$ & 0.302 \\
$\mathrm{~B}_{2}$ & -0.0128 \\
$\mathrm{~B}_{3}$ & 0.31 \\
$\mathrm{C}_{1}$ & -0.2575 \\
$\mathrm{C}_{2}$ & -0.1255 \\
$\mathrm{C}_{3}$ & -0.5560 \\
$\% \mathrm{ARD}$ & $0.12 \%$ \\
$\% \mathrm{MAX}$ & $0.51 \%$ \\
\hline
\end{tabular}


The value of the \%ARD implies an excellent description of the studied system. The comparison between the experimental and the correlated are presented in Figure 8 and Figure 9.

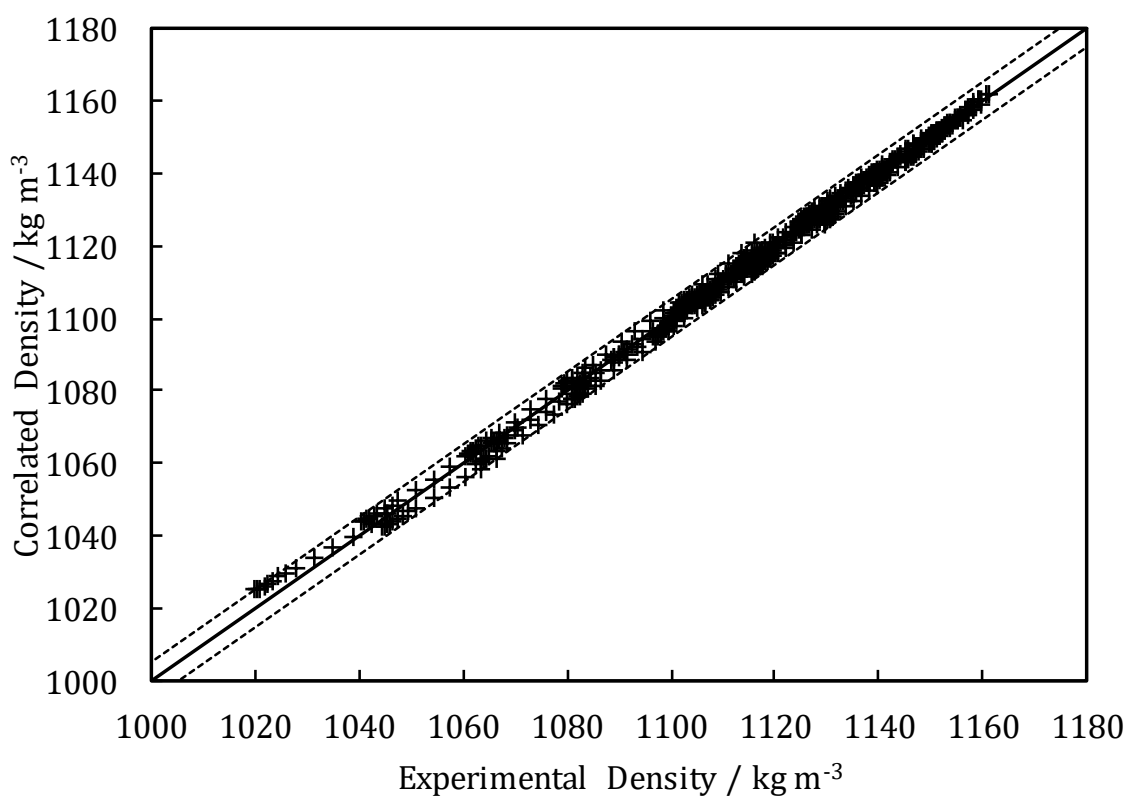

Figure 8. Comparison between the experimental data and the correlated with equation (3). Dotted lines represent $0.51 \%$ of maximum deviation.

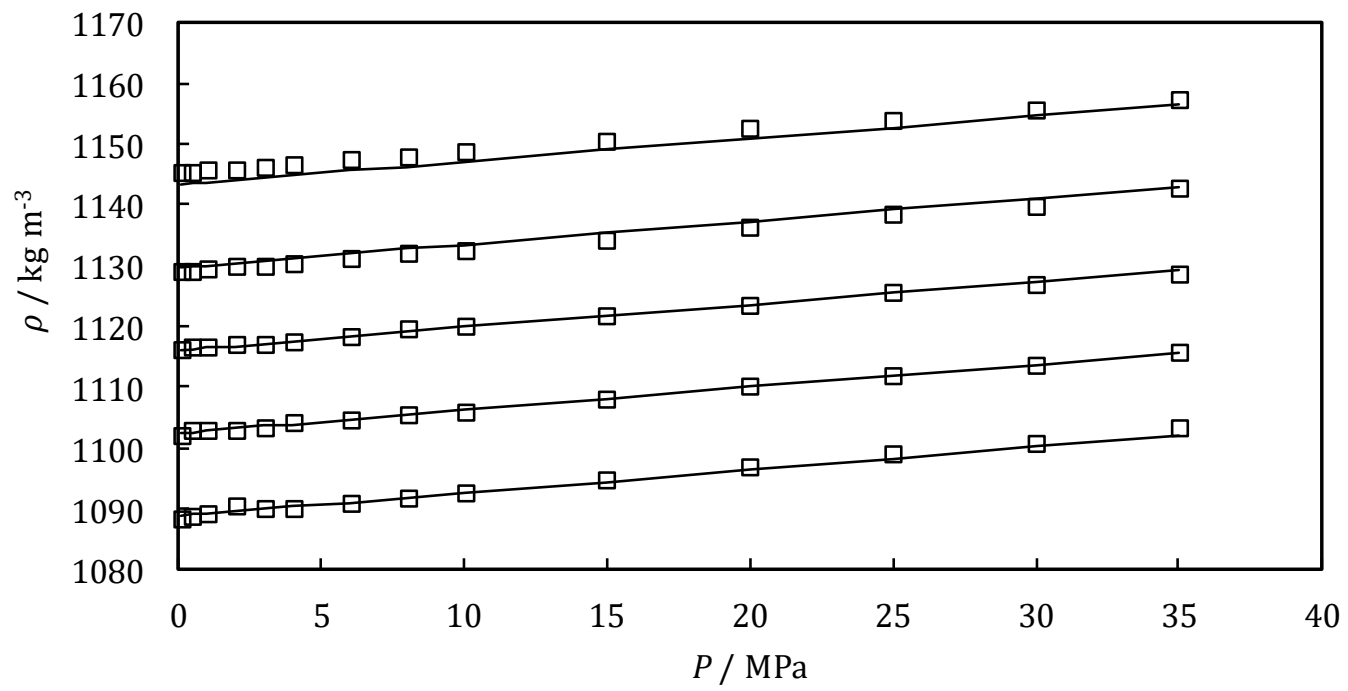

Figure 9. Comparison between the experimental and the correlated data at different temperatures; open squares, experimental data; lines, correlated data for the mixture $x_{\mathrm{DMSO}}$ $=0.496$. 


\section{Conclusions}

In this work density and excess molar volume of mixtures of dimethyl sulfoxide (DMSO) with 1-allyl-3-metkylimidazolium chloride (AmimCl) at a wide range of concentrations (molar fraction $x_{\text {DMSO }}=0.0 .05$ 0.1. 0.15. 0.25. 0.5. 0.75. 0.9 and 1), temperatures (293.15 to 373.15) $\mathrm{K}$ and pressures ( 0.1 to $35 \mathrm{MPa}$ ) were determined. The density has a linear trend with pressure and temperature, increasing with the ionic liquid concentration and with the pressure, and decreasing with the temperature.

Excess molar volumes of the mixtures were found to be negative with a minimum around $\mathrm{x}_{\mathrm{DMSO}}=0.5$. This fact indicates that molecules of DMSO and AmimCl at this concentration have a better "packaging degree" between them. The Excess molar volume is slightly more negative at lower pressure. It was observed for first time that the excess molar volume has a maximum at $333.15 \mathrm{~K}$ for several DMSO concentrations.

Density was correlated as a function of the temperature, pressure and composition of the mixture. A good fitting has been achieved with an \%ARD $=0.12 \%$.

\section{List of symbols}

$\begin{array}{ll}\text { ARD \% } & \text { Average relative deviation } \\ \text { DMSO } & \text { Dimethyl sulfoxide } \\ \text { IL } & \text { Ionic liquid } \\ M_{\mathrm{i}} & \text { Molecular weight of the substance i in } \mathrm{g} \mathrm{cm}^{-3} \\ V_{\mathrm{E}} & \text { Molar excess volume in } \mathrm{cm}^{3} \mathrm{~mol}^{-1} \\ \text { VTD } & \text { Vibrating Tube Densimeter } \\ x_{\mathrm{i}} & \text { Molar concentration of the substance i } \\ \rho_{\mathrm{i}} & \text { Density of the substance i in } \mathrm{kg} \mathrm{m}^{-3} \\ \tau & \text { Period in } \mu \mathrm{s}\end{array}$

\section{Acknowledgements}

Authors thank the Junta de Castilla y León for funding through the project VA295U14. MDB thanks the Spanish Ministry of Economy and Competitiveness for the Ramón y Cajal research fellowship. 


\section{References}

(1) Holbrey, J. D.; Seddon, K. R. Clean Technol. Environ. Policy 1999, 1 (4), 223-236.

(2) Aschenbrenner, O.; Supasitmongkol, S.; Taylor, M.; Styring, P. Green Chem. 2009, 11 (8), 1217-1221.

(3) Vitz, J.; Erdmenger, T.; Schubert, U. S. Cellul. Solvents Anal. Shap. Chem. Modif. 2010, 299-317.

(4) Tim Liebert. Cellulose Solvents: For Analysis, Shaping and Chemical Modification; 2010; Vol. 1033.

(5) Zhang, H.; Wu, J.; Zhang, J.; He, J. Macromolecules 2005, 38 (20), 8272-8277.

(6) Jimenez de la Parra, C.; Navarrete, A.; Bermejo, M. D.; Cocero, M.J. Recent Pat. Eng 2012, 6 (3), 159-182.

(7) Vitz, J.; Erdmenger, T.; Haensch, C.; Schubert, U. S. Green Chem. 2009, 11 (3), 417.

(8) Zhu, S.; Wu, Y.; Chen, Q.; Yu, Z.; Wang, C.; Jin, S.; Ding, Y.; Wu, G. Green Chem. 2006, 8 (4), 325.

(9) Meng, Z.; Zheng, X.; Tang, K.; Liu, J.; Qin, S. E-Polymers 2012, No. 28, 1-29.

(10) Suopajärvi, T.; Sirviö, J. A.; Liimatainen, H. Carbohydr. Polym. 2017, 169, 167-175.

(11) Elgharbawy, A. A.; Alam, M. Z.; Moniruzzaman, M.; Goto, M. Biochem. Eng.J. 2016, 109, 252-267.

(12) Brennecke, J. F.; Maginn, E. J. AIChEJ. 2001,47 (11), 2384-2389.

(13) Sescousse, R.; Le, K. A.; Ries, M. E.; Budtova, T. J. Phys. Chem. B 2010, 114 (21), 72227228.

(14) Lv, Y.; Wu, J.; Zhang, J. J.; Niu, Y.; Liu, C. Y.; He, J.; Zhang, J. J. Polymer (Guildf). 2012, 53 (12), 2524-2531.

(15) Jan, R.; Rather, G. M.; Bhat, M. A. J. Solution Chem. 2014, 43 (4), 685-695.

(16) Seddon, K. R.; Stark, A.; Torres, M.-J.Pure Appl. Chem. 2000, 72 (12), 2275-2287. 
(17) Wang, J.; Zhu, A.; Zhao, Y.; Zhuo, K. J. Solution Chem. 2005, 34 (5), 585-596.

(18) Cuissinat, C.; Navard, P.; Heinze, T. Carbohydr. Polym. 2008, 72 (4), 590-596.

(19) Wang, X.; Li, H.; Cao, Y.; Tang, Q. Bioresour. Technol. 2011,102 (17), 7959-7965.

(20) Fort, D. a.; Remsing, R. C.; Swatloski, R. P.; Moyna, P.; Moyna, G.; Rogers, R. D. Green Chem. 2007, 9 (1), 63.

(21) Sastry, N. V.; Vaghela, N. M.; Macwan, P. M. J. Mol. Liq. 2013, 180, 12-18.

(22) Tariq, M.; Moscoso, F.; Deive, F. J.; Rodriguez, A.; Sanromán, M. A.; Esperança, J. M. S. S.; Canongia Lopes, J. N.; Rebelo, L. P. N. J. Chem. Thermodyn. 2013, 59, 43-48.

(23) Liu, W.; Cheng, L.; Zhang, Y.; Wang, H.; Yu, M. J. Mol. Liq. 2008, 140 (1-3), 68-72.

(24) Singh, T.; Kumar, A. J. Chem. Thermodyn. 2011, 43 (6), 958-965.

(25) Gómez, E.; González, B.; Domínguez, a; Tojo, E.; Tojo, J. J. Chem. Eng. Data 2006, 51, 696-701.

(26) Xu, H.; Zhao, D.; Xu, P.; Liu, F.; Gao, G. J. Chem. Eng. Data 2005, 50 (1), 133-135.

(27) Wu, D.; Wu, B.; Zhang, Y. M.; Wang, H. P.J. Chem. Eng. Data 2010, 55 (2), 621-624.

(28) Jiménez de la Parra, C.; Zambrano, J. R.; Bermejo, M. D.; Martín, Á.; Segovia, J. J.; Cocero, M. J. J. Chem. Thermodyn. 2015, 91, 8-16.

(29) Kumar, B.; Singh, T.; Rao, K. S.; Pal, A.; Kumar, A. J. Chem. Thermodyn. 2012, 44 (1), 121-127.

(30) Lopes, J. M.; Kareth, S.; Bermejo, M. D.; Martín, Á.; Weidner, E.; Cocero, M. J. J. Supercrit. Fluids 2016, 111, 91-96.

(31) Tomé, L. I. N.; Gardas, R. L.; Carvalho, P. J.; Pastoriza-Gallego, M. J.; Piñeiro, M. M.; Coutinho, J. A. P.J. Chem. Eng. Data 2011, 56 (5), 2205-2217.

(32) Machida, H.; Taguchi, R.; Sato, Y.; Smith, J. R. L. J. Chem. Eng. Data 2010, 56 (4), 923928.

(33) Safarov, J.; Geppert-Rybczyńska, M.; Kul, I.; Hassel, E. Fluid Phase Equilib. 2014,383, 144-155. 
(34) Gardas, R. L.; Costa, H. F.; Freire, M. G.; Carvalho, P. J.; Marrucho, I. M.; Fonseca, I. M. A.; Ferreira, A. G. M.; Coutinho, J. A. P. J. Chem. Eng. Data 2008, 53 (3), 805-811.

(35) Currás, M. R.; Husson, P.; Pádua, A. A. H.; Costa Gomes, M. F.; García, J. Ind. Eng. Chem. Res. 2014, 53 (26), 10791-10802.

(36) Abdulagatov, I. M.; Tekin, A.; Safarov, J.; Shahverdiyev, A.; Hassel, E. J. Chem. Thermodyn. 2008, 40 (9), 1386-1401.

(37) Widowati, E.; Lee, M. J.J. Chem. Thermodyn. 2012, 49, 54-61.

(38) Qiao, Y.; Yan, F.; Xia, S.; Yin, S.; Ma, P. J. Chem. Eng. Data 2011, 56 (5), 2379-2385.

(39) Bahadur, I.; Letcher, T. M.; Singh, S.; Redhi, G. G.; Venkatesu, P.; Ramjugernath, D. J. Chem. Thermodyn. 2015, 82, 34-46.

(40) Sandhya, M. S.; Rao, C. N.; Sivakumar, K.; Bhanuprakash, P.; Venkateswarlu, P. J. Mol. Liq. 2016, 222, 981-987.

(41) Mokhtarani, B.; Sharifi, A.; Mortaheb, H. R.; Mirzaei, M.; Mafi, M.; Sadeghian, F. J. Chem. Thermodyn. 2009, 41 (3), 323-329.

(42) Lemmon, E.W.; Span, R. J. Chem. Eng. Data 2006, 51, 785-850.

(43) Segovia, J. J.; Fandiño, O.; López, E. R.; Lugo, L.; Carmen Martín, M.; Fernández, J. J. Chem. Thermodyn. 2009, 41 (5), 632-638.

(44) Comuñas, M. J. P.; Bazile, J. P.; Baylaucq, A.; Boned, C. J. Chem. Eng. Data 2008, 53, 986-994.

(45) Lagourette, B.; Boned, C.; Saint-Guirons, H.; Xans, P.; Zhou, H. Meas. Sci. Technol. 1992, 3, 699-703.

(46) Joint Committee for Guides in Metrology. Int. Organ. Stand. 2008.

(47) Fan, X.-H.; Chen, Y.-P.; Su, C.-S. J. Taiwan Inst. Chem. Eng. 2016, 61, 117-123.

(48) Zec, N.; Bešter-Rogač, M.; Vraneš, M.; Gadžurić, S. J. Chem. Thermodyn. 2016, 97, 307314.

(49) Lopes, J. M.; Sánchez, F. A.; Reartes, S. B. R.; Bermejo, M. D.; Martín, Á.; Cocero, M. J. J. Supercrit. Fluids 2016, 107, 590-604. 


\title{
Chapter 4: Determination of density and viscosity of binary mixtures of water and dimethylsulfoxide with 1-ethyl-3-methylimidazolium diethylphosphate $[\text { EtMeIm] }]^{+}\left[\mathrm{Et}_{2} \mathrm{PO}_{4}\right]^{-}$at atmospheric pressure*
}

\begin{abstract}
In this work densities and viscosities of 1-ethyl-3-methylimidazolium diethylphosphate ([EtMeIm $\left.]^{+}\left[\mathrm{Et}_{2} \mathrm{PO}_{4}\right]^{-}\right)$in binary mixtures with water and dimethylsulfoxide (DMSO) at atmospheric pressure and temperatures between $293.15 \mathrm{~K}$ and $373.15 \mathrm{~K}$ were determined. The properties were measured in a Stabinger densimeter-viscosimeter SVM 3000 model. In addition, a correlation of the viscosity data was made with a modification of the Grunberg and Nissan correlation, in which corrections for the interaction between the Ionic Liquid and the water, DMSO or both were introduced. For the mixture $\mathrm{H}_{2} \mathrm{O}+\left([\mathrm{EtMeIm}]^{+}\left[\mathrm{Et}_{2} \mathrm{PO}_{4}\right]^{-}\right)$the \%AARD is $13 \%$ with a maximum deviation (\%Max) of $49 \%$, for the mixture DMSO + ([EtMeIm]+ $\left.\left[\mathrm{Et}_{2} \mathrm{PO}_{4}\right]^{-}\right)$the \%AARD is $9.5 \%$ and the $\% \operatorname{Max}=49 \%$.
\end{abstract}

Keywords: ionic liquid, 1-ethyl-3-methylimidazolium diethylphosphate, dimethylsulfoxide, water, viscosity, density, viscosity correlation.

* This Chapter is published as "de Pablo, L.; Segovia Puras, J. J.; Martín, C.; Bermejo, M. D. Determination of Density and Viscosity of Binary Mixtures of Water and Dimethyl Sulfoxide with 1-Ethyl-3-Methylimidazolium Diethylphosphate [EtMeIm $]^{+}\left[\mathrm{Et}_{2} \mathrm{PO}_{4}\right]^{-}$at Atmospheric Pressure. J. Chem. Eng. Data 2018, 63 (4), 1053-1064" 
Chapter 4 


\section{Introduction}

Ionic liquids are substances composed entirely by ions. Their complex structures hinder the crystallization process making them substances with a very low fusion temperature. They are also considered "green" solvents because they have very low vapor pressures. In addition, they have high thermal and chemical stability. Their properties are easily tunable by changing the ion substituents ${ }^{1}$, making ionic liquids highly versatile. Thus, ionic liquids have become a promising alternative of conventional solvents. ${ }^{2}$

In the past few years, the global interest in the use of environmentally sustainable resources has increased. Therefore, the biopolymers, and more specifically cellulose, have focused most of the attention in the search of new natural, biodegradable and renewable resources. However, cellulose, due to its complex structure, is not easily processed because is not soluble in water at room temperature or other conventional solvents. Some ionic liquids have demonstrated its capacity to dissolve cellulose, ${ }^{3}$ however the solution of cellulose in ionic liquids increases dramatically the viscosity of the mixture. Therefore, co-solvents are frequently added to these mixtures. One of the most common co-solvents is dimethylsulfoxide (DMSO). This substance is frequently used in the cellulose processing with ILs because it decreases the friction between monomers ${ }^{4}$ and it does not affect cellulose solubility. ${ }^{5,6}$ The recovery of the dissolved cellulose is frequently made using water as an anti-solvent. ${ }^{7}$ Thus, physical properties of mixtures of water and DMSO with cellulose dissolving ILs are of great interest for the development of the processing of cellulose in ionic liquid media.

After studying the dissolution of cellulose in several ionic liquids, Vitz et al. ${ }^{8}$ concluded that 1ethyl-3-methylimidazolium diethylphosphate, [EtMeIm] ${ }^{+}\left[\mathrm{Et}_{2} \mathrm{PO}_{4}\right]$; is the most suitable for cellulose processing because it does not cause any degradation of the cellulose. Lall-Ramnarine et al. ${ }^{9}$ found that alkylimidazolium IL's with alkylphosphate derived anions are more stable for enzymatic reactions and less toxic for the fermentative bacteria than the imidazolium acetate ionic liquids. Alkylphosphate IL's also present the advantages over other cellulose dissolving ILs of having a much lower melting point $\left(20^{\circ} \mathrm{C}\right.$ vs $\left.80^{\circ} \mathrm{C}\right)$, less viscosity and of being able to dissolve cellulose at room temperature. ${ }^{3,10}$

Some physical properties of ionic liquids of this family can be found in literature. Ficke et al. 11 show that ionic liquids with diethylphosphate anions have a large negative excess enthalpy. J.-Y. Wang et al. ${ }^{12}$ measured the density of pure 1-methyl-3-methylimidazolium dimethylphosphate and pure 1-ethyl-3-methylimidazolium diethylphosphate at atmospheric pressures. Other authors have studied the physical properties of the [EtMeIm] ${ }^{+}\left[\mathrm{Et}_{2} \mathrm{PO}_{4}\right]^{\prime}, \mathrm{Ge}$ et al. ${ }^{13}$ measured 
activity coefficients at infinite dilution of the $[\mathrm{EtMeIm}]^{+}\left[\mathrm{Et}_{2} \mathrm{PO}_{4}\right]^{-}$with aromatic and aliphatic compounds, Cao et al. ${ }^{14}$ discover that it is possible to break the azeotrope of the methyl acetate and the methanol by adding 1-alkyl-3-methylimidazolium dialkylphosphate ionic liquids by studding the vapor liquid equilibrium of the three components and Ghani et al. ${ }^{15}$ measured density, surface tension and viscosity of ternary mixtures of water $+\mathrm{N}$-methyldiethanolamine $(\mathrm{MDEA})+[\text { EtMeIm }]^{+}\left[\mathrm{Et}_{2} \mathrm{PO}_{4}\right]^{-} /$1,3-Dimethylimidazolium dimethylphosphate $\left(\left[\mathrm{Me}_{2} \mathrm{Im}\right]^{+}\left[\mathrm{Me}_{2} \mathrm{PO}_{4}\right]^{-}\right)$. Nevertheless, more work has to been done in order to fully understand the dissolution and recovery process of cellulose in ionic liquids. ${ }^{16}$

In this work, the density $(\rho)$ and the viscosity $(\mu)$ of pure 1-ethyl-3-methylimidazolium diethylphosphate and its binary mixtures with water and DMSO were measured over 9 isotherms within the temperature range of 293.15 - $373.15 \mathrm{~K}$ at atmospheric pressure. In addition, experimental viscosity data were correlated.

\section{Experimental}

\subsection{Materials}

The DMSO used in the experiments was provided by Sigma- Aldrich and have a purity of $99.90 \%$ and a water content of $\approx 200 \mathrm{ppm}$. Deionized water was provided by Sigma-Aldrich and used to prepare the aqueous solutions. The compound data are summarized in Table 1. The ionic liquid 1-ethyl-3-methylimidazolium diethylphosphate was purchased from Iolitec (assay (NMR, Nuclear Magnetic Resonance) = 98 \%; 1-ethyl-3-methylimidazolium (IC, Ion Chromatography) = 99.1 \%; diethylphosphate (IC) $=98.2 \%$ and 1-Methylimidazole (IC) $<1 \%$ and water content of 0.012 molar fraction). In Figure 1 a representation of the chemical structure can be observed. Due to the low moisture of the ionic liquid it was not dried before used. Nevertheless, the final humidity of every binary mixture was determined by Karl - Fischer Coulometric titration using Mettler Toledo C20 KF. The mixtures were prepared gravimetrically by using a high precision balance (Sartorius Basic BA 310P, precision $=0.001 \mathrm{~g}$ ) and then isolated from the environment using a hermetically sealed crystal vial until a sample is extracted for the measurements, in order to avoid water absorption. The measurements were carried out just after the preparation of the mixture. 

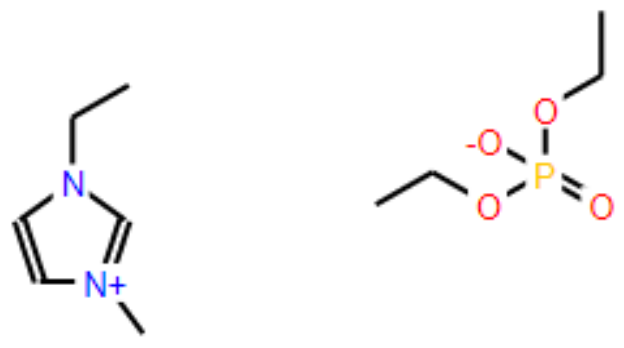

Figure 1. 1-ethyl-3-methylimidazolium diethylphosphate ionic liquid.

Table 1. Materials and purification methods.

\begin{tabular}{llllll}
\hline Chemical name & Source & $\begin{array}{l}\text { Initial mole } \\
\text { fraction purity }\end{array}$ & $\begin{array}{l}\text { Purification } \\
\text { method }\end{array}$ & $\begin{array}{l}\text { Final mole } \\
\text { fraction purity }\end{array}$ & $\begin{array}{l}\text { Analysis } \\
\text { method }\end{array}$ \\
\hline $\begin{array}{l}\text { 1-ethyl-3-methylimidazolium } \\
\text { diethylphosphate }\end{array}$ & Iolitec & 0.98 & none & - & $\mathrm{KFa}$ \\
$\begin{array}{l}\text { Dimethyl sulfoxide } \\
\text { Water }\end{array}$ & Sigma & 0.999 & none & - & $\mathrm{KFa}$ \\
\hline
\end{tabular}

a: Karl - Fischer Coulometric titration

\subsection{Measurements with Stabinger viscometer}

The Stabinger viscometer used in this work is a SVM 3000 model. It is based on the principle of Couette. It consists of two rotating concentric tubes, and between them the fluid of interest. It measures the torque difference between the rotating cylinders that is proportional to the viscosity of the fluid. For the calculations, it is necessary the density of the fluid, so the Stabinger viscometer has a vibrating tube densimeter integrated into its structure. Both measurements were carried out simultaneously, being the densimeter and the viscometer filled in one single step. The measurements were performed thought a cycle of temperatures. The range of temperature of the equipment is from 233.15 to $373.15 \mathrm{~K}$, in a viscosity range from $0.2 \mathrm{mPa} \cdot \mathrm{s}$ to $20,000 \mathrm{mPa} \cdot \mathrm{s}$ and in

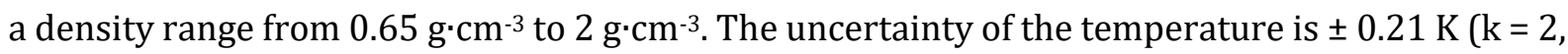
$95.45 \%$ of coverage factor) from (278.15 to 343.15) K. The apparatus performs five measurements automatically with a relative uncertainty of the viscosity $2.0 \%(\mathrm{k}=2)$, and the expanded uncertainty of the density is $\pm 0.26 \mathrm{~kg} \cdot \mathrm{m}^{-3} .(\mathrm{k}=2$ ) (level of confidence $95.45 \%$ ). Expanded uncertainty $(\mathrm{k}=2)$ of the molar fraction is \pm 0.001 . After the measurements, the water content of the mixture was not possible to determine. 
The uncertainty of the density and the viscosity of the Stabinger viscometer was calculated following the law of propagation of uncertainty described in GUM 2008. ${ }^{17}$ The results are summarized in Table 2 and 3.

Table 2. Uncertainty budget of density for Stabinger Viscometer. Values calculated for $x_{\mathrm{H} 20}=$ $0.259, T=333.15 \mathrm{~K}$ and $\rho=1126.0 \mathrm{~kg} \cdot \mathrm{m}^{-3}$

\begin{tabular}{|c|c|c|c|c|c|}
\hline \multicolumn{2}{|c|}{ Uncertainty } & \multirow[t]{2}{*}{ Units } & \multirow{2}{*}{$\begin{array}{l}\text { Estimate } \\
0.020\end{array}$} & \multirow{2}{*}{$\begin{array}{l}\text { Divisor } \\
1\end{array}$} & \multirow[t]{2}{*}{$\begin{array}{l}\mathrm{u}(\mathrm{x}) / \\
\mathrm{kg} \cdot \mathrm{m}^{-3}\end{array}$} \\
\hline & Calibration & & & & \\
\hline \multirow[t]{3}{*}{$\mathrm{u}(T)$} & Resolution & K & 0.001 & $2 \sqrt{3}$ & $1.1 \mathrm{E}-04$ \\
\hline & Repeatability & & 0.005 & 1 & \\
\hline & Calibration & & 0.0005 & 2 & \\
\hline \multirow[t]{2}{*}{$\mathrm{u}(\rho)$} & Resolution & $\mathrm{g} \cdot \mathrm{cm}^{-3}$ & 0.0001 & $2 \sqrt{3}$ & 2.6 E-01 \\
\hline & Repeatability & & 0.0001 & 2 & \\
\hline $\mathrm{U}(\rho)$ & & $\mathrm{g} \cdot \mathrm{cm}^{-3}$ & & $\mathrm{k}=2$ & 5.2 E-01 \\
\hline $\mathrm{U}(\rho)$ & & $\mathrm{g} \cdot \mathrm{cm}^{-3}$ & & $\mathrm{k}=2$ & $4.6 \mathrm{E}-01$ \\
\hline
\end{tabular}

Table 3. Uncertainty budget of viscosity for the Stabinger viscometer. Values calculated for $x_{\mathrm{H} 20}=$ $0.183,313.15 \mathrm{~K}$ and $\mu=135 \mathrm{mPa} \cdot \mathrm{s}$.

\begin{tabular}{llllll}
\hline \multirow{2}{*}{ Uncertainty } & & Units & Estimate & Divisor & $\mathrm{u}(\mathrm{x}) / \mathrm{mPa} \cdot \mathrm{s}$ \\
\hline \multirow{3}{*}{$\mathrm{u}(T)$} & Calibration & & 0.020 & 1 & \\
& Resolution & $\mathrm{K}$ & 0.001 & $2 \sqrt{3}$ & 0.11 \\
& Repeatability & & 0.005 & 1 & \\
\hline \multirow{4}{*}{$\mathrm{u}(\mu)$} & Calibration & & 1.3 & 1 & \\
& Resolution & $\mathrm{mPa} \cdot \mathrm{s}$ & 0.0001 & $2 \sqrt{3}$ & 1.3 \\
& Repeatability & & 0.13 & 1 & \\
\hline $\mathrm{U}(\mu)$ & $\mathrm{mPa} \cdot \mathrm{s}$ & & $\mathrm{k}=2$ & 2.6 \\
\hline $\mathrm{U}(\mu)$ & & $\mathrm{mPa} \cdot \mathrm{s} / \mathrm{mPa} \cdot \mathrm{s}$ & & $\mathrm{k}=2$ & $1.9 \mathrm{E}-02$ \\
\hline
\end{tabular}

The final uncertainty is similar to those obtained by other authors 18,19 using the same equipment. 


\section{Experimental results}

\subsection{Densities and determination of excess molar volumes}

The density measurements in the systems $\mathrm{H}_{2} \mathrm{O}+[\text { EtMeIm }]^{+}\left[\mathrm{Et}_{2} \mathrm{PO}_{4}\right]^{-}$and DMSO + [EtMeIm] $]^{+}\left[\mathrm{Et}_{2} \mathrm{PO}_{4}\right]^{-}$are reported in Table 4 and 5 respectively.

Table 4. Experimental value of densities $\rho$ for the system water $(1)+[\text { EtMeIm }]^{+}\left[\mathrm{Et}_{2} \mathrm{PO}_{4}\right]^{-}$as a function of temperature $T$ and mole fraction of water $x_{1}^{\text {a }}$.

\begin{tabular}{|c|c|c|c|c|c|c|c|c|c|}
\hline$x_{1}$ & 0.012 & 0.061 & 0.123 & 0.183 & 0.259 & 0.502 & 0.765 & 0.880 & 1.000 \\
\hline$T / \mathrm{K}$ & \multicolumn{9}{|c|}{$\rho / \mathrm{kg} \cdot \mathrm{m}^{-3}$} \\
\hline 293.15 & 1151.2 & 1151.7 & 1152.1 & 1152.4 & 1153.0 & 1154.6 & 1150.2 & 1124.0 & 1000.1 \\
\hline 303.15 & 1144.2 & 1144.7 & 1145.2 & 1145.5 & 1146.1 & 1147.8 & 1143.1 & 1116.7 & 998.0 \\
\hline 313.15 & 1137.4 & 1137.9 & 1138.4 & 1138.7 & 1139.3 & 1141.1 & 1135.9 & 1109.2 & 994.3 \\
\hline 323.15 & 1130.7 & 1131.2 & 1131.7 & 1132.0 & 1132.6 & 1134.3 & 1128.6 & 1101.7 & 990.2 \\
\hline 333.15 & 1124.1 & 1124.6 & 1125.0 & 1125.4 & 1126.0 & 1127.4 & 1121.2 & 1094.0 & 985.2 \\
\hline 343.15 & 1117.5 & 1118.0 & 1118.4 & 1118.8 & 1119.3 & 1120.5 & 1113.8 & 1086.1 & 979.6 \\
\hline 353.15 & 1111.0 & 1111.5 & 1111.9 & 1112.1 & 1112.7 & 1113.7 & 1106.3 & 1078.1 & 973.3 \\
\hline 363.15 & 1104.5 & 1104.9 & 1105.2 & 1105.6 & 1106.1 & 1106.8 & 1098.7 & 1070.0 & $\mathrm{~b}$ \\
\hline 373.15 & 1098.2 & 1098.5 & 1098.9 & 1099.1 & 1099.6 & 1099.9 & 1091.2 & 1061.9 & $\mathrm{~b}$ \\
\hline
\end{tabular}

a Standard uncertainties are $\mathrm{u}\left(x_{1}\right)=0.001, \mathrm{u}(T)=0.21 \mathrm{~K}$ and $\mathrm{U}(\rho)=5.2 \mathrm{E}-01 \mathrm{~kg} \cdot \mathrm{m}^{-3}(0.95$ level of confidence).

b Due to the limitations of the equipment used, it was not possible to measure densities and viscosities at temperatures nearby to the boiling point of the water. 
Table 5. Experimental values of Density $\rho$ for the system Water (1) + DMSO (2) + [EtMeIm] $]^{+}\left[\mathrm{Et}_{2} \mathrm{PO}_{4}\right]^{-}$as a function of temperature $T$ and mole fraction of DMSO $X_{2}$ a and water (1) impurities molar fraction $x_{1}$ a.

\begin{tabular}{|l|llllllll|}
\hline$x_{1}$ & 0.019 & 0.003 & 0.004 & 0.004 & 0.004 & 0.005 & 0.008 & 0.000 \\
\hline$x_{2}$ & 0.048 & 0.100 & 0.150 & 0.249 & 0.497 & 0.768 & 0.886 & 1.000 \\
\hline$T / \mathrm{K}$ & & \multicolumn{7}{c|}{$\rho / \mathrm{kg} \cdot \mathrm{m}^{-3}$} \\
\hline 293.15 & 1150.9 & 1150.2 & 1149.6 & 1148.2 & 1143.7 & 1132.3 & 1120.7 & 1101.2 \\
303.15 & 1143.8 & 1143.1 & 1142.6 & 1141.2 & 1136.4 & 1124.6 & 1111.6 & 1091.2 \\
313.15 & 1137.0 & 1136.3 & 1135.7 & 1134.2 & 1129.0 & 1116.3 & 1102.6 & 1081.1 \\
323.15 & 1130.3 & 1129.4 & 1128.8 & 1127.3 & 1121.2 & 1108.1 & 1093.5 & 1071.1 \\
333.15 & 1123.7 & 1122.8 & 1121.9 & 1120.3 & 1113.4 & 1099.9 & 1084.7 & 1061.2 \\
343.15 & 1117.1 & 1116.1 & 1115.2 & 1113.4 & 1106.0 & 1091.7 & 1075.6 & 1051.3 \\
353.15 & 1110.4 & 1109.4 & 1108.5 & 1106.6 & 1098.8 & 1083.6 & 1066.8 & 1041.1 \\
363.15 & 1103.8 & 1102.8 & 1101.8 & 1099.9 & 1091.5 & 1075.6 & 1057.8 & 1031.3 \\
373.15 & 1097.3 & 1096.2 & 1095.2 & 1093.2 & 1084.3 & 1067.5 & 1049.0 & 1021.4 \\
\hline
\end{tabular}

$\mathrm{kg} \cdot \mathrm{m}^{-3}(0.95$ level of confidence).

Our experimental data of pure $[\mathrm{EtMeIm}]+\left[\mathrm{Et}_{2} \mathrm{PO}_{4}\right]^{-}$were compared to literature data reported by several authors. ${ }^{11,12,20-23}$ The relative deviations of the density measurements are presented in Figure 2.

The discrepancies between our data and the literature data can be caused by the different amount of water present in the samples and different purities of the ionic liquid. It can be expected that a higher content in water and a lower purity can make the samples less dense. However, our density data are slightly higher $(0.26 \%)$ than data from Hiraga et al. ${ }^{20}$ despite having less water content and higher purity in their samples. This behavior can be due to the presence of other impurities in the ionic liquid. Purity and water contents of the ILs used by the different authors are presented in Table 6. 


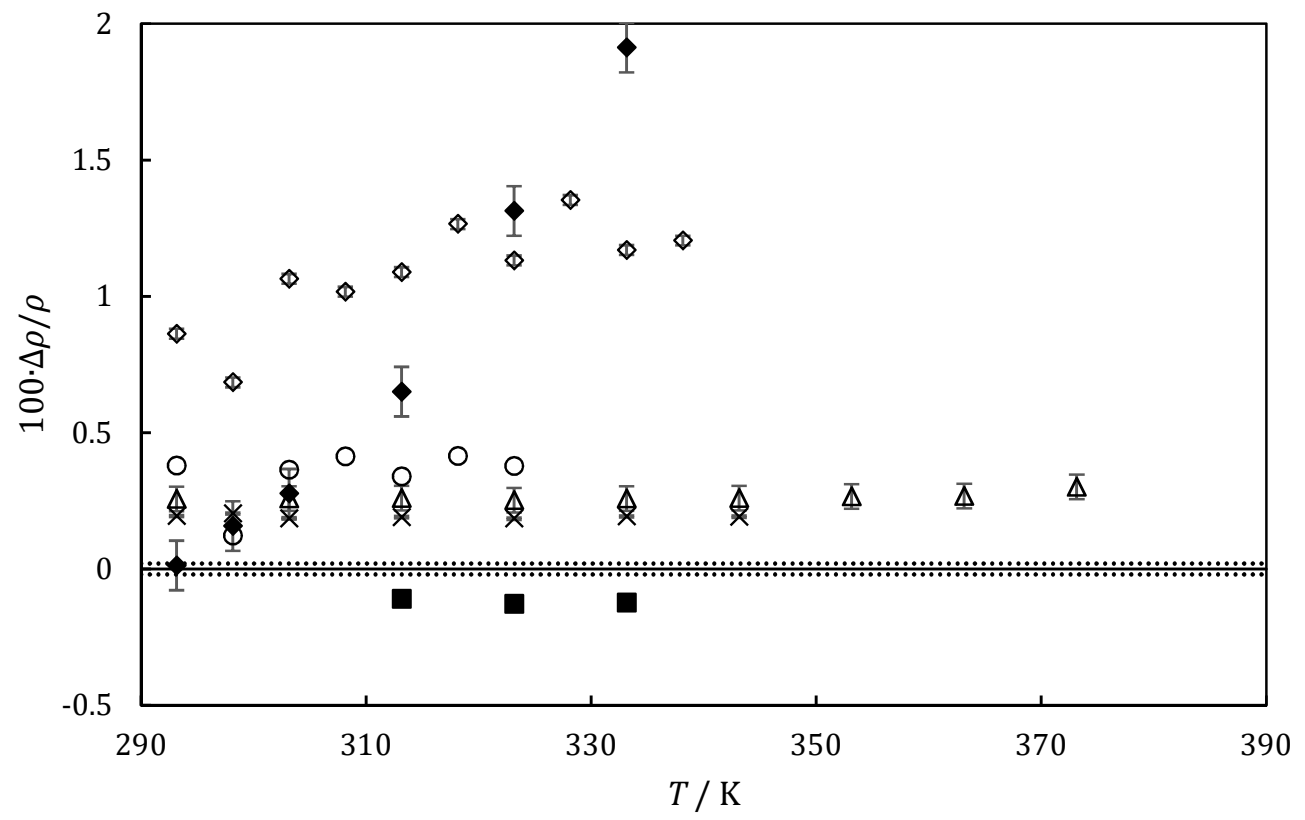

Figure 2. Relative deviations $\Delta \rho=\rho$ (expt.) - $\rho$ (lit.) of experimental densities $\rho$ of pure [EtMeIm] $]^{+}\left[\mathrm{Et}_{2} \mathrm{PO}_{4}\right]^{-}$measured in this work and those reported by other authors: J.-y. Wang. ${ }^{12}(\diamond)$; Hiraga et al. ${ }^{20}(\triangle)$; Ficke et al. ${ }^{11}(\times)$; J. Wang et al. ${ }^{21}(\bigcirc)$; Normazlan et al. ${ }^{22}(\diamond)$ and Palgunadi et al. ${ }^{23}(\boldsymbol{\square})$ as a function of temperature $T$. Dotted lines represents the uncertainty of our data. Error bars represents the expanded uncertainty reported by every author.

Table 6. Source and purity of pure [EtMeIm $]^{+}\left[\mathrm{Et}_{2} \mathrm{PO}_{4}\right]^{-}$used by researchers reporting density and their reported uncertainties.

\begin{tabular}{|c|c|c|c|c|c|c|c|}
\hline First author & Journal & Year & Supplier & Purity & $\begin{array}{l}\text { Water } \\
\text { content }\end{array}$ & Other impurities & Uncertainty \\
\hline $\begin{array}{l}\text { de Pablo (this } \\
\text { article) }\end{array}$ & & - & Iolitec & $98 \%$ & $0.09 \%$ & 1-Methylimidazole & $\pm 0.26 \mathrm{~kg} \cdot \mathrm{m}^{-3}$ \\
\hline J.-y. Wang. ${ }^{12}$ & $\begin{array}{l}\text { J. Chem. } \\
\text { Thermodynamics }\end{array}$ & 2011 & $\begin{array}{l}\text { Shanghai Chengjie } \\
\text { Chemical Co. }\end{array}$ & $>99 \%$ & $0.03 \%$ & Not reported & $\pm 0.2 \mathrm{~kg} \cdot \mathrm{m}^{-3}$ \\
\hline Ficke et al. 11 & J. Chem. Eng. Data & 2010 & EMD Chemicals, Inc. & $\geq 99 \%$ & $0.065 \%$ & Not reported & $\pm 0.05 \mathrm{~kg} \cdot \mathrm{m}^{-3}$ \\
\hline Hiraga et al. ${ }^{20}$ & J. Chem. Eng. Data & 2015 & Merck & $>99 \%$ & $0.01 \%$ & Not reported & $\pm 0.5 \mathrm{~kg} \cdot \mathrm{m}^{-3}$ \\
\hline J. Wang et al. 21 & $\begin{array}{l}\text { Fluid Phase } \\
\text { Equilibria }\end{array}$ & 2009 & Own synthesis & $>98 \%$ & $0.54 \%$ & Not reported & Not reported \\
\hline Normazlan et al. ${ }^{22}$ & J. Chem. Eng. Data & 2014 & Merck & $95.2 \%$ & $0.34 \%$ & Not reported & $\pm 1 \mathrm{~kg} \cdot \mathrm{m}^{-3}$ \\
\hline Palgunadi et al. ${ }^{23}$ & $\begin{array}{l}\text { Thermochimica } \\
\text { Acta }\end{array}$ & 2009 & $\begin{array}{l}\text { Own synthesis, } \\
\text { reactives from } \\
\text { Aldrich Chemicals } \\
\text { Co. }\end{array}$ & $>98 \%$ & $0.02 \%$ & Not reported & Not reported \\
\hline
\end{tabular}

Density of pure DMSO has been compared with others authors. Figure 3 shows the relative deviation with data found in the literature. ${ }^{24-31}$ Despite the high purity and low moisture of the DMSO reported in this work some differences are observed between the literature data and this article data. Wang et al. ${ }^{26}$ reported a purity of $\leq 99 \%$ in mass fraction. Ivanov et al. ${ }^{27}$ reported a 
drying process before the experiments reaching a water content below $0.01 \%$ in mass fraction. Krakowiak et al. ${ }^{29}$ also dry the DMSO sample up to achieve a water content below $0.01 \%$ in mass fraction. Zarei et al. ${ }^{30}$ did not dry the samples before the measurements, whose samples have a maximum water content $0.05 \%$ in mass, and finally Casteel et al. 25 and Clever et al. ${ }^{31}$ dry the DMSO samples without report the final water content. Discrepancies can be due to different water content or other impurities present in the samples, however, all the authors report similar purities and water contents that the reported in this work. In general, density data reported in this work are less than $0.2 \%$ higher than most of the literature data.

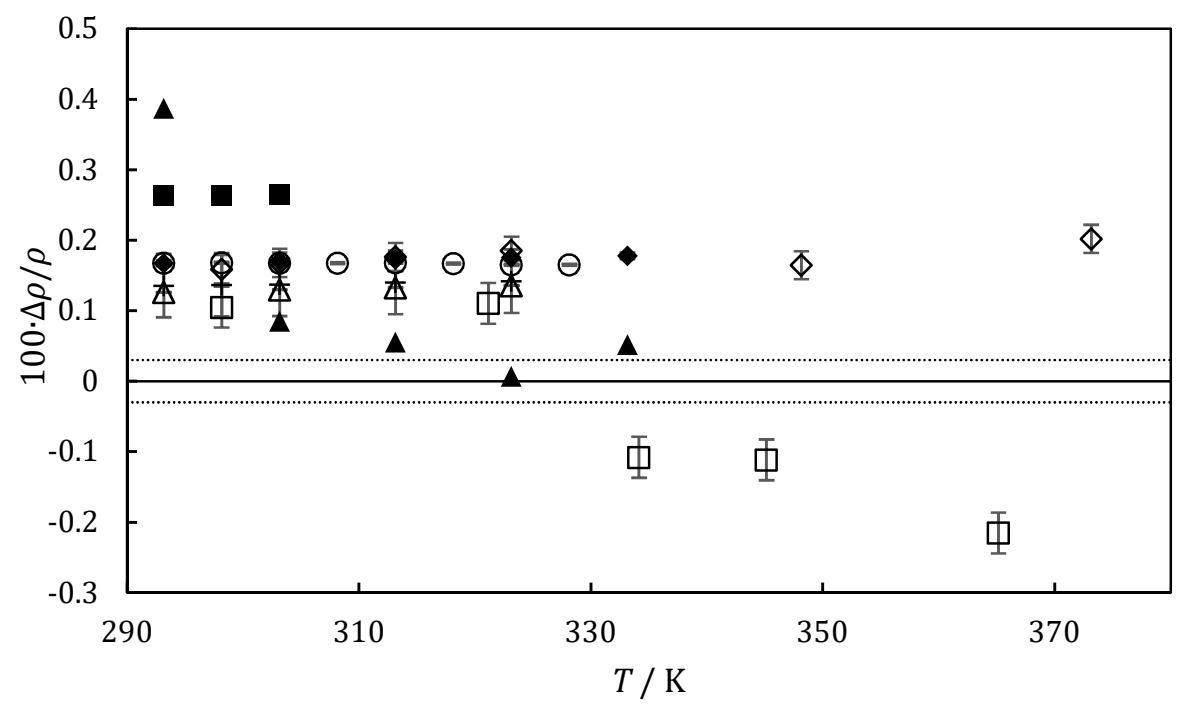

Figure 3. Relative deviations $\Delta \rho=\rho$ (expt.) - $\rho$ (lit.) of experimental densities $\rho$ of pure DMSO of this work and those reported by: Campbell ${ }^{24}(\square)$; Casteel et al. ${ }^{25}(\diamond)$; Wang et al. ${ }^{26}(\triangle)$; Ivanov et al. ${ }^{27}(\bigcirc)$; Iulian et al. ${ }^{28}(+)$; Krakowiak et al. ${ }^{29}(\mathbf{\square})$; Zarei et al. ${ }^{30}(\bullet)$ and Clever et al. ${ }^{31}(\mathbf{\Delta})$ (uncertainty not reported) as a function of temperature $T$. 


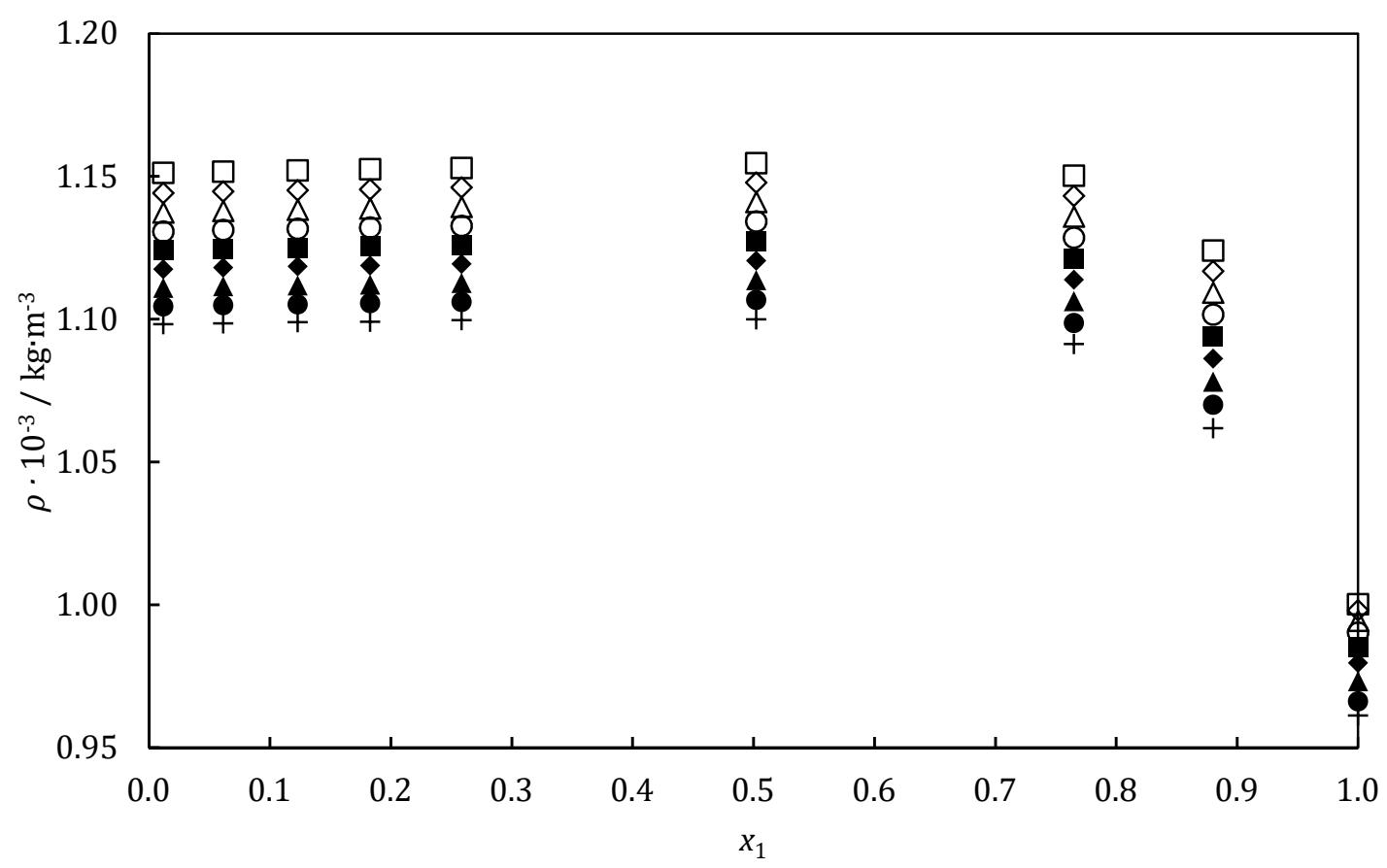

Figure 4. Experimental Densities $\rho$ of mixtures of $\mathrm{H}_{2} \mathrm{O}(1)+[\text { EtMeIm }]^{+}\left[\mathrm{Et}_{2} \mathrm{PO}_{4}\right]^{-}$at $293.15 \mathrm{~K}(\square)$;

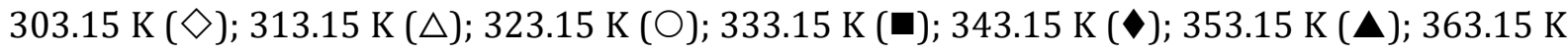
$(\bullet) ; 373.15 \mathrm{~K}(+)$, as a function of water molar fraction $x_{1}$.

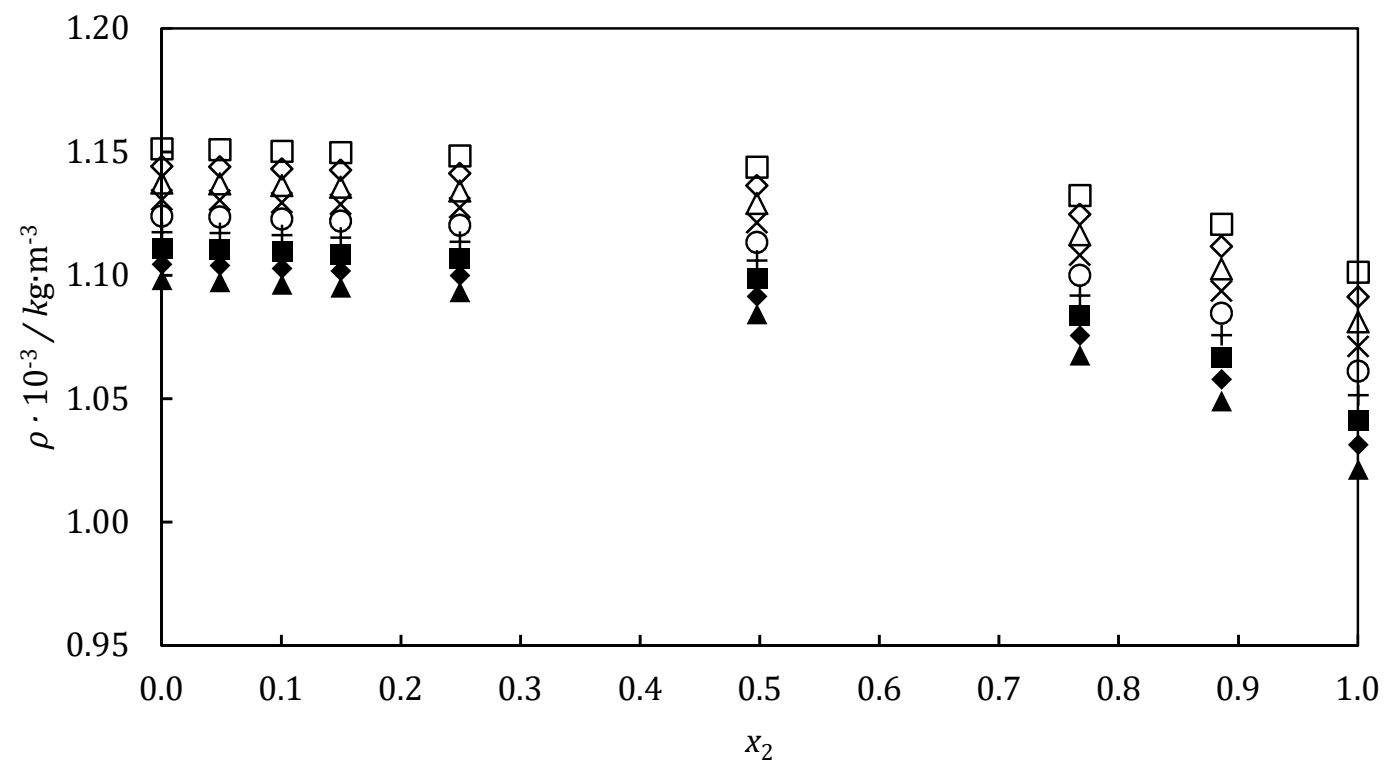

Figure 5. Experimental Densities $\rho$ of mixtures of DMSO (2) + [EtMeIm $]+\left[\mathrm{Et}_{2} \mathrm{PO}_{4}\right]-$ at $293.15 \mathrm{~K}(\square)$;

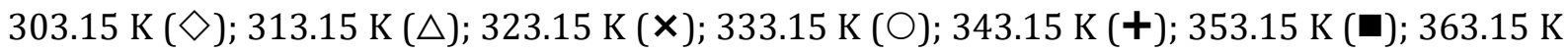
$(\diamond)$; $373.15 \mathrm{~K}(\boldsymbol{\Delta})$, as a function of DMSO molar fraction $x_{2}$. 
The density of water + IL and water + DMSO + IL are plotted in Figures 4 and 5 respectively. It is observed that both systems present positive deviations from the ideal behavior, which implies negative excess volumes, as observed in Figures 6 and 7, where the excess volumes of both systems are plotted as a function of water and DMSO molar fraction respectively. For the excess molar volume calculations of the mixtures $\mathrm{H}_{2} \mathrm{O}+[\text { EtMeIm }]^{+}\left[\mathrm{Et}_{2} \mathrm{PO}_{4}\right]^{-}$, pure water density data at 363 and $373 \mathrm{~K}$ was taken from Refprop software. ${ }^{32}$

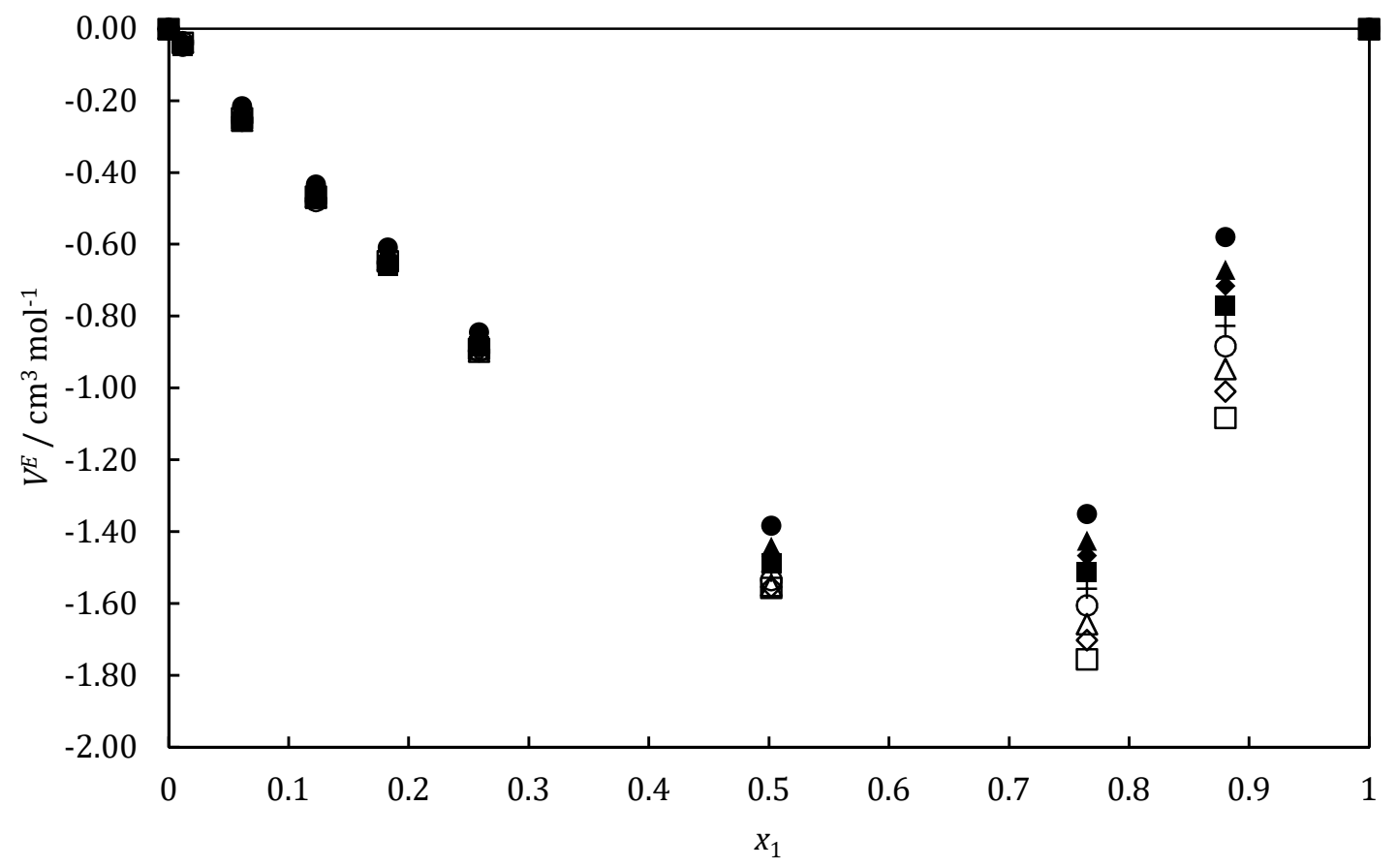

Figure 6. Excess volumes $\left(V^{E}\right)$ of mixtures of $\mathrm{H}_{2} \mathrm{O}(1)+[$ EtMeIm $]+\left[\mathrm{Et}_{2} \mathrm{PO}_{4}\right]-$ at $293.15 \mathrm{~K}(\square) ; 303.15$

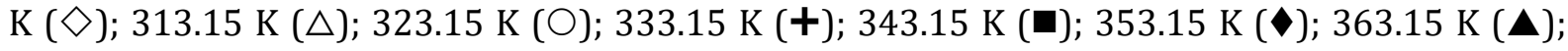
$373.15 \mathrm{~K}(\bullet)$, as a function of water molar fraction $x_{1}$. 


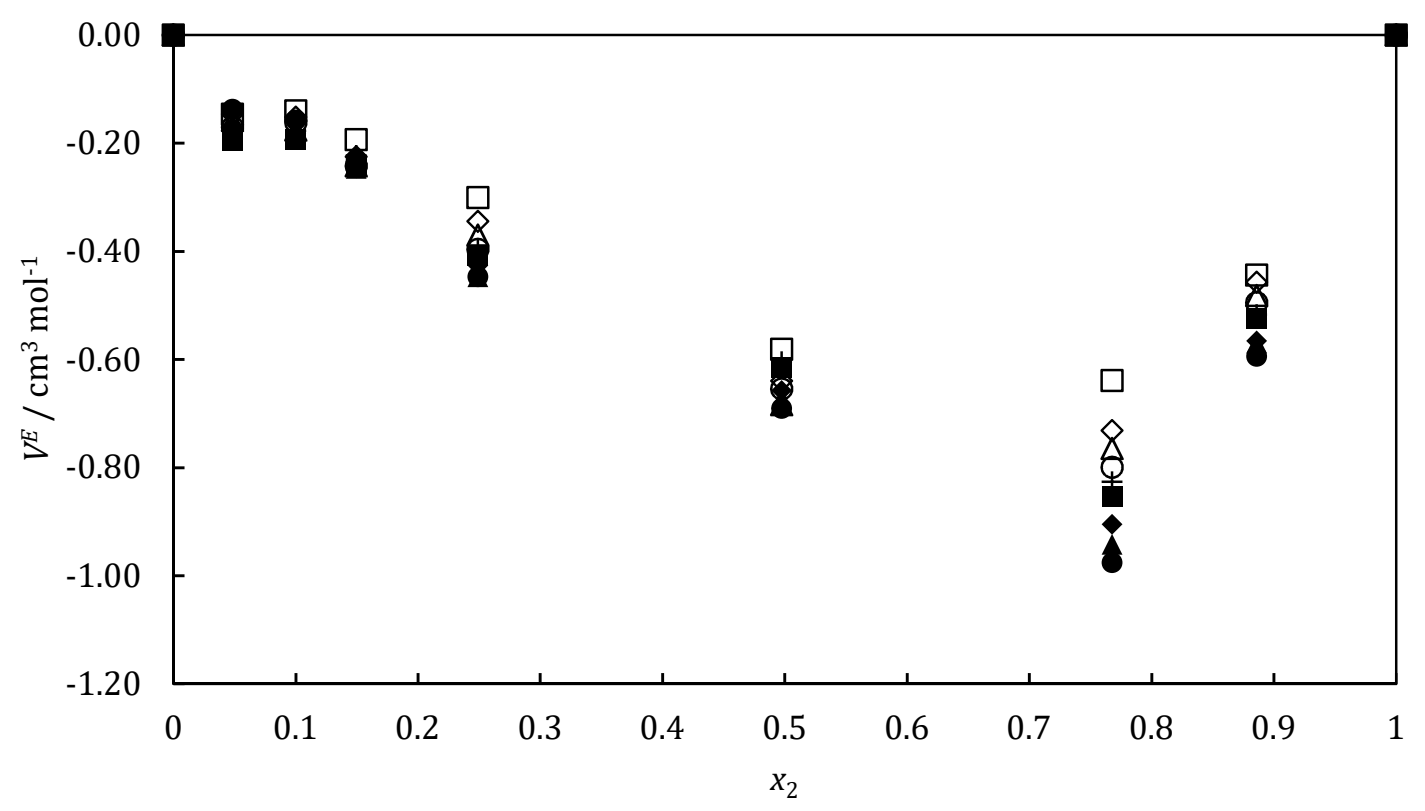

Figure 7. Excess volumes $\left(V^{E}\right)$ of mixtures of DMSO (2) + [EtMeIm] $+\left[\mathrm{Et}_{2} \mathrm{PO}_{4}\right]^{-}$at $293.15 \mathrm{~K}(\square)$;

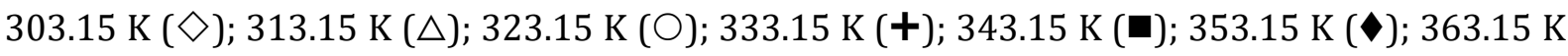
$(\boldsymbol{\Delta}) ; 373.15 \mathrm{~K}(\bullet)$, as a function of DMSO molar fraction $x_{2}$.

The mixtures of ionic liquid with water are less ideal than the mixtures with DMSO, as observed in Figure 6 and Figure 7, where the excess volume is represented versus the molar fraction of $\mathrm{H}_{2} \mathrm{O}$ and DMSO respectively. In both mixtures, there is a negative excess volume, however the influence of the temperature of both systems in the excess volume is completely reverse. While in the aqueous mixtures, the absolute value of the excess molar volume decreases with temperature, in the mixtures with DMSO the absolute excess volume is higher with temperature. In aqueous mixtures, an increase in the temperature indicates a weakening of the interactions between the molecules resulting in a higher ideality in the mixture. ${ }^{33}$ On the other hand, the mixtures with DMSO present a reverse behavior. The explanation of this behavior can be that the temperature increases the "free volume" availability and the mixture has, in this way, a bigger capacity to "accommodate" DMSO molecules in its structure. ${ }^{34}$

The isobaric expansion coefficient, $\alpha_{\mathrm{p}}$, was calculated from experimental density data, and it is presented for each concentration in Table 7 and 8. 
Table 7. Isobaric compressibility $\alpha_{\mathrm{p}}$ of mixtures of $\mathrm{H}_{2} \mathrm{O}(1)+[\text { EtMeIm }]^{+}\left[\mathrm{Et}_{2} \mathrm{PO}_{4}\right]^{-}$as a function of molar fraction of water $x_{1}{ }^{\text {a }}$.

\begin{tabular}{cc}
\hline$x_{1}$ & $\alpha_{\mathrm{p}}$ \\
\hline 0.012 & $5.88 \mathrm{E}-04$ \\
0.061 & $5.90 \mathrm{E}-04$ \\
0.123 & $5.91 \mathrm{E}-04$ \\
0.183 & $5.91 \mathrm{E}-04$ \\
0.259 & $5.92 \mathrm{E}-04$ \\
0.502 & $6.07 \mathrm{E}-04$ \\
0.765 & $6.59 \mathrm{E}-04$ \\
0.880 & $7.11 \mathrm{E}-04$ \\
1.000 & $5.40 \mathrm{E}-04$ \\
\cline { 2 - 2 } a Stand uncertainty u is u $\left(\alpha_{\mathrm{p}}\right)=2 \%$.
\end{tabular}

Table 8. Isobaric compressibility $\alpha_{\mathrm{p}}$ of mixtures DMSO (2) $+[\text { EtMeIm }]^{+}\left[\mathrm{Et}_{2} \mathrm{PO}_{4}\right]-$ as a function of DMSO molar fraction $x_{2}$ a.

\begin{tabular}{ll}
\hline$x_{2}$ & $\alpha_{\mathrm{p}}$ \\
\hline 0.000 & $5.89 \mathrm{E}-04$ \\
0.048 & $5.94 \mathrm{E}-04$ \\
0.100 & $6.00 \mathrm{E}-04$ \\
0.150 & $6.06 \mathrm{E}-04$ \\
0.249 & $6.14 \mathrm{E}-04$ \\
0.497 & $6.70 \mathrm{E}-04$ \\
0.768 & $7.40 \mathrm{E}-04$ \\
0.886 & $8.26 \mathrm{E}-04$ \\
1 & $9.44 \mathrm{E}-04$ \\
\hline dard uncertainty u is $\mathrm{u}\left(\alpha_{\mathrm{p}}\right)=2 \%$.
\end{tabular}




\subsection{Viscosity}

Viscosity data of the systems $\mathrm{H}_{2} \mathrm{O}(1)+[\text { EtMeIm }]^{+}\left[\mathrm{Et}_{2} \mathrm{PO}_{4}\right]^{-}$and DMSO (2) $+[\text {EtMeIm }]^{+}\left[\mathrm{Et}_{2} \mathrm{PO}_{4}\right]^{-}$ are reported in Table 9 and 10. The experiments were performed in 9 isotherms ranging from $293.15 \mathrm{~K}$ and $373.15 \mathrm{~K}$. All measurements were performed at atmospheric pressure.

Table 9. Experimental values of Viscosity $\mu$ of mixtures of $\mathrm{H}_{2} \mathrm{O}(1)+[\text { EtMeIm }]^{+}\left[\mathrm{Et}_{2} \mathrm{PO}_{4}\right]^{-}$as a function of temperature $T$ and molar fraction of water $x_{1}$ a.

\begin{tabular}{|l|lllllllll|}
\hline$x_{1}$ & 0.012 & 0.061 & 0.123 & 0.183 & 0.259 & 0.502 & 0.765 & 0.880 & 1.000 \\
\hline$T / \mathrm{K}$ & \multicolumn{1}{l}{$\mu / \mathrm{mPa} \cdot \mathrm{s})$} & & & & & & & \\
\hline 293.15 & 540 & 513 & 487 & 462 & 422 & 202 & 51.1 & 12.5 & 1.00 \\
303.15 & 274 & 262 & 250 & 238 & 219 & 111 & 31.2 & 8.35 & 0.805 \\
313.15 & 154 & 148 & 141 & 135 & 125 & 65.8 & 20.3 & 5.91 & 0.651 \\
323.15 & 94.0 & 90.2 & 86.4 & 83.1 & 76.5 & 40.7 & 14.0 & 4.38 & 0.544 \\
333.15 & 61.2 & 58.8 & 56.2 & 54.3 & 49.3 & 27.6 & 10.1 & 3.36 & 0.472 \\
343.15 & 42.1 & 40.4 & 38.6 & 37.4 & 34.1 & 19.6 & 7.58 & 2.67 & 0.417 \\
353.15 & 30.2 & 29.0 & 27.7 & 26.9 & 24.5 & 14.4 & 5.88 & 2.18 & 0.342 \\
363.15 & 22.5 & 21.6 & 20.6 & 20.0 & 18.3 & 11.2 & 4.69 & 1.83 & $*$ \\
373.15 & 17.3 & 16.5 & 15.8 & 15.3 & 14.1 & 8.9 & 3.83 & 1.55 & $*$ \\
\hline
\end{tabular}

a Standard uncertainties $\mathrm{u}$ are $\mathrm{u}\left(x_{1}\right)=0.001, \mathrm{u}(T)=0.21 \mathrm{~K}$ and $\mathrm{u}(\mu)=2 \%$

* Due to the limitations of the equipment used, it was not possible to measure densities and viscosities at temperatures nearby to the boiling point of the water.

Table 10. Experimental values of Viscosity $\mu$ for the system Water (1) + DMSO (2) + [EtMeIm] $]^{+}\left[\mathrm{Et}_{2} \mathrm{PO}_{4}\right]^{-}$as a function of temperature $T$ and mole fraction of DMSO $x_{2}{ }^{\mathrm{a}}$ and water (1) impurities molar fraction $x_{1}$ a.

\begin{tabular}{|lllllllll|}
\hline$x_{1}$ & 0.019 & 0.003 & 0.004 & 0.004 & 0.004 & 0.005 & 0.008 & 0.000 \\
\hline$x_{2}$ & 0.048 & 0.100 & 0.150 & 0.249 & 0.497 & 0.768 & 0.886 & 1.000 \\
\hline$T / \mathrm{K}$ & $\mu / \mathrm{mPa} \cdot \mathrm{s}$ & & & & & & & \\
\hline 293.15 & 481 & 421 & 329 & 243 & 87.0 & 19.0 & 5.91 & 2.31 \\
303.15 & 245 & 217 & 175 & 134 & 52.9 & 13.2 & 4.50 & 1.89 \\
313.15 & 137 & 123 & 102 & 80.6 & 34.6 & 9.59 & 3.54 & 1.57 \\
323.15 & 81.1 & 73.7 & 64.6 & 51.8 & 23.9 & 7.14 & 2.87 & 1.33 \\
333.15 & 50.6 & 48.8 & 43.1 & 35.3 & 15.7 & 5.72 & 2.38 & 1.15 \\
343.15 & 34.8 & 33.9 & 30.2 & 25.2 & 11.8 & 4.60 & 2.02 & 1.01 \\
353.15 & 23.9 & 22.5 & 21.7 & 18.7 & 9.22 & 3.80 & 1.73 & 0.893 \\
363.15 & 17.8 & 16.8 & 16.5 & 14.3 & 7.36 & 3.18 & 1.51 & 0.799 \\
373.15 & 13.4 & 12.9 & 12.8 & 11.2 & 6.01 & 2.71 & 1.32 & 0.721 \\
\hline
\end{tabular}

a Standard uncertainties $\mathrm{u}$ are $\mathrm{u}\left(x_{1}\right)=0.001, \mathrm{u}\left(x_{2}\right)=0.001, \mathrm{u}(T)=0.21 \mathrm{~K}$ and $\mathrm{u}(\mu)=2 \%$. 
Our experimental data were compared to literature data reported by other authors. ${ }^{20,22,35}$ The relative deviations of the viscosity measurements are presented in Figure 8. It can be observed that there is some scattering between all the authors.

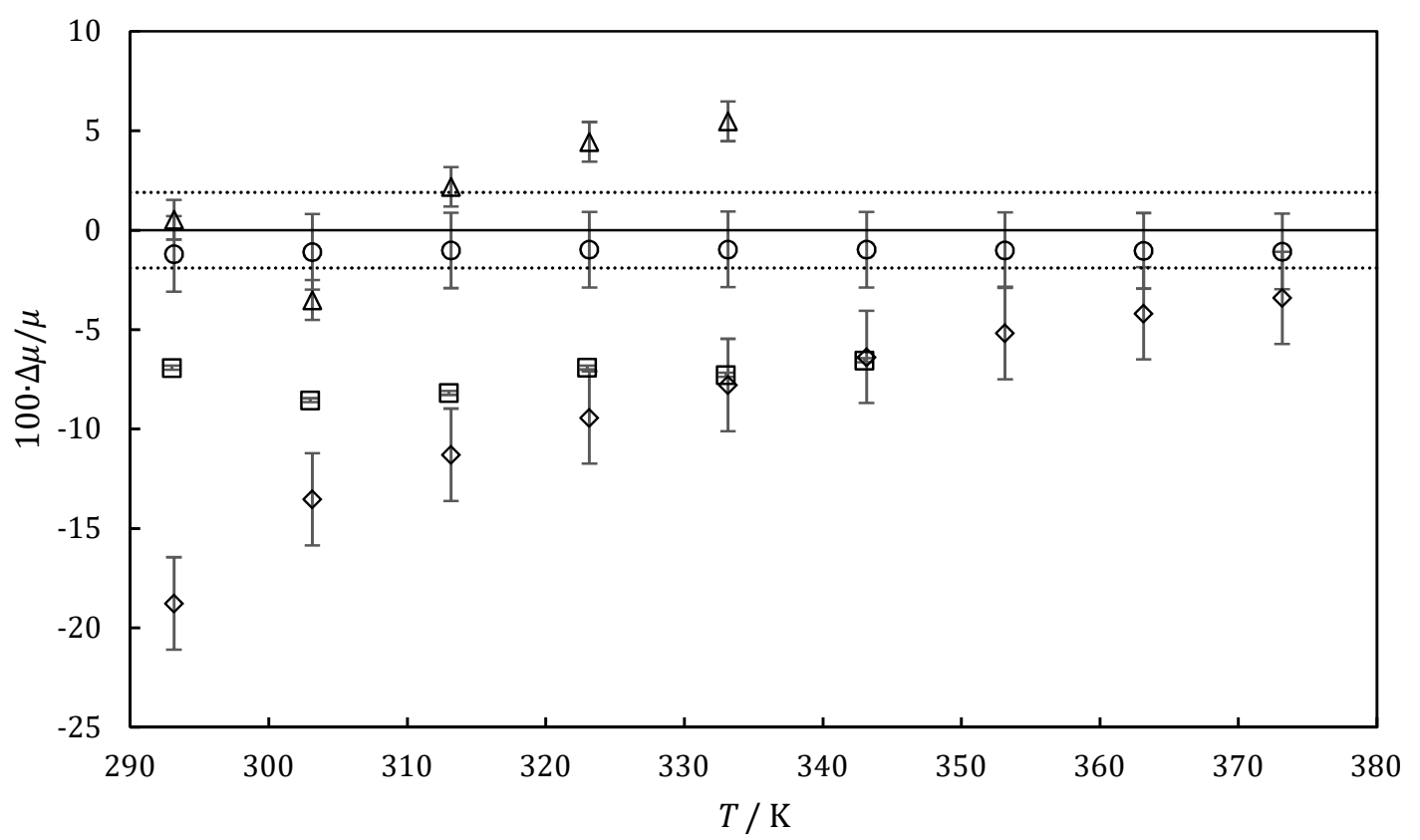

Figure 8. Relative deviations $\Delta \mu=\mu$ (expt.) - $\mu$ (lit.) of experimental viscosity $\mu$ data of pure $[\mathrm{EtMeIm}]^{+}\left[\mathrm{Et}_{2} \mathrm{PO}_{4}\right]^{-}$measured in this work and those reported by other authors: Hiraga et al. ${ }^{20}$ $(\diamond)$; Tenney et al. ${ }^{35}(\square)$; Normazlan et al. ${ }^{22}(\triangle)$; This work when viscosity is extrapolated to zero water content $(\bigcirc)$. Error bars represents the expanded uncertainty reported by the authors.

When comparing our data to literature data it was found big discrepancy in literature data, and also with our data. The discrepancies can be caused by the different amount of water (that decreases the viscosity of the samples) and other impurities present in the samples. The water contents and purities of the IL's used by the different authors are presented in Table 11. Our data present lower viscosities than those reported by Tenney et al. ${ }^{35}$ (10\% discrepancy) and $20 \%$ of maximum deviation with the data reported by Hiraga et al. ${ }^{20}$ Discrepancies are more important at lower temperatures. Maybe this can be explained because the viscosity is higher at these temperatures being also higher the influence of the impurities. While Tenney et al., ${ }^{27}$ with a similar purity than Hiraga et al., ${ }^{20}$ reported a data content of 1000 ppm water, much higher than the 175 ppm reported in this work, they present higher viscosities instead of lower as it would be expected. The data of Hiraga et al. ${ }^{20}$ present higher viscosities as expected by the lower water content of $60 \mathrm{ppm}$ reported by the authors. In order to better compare, an extrapolation of the viscosity to zero water content has been calculated. In the literature data, it was not possible to 
make this correction due to the lack of experimental data at other water concentrations. Despite this extrapolation makes the data become closer to the data of Hiraga et al. ${ }^{20}$ (with only $60 \mathrm{ppm}$ water reported versus $175 \mathrm{ppm}$ of the samples measured in this work) still important deviation can be found between them. This can be explained though the fact that not only water impurities can be found in the samples but other impurities that can affect the viscosity, and its influence with the temperature. In this work is reported the presence of 1-Methylimidazole, however others authors have not reported any impurity than water in their respective articles. The influence of chlorine as an impurity in ionic liquids has been already measured ${ }^{36}$ and shows a high increase of the viscosity with a presence of low concentration of chlorine. Maybe the presence of 1Methylimidazole have a similar effect in the system studied in this article. In the other hand, Normazlan et al. ${ }^{22}$ shows lower viscosity values, what it is consistent to the high humidity of his sample (3400 ppm).

Table 11. Source and purity of pure $[\mathrm{EtMeIm}]+\left[\mathrm{Et}_{2} \mathrm{PO}_{4}\right]-$ used by researchers reporting viscosity and their reported uncertainties.

\begin{tabular}{llllllll}
\hline First author & Journal & Year & Supplier & Purity & $\begin{array}{l}\text { Water } \\
\text { content }\end{array}$ & Other impurities & $\begin{array}{l}\text { Uncertainty } \\
(\mathrm{k}=2)[\%]\end{array}$ \\
\hline de Pablo (this article) & & - & Iolitec & $98 \%$ & $0.09 \%$ & 1-Methylimidazole & $2 \%$ \\
Hiraga et al. ${ }^{20}$ & J. Chem. Eng. Data & 2015 & Merck & $>99 \%$ & $0.01 \%$ & Not reported & $4.65 \%$ \\
Tenney et al. $^{35}$ & J. Chem. Eng. Data & 2014 & Merck & $>99 \%$ & $0.10 \%$ & Not reported & $0.10 \%$ \\
Normazlan et al. ${ }^{22}$ & J. Chem. Eng. Data & 2014 & Merck & $95.2 \%$ & $0.34 \%$ & Not reported & $1 \%$ \\
\hline
\end{tabular}

Viscosity of pure DMSO has been compared with data found in the literature in Figure 9. ${ }^{25,37-44}$ All the authors report a purity which varies between $98 \%$ and $99.9 \%$ in mass fraction. However, some discrepancy is found between the literature data itself and between the same and this article data. Discrepancies can be caused by different water content in the samples. Most of the authors report a purification / drying process before the measurements, 25,37,39,41,43 but do not report the water content in the samples. Data of Zhao et al. ${ }^{43}$ with an initial $98 \%$ mass fraction purity before a desiccation and degasification process are in agreement with the uncertainty of our data. 


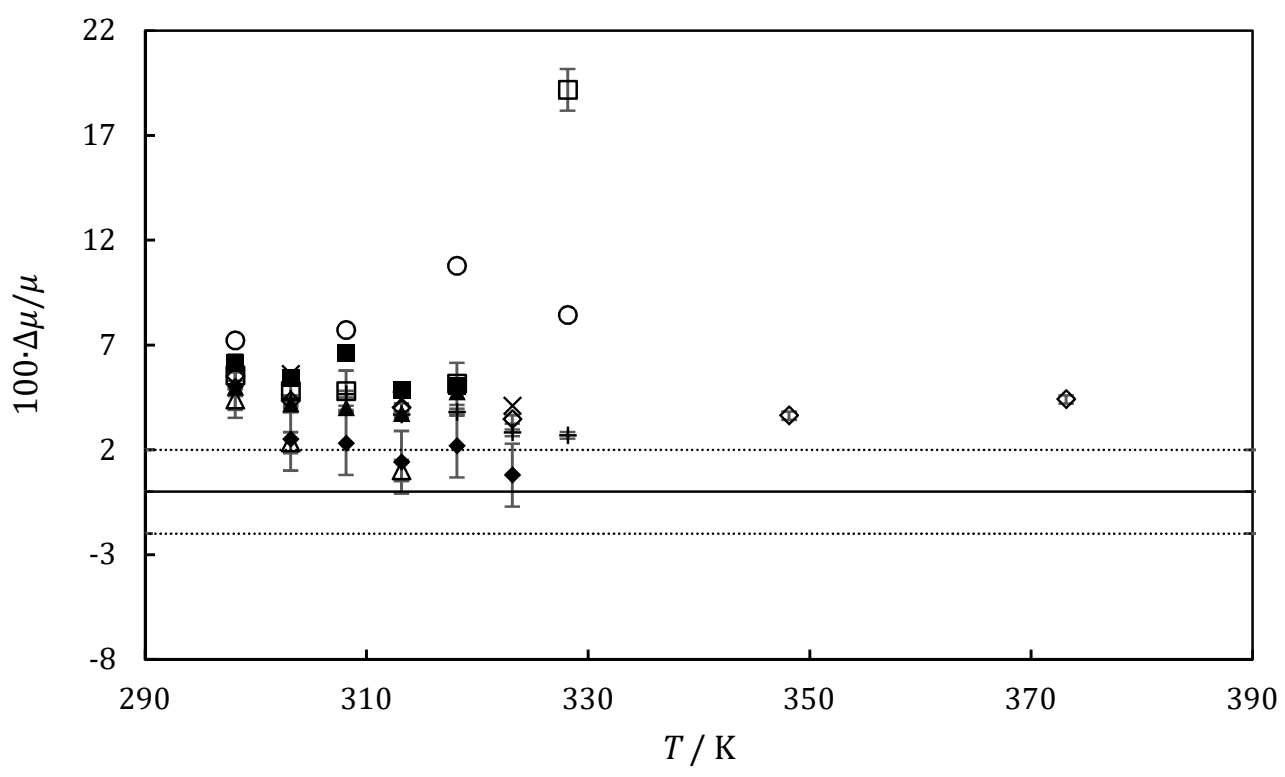

Figure 9. Relative deviation $\Delta \mu=\mu$ (expt.) - $\mu$ (lit.) of experimental viscosity $\mu$ of pure DMSO against the temperature between the experimental viscosity data of this work and those reported by: Casteel et al. ${ }^{25}(\diamond)$; Ciocirlan et al. $37(\triangle)$; Yang et al. ${ }^{38}(\times)$ (uncertainty not reported); Govinda et al. ${ }^{39}(\square)$; Gokavl et al. ${ }^{40}(\bigcirc)$ (uncertainty not reported); Saleh et al. ${ }^{41}(+)$; Ali et al. ${ }^{42}$ (看) (uncertainty not reported); Zhao et al. ${ }^{43}(\bullet)$ and Kapadi et al. ${ }^{44}(\boldsymbol{\Delta})$ as a function of temperature $T$.

Experimental viscosities are plotted as a function of co-solvent molar fraction in Figures 10 and 11, for the systems Water $+[\text { EtMeIm }]^{+}\left[\mathrm{Et}_{2} \mathrm{PO}_{4}\right]^{-}$and DMSO $+[\text {EtMeIm }]^{+}\left[\mathrm{Et}_{2} \mathrm{PO}_{4}\right]^{-}$respectively. It is observed that the viscosity decreases drastically with temperature and co-solvent concentration. At low co-solvent concentrations, the decreasing rate is linear. 


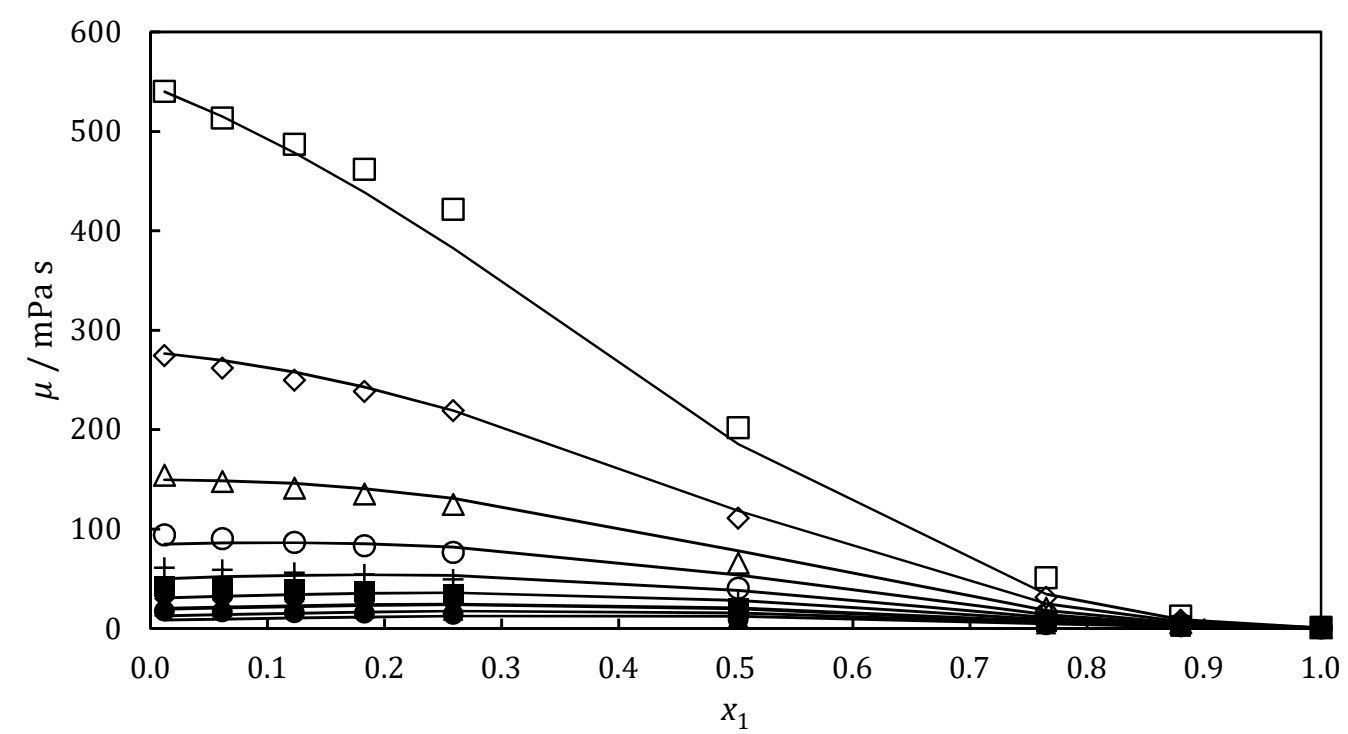

Figure 10. Experimental viscosity $\mu$ of mixtures of $\mathrm{H}_{2} \mathrm{O}(1)+[\text { EtMeIm }]^{+}\left[\mathrm{Et}_{2} \mathrm{PO}_{4}\right]^{-}$at $293.15 \mathrm{~K}(\square)$;

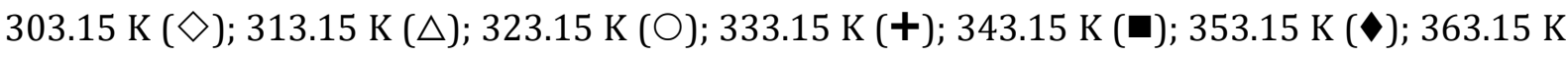
$(\Delta)$; $373.15 \mathrm{~K}(\bullet)$ as a function of molar fraction of water $x_{1}$. The solid line represents correlation prediction using eq. 3 .

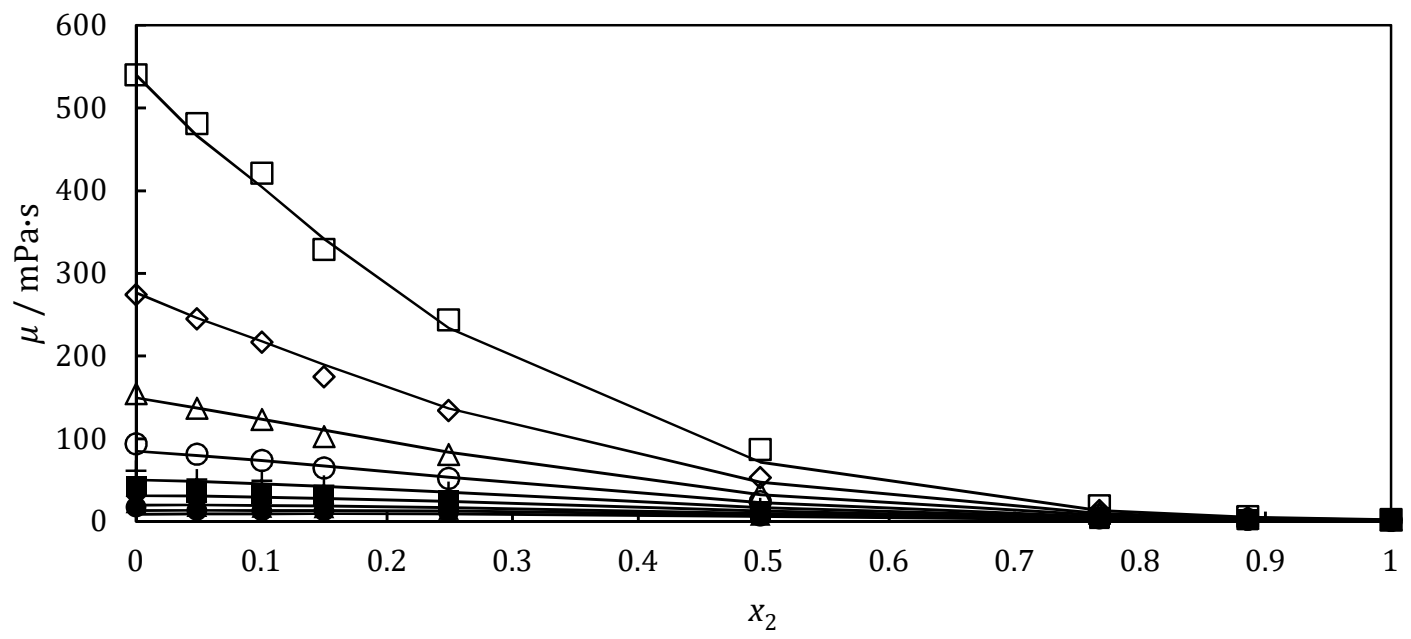

Figure 11. Experimental Viscosity $\mu$ of mixtures of DMSO (2) $+[\text { EtMeIm }]^{+}\left[\mathrm{Et}_{2} \mathrm{PO}_{4}\right]^{-}$at $293.15 \mathrm{~K}$ $(\square) ; 303.15 \mathrm{~K}(\diamond) ; 313.15 \mathrm{~K}(\triangle)$; 323.15 K (○); 333.15 K (+); 343.15 K(匹); $353.15 \mathrm{~K}(\diamond) ; 363.15$ $\mathrm{K}(\mathbf{\Delta}) ; 373.15 \mathrm{~K}(\bullet)$ as a function of DMSO molar fraction $x_{2}$. The solid line represents correlation prediction using eq. 4 . 


\subsection{Viscosity correlation}

The viscosity of both systems was correlated as a function of the temperature and the concentration of the co-solvent using two modifications from the correlation of Grunberg and Nissan ${ }^{45}$ previously used by our research group. ${ }^{46,47}$ The expression shown in eq. 1 represents the viscosity of the pure ionic liquid, and it is adjusted in first place.

$$
\ln (\mu / m P a \cdot s)=\left(\frac{E}{(T / K)^{2}}+\frac{A}{T / K}+B\right)
$$

Where $\mu$ is the viscosity and $\mathrm{T}$ is the temperature.

The parameters were adjusted by minimizing the objective function Absolute Average Relative Deviation (AARD\%) defined in eq. 2, with $n$ being the number of experimental data, and $\mu_{\text {exp }}$ and $\mu_{\text {calc }}$ are experimental and calculated viscosities respectively.

$$
A A R D \%=\frac{\sum\left(\frac{\left|\mu_{\text {exp }}-\mu_{\text {calc }}\right|}{\mu_{\exp }}\right)}{n} \cdot 100
$$

The viscosity of mixtures water $+[\text { EtMeIm }]^{+}\left[\mathrm{Et}_{2} \mathrm{PO}_{4}\right]^{-}$in all the concentration range was correlated using eq. 3 , where $T$ is the temperature, and $\mu_{i}$ and $x_{i}$ are the viscosity and molar fraction of component $i$, respectively.

$$
\begin{aligned}
& \ln (\mu /(m P a \cdot s)) \\
& =x_{I L} \cdot\left(\frac{E}{(T / K)^{2}}+\frac{A}{(T / K)}+B\right)+x_{H_{2} O} \\
& \cdot \ln \left(\mu_{\mathrm{H}_{2} O} /(m P a \cdot s)\right)+\frac{x_{I L} \cdot x_{\mathrm{H}_{2} O}}{x_{I L}+F}(C+D \cdot(T / K))
\end{aligned}
$$

An AARD $\%$ of $13 \%$ and a maximum deviation of $49 \%$ at $373.15 \mathrm{~K}$ and $x_{\mathrm{H} 20}=0.012$. Even when the deviations are high, due to the complex behavior of this system, these results represent a good fitting of the system $\mathrm{H}_{2} \mathrm{O}+[\text { EtMeIm }]^{+}\left[\mathrm{Et}_{2} \mathrm{PO}_{4}\right]^{-}$for engineering purposes. Correlation and experimental data are compared in Figure 10. Fitting parameters are summarized in Table 12.

To correlate the viscosity of the system DMSO $+[\text { EtMeIm }]^{+}\left[\mathrm{Et}_{2} \mathrm{PO}_{4}\right]^{-}$, the amount of water present in the ionic liquid was also taken into account, due to the important influence of water in the viscosity. Thus, the expression used is the one presented in eq. 4 and it is also a modification of 
the Grunberg and Nissan correlation. Parameters E, A, B, C, D and F, are the same for the aqueous mixtures of the IL. The rest of the parameters were adjusted for the DMSO by minimization of the average relative deviation (AARD \%) in the same way defined in eq. 1. An AARD\% of $9.5 \%$ was obtained with a maximum deviation of $49 \%$ at $373.15 \mathrm{~K}$ and $x_{D M S O}=0$. Even when in this case the behavior of the system is better described, the deviations are high. But, again, due to the complex behavior of this system, these results represent a good fitting of the system for engineering purposes. The correlated and the experimental data are represented in Figure 11.

$$
\begin{aligned}
\ln (\mu /(m P a \cdot s)) & \\
= & x_{I L} \cdot\left(\frac{E}{(T / K)^{2}}+\frac{A}{(T / K)}+B\right)+x_{H_{2} O} \\
& \cdot \ln \left(\mu_{H_{2} O} /(m P a \cdot s)\right)+\frac{x_{I L} \cdot x_{H_{2} O}}{x_{I L}+F}(C+D \cdot T / K)+x_{D M S O} \\
& \cdot \ln \left(\mu_{D M S O} /(m P a \cdot s)\right)+\frac{x_{I L} \cdot x_{D M S O}}{x_{I L}+G}(H+I \cdot T / K)
\end{aligned}
$$

Table 12. Parameters fitted for the eq. 3 and eq. 4.

\begin{tabular}{lll}
\hline & Equation 3 & Equation 4 \\
\hline $\mathrm{E}$ & $5.18 \mathrm{E}+05$ & $5.18 \mathrm{E}+05$ \\
$\mathrm{~A}$ & $2.51 \mathrm{E}+03$ & $2.51 \mathrm{E}+03$ \\
$\mathrm{~B}$ & $-8.31 \mathrm{E}+00$ & $-8.31 \mathrm{E}+00$ \\
$\mathrm{C}$ & $7.98 \mathrm{E}+00$ & $7.98 \mathrm{E}+00$ \\
D & $0.00 \mathrm{E}+00$ & $0.00 \mathrm{E}+00$ \\
F & $4.60 \mathrm{E}-01$ & $4.60 \mathrm{E}-01$ \\
G & & $9.98 \mathrm{E}+01$ \\
H & & $2.08 \mathrm{E}-01$ \\
$\mathrm{I}$ & & $9.61 \mathrm{E}-01$ \\
$\%$ AARD & $13 \%$ & $9.5 \%$ \\
$\%$ Max & $49 \%$ & $49 \%$ \\
\hline
\end{tabular}

In Figure 12 and 13 can be observed the relative deviation between the experimental data and the calculated by equations 3 and 4 . In general higher deviations, as high as $49 \%$ can be found, it is observed that deviations are higher at higher temperature. Nevertheless, the data deviation is distributed uniformly between both positive and negative sides showing a good correlation of the equation. 


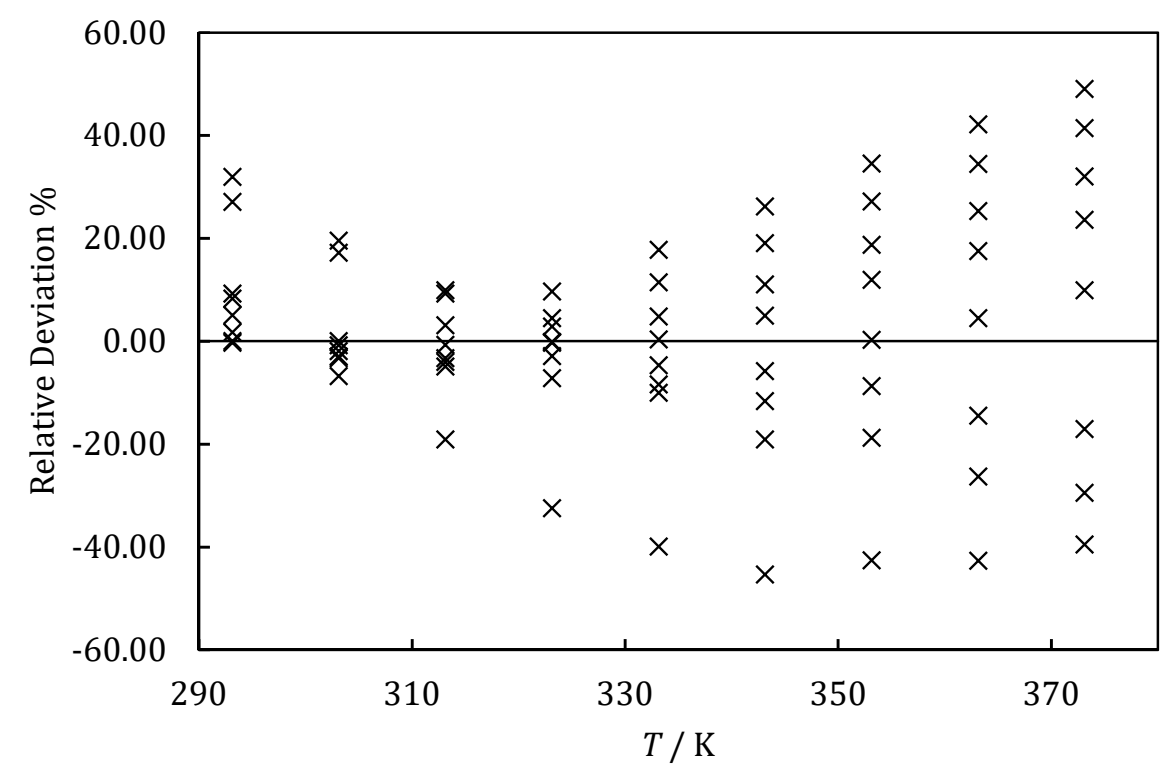

Figure 12. Relative deviation plot of viscosities $\mu$ for mixtures of $\mathrm{H}_{2} \mathrm{O}(1)+[\text { EtMeIm] }]^{+}\left[\mathrm{Et}_{2} \mathrm{PO}_{4}\right]^{-}$at atmospheric pressure. Values were calculated by eq. 3 with parameters used in the correlation of experimental data measured in this work.

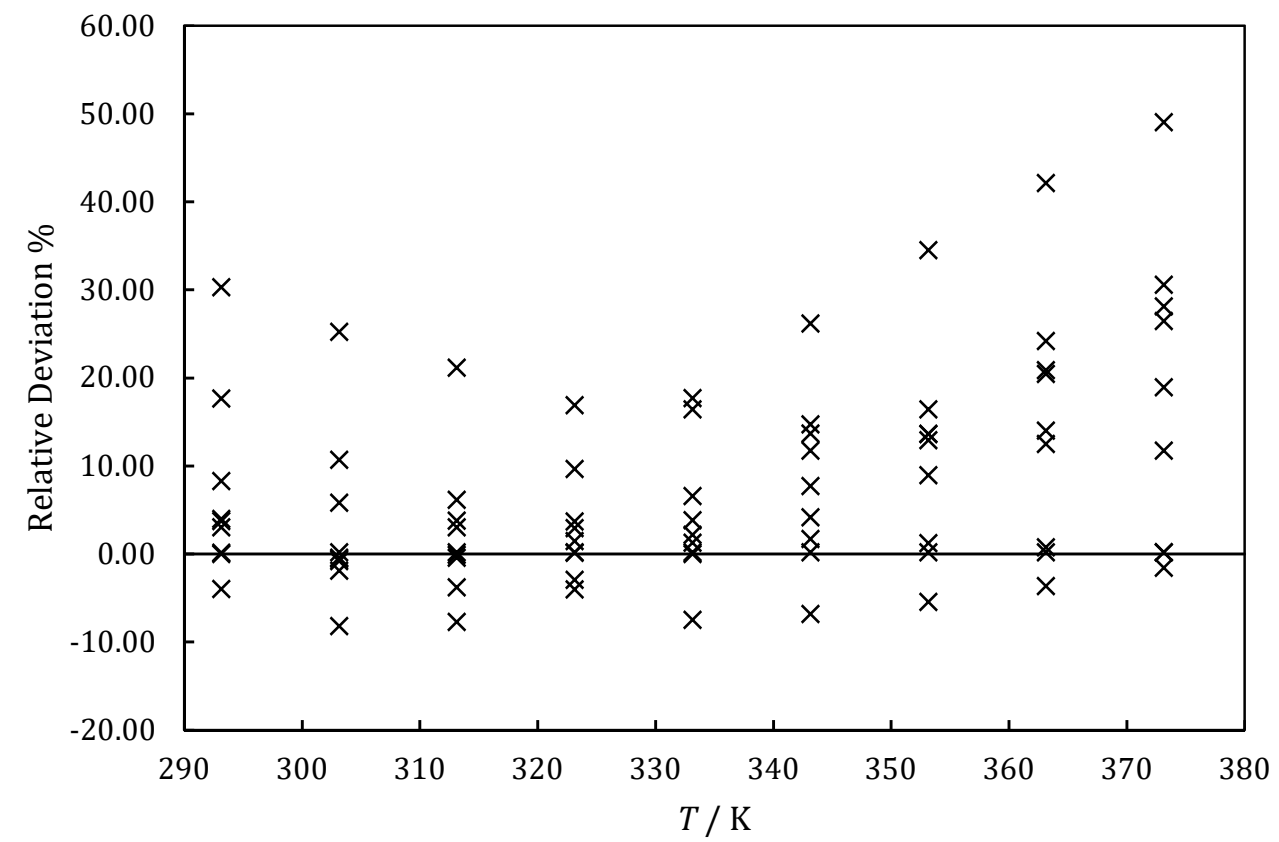

Figure 13. Relative deviation plot of viscosities $\mu$ for mixtures of DMSO (2) $+[\text { EtMeIm }]^{+}\left[\mathrm{Et}_{2} \mathrm{PO}_{4}\right]^{-}$ at atmospheric pressure. Values were calculated by eq. 4 with parameters used in the correlation of experimental data measured in this work. 
In Figure 14 can be seen a comparison between the results of viscosity of pure $\left(x_{1}=0.012\right)$ [EtMeIm] $]^{+}\left[\mathrm{Et}_{2} \mathrm{PO}_{4}\right]^{-}$given by the equation 3 and the literature data of different authors. ${ }^{20,22,35}$ The results of the equation 3 shows a good prediction capability despite the scattering of the data.

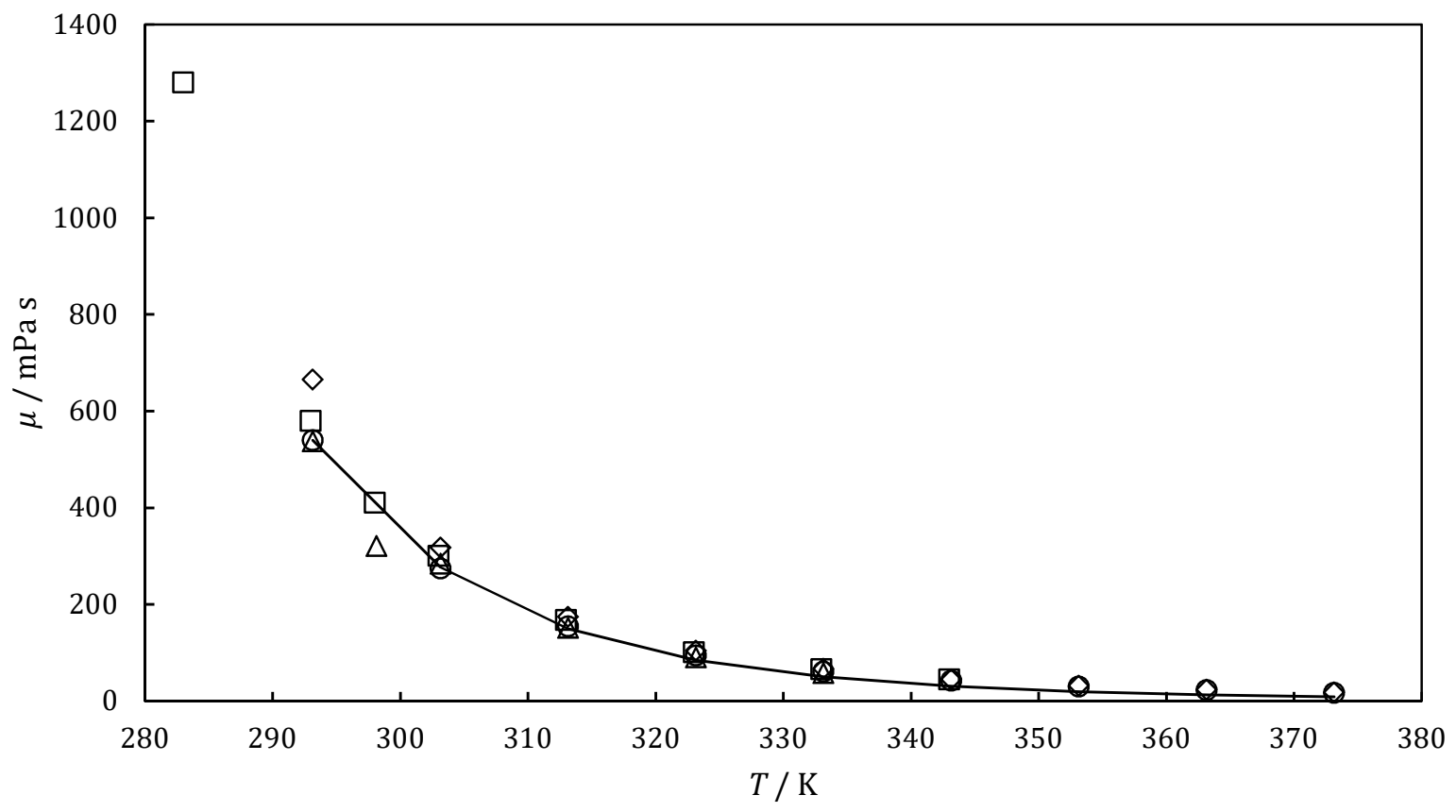

Figure 14. Comparison of literature data and authors data for pure $\left(x_{\mathrm{H} 20}=0.012\right)$ [EtMeIm] $]^{+}\left[\mathrm{Et}_{2} \mathrm{PO}_{4}\right]^{-}$of viscosity $\mu$ with the results calculated from equation 3 as a function of temperature T. Hiraga et al. ${ }^{20}(\diamond)$; Tenney et al. ${ }^{35}(\square)$; Normazlan et al. ${ }^{22}(\triangle)$ and this work $(\bigcirc)$.

\section{Conclusions}

Experimental densities and viscosities of mixtures water (1) +1-ethyl-3-methylimidazolium diethylphosphate and DMSO (2) + 1-ethyl-3-methylimidazolium diethylphosphate were determined at a range of temperature of 9 isotherms between $293.15 \mathrm{~K}$ and $373.15 \mathrm{~K}$ and molar fractions of cosolvent $x_{1}$ or $x_{2}=0,0.05,0.1,0.15,0.25,0.5,0.75,0.9$ and 1 . It was found that density decreases linearly with the temperature while the viscosity decreases exponentially with the same parameter. Excess molar volumes were also calculated. Both systems presented negative excess molar volumes. Nevertheless, while in the mixtures with water an increase of the temperature increases the negative excess volume, in the mixtures with DMSO the negative excess molar volume decreases with the temperature.

Experimental viscosity data were correlated with modified Grunberg and Nissan correlations, achieving good results with $\%$ AARD $=13 \%$ for the mixtures with water and $\%$ AARD $=9.5 \%$ for the mixtures with DMSO. 


\section{List of symbols}

$\mathrm{k} \quad$ coverage factor

$P \quad$ pressure $|=|$ bar

$T \quad$ temperature $|=| \mathrm{K}$

$V^{E} \quad$ excess molar volume $|=| \mathrm{cm}^{3} \cdot \mathrm{mol}^{-1}$

$\mathrm{u}(\mathrm{z}) \quad$ uncertainty of the measurement $\mathrm{z}$

$x_{\mathrm{i}} \quad$ molar fraction of the component $\mathrm{i}|=| \mathrm{mol} \cdot \mathrm{mol}^{-1}$

Greek symbols

$\alpha_{\mathrm{P}} \quad$ isobaric expansion coefficient

$\mu \quad$ viscosity $|=| \mathrm{mPa} \cdot \mathrm{s}$

$\rho \quad$ density $|=| \mathrm{g} \cdot \mathrm{cm}^{-3}$

\section{Acknowledgements}

Authors thank the Junta de Castilla y León for funding through the project VA295U14 and to the Spanish Ministry of Economy and Competitiveness (MINECO) for the project ENE2014-53459-R. MDB thanks the MINECO for the Ramón y Cajal research fellowship (RYC-2013-13976). 


\section{References}

(1) Marsh, K. N.; Boxall, J. A.; Lichtenthaler, R. Fluid Phase Equilib. 2004, 219 (1), 93-98.

(2) Brennecke, J. F.; Maginn, E. J. AIChE J. 2001, 47 (11), 2384-2389.

(3) Vitz, J.; Erdmenger, T.; Schubert, U. S. Cellul. Solvents Anal. Shap. Chem. Modif. 2010, 299317.

(4) Lv, Y.; Wu, J.; Zhang, J. J.; Niu, Y.; Liu, C. Y.; He, J.; Zhang, J. J. Polymer (Guildf). 2012, 53 (12), 2524-2531.

(5) Wang, X.; Li, H.; Cao, Y.; Tang, Q. Bioresour. Technol. 2011, 102 (17), 7959-7965.

(6) Andanson, J.-M.; Bordes, E.; Devémy, J.; Leroux, F.; Pádua, A. a. H.; Gomes, M. F. C. Green Chem. 2014, 16 (5), 2528.

(7) Pinkert, A.; Marsh, K. N.; Pang, S.; Staiger, M. P. Chem. Rev. 2009, 109 (12), 6712-6728.

(8) Vitz, J.; Erdmenger, T.; Haensch, C.; Schubert, U. S. Green Chem. 2009, 11 (3), 417.

(9) Lall-Ramnarine, S. I.; Thomas, M. F.; Jalees, M.; Payen, F.; Boursiquot, S.; Ramati, S.; Ewko, D.; Zmich, N. V.; Wishart, J. F. Phosphorus. Sulfur. Silicon Relat. Elem. 2015, 190 (5-6), 891895.

(10) Zhao, D.; Li, H.; Zhang, J.; Fu, L.; Liu, M.; Fu, J.; Ren, P. Carbohydr. Polym. 2012, 87 (2), 14901494.

(11) Ficke, L. E.; Novak, R. R.; Brennecke, J. F. J. Chem. Eng. Data 2010, 55 (11), 4946-4950.

(12) Wang, J. Y.; Zhao, F. Y.; Liu, R. J.; Hu, Y. Q. J. Chem. Thermodyn. 2011, 43 (1), 47-50.

(13) Ge, M.-L.; Chen, J.-B. J. Chem. Eng. Data 2011, 56, 3183-3187.

(14) Cao, J.; Yu, G.; Chen, X.; Abdeltawab, A. A.; Al-Enizi, A. M. J. Chem. Eng. Data 2017, 62 (2), 816-824.

(15) Ghani, N. A.; Sairi, N. A.; Aroua, M. K.; Alias, Y.; Yusoff, R. J. Chem. Eng. Data 2014, 59 (6), 1737-1746.

(16) Huber, T.; Müssig, J.; Curnow, O.; Pang, S.; Bickerton, S.; Staiger, M. P. J. Mater. Sci. 2012, 47 (3), 1171-1186. 
(17) Joint Committee for Guides in Metrology. Int. Organ. Stand. 2008.

(18) Sobrino, M.; Concepción, E. I.; Gómez-hernández, Á.; Martín, M. C.; Segovia, J. J. J. Chem. Thermodyn. 2016, 98, 231-241.

(19) Concepción, E. I.; Gómez-hernández, Á.; Martín, M. C.; Segovia, J. J. J. Chem. Thermodyn. 2017, 112, 227-239.

(20) Hiraga, Y.; Kato, A.; Sato, Y.; Smith, R. L. J. Chem. Eng. Data 2015, 60 (3), 876-885.

(21) Wang, J.; Li, C.; Shen, C.; Wang, Z. Fluid Phase Equilib. 2009, 279 (2), 87-91.

(22) Normazlan, W. D. M. W.; Sairi, N. A.; Alias, Y.; Udaiyappan, A. F.; Jouyban, A.; Khoubnasabjafari, M. J. Chem. Eng. Data 2014, 59, 2337-2348.

(23) Palgunadi, J.; Kang, J. E.; Nguyen, D. Q.; Kim, J. H.; Min, B. K.; Lee, S. D.; Kim, H.; Kim, H. S. Thermochim. Acta 2009, 494 (1-2), 94-98.

(24) Campbell, A. N. Can. J. Chem. 1979, 57, 705-707.

(25) Casteel, J. F.; Sears, P. G. J. Chem. Eng. Data 1974, 19 (3), 196-200.

(26) Wang, X.; Yang, F.; Gao, Y.; Liu, Z. J. Chem. Thermodyn. 2013, 57, 145-151.

(27) Ivanov, E. V.; Lebedeva, E. Y.; Abrosimov, V. K.; Ivanova, N. G. J. Solution Chem. 2012, 41 (8), 1311-1313.

(28) Iulian, O.; Ciocirlan, O. J. Chem. Eng. Data 2012, 57 (10), 2640-2646.

(29) Krakowiak, J.; Bobicz, D.; Grzybkowski, W. J. Mol. Liq. 2000, 88 (2-3), 197-207.

(30) Zarei, H. A.; Shahvarpour, S. 2008, No. 1, 1660-1668.

(31) Clever, H. L.; Snead, C. C. J. Phys. Chem. 1963, 67 (4), 918-920.

(32) Lemmon, E. W.; Span, R. J. Chem. Eng. Data 2006, 51, 785-850.

(33) Marium, M.; Auni, A.; Rahman, M. M.; Mollah, M. Y. A.; Susan, M. A. B. H. J. Mol. Liq. 2017, $225,621-630$.

(34) Reddy, M. S.; Raju, K. T. S. S.; Sk. Md, N.; Bala Murali Krishna, K.; Bollikolla, H. B. Phys. Chem. Liq. 2017, 55 (6), 775-795.

(35) Tenney, C. M.; Massel, M.; Mayes, J. M.; Sen, M.; Brennecke, J. F.; Maginn, E. J. J. Chem. Eng. Data 2014, 59 (2), 391-399. 
(36) Seddon, K. R.; Stark, A.; Torres, M.-J. Pure Appl. Chem. 2000, 72 (12), 2275-2287.

(37) Ciocirlan, O.; Iulian, O. J. Chem. Eng. Data 2012, 57 (11), 3142-3148.

(38) Yang, C.; Wei, G.; Li, Y. J. Chem. Eng. Data 2008, 53 (5), 1211-1215.

(39) Govinda, V.; Attri, P.; Venkatesu, P.; Venkateswarlu, P. Fluid Phase Equilib. 2011, 304 (1-2), 35-43.

(40) Gokavl, G. S.; Raju, J. R.; Aminabhavi, T. M.; Balundgi, R. H.; Muddapur, M. V. J. Chem. Eng. Data 1986, 31 (1), 15-18.

(41) Saleh, M. A.; Ahmed, 0.; Ahmed, M. S. J. Mol. Liq. 2004, 115 (1), 41-47.

(42) Ali, A.; Nain, A. K.; Chand, D.; Ahmad, R. J. Chinese Chem. Soc. 2006, No. 53, 531-543.

(43) Zhao, T.; Zhang, J.; Guo, B.; Zhang, F.; Sha, F.; Xie, X.; Wei, X. J. Mol. Liq. 2015, 207 (July), 315322.

(44) Kapadi, U. R.; Chavan, S. K.; Yemul, O. S. J. Chem. Eng. Data 1997, 42 (96), 548-550.

(45) Grunberg, L.; Alfred H., N. Mixture Law of Viscosity. Nature 1949, 164, 799-800

(46) Jiménez de la Parra, C.; Zambrano, J. R.; Bermejo, M. D.; Martín, Á.; Segovia, J. J.; Cocero, M. J. J. Chem. Thermodyn. 2015, 91, 8-16.

(47) Lopes, J. M.; Sánchez, F. A.; Reartes, S. B. R.; Bermejo, M. D.; Martín, Á.; Cocero, M. J. J. Supercrit. Fluids 2016, 107, 590-604 
Chapter 4 
Part III: Phase equilibrium of selected cellulose dissolving Ionic Liquids 


\title{
Chapter 5: GC-EoS extension to model phosphate imidazolium ionic liquids
}

\begin{abstract}
In this work, the Group Contribution Equation of State (GC-EoS) is used to model two new groups for the 1-alkyl-3-methylimidazolium dimethylphosphate [-MeIm] ${ }^{+}\left[\mathrm{Me}_{2} \mathrm{PO}_{4}\right]^{-}$and 1alkyl-3-methylimidazolium diethylphosphate families [-MeIm $]^{+}\left[\mathrm{Et}_{2} \mathrm{PO}_{4}\right]^{-}$. Pure group parameters for the functional groups $[-\mathrm{MeIm}]^{+}\left[\mathrm{Me}_{2} \mathrm{PO}_{4}\right]^{-}$and $[-\mathrm{MeIm}]^{+}\left[\mathrm{Et}_{2} \mathrm{PO}_{4}\right]^{-}$and interaction parameters between these groups and the main paraffinic and aromatic subgroups $\left(\mathrm{CH}_{3}, \mathrm{CH}_{2}, \mathrm{ACH}, \mathrm{AC}, \mathrm{ACCH}_{3}, \mathrm{CH}_{2}=\mathrm{CH}\right)$ were estimated from infinite dilution activity coefficients from literature. In order to evaluate the performance of the new parameters, they were used to predict experimental phase behavior of binary mixtures from literature. The average relative deviations (ARD\%) achieved is $4.52 \%$.
\end{abstract}

Keywords: Ionic liquids, Group contribution equation of state, 1-alkyl-3methylimidazolium dimethylphosphate, 1-alkyl-3-methylimidazolium diethylphosphate, GC-EoS 


\section{Introduction}

In the last years, the interest on new and "green" solvents have increased, and the ionic liquids are promising substances that can be used as an alternative to conventional solvents. By definition, Ionic Liquids are substances composed entirely by ions that are liquid at room temperature. Some of their properties make them sustainable solvents, for example, their low vapor pressure and high thermal and chemical stability, which avoid the contamination through evaporation and allow high recycling ratio, respectively. Some of them are also able to dissolve biopolymers, like the alkylphosphate, chloride and acetate ionic liquids that have good cellulose dissolving properties. Specifically, the ionic liquids of the families of 1-alkyl3-methylimidazolium dimethylphosphate $[\text {-MeIm }]^{+} \quad\left[\mathrm{Me}_{2} \mathrm{PO}_{4}\right]^{-}$and 1-alkyl-3methylimidazolium diethylphosphate [-MeIm] $]^{+}\left[\mathrm{Et}_{2} \mathrm{PO}_{4}\right]^{-}$show other favorable properties like low viscosity and are halogen free ${ }^{1}$ cellulose processing solvents ${ }^{2}$. Besides, 1 -ethyl-3methylimidazolium diethylphosphate ([EtMeIm $\left.]^{+}\left[\mathrm{Et}_{2} \mathrm{PO}_{4}\right]^{-}\right)$depicts a low melting point which makes it very easy to handle. ${ }^{2}$

Phase equilibrium knowledge is required for the design and optimization of cellulose processing units. However, there are a great deal of possible combinations of anion, cation and alkyl chain substituents to tune the ionic liquid properties, and the experimental determination of all possible combinations is an impossible task in terms of time and costs. The Group Contribution Equation of State (CG-EoS) ${ }^{3}$ is able to correlate experimental data of mixtures by adjusting a set of parameters related to the functional groups present in the mixture. With this equation it is only necessary to correlate data of a few ionic liquids and it is able to predict the behavior of the other members of a given family. It has proved to be an appropriate method to describe phase equilibrium of several ionic liquids in mixtures with different solvents, ${ }^{4-12}$ not only for data interpolation, but a reliable method to predict phase equilibria beyond the measured conditions. ${ }^{13,14}$

In this work, the GC-EoS is extended to new groups needed to describe the phase behavior of the 1-alkyl-3-methylimidazolium dimethylphosphate [-MeIm $]^{+}\left[\mathrm{Me}_{2} \mathrm{PO}_{4}\right]^{-}$and 1-alkyl-3methylimidazolium diethylphosphate $[-\mathrm{MeIm}]^{+}\left[\mathrm{Et}_{2} \mathrm{PO}_{4}\right]^{-}$and the binary interaction parameters with $\mathrm{CH}_{3}, \mathrm{CH}_{2}, \mathrm{ACH}, \mathrm{AC}, \mathrm{ACCH}_{3}$ and $\mathrm{CH}_{2}=\mathrm{CH}$ were calculated on the basis of experimental information of ionic liquids found in literature. The extended GC-EoS is then used to predict experimental data not included in the correlation database. In this work, the experimental data used are saturation equilibrium points and infinite dilution coefficient of different short alkyl chain paraffins and aromatic compounds. 


\section{Thermodynamic modeling}

\subsection{The Group Contribution Equation of State}

The GC-EoS was originally developed by Skjold-Jørgensen ${ }^{3,15}$ to study equilibria at high pressures. This EoS is based on the Van der Waals function combined with the local composition principle. It can be written as the sum of two contributions of the residual Helmholtz free energy ( $A^{\text {res}}$ ): the repulsive (rep) (also called free volume) and the attractive (att) contributions. The equation (1) summarizes the sum of two contributions.

$$
A^{r e s}=A^{r e p}+A^{a t t}
$$

The repulsive term uses the expression developed by Mansoori and Leland 16 for hard spheres, is described in the equation (2):

$$
\left(\frac{A}{R T}\right)_{r e p}=3\left(\frac{\lambda_{1} \lambda_{2}}{\lambda_{3}}\right)(Y-1)+\left(\frac{\lambda_{2}^{3}}{\lambda_{3}^{2}}\right)\left(-Y+Y^{2}-\ln Y\right)+n \ln Y
$$

Where

$$
\begin{gathered}
\lambda_{k}=\sum_{i}^{N C} n_{i} d_{i}^{k} \\
Y=\left(1-\frac{\pi \lambda_{3}}{6 V}\right)^{-1}
\end{gathered}
$$

being $n_{i}$ the number of moles of component $i, V$ the total volume, $N C$ the total number of components in the mixture, and $d_{i}$ the hard-sphere diameter per mole.

The hard-sphere diameter $\left(d_{i}\right)$ is considered to be temperature dependent in equation (5):

$$
d_{i}=1.065655 d_{c i}\left[1-0.12 \exp \left(-\frac{2 T_{c i}}{3 T}\right)\right]
$$

Where $d_{c i}$ is the value of the hard-sphere diameter at the critical temperature $T_{c i}$ for the pure component $i$.

The value of the $d_{\text {ci }}$ can be evaluated from the critical properties of the corresponding component with the equation (6):

$$
d_{c i}=\left(0.08943 \frac{R T_{c i}}{P_{c i}}\right)^{1 / 3}
$$

The attractive contribution of the residual Helmholtz free energy is a group contribution version of a density-dependent NRTL model ${ }^{17}$. In this contribution the interactions are assumed to take place through the surface. See equation (7). 


$$
\left(\frac{A}{R T}\right)_{a t t}=-\left(\frac{Z}{2}\right) \sum_{i=1}^{N_{C}} n_{i} \sum_{j=1}^{N_{G}} v_{j}^{i} q_{j} \frac{\sum_{k=1}^{N_{G}} \theta_{k}\left(\frac{g_{k j} \tilde{q} \tau_{k j}}{R T V}\right)}{\sum_{l=1}^{N_{G}} \theta_{l} \tau_{l j}}
$$

where:

$$
\begin{gathered}
\tau_{k j}=\exp \left(\frac{\alpha_{k j} \Delta g_{k j} q}{R T V}\right) \\
\Delta g_{k j}=g_{k j}-g_{j j}
\end{gathered}
$$

with:

$$
\tau_{k j}=\exp \left(\frac{\alpha_{k j} \Delta g_{k j} \tilde{q}}{R T V}\right)
$$

and:

$$
\Delta g_{k j}=g_{k j}-g_{j j}
$$

In equations (7) to (9), $z$ is the coordination number set equal to $10 ; N_{G}$ is the number of groups, $v_{j}^{i}$ is the number of groups $j$ in component $i ; q_{j}$ is the number of surface segments assigned to group $j ; \theta_{k}$ is the surface fraction of group $k ; q$ is the total number of surface segments; $g_{i j}$ is the attractive energy parameter for interactions between segments $j$ and $i$; and $\alpha_{i j}$ is the corresponding non-randomness parameter.

The interactions between unlike segments are defined by equation (12):

$$
g_{j i}=k_{i j} \sqrt{g_{i i} g_{j j}}
$$

Where the symmetrical parameter $k_{i j}\left(k_{i j}=k_{j i}\right)$ is the binary interaction parameter. Both, the attractive energy $\left(g_{i j}\right)$ and the binary interaction parameter $\left(k_{i j}\right)$ have a temperature dependence described in (13) and (14) respectively:

$$
\begin{gathered}
g_{i i}=g_{i i}^{*}\left[1+g_{i i}^{\prime}\left(\frac{T}{T_{i}^{*}}-1\right)+g_{i i}^{\prime \prime} \ln \left(\frac{T}{T_{i}^{*}}\right)\right] \\
k_{i j}=k_{i j}^{*}\left[1+k_{i j}^{\prime} \ln \left(\frac{2 T}{T_{i}^{*}+T_{j}^{*}}\right)\right]
\end{gathered}
$$

Where $g_{i i}^{*}$ and $k_{i j}^{*}$ are the attractive energy and binary interaction parameters at the arbitrary, but fixed, reference temperature $T_{i}^{*}$ and $\left(T_{i}^{*}+T_{j}^{*}\right) / 2$ respectively.

\subsection{Ionic Liquid functional group}

To apply the GC-EoS it is necessary to divide the ionic liquid molecule into functional groups. Breure et al. ${ }^{4}$ showed that the anion and part of the cation, except for its alkyl chain, should be kept together in a single electroneutral group. Therefore, by adding the $\mathrm{CH}_{2}, \mathrm{CH}_{3}$ or other 
functional groups to the side alkyl chain, any ionic liquid of the same family can be assembled. The characteristic groups defined in this work, $[-\mathrm{MeIm}]^{+}\left[\mathrm{Me}_{2} \mathrm{PO}_{4}\right]^{-}$and $[-$ MeIm] $]^{+}\left[\mathrm{Et}_{2} \mathrm{PO}_{4}\right]^{\text {; }}$, are shown in Figure 1.
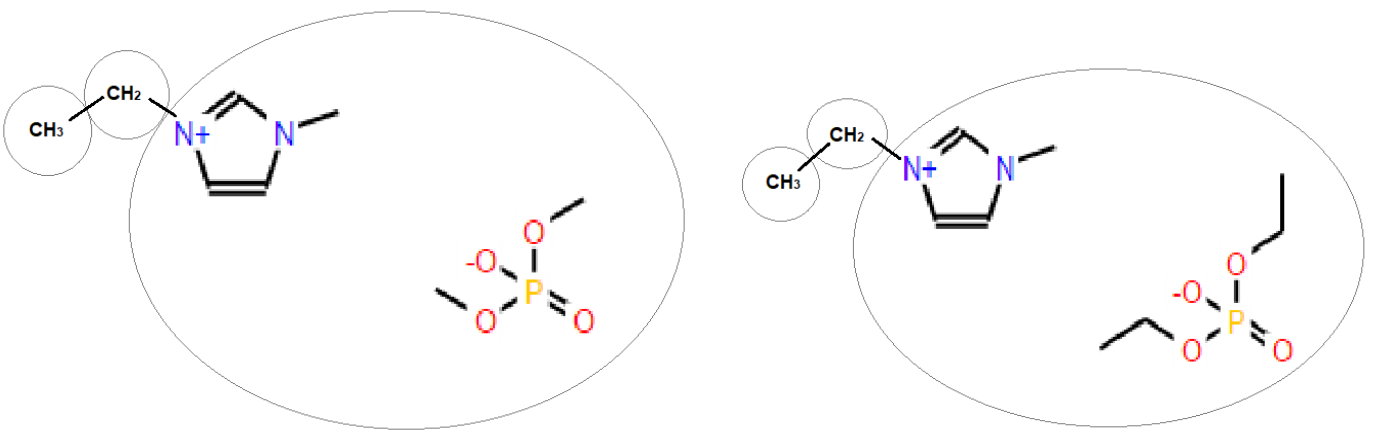

Figure 1. Group definition for [-MeIm] $]^{+}\left[\mathrm{Me}_{2} \mathrm{PO}_{4}\right]^{-}$(left) and for [-MeIm] $]^{+}\left[\mathrm{Et}_{2} \mathrm{PO}_{4}\right]^{-}$(right).

\subsection{Parametrization of the repulsive term}

The repulsive term comprises one unique characteristic parameter, which is the hardsphere diameter at critical temperature $\left(d_{c i}\right)$. Usually this parameter is derived from the pure component critical properties as with the eq. (6) or by fitting a vapor pressure data point. However, none of these data are available for the ionic liquids. In this work, $d_{c i}$ was calculated using the correlation developed by Espinosa et al. ${ }^{18}$ (see equation 15) for high molecular weight natural compounds, and applied later to ionic liquids by Breure et al. ${ }^{4}$ and Bermejo et al. 5. As shown in Equation (16), the correlation estimates $d_{c i}$ based on the normalized Van der Waals molecular volume of the compund $\left(r_{v d W}\right)$, information easy to calculate in the case of any organic compound but not available for the ionic liquids, which require a number of assumptions to attain a representative value. Later, Pereda et al. 9 showed that the $r_{v d W}$ can be estimated by a simple linear relation with respect to the molar volume of the ionic liquid at $298 \mathrm{~K}\left(V_{298 K}\right)$.

$$
\begin{aligned}
\log \left(d_{c i}\right) & =0.4152+0.4128 \log \left(r_{v d W}\right) \\
r_{v d W} & =0.039 \cdot V_{298 K}\left(\mathrm{~cm}^{3} \mathrm{~mol}^{-1}\right)
\end{aligned}
$$

Table 1 summarizes the van der Waals volume and critical diameters for the ionic liquids studied in this work. 
Table 1. Molecular weight $(M w)$, molar volume $(V)$ at $298 \mathrm{~K}$, van der Waals volume $\left(r_{V d W}\right)$, and critical diameter $\left(d_{c}\right)$ for the ionic liquids.

\begin{tabular}{llllll}
\hline Ionic Liquid & $M w / \mathrm{g} \cdot \mathrm{mol}^{-1}$ & $V / \mathrm{cm}^{3} \cdot \mathrm{mol}^{-1}$ & Source & $r_{v d W}$ & $d_{c} / \mathrm{cm} \cdot \mathrm{mol}-1 / 3$ \\
\hline$\left[\right.$ EtMeIm] ${ }^{+}\left[\mathrm{Et}_{2} \mathrm{PO}_{4}\right]^{-}$ & 264.26 & 230.57 & 19 & 8.992 & 6.4432 \\
{$\left[\right.$ EtMeIm] ${ }^{+}\left[\mathrm{Me}_{2} \mathrm{PO}_{4}\right]^{-}$} & 194.17 & 194.10 & 20 & 7.570 & 6.0000 \\
{$[\mathrm{BuMeIm}]^{+}\left[\mathrm{Me}_{2} \mathrm{PO}_{4}\right]^{-}$} & 264.26 & 227.43 & 21 & 8.870 & 6.4033 \\
{$\left[\mathrm{Me}_{2} \mathrm{Im}\right]^{+}\left[\mathrm{Me}_{2} \mathrm{PO}_{4}\right]^{-}$} & 222.18 & 176.57 & 22 & 6.886 & 5.7671 \\
\hline
\end{tabular}

\subsection{Parametrization of the attractive term}

The molecule is divided in smaller groups, and each functional group is characterized by a surface area $q_{i}$, a reference temperature $T_{i}^{*}$, and the pure group energy parameters: $g_{i i}^{*}, g_{i i}^{\prime}, g_{i i}^{\prime \prime}$. In addition, there are necessary group-group interaction parameters: $k_{i j}^{*}, k_{i j}^{\prime}, \alpha_{i j}, \alpha_{j i}$.

The pure group parameters and their respective binary interaction parameters for the groups $\mathrm{CH}_{3}, \mathrm{CH}_{2}, \mathrm{ACH}, \mathrm{AC}, \mathrm{ACCH}_{3}$ and $\mathrm{CH}_{2}=\mathrm{CH}$ were taken from bibliography ${ }^{23}$.

The surface area $q_{i}$ for the new groups, $[-\mathrm{MeIm}]^{+}\left[\mathrm{Me}_{2} \mathrm{PO}_{4}\right]^{-}$and $[-\mathrm{MeIm}]^{+}\left[\mathrm{Et}_{2} \mathrm{PO}_{4}\right]^{-}$, were calculated by subtracting the surface area parameter of the alkyl chain substituents $\left(q_{\text {снз }}\right.$ and $\left.\cdot q_{\mathrm{CH} 2}\right)$ from the total van der Waals area of the ionic liquid molecules $\left(q_{i}\right)$, which can be derived from their van der Waals volume $\left(r_{v d W}\right)$ using equation (17).

$$
q_{i}=\frac{z-2}{z} r_{v d W, i}+\frac{z}{2}
$$

Where $\mathrm{z}$ is the coordination number. The pure group parameters of [-MeIm] $]^{+}\left[\mathrm{Me}_{2} \mathrm{PO}_{4}\right]^{-}$and $[-\mathrm{MeIm}]^{+}\left[\mathrm{Et}_{2} \mathrm{PO}_{4}\right]^{-}$and the binary interaction parameter involving the said groups were fitted by correlation of the infinite dilution activity coefficient and binary solubility equilibrium.

Table 2 summarizes the experimental data base of the binary systems used for correlating the model parameters and to challenge its predictive capacity. The tables also report the range of temperature and pressure covered by the data and the source of the experimental data. In the case of activity coefficients data, authors report a typical uncertainty of $5 \%$ in all cases. 
Table 2. Infinite dilution activity coefficient database. Data uncertainty reported in all cases is $5 \%$.

\begin{tabular}{|c|c|c|c|c|c|c|}
\hline \multicolumn{2}{|l|}{ Compound } & \multirow{2}{*}{$T(\mathrm{~K})$} & \multirow{2}{*}{$\begin{array}{l}P \\
\text { (bar) }\end{array}$} & \multirow{2}{*}{$\begin{array}{l}\text { No exp. } \\
\text { points }\end{array}$} & \multirow{2}{*}{$\begin{array}{l}\text { ARD \% } \\
(\gamma)\end{array}$} & \multirow{2}{*}{ Source } \\
\hline Ionic liquid & Solute & & & & & \\
\hline \multirow[t]{12}{*}[\mathrm{EtMeIm}]{$^{+}\left[\mathrm{Et}_{2} \mathrm{PO}_{4}\right]^{-}$} & Pentane* & $303.15-343.15$ & 1.01 & 5 & 12 & 24 \\
\hline & Hexane & $303.15-343.15$ & 1.01 & 5 & 5.0 & 24 \\
\hline & Heptane* & $303.15-343.15$ & 1.01 & 5 & 12 & 24 \\
\hline & Octane & $303.15-343.15$ & 1.01 & 5 & 8.2 & 24 \\
\hline & Nonane* & $303.15-343.15$ & 1.01 & 5 & 3.0 & 24 \\
\hline & Decane* & $303.15-343.15$ & 1.01 & 5 & 7.9 & 24 \\
\hline & Styrene* & $303.15-343.15$ & 1.01 & 5 & 0.22 & 24 \\
\hline & Benzene* & $303.15-343.15$ & 1.01 & 5 & 0.23 & 24 \\
\hline & Toluene & $303.15-343.15$ & 1.01 & 5 & 7.5 & 24 \\
\hline & o-Xilene* & $303.15-343.15$ & 1.01 & 5 & 7.5 & 24 \\
\hline & m-Xilene* & $303.15-343.15$ & 1.01 & 5 & 2.8 & 24 \\
\hline & p-Xilene* & $303.15-343.15$ & 1.01 & 5 & 7.9 & 24 \\
\hline \multirow[t]{12}{*}[\mathrm{Me}_{2}\mathrm{Im}]{$^{+}\left[\mathrm{Me}_{2} \mathrm{PO}_{4}\right]^{-}$} & Pentane* & $313.15-363.15$ & 1.01 & 6 & 3.1 & 25 \\
\hline & Hexane & $313.15-363.15$ & 1.01 & 6 & 1.1 & 25 \\
\hline & Heptane & $313.15-363.15$ & 1.01 & 6 & 3.1 & 25 \\
\hline & Octane & 313.15 - 363.15 & 1.01 & 6 & 5.0 & 25 \\
\hline & Nonane & $313.15-363.15$ & 1.01 & 6 & 3.4 & 25 \\
\hline & Decane* & $313.15-363.15$ & 1.01 & 6 & 5.2 & 25 \\
\hline & Styrene* & $313.15-363.15$ & 1.01 & 6 & 0.72 & 25 \\
\hline & Benzene* & $313.15-363.15$ & 1.01 & 6 & 3.3 & 25 \\
\hline & Toluene & $313.15-363.15$ & 1.01 & 6 & 7.0 & 25 \\
\hline & o-Xilene* & $313.15-363.15$ & 1.01 & 6 & 1.2 & 25 \\
\hline & m-Xilene* & $313.15-363.15$ & 1.01 & 6 & 2.9 & 25 \\
\hline & p-Xilene* & 313.15 - 363.15 & 1.01 & 6 & 5.2 & 25 \\
\hline \multirow[t]{5}{*}[\mathrm{EtMeIm}]{$^{+}\left[\mathrm{Me}_{2} \mathrm{PO}_{4}\right]^{-}$} & Benzene* & $313.15-363.15$ & 1.01 & 6 & 3.5 & 25 \\
\hline & Toluene & $313.15-363.15$ & 1.01 & 6 & 2.2 & 25 \\
\hline & Styrene* & $313.15-363.15$ & 1.01 & 6 & 2.0 & 25 \\
\hline & o-Xilene* & $313.15-363.15$ & 1.01 & 6 & 0.80 & 25 \\
\hline & m-Xilene* & $313.15-363.15$ & 1.01 & 6 & 4.2 & 25 \\
\hline
\end{tabular}




\begin{tabular}{lllllll} 
& p-Xilene* & $313.15-363.15$ & 1.01 & 6 & 4.0 & 25 \\
& & & & & & \\
{$[\text { BuMeIm }]^{+}\left[\mathrm{Me}_{2} \mathrm{PO}_{4}\right]^{-}$} & Octane* & $313.15-363.15$ & 1.01 & 6 & 8.8 & 26 \\
& Nonane & $313.15-363.15$ & 1.01 & 6 & 4.4 & 26 \\
& Decane* & $313.15-363.15$ & 1.01 & 6 & 8.9 & 26 \\
& Ethylbenzene* & $313.15-363.15$ & 1.01 & 6 & 2.7 & 26 \\
\hline
\end{tabular}

* Data used for the correlation

\section{Results and discussion}

The first parameters fitted were those required to describe the ionic liquids properties, i.e. pure group energy parameters $\left(g_{i i}^{*}, g_{i i}^{\prime}, g_{i i}^{\prime \prime}\right)$ of the ionic core and the interaction parameters with groups forming the alkyl chain $\left(\mathrm{CH}_{2}\right.$ and $\left.\mathrm{CH}_{3}\right)$, and therefore, only binary data with nalkanes are first considered. In particular, the correlation of these parameters is based on experimental infinite dilution activity coefficients of $n$-alkanes in the ionic liquids under study here. On the other hand, the parameter $q$ is not fitted, since it is estimated from literature molar volume using the method described in section 2.4. The data sets used in the correlation were selected in order to fit the widest temperature range as possible. The rest of the data sets were used to challenge the GC-EoS, predictive capacity with the new parameters.

Table 3 and 5 report the new GC-EoS pure group, pure compound and binary interaction parameters, respectively. As can be seen in Table 3, only the pure group parameters of the ionic liquids are fitted in this work, while the parameters of all other groups were taken from literature ${ }^{23}$. This new set of parameters is able to correlate and predict all the assessed experimental data with the accuracy indicated in Table 2. In Table 4 shows the critical temperature and pressure of the ionic liquids used for the correlation. 
Table 3. GC-EoS pure group parameters. $T_{i}^{*}$ is the reference temperature, $q_{i}$ is the surface area of $i$ and $g^{*}, g^{\prime}$, and $g^{\prime \prime}$ are the pure group energy parameters and its temperature dependence (see equation 12).

\begin{tabular}{|c|c|c|c|c|c|c|}
\hline Group & $T^{*} / \mathrm{K}$ & $q$ & $g^{*} / \mathrm{atm} \cdot \mathrm{cm}^{6} \cdot \mathrm{mol}^{-2}$ & $g^{\prime}$ & $g^{\prime \prime}$ & Source \\
\hline -MeImMe ${ }_{2} \mathrm{PO}_{4}$ & 600 & 4.8513 & 1154081 & -0.2941 & 0 & This work \\
\hline$-\mathrm{MeImEt}_{2} \mathrm{PO}_{4}$ & 600 & 6.0116 & 1170489 & -0.1153 & 0 & This work \\
\hline $\mathrm{CH}_{3}$ & 600 & 0.848 & 316910 & -0.9274 & 0 & 23 \\
\hline $\mathrm{CH}_{2}$ & 600 & 0.540 & 356080 & -0.8755 & 0 & 23 \\
\hline $\mathrm{ACH}$ & 600 & 0.400 & 723210 & -0.606 & 0 & 23 \\
\hline $\mathrm{AC}$ & 600 & 0.285 & 723210 & -0.606 & 0 & 23 \\
\hline $\mathrm{ACCH}_{3}$ & 600 & 0.968 & 506290 & -0.8013 & 0 & 23 \\
\hline $\mathrm{CH}_{2}=\mathrm{CH}$ & 600 & 1.176 & 337980 & -0.6764 & 0 & 23 \\
\hline
\end{tabular}

Table 4. GC-EoS pure compounds parameters. $T_{c}$ and $P_{c}$ are the critical temperature and pressure respectively.

\begin{tabular}{llll}
\hline Compound & $T_{c} / \mathrm{K}$ & $P_{c} / \mathrm{atm}$ & Source \\
\hline$[\text { EtMeIm }]^{+}\left[\mathrm{Et}_{2} \mathrm{PO}_{4}\right]^{-}$ & 789.00 & 27.4855 & 27 \\
{$\left[\mathrm{Me}_{2} \mathrm{Im}\right]^{+}\left[\mathrm{Me}_{2} \mathrm{PO}_{4}\right]^{-}$} & 869.40 & 20.0345 & 27 \\
{$[\text { EtMeIm }]^{+}\left[\mathrm{Me}_{2} \mathrm{PO}_{4}\right]^{-}$} & 748.60 & 34.2000 & 27 \\
{$[\text { BuMeIm }]^{+}\left[\mathrm{Me}_{2} \mathrm{PO}_{4}\right]^{-}$} & 951.50 & 10.0000 & 27 \\
\hline
\end{tabular}


Table 5. GC-EoS binary interaction parameters correlated in this work.

\begin{tabular}{|c|c|c|c|c|c|c|}
\hline Group $i$ & Group $j$ & $k_{i j}^{*}$ & $k_{i j}^{\prime}$ & $\alpha_{i j}$ & $\alpha_{j i}$ & Source \\
\hline \multirow[t]{6}{*}{$-\mathrm{MeImMe}_{2} \mathrm{PO}_{4}$} & $\mathrm{CH}_{3}$ & 1.0169 & -0.0477 & -1.868 & -3.1969 & This work \\
\hline & $\mathrm{CH}_{2}$ & 1.0169 & -0.0477 & -2.3677 & -1.1145 & This work \\
\hline & $\mathrm{ACH}$ & 0.9144 & 0.0939 & 0 & 0 & This work \\
\hline & $\mathrm{AC}$ & 0.9822 & -0.0761 & 4.0314 & -12.0482 & This work \\
\hline & $\mathrm{ACCH}_{3}$ & 0.8826 & 0.0618 & 12.8818 & -0.767 & This work \\
\hline & $\mathrm{CH}_{2}=\mathrm{CH}-$ & 1.0076 & 0.0894 & -2.0427 & -1.6513 & This work \\
\hline \multirow[t]{4}{*}{$-\mathrm{MeImEt}_{2} \mathrm{PO}_{4}$} & $\mathrm{CH}_{3}$ & 0.999 & -0.0084 & 8.7504 & -1.8958 & This work \\
\hline & $\mathrm{CH}_{2}$ & 0.999 & -0.0084 & 1.3137 & -1.0597 & This work \\
\hline & $\mathrm{ACH}$ & 0.9677 & 0.0614 & 0 & 0 & This work \\
\hline & $\mathrm{ACCH}_{3}$ & 0.9822 & 0.0563 & 1.5544 & -0.8988 & This work \\
\hline \multirow[t]{5}{*}{$\mathrm{CH}_{3}$} & $\mathrm{CH}_{2}$ & 1 & 0 & 0 & 0 & 23 \\
\hline & $\mathrm{ACH}$ & 1.041 & 0.094 & 0.391 & 0.391 & 23 \\
\hline & $\mathrm{AC}$ & 1.041 & 0.094 & 0.391 & 0.391 & 23 \\
\hline & $\mathrm{ACCH}_{3}$ & 0.975 & 0 & 0 & 0 & 23 \\
\hline & $\mathrm{CH}_{2}=\mathrm{CH}-$ & 1 & 0 & 0 & 0 & 23 \\
\hline \multirow[t]{4}{*}{$\mathrm{CH}_{2}$} & $\mathrm{ACH}$ & 1.041 & 0.094 & 0.391 & 0.391 & 23 \\
\hline & AC & 1.041 & 0.094 & 0.391 & 0.391 & 23 \\
\hline & $\mathrm{ACCH}_{3}$ & 0.975 & 0 & 0 & 0 & 23 \\
\hline & $\mathrm{CH}_{2}=\mathrm{CH}-$ & 1 & 0 & 0 & 0 & 23 \\
\hline \multirow[t]{3}{*}{$\mathrm{ACH}$} & $\mathrm{AC}$ & 1 & 0 & 0 & 0 & 23 \\
\hline & $\mathrm{ACCH}_{3}$ & 1.007 & 0 & 0 & 0 & 23 \\
\hline & $\mathrm{CH}_{2}=\mathrm{CH}-$ & 0.984 & 0 & 0 & 0 & 23 \\
\hline \multirow[t]{2}{*}{$\mathrm{AC}$} & $\mathrm{ACCH}_{3}$ & 1.007 & 0 & 0 & 0 & 23 \\
\hline & $\mathrm{CH}_{2}=\mathrm{CH}-$ & 0.984 & 0 & 0 & 0 & 23 \\
\hline $\mathrm{ACCH}_{3}$ & $\mathrm{CH}_{2}=\mathrm{CH}-$ & 1.034 & 0 & 0 & 0 & 23 \\
\hline
\end{tabular}

Figure 2 and 3 shows some data sets available, the correlated (dashed lines) and the ones used for the prediction (solid lines). As can be seen, in both cases, good accuracy is attained between the experimental data and GC-EoS. 


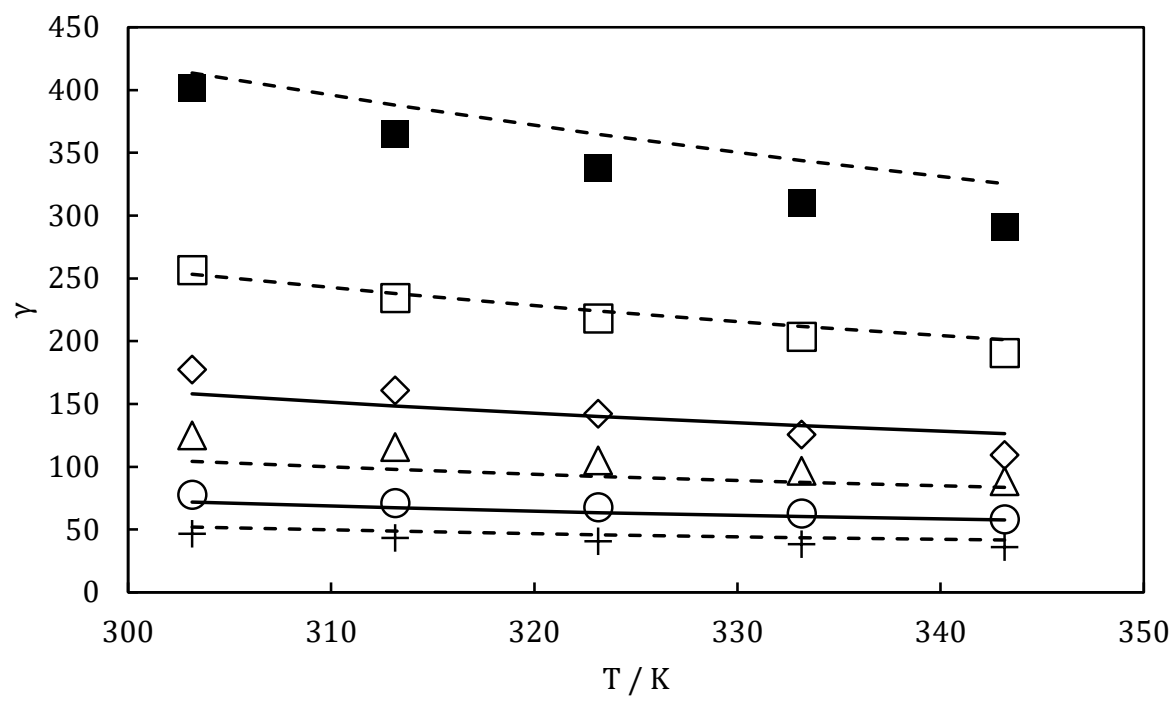

Figure 2. Activity coefficients at infinite dilution $(\gamma)$ in [EtMeIm $]^{+}\left[\mathrm{Et}_{2} \mathrm{PO}_{4}\right]^{-}$as a function of the temperature $(T)$ of different hydrocarbons: Decane ( $\square$ ); Nonane $(\square)$; Octane $(\diamond)$; Heptane $(\triangle)$; Hexane $(\bigcirc)$ and Pentane $(+)$. Dashed lines represent the correlation and solid lines represent the prediction using GC-EoS.

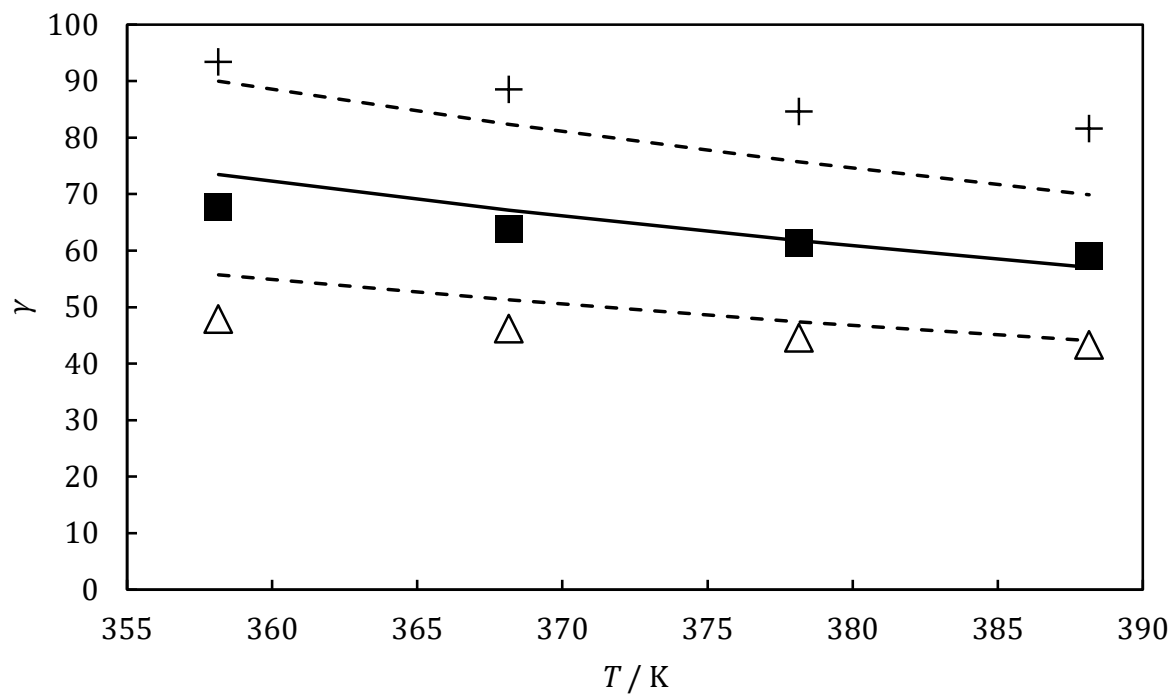

Figure 3. Activity coefficients at infinite dilution $(\gamma)$ in $[\mathrm{BuMeIm}]^{+}\left[\mathrm{Me}_{2} \mathrm{PO}_{4}\right]^{-}$as a function of the temperature $(T)$ of different hydrocarbons: Decane $(+)$; Nonane $(\mathbf{\square})$, and Octane $(\triangle)$. Dashed lines represent the correlation and solid lines represent the prediction using GCEoS. 


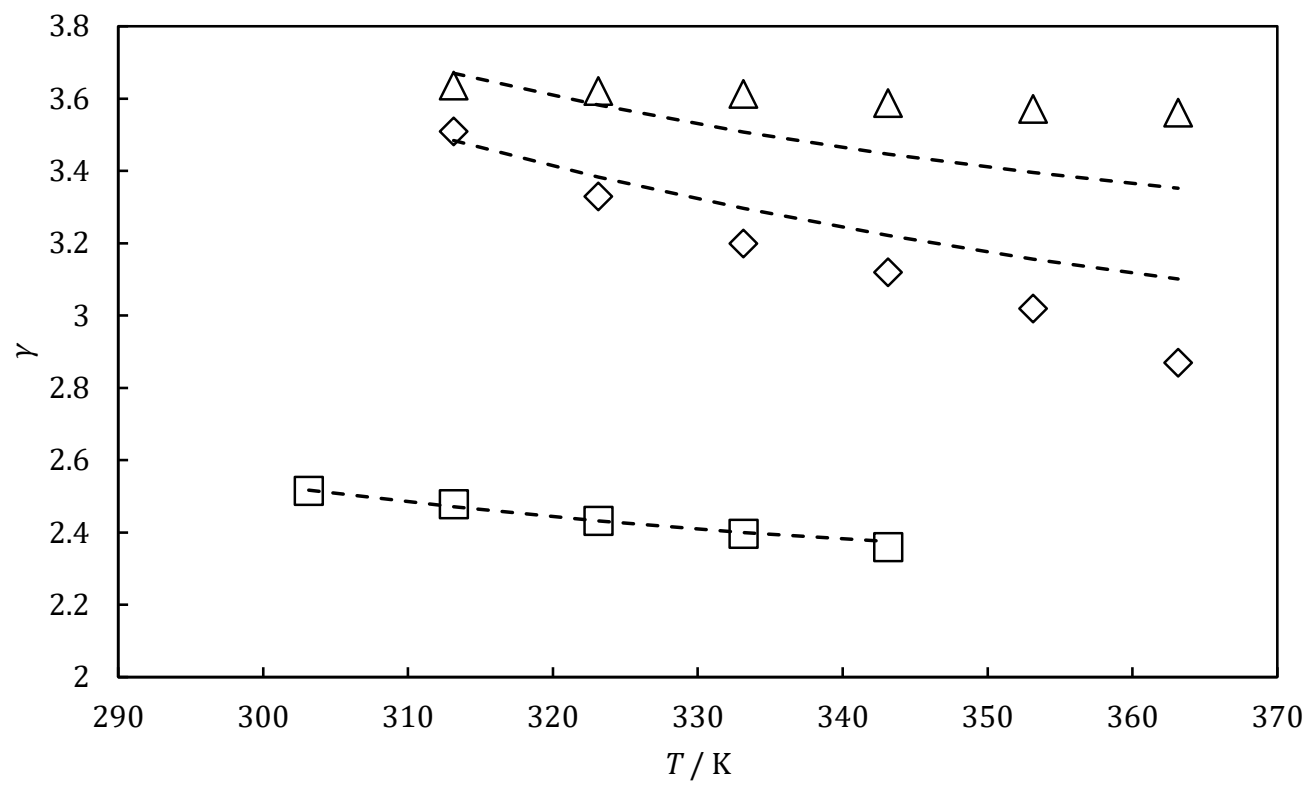

Figure 4. Infinite dilution activity coefficients $(\gamma)$ of benzene in: [EtMeIm $]^{+}\left[\mathrm{Et}_{2} \mathrm{PO}_{4}\right]^{-}(\square)$; $\left[\mathrm{Me}_{2} \mathrm{Im}\right]^{+}\left[\mathrm{Me}_{2} \mathrm{PO}_{4}\right]^{-}(\triangle)$; and $[\text { EtMeIm }]^{+}\left[\mathrm{Me}_{2} \mathrm{PO}_{4}\right]^{-}(\diamond)$. Dashed lines: GC-EoS correlation.

In a second step, aromatic compounds were considered, thus, binary interaction parameters of the ACH groups were fitted with experimental of benzene infinite dilution activity coefficients in ionic liquid, the results are shown in Figure 4. Moreover, data of xylene derivatives allows correlating the parameters for $\mathrm{ACCH}_{3}$ group. The GC-EoS correlation of experimental data is represented in Figure 5 and Figure 6.

In the case of benzene (Figure 4), up to our knowledge, there are no more data available to check the predictive capacity of the model. The model correlates with high precision the data corresponding to benzene in [EtMeIm] $]^{+}\left[\mathrm{Et}_{2} \mathrm{PO}_{4}\right]$; however, is less accurate in the case of benzene in $\left[\mathrm{Me}_{2} \mathrm{Im}\right]^{+}\left[\mathrm{Me}_{2} \mathrm{PO}_{4}\right]^{-}$and $[\text {EtMeIm }]^{+}\left[\mathrm{Me}_{2} \mathrm{PO}_{4}\right]^{-}$. In particular, for the two latter the model fails to correlate the temperature dependence of the benzene activity coefficient. It is worth noting that in these cases the ionic liquids share the same group - MeImMe $\mathrm{PO}_{4}$. In consequence, the result is a compromise solution between both data sets. 


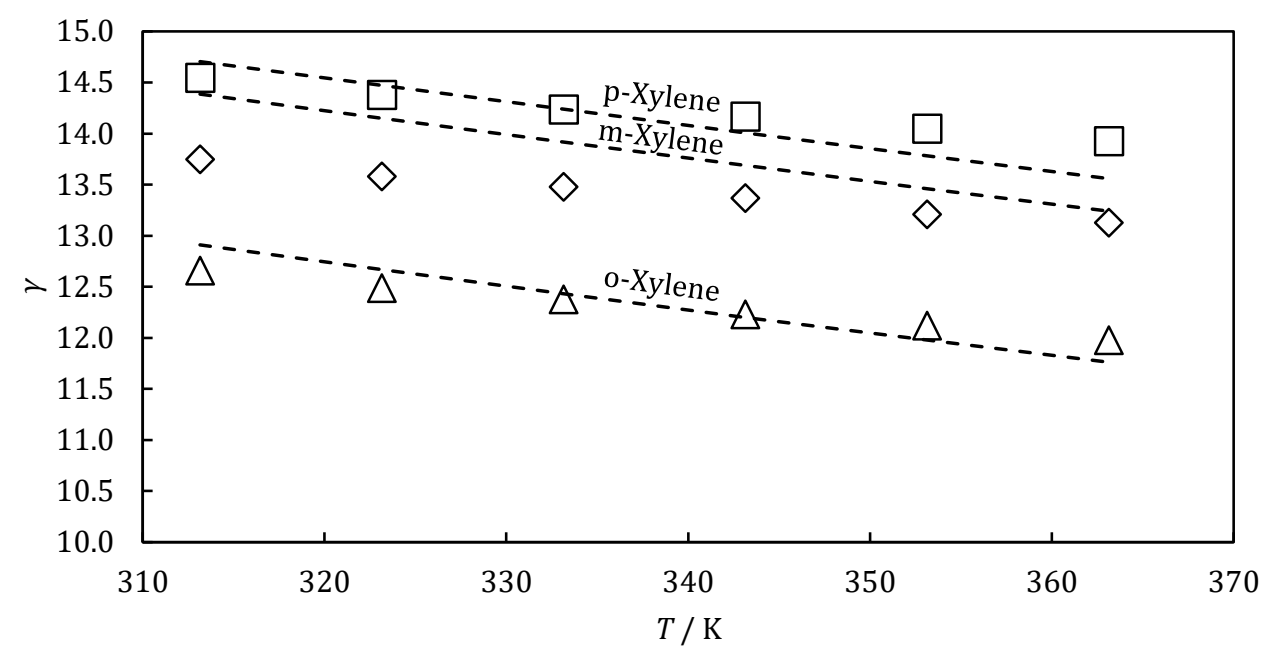

Figure 5. Activity coefficients at infinite dilution $(\gamma)$ in $\left[\mathrm{Me}_{2} \mathrm{Im}\right]^{+}\left[\mathrm{Me}_{2} \mathrm{PO}_{4}\right]^{-}$of: o-Xylene $(\triangle)$; m-Xylene $(\square)$; and p-Xylene $(\diamond)$. Dashed lines: GC-EoS correlation.

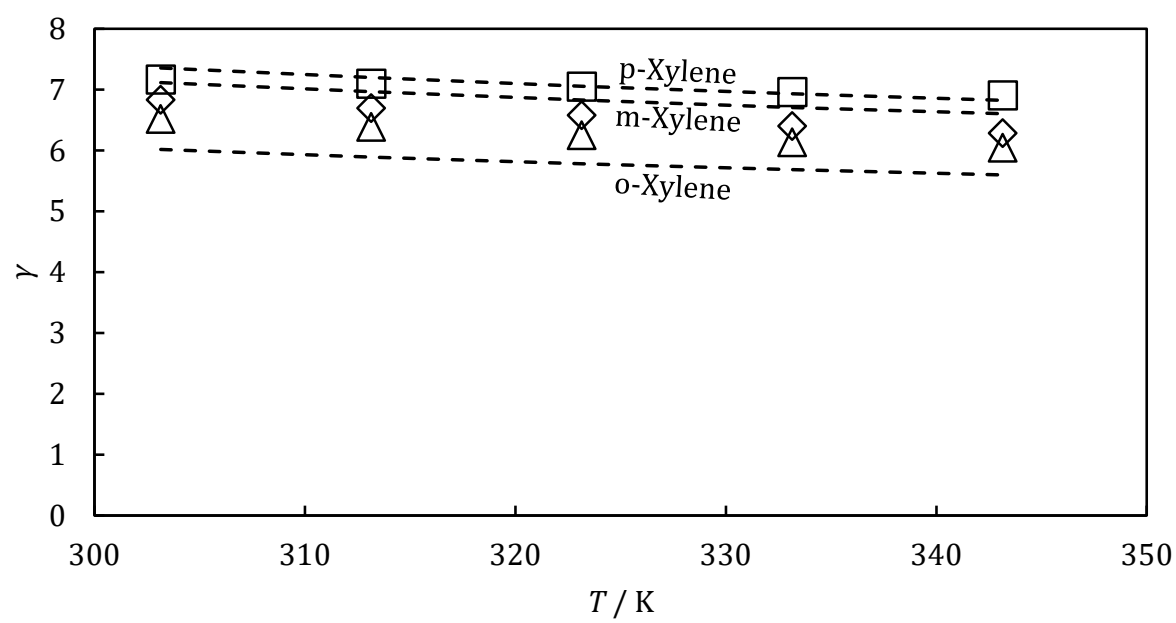

Figure 6. Activity coefficients at infinite dilution $(\gamma)$ in [EtMeIm $]^{+}\left[\mathrm{Et}_{2} \mathrm{PO}_{4}\right]^{-}$of: o-Xylene $(\triangle)$; m-Xylene ( $\square$ ); and p-Xylene $(\diamond)$. Dashed lines: GC-EoS correlation.

In Figure 5 and 6, the correlation of experimental data of xylenes with the parameters adjusted for the group $\mathrm{ACCH}_{3}$ are presented. Due to the small chemical differences between the o-, m-, and p-Xylenes, the GC-EoS could not represent the experimental behavior of the components shown in literature. The model predictive capacity with the adjusted parameters was checked with experimental data on infinite dilution activity coefficients of toluene in ionic liquids, as shown in Figure 7, which depicts a good agreement between the model and the experimental data. In this work also styrene behavior with phosphate derived ionic liquids was modeled (see Figure 8), which allows fitting the binary parameters of the double bond with the new groups described in this work. 


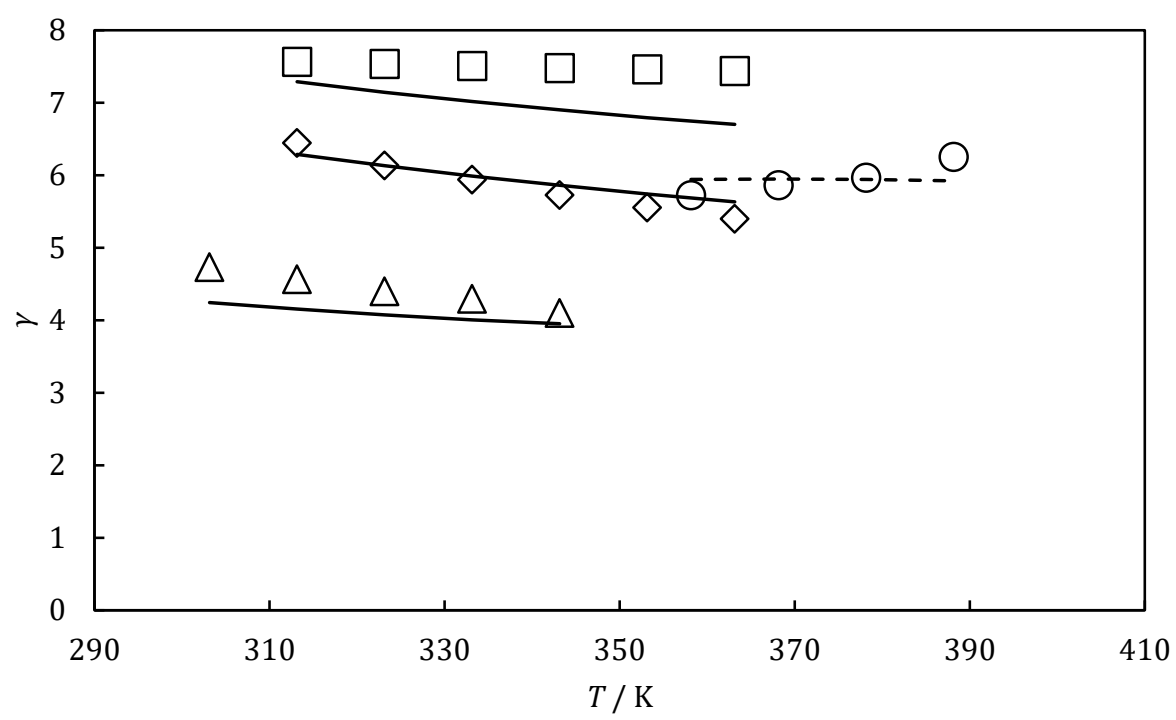

Figure 7. Activity coefficients at infinite dilution $(\gamma)$ of toluene in: $(\square)\left[\mathrm{Me}_{2} \mathrm{Im}\right]^{+}\left[\mathrm{Me}_{2} \mathrm{PO}_{4}\right]^{\text {; }}$; $(\diamond)[\text { EtMeIm }]^{+}\left[\mathrm{Me}_{2} \mathrm{PO}_{4}\right]^{;} ;(\triangle)\left[\right.$ EtMeIm] ${ }^{+}\left[\mathrm{Et}_{2} \mathrm{PO}_{4}\right]^{-} ;(O)$ Ethylbenzene in [BuMeIm] ${ }^{+}$ $\left[\mathrm{Me}_{2} \mathrm{PO}_{4}\right]$-Solid lines: GC-EoS predictions. Dashed lines: GCA-EoS correlation.

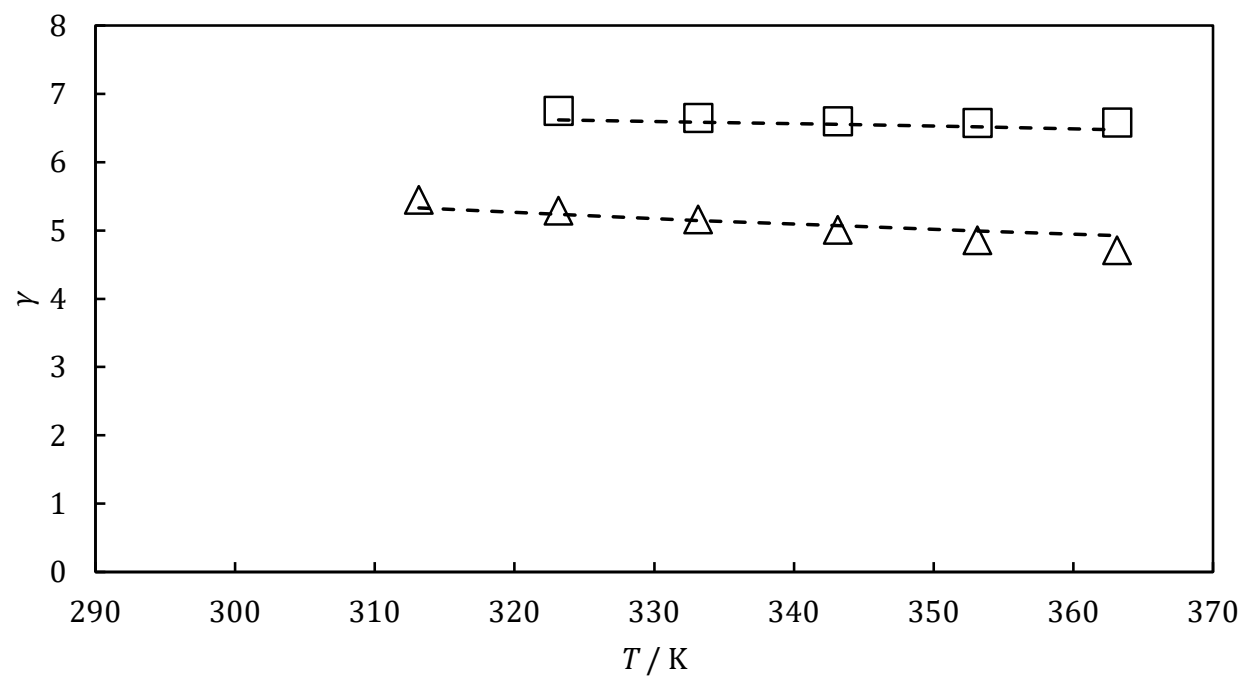

Figure 8. Activity coefficients at infinite dilution $(\gamma)$ of: $(\square)$, Styrene in $\left[\mathrm{Me}_{2} \mathrm{Im}\right]^{+}\left[\mathrm{Me}_{2} \mathrm{PO}_{4}\right]$; $(\triangle)$, Styrene in [EtMeIm] $]^{+}\left[\mathrm{Me}_{2} \mathrm{PO}_{4}\right]^{-}$. Dashed lines: GCA-EoS correlation.

\section{Conclusions}

In this work, the GC-EoS table of parameters was extended to model two new families of ionic liquids, namely, 1-alkyl-3-methylimidazolium dimethylphosphate and 1-alkyl-3methylimidazolium diethylphosphate. This required the definition of two new groups, (MeImMe $\left.{ }_{2} \mathrm{PO}_{4}\right)$ and $\left(-\mathrm{MeImEt}_{2} \mathrm{PO}_{4}\right)$, and fit their pure energy and binary interaction 
parameters with other functional groups: $\mathrm{CH}_{3}, \mathrm{CH}_{2}, \mathrm{ACH}, \mathrm{AC}, \mathrm{ACCH}_{3}$ and $\mathrm{CH}_{2}=\mathrm{CH}$. Most of the parameters were correlated to experimental infinite dilution activity coefficients of a variety of paraffins and aromatic compounds. The results show a good correlation of the experimental data; it is possible to describe infinite dilution activity coefficient $(\gamma)$ with an $\operatorname{ARD} \%(\gamma)$ of $4.52 \%$.

\section{List of symbols}

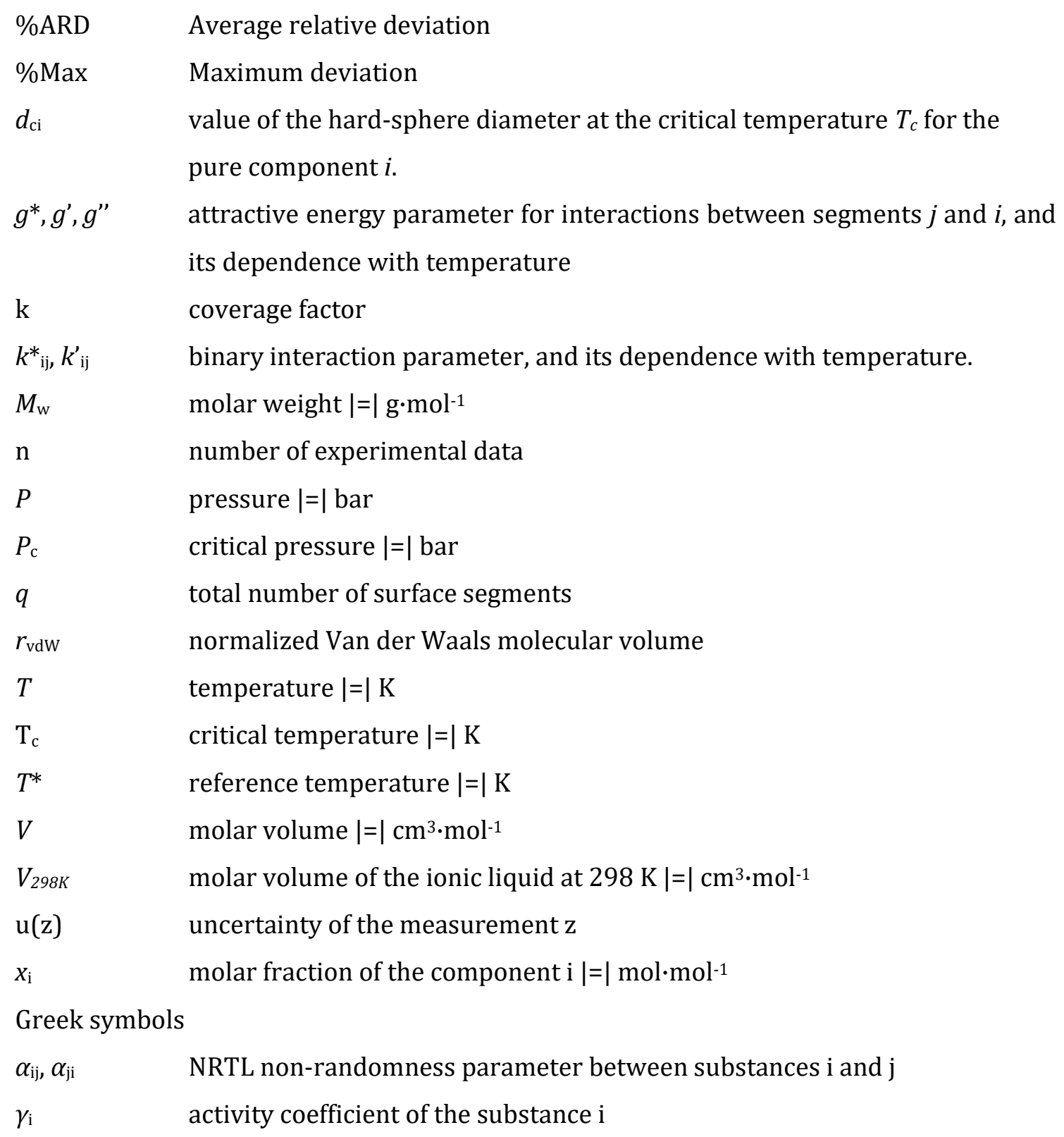

\section{Acknowledgements}

Authors thank MINECO for project ENE2014-53459-R. LP thank the Erasmus Mundus Eurica PhD student grant for the economic support. MDB thanks the Spanish Ministry of Economy and Competitiveness for the Ramón y Cajal research fellowship. 


\section{References}

(1) Kuhlmann, E.; Himmler, S.; Giebelhaus, H.; Wasserscheid, P. Green Chem. 2007, 9 (3), 233.

(2) Vitz, J.; Erdmenger, T.; Schubert, U. S. Cellulose Solvents: For Analysis, Shaping and Chemical Modification; 2010; pp 299-317.

(3) Skjold-Jørgensen, S. Ind. Eng. Chem. Res. 1988, 27 (1), 110-118.

(4) Breure, B.; Bottini, S. B.; Witkamp, G.; Peters, C. J. J. Phys. Chem. B 2007, 111 (51), 14265-14270.

(5) Bermejo, M. D.; Martin, A.; Foco, G.; Cocero, M. J.; Bottini, S. B.; Peters, C. J. J. Supercrit. Fluids 2009, 50 (2), 112-117.

(6) Martín, Á.; Méndez, D.; Bermejo, M. D. J. Chem. Thermodyn. 2010, 42 (Vl), 524-529.

(7) Bermejo, M. D.; Méndez, D.; Martín, Á. Ind. Eng. Chem. Res. 2010, 49 (10), 4966-4973.

(8) González, E. J.; Bottini, S. B.; Pereda, S.; Macedo, E. A. Fluid Phase Equilib. 2014, 362, 163-169.

(9) Pereda, S.; Raeissi, S.; Andreatta, A. E.; Bottini, S. B.; Kroon, M.; Peters, C. J. Fluid Phase Equilib. 2016, 409, 408-416.

(10) González, E. J.; Bottini, S. B.; Macedo, E. A. Fluid Phase Equilib. 2015, 387, 32-37.

(11) Mota Martinez, M. T.; Kroon, M. C.; Peters, C. J. J. Supercrit. Fluids 2015, 101, 54-62.

(12) Lopes, J. M.; Sánchez, F. A.; Reartes, S. B. R.; Bermejo, M. D.; Martín, Á.; Cocero, M. J. J. Supercrit. Fluids 2016, 107, 590-604.

(13) Bottini, S. B.; Fornari, T.; Brignole, E. A. Fluid Phase Equilib. 1999, 158-160, 211-218.

(14) Espinosa, S.; Díaz, M. S.; Brignole, E. A. Ind. Eng. Chem. Res. 2002, 41, 1516-1527.

(15) Skjold-Jørgensen, S. Fluid Phase Equilib. 1984, 16 (3), 317-351.

(16) Mansoori, G. A.; Carnahan, N. F.; Starling, K. E.; Leland, T. W. J. Chem. Phys. 1971, 54 (4), 1523-1525.

(17) Renon, H.; Pruasnitz, J. M. AIChE J. 1968, 14 (1), 116-128.

(18) Espinosa, S.; Fornari, T.; Bottini, S. B.; Brignole, E. A. J. Supercrit. Fluids 2002, 23 (2), 91-102. 
(19) Cai, F.; Ibrahim, J. J.; Gao, L.; Wei, R.; Xiao, G. A Fluid Phase Equilib. 2014, 382, 254259.

(20) Freire, M. G.; Teles, A. R. R.; Rocha, M. A. A.; Schröder, B.; Neves, C. M. S. S.; Carvalho, P. J.; Evtuguin, D. V.; Santos, L. M. N. B. F.; Coutinho, J. A. P. J. Chem. Eng. Data 2011, 56 (12), 4813-4822.

(21) Gong, Y.; Shen, C.; Lu, Y.; Meng, H.; Li, C. J. Chem. Eng. Data 2012, 57, 33-39.

(22) Wang, J.; Li, C.; Shen, C.; Wang, Z. Fluid Phase Equilib. 2009, 279 (2), 87-91.

(23) Fornari, T. Fluid Phase Equilib. 2007, 262 (1-2), 187-209.

(24) Ge, M.-L.; Chen, J.-B J. Chem. Eng. Data 2011, 56, 3183-3187.

(25) Ge, M. L.; Lu, C. Y.; Liu, X. Y.; Li, X. B.; Chen, J. Y.; Xiong, J. M. J. Chem. Thermodyn. 2015, 91, 279-285.

(26) Martins, M. A. R.; Coutinho, J. A. P.; Pinho, S. P.; Domańska, U. J. Chem. Thermodyn. 2015, 91, 194-203.

(27) Valderrama, J. O.; Rojas, R. E. Ind. \{\&\} Eng. Chem. Res. 2009, 48 (14), 6890-6900. 


\title{
Chapter 6. Determination of the solubility of $\mathrm{CO}_{2}$ in selected cellulose dissolving ILs at high pressure and modeling with the GC-EoS.
}

\begin{abstract}
The solubility of $\mathrm{CO}_{2}$ in 1-ethyl-3-methylimidazolium diethylphosphate [EtMeIm]+[Et $\left.2 \mathrm{PO}_{4}\right]$ has been measured at $313.15 \mathrm{~K}, 333.15 \mathrm{~K}$ and $353.15 \mathrm{~K}$ and at pressures up to 60 bar. Binary interaction parameters for the new groups 1-alkyl-3-methylimidazolium diethylphosphate $[-\mathrm{MeIm}]^{+}\left[\mathrm{Et}_{2} \mathrm{PO}_{4}\right]^{-}$and 1-alkyl-3-methylimidazolium dimethylphosphate [-MeIm] ${ }^{+}$ $\left[\mathrm{Me}_{2} \mathrm{PO}_{4}\right]^{-}$were estimated using the solubility data measured in this work and data measured from literature with the Group Contribution Equation of State. The correlation presents an Average Relative Deviation, ARD\%, of 8.9\% for the data measured in this work.
\end{abstract} Keywords: solubility, carbon dioxide, 1-ethyl-3-methylimidazolium diethylphosphate, GCEoS. 


\section{Introduction}

Ionic liquids are proved to present a high capacity to dissolve $\mathrm{CO}_{2}$. Some of them even concentrations as high as $70 \%$ in mole. ${ }^{1}$ In contrast, most ILs are not soluble in $\mathrm{CO}_{2} .{ }^{2-4}$ This fact has made that some applications were proposed in literature, such as carbon capture, 5 $\mathrm{CO}_{2}$ separation from gas stream 6 and extraction of reaction products from IL. 7,8 Nevertheless, $\mathrm{CO}_{2}$ also presents the interesting effect of reducing the viscosity and melting points of ionic liquids. ${ }^{9-14}$ This makes it interesting also as a co-solvent in applications were the high viscosity of the medium might be a major limitation, such as in the processing of cellulose and other biopolymers. ${ }^{15-17} \mathrm{CO}_{2}$ is a cheap abundant solvent and it is known that $\mathrm{CO}_{2}$ can improve synthesis of cellulose acetate in the ionic liquid AmimCl. ${ }^{18}$ Nevertheless, the melting point of chloride based ionic liquids is only reduced by $10^{\circ} \mathrm{C}$ under $100 \mathrm{bar}$ pressure of $\mathrm{CO}_{2} .{ }^{9}$ In ionic liquids with acetate anion, $\mathrm{CO}_{2}$ acts as antisolvent of cellulose because of its reaction with the IL to from a carboxylate zwitterion ${ }^{19,20}$. Their effect in viscosity was study by Iguchi et al. ${ }^{21}$ showing a viscosity reduction up to $80 \%$ at $4 \mathrm{MPa}$ and 33 hours.

In this work, the solubility of $\mathrm{CO}_{2}$ in 1-ethyl-3-methylimidazolium diethylphosphate is studied. Alkylimidazolium alkylphosphate ionic liquid family are able to dissolve amounts of up to $10 \%$ of cellulose at $45^{\circ} \mathrm{C}$ in $30 \mathrm{~min}$, and even $2-4 \%$ cellulose at room temperature. 22 In addition, viscosities of this family of ILs (between $100-500 \mathrm{mPa} \cdot \mathrm{s}$ ) are much lower than those of chloride based ionic liquids (between 1000 and $1500 \mathrm{mPa} \cdot \mathrm{s}$ ). Nevertheless, these viscosities are still high compared to water or other conventional solvents. Also, other co-solvents, such as DMSO, have been proposed to decrease this physicochemical property.

Just a few authors have reported solubility of $\mathrm{CO}_{2}$ in imidazolium alkylphosphate based ionic liquids. Palgunadi et al. ${ }^{23}$ studied in 2009 the solubility of $\mathrm{CO}_{2}$ in 1-ethyl-3methylimidazolium diethylphosphate and in 1-butyl-3-methylimidazolium dibuthylphosphate at $313-333 \mathrm{~K}$ at low pressures up to 2 bar, and thereafter calculate thermodynamic properties such as the Henry's constant, standard Gibbs free energy and changes in solvation enthalpy and entropy. Mejía et al. ${ }^{24}$ measured the solubilities of $\mathrm{CO}_{2}$ in

several IL, including the 1-ethyl-3-methylimidazolium diethylphosphate ([EtMeIm] $]^{+}\left[\mathrm{Et}_{2} \mathrm{PO}_{4}\right]$ ) ) studied in this work up to 7 bar and at three temperatures: $298 \mathrm{~K}, 313$ $\mathrm{K}$ and $333 \mathrm{~K}$. In addition, they reported the density of the $\mathrm{CO}_{2}$ - IL mixture, data that it is used for the calculations in this work. Finally, Ramdin et al. ${ }^{25}$ also described the distribution of mixtures $\mathrm{CH}_{4} / \mathrm{CO}_{2}$ in a variety of IL, including [EtMeIm] $\left[\mathrm{Et}_{2} \mathrm{PO}_{4}\right]$. They found that the 
selectivity towards $\mathrm{CO}_{2}$ decreases with increasing temperature and decreasing molecular weight.

The Group Contribution Equation of State (CG - EoS) ${ }^{26}$ is used to correlate and predict phase behavior of mixtures, based on the functional groups present in the mixture. So far, it has been used to successfully describe the phase behavior of several mixtures comprising ionic liquids. 9,27-34 Here, the GC-EoS table of parameters is extended to describe the phase behavior of the 1-alkyl-3-methylimidazolium dimethylphosphate [-MeIm]+ $\left[\mathrm{Me}_{2} \mathrm{PO}_{4}\right]$ - and 1alkyl-3-methylimidazolium diethylphosphate [-MeIm] $]^{+}\left[\mathrm{Et}_{2} \mathrm{PO}_{4}\right]-$ in mixtures with $\mathrm{CO}_{2}$. The new parameters are fitted to both, new experimental data of ionic liquids measured in this work and those found in the literature. Finally, the new parameters are used to predict experimental data available in the open literature.

In this work, the solubility of $\mathrm{CO}_{2}$ in 1-ethyl-3-methylimidazolium diethylphosphate ([EtMeIm] ${ }^{+}\left[\mathrm{Et}_{2} \mathrm{PO}_{4}\right]^{-}$) (structure shown in Figure 1) at 313.15 K, 333.15 K and 353.15 K at pressures up to 60 bar is measured.

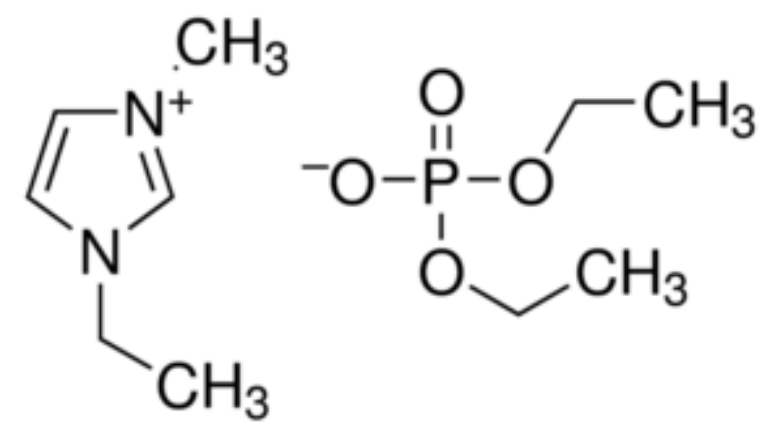

Figure 1.1-ethyl-3-methylimidazolium diethylphosphate structure

\section{Experimental}

\subsection{Materials}

The $\mathrm{CO}_{2}$ (99.9961wt.\%) was purchased from Carburos Metalicos (Spain). On the other hand, the IL was purchased from Iolitec GmbH (assay (NMR, Nuclear Magnetic Resonance) $=98$ $\%$; 1-ethyl-3-methylimidazolium (IC, Ion Chromatography) = 99.1\%; diethylphosphate (IC) $=98.2 \%$ and 1 -Methylimidazole (IC) $<1 \%$ and water content of $0.04 \%$ mass fraction). Due to the low moisture content an additional drying process before the experiment was considered unnecessary. The humidity of the samples was determined before charging in the equilibrium cell by using Karl - Fischer Coulometric titration using Mettler Toledo C20 KF. After loading the IL inside the cell it was put under vacuum $\left(10^{-4} \mathrm{mbar}\right)$ at least four hours at $333 \mathrm{~K}$ in order to remove the air and other volatile impurities. 


\subsection{Experimental procedure}

A static method was used to measure isothermal vapor - liquid equilibrium data. . The device is based in an original design of Van Ness and coworkers. 35 Some modifications have been introduced to allow the measurements at higher pressure.

This experimental device is composed by an equilibrium SS 316 cell of $200 \mathrm{ml}$ sealed with an encapsulated PFA/FKM o-ring and with a magnetic stirrer inside. It is introduced in a thermostatic bath (Hart Scientific, model 6020, filled with water, with an uncertainty u(T) $= \pm 0.01 \mathrm{~K}$ for $\mathrm{k}=1$ ). The top flange of the cell is connected to the entrance of $\mathrm{CO}_{2}$, vacuum pump Edwards RV5. Pressure is measured with two sensors, for pressures up to 20 bar a Druck model PDCR-910-1422 is used and for higher pressures Paroscientific 42K-101 (calibrated from 0 to 137 bar). Low- and high-pressure measurements are displayed in different sensors (Druck model DPI 145 and Paroscientific 735, respectively) to reduce the reading uncertainty. The experimental setup is such that the first sensor is protected from overpressure, thus at pressures higher than 20 bar, the pressure measurements continue with the high-pressure sensor through a valve switch.

A known amount of IL is introduced in the cell and the mass is determined using a high precision balance (Sartorius Basic BA 310P, precision $=0.001 \mathrm{~g}$ ). Then the cell is hermetically closed and evacuated from all the volatile components by applying vacuum at $333 \mathrm{~K}$ reaching pressures up to $10^{-4}$ mbar while stirring at the same time for a period of at least 4 hours. Then the $\mathrm{CO}_{2}$ is introduced in the cell by using a syringe pump ISCO 260D, which allow knowing the exact mass of $\mathrm{CO}_{2}$ that is introduced. The uncertainty of the volume of $\mathrm{CO}_{2}$ introduced is $\pm 0.005 \mathrm{ml}$. Taking into account different sources of uncertainty, as the repeatability, the scattering, the dispersion of the data points and the influence of the temperature and pressure of the cell, the solubility uncertainty is estimated to be $\pm 2 \%$.

The cell volume was calibrated by introducing a known amount of $\mathrm{CO}_{2}$ with no IL inside, the pressure and the temperature allows determining the system density with Refprop software ${ }^{36}$ and finally the cell volume $(V=202 \mathrm{ml})$ is obtained with an uncertainty of $\mathrm{u}(V)$ $=0.34 \%$.

For the solubility measurements, after feeding $\mathrm{CO}_{2}$, the system is left to equilibrate during 8 to12 hours, until constant pressure is sensed. Once the equilibrium is reached, the pressure is recorded, and more $\mathrm{CO}_{2}$ is introduced to change the composition of the system and measure another point. 
Once all the experimental points are measured at the same temperature, or the maximum operating conditions at 60 bar are reached, the cell is evacuated, disassembled, cleaned and prepared for the next experiment. No "recycling" of the materials was performed: new seal and fresh ionic liquid was used for each experiment.

\subsection{Calculation of the composition}

For the calculation of the solubility, it was necessary to know the density of the liquid phase at different $\mathrm{CO}_{2}$ concentrations measured by Mejía et al. ${ }^{24}$ The equilibrium composition was obtained through the calculation of the volume that occupies the gas phase, which is the difference between the total volume (cell volume) and the liquid phase. With this volume, the pressure and the temperature, it is possible to calculate the mass of $\mathrm{CO}_{2}$ in the gas phase, and by difference, the mass of $\mathrm{CO}_{2}$ in the liquid phase. The equations used are shown from (1) to (5). The calculation procedure is represented with a block diagram in Figure 2.

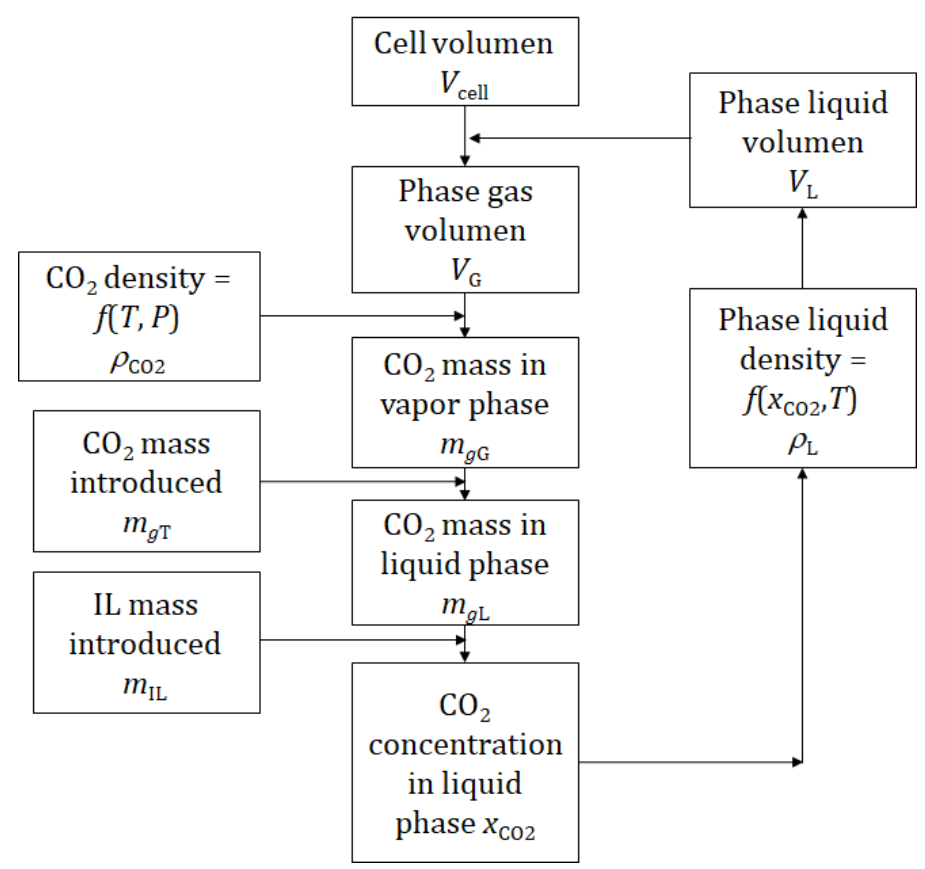

Figure 2. Block diagram for the solubility calculations

$$
\begin{gathered}
V_{G}=V_{\text {cell }}-V_{L} \\
m_{g G}=\rho_{C O 2} \cdot V_{G} \\
m_{g L}=m_{g T}-m_{g G} \\
x_{C O 2}=\frac{m_{g L}}{m_{I L}}
\end{gathered}
$$




$$
V_{L}=\frac{m_{g L}+m_{I L}}{\rho_{L}}
$$

where $V_{\mathrm{G}}$ and $V_{\mathrm{L}}$ is the volume of the gas and liquid phase, respectively. The $V_{\text {cell }}$ is the total volume of the cell, $m_{\mathrm{IL}}$ is the mass of the IL, and $m_{\mathrm{gG}}$ and $m_{\mathrm{gL}}$ is the mass of $\mathrm{CO}_{2}$ in the gas and liquid phase, respectively.

\section{Results and discussion}

The isothermal solubility of $\mathrm{CO}_{2}$ in the ionic liquid [EtMeIm] [Et $\left.2 \mathrm{PO}_{4}\right]$ is presented in Table 1. As usual with $\mathrm{CO}_{2}$ solubility in ILs, it increases with the pressure and decreases with the temperature.

Table 1. Experimental vapor-liquid equilibrium data of the system $\mathrm{CO}_{2}$ (1) + $[$ EtMeIm $]+\left[\mathrm{Et}_{2} \mathrm{PO}_{4}\right] \cdot(2)$ at different temperatures.

\begin{tabular}{llllll}
\hline$x 1$ & $P /$ bar & $x 1$ & $P /$ bar & $x 1$ & $P /$ bar \\
\hline$T=313.15 \mathrm{~K}$ & & $T=333.15 \mathrm{~K}$ & & $T=350.15 \mathrm{~K}$ & \\
0 & 0 & 0 & 0 & 0 & 0 \\
0.011 & 0.7457 & 0.035 & 1.6785 & 0.047 & 4.8250 \\
0.021 & 2.1519 & 0.060 & 5.0101 & 0.099 & 10.4610 \\
0.063 & 4.5626 & 0.115 & 10.1375 & 0.143 & 15.4710 \\
0.076 & 6.5361 & 0.116 & 9.4831 & 0.178 & 20.2490 \\
0.124 & 9.6196 & 0.155 & 15.8980 & 0.213 & 25.9440 \\
0.133 & 10.8182 & 0.159 & 15.4116 & 0.241 & 30.5320 \\
0.151 & 12.3376 & 0.187 & 19.5633 & 0.274 & 39.7820 \\
0.172 & 14.3416 & 0.198 & 20.8322 & 0.317 & 49.5610 \\
0.178 & 15.4287 & 0.230 & 25.8841 & & \\
0.205 & 17.3534 & 0.235 & 25.6017 & & \\
0.217 & 19.2818 & 0.262 & 30.6368 & & \\
0.248 & 21.9550 & 0.304 & 35.4240 & & \\
0.257 & 22.6660 & 0.325 & 39.8281 & & \\
0.266 & 25.1550 & 0.375 & 48.4334 & & \\
0.319 & 31.4913 & 0.409 & 54.3800 & & \\
0.369 & 38.8205 & 0.434 & 59.9670 & & \\
0.439 & 49.8063 & & & & \\
0.503 & 60.9220 & & & & \\
\hline
\end{tabular}

Standard uncertainties with $\mathrm{k}=1$ of the temperature $\mathrm{u}(T)= \pm 0.01 \mathrm{~K}$ and of the pressure $\mathrm{u}(P)= \pm 5 \cdot 10^{-4}$ bar; Standard uncertainty $(\mathrm{k}=1)$ of the composition is $2 \%$. 
The solubility of this system was compared to literature data 24,25 in Figures 3 can be seen the results compared with other authors. It is observed that at moderate pressures and temperatures the experiments agree with the literature data, however, at $353.15 \mathrm{~K}$ the discrepancies are bigger. At higher pressure the effect is similar, presenting also discrepancies between the two authors from the literature.
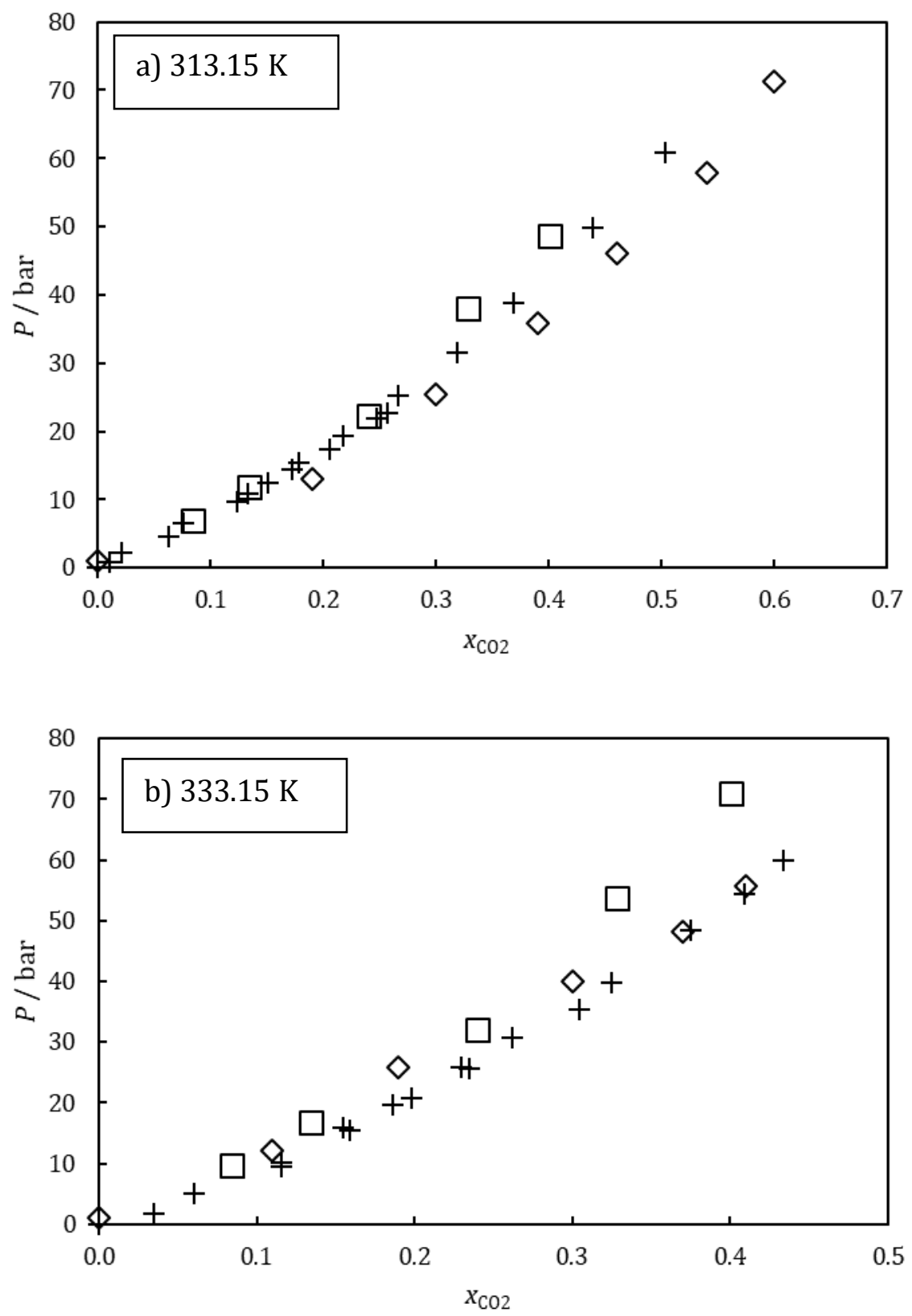


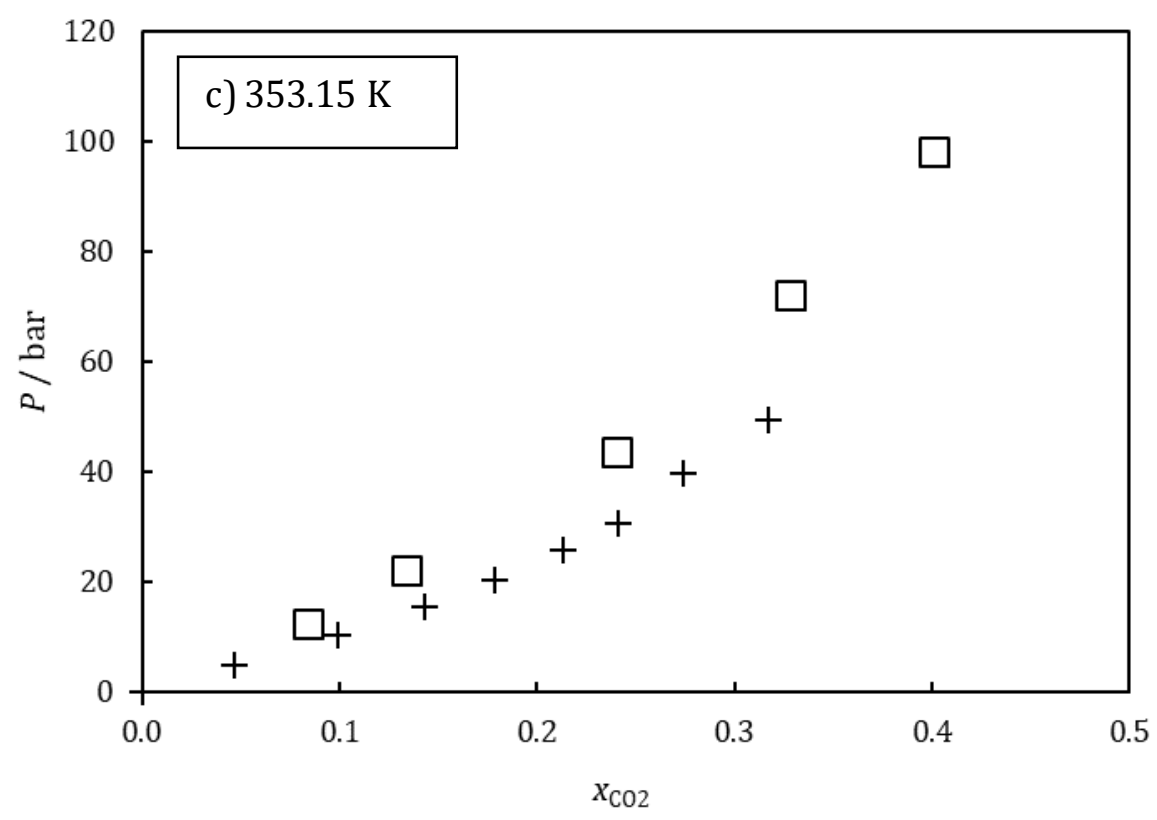

Figure 3. Solubility comparison of our data $(+)$ with Mejía et al. ${ }^{24}(\diamond)$ and Ramdin et al. 25 ( $\square$ ) a) at $313.15 \mathrm{~K}, \mathrm{~b}$ ) at $333.15 \mathrm{~K}$ and c) at $353.15 \mathrm{~K}$

The discrepancies between the authors can be explained with different impurities in the samples, like water and 1-methylimidazole. Ramdin et al. 25 reported a purity of $\geq 98.0 \%$ in mole fraction and $<250 \mathrm{ppm}$ of water content. Mejía et al. ${ }^{24}$ reported a purity of $\geq 99.0 \%$ in mass fraction and 900 ppm of water content. 


\section{Modeling with the GC-EoS}

\subsection{The Gro up Con tributi on Equation of State}

The GC-EoS was originally developed by Skjold-Jørgensen 26,37 to calculate VL equilibria at pressures up to $30 \mathrm{MPa}$. This EoSis based on the Van der Waals function combined with the local composition principle. It can be expressed as the sum of two contributions of the residual Helmholtz free energy ( $\left.A^{\text {res}}\right)$ : the repulsive (rep) and the attractive (att) contributions represented in equation (1).

$$
\left(\frac{A}{R T}\right)_{\text {res }}=\left(\frac{A}{R T}\right)_{\text {rep }}+\left(\frac{A}{R T}\right)_{\text {att }}
$$

Where $R$ is the gas constant and $T$ is the temperature.

The repulsive term uses the expression developed by Mansoori and Leland 38 for hard spheres, is described in the equation (2):

$$
\left(\frac{A}{R T}\right)_{r e p}=3\left(\frac{\lambda_{1} \lambda_{2}}{\lambda_{3}}\right)(Y-1)+\left(\frac{\lambda_{2}^{3}}{\lambda_{3}^{2}}\right)\left(-Y+Y^{2}-\ln Y\right)+n \ln Y
$$

Where

$$
\begin{gathered}
\lambda_{k}=\sum_{i}^{N C} n_{i} d_{i}^{k} \\
Y=\left(1-\frac{\pi \lambda_{3}}{6 V}\right)^{-1}
\end{gathered}
$$

being $n_{i}$ the number of moles of component $i, V$ the total volume, $N C$ the total number of components in the mixture, and $d_{i}$ the hard-sphere diameter per mole.

The hard-sphere diameter $\left(d_{i}\right)$ is a function of temperature, the relationship is expressed in equation (5):

$$
d_{i}=1.065655 d_{c i}\left[1-0.12 \exp \left(-\frac{2 T_{c i}}{3 T}\right)\right]
$$

Where $d_{c i}$ is the value of the hard-sphere diameter at the critical temperature $T_{c i}$ for the pure component $i$.

The value of the $d_{\mathrm{ci}}$ can be evaluated from the critical properties of the corresponding component with the equation (6): 


$$
d_{c i}=\left(0.08943 \frac{R T_{c i}}{P_{c i}}\right)^{1 / 3}
$$

The attractive contribution of the residual Helmholtz free energy ( $A^{a t t}$ ) is a group contribution version of a density-dependent NRTL model. ${ }^{39}$ It is represented in equation (7).

$$
\left(\frac{A}{R T}\right)_{a t t}=-\left(\frac{Z}{2}\right) \sum_{i=1}^{N_{C}} n_{i} \sum_{j=1}^{N_{G}} v_{j}^{i} q_{j} \frac{\sum_{k=1}^{N_{G}} \theta_{k}\left(\frac{g_{k j} \tilde{q} \tau_{k j}}{R T V}\right)}{\sum_{l=1}^{N_{G}} \theta_{l} \tau_{l j}}
$$

where:

$$
\begin{gathered}
\tau_{k j}=\exp \left(\frac{\alpha_{k j} \Delta g_{k j} q}{R T V}\right) \\
\Delta g_{k j}=g_{k j}-g_{j j}
\end{gathered}
$$

with:

$$
\tau_{k j}=\exp \left(\frac{\alpha_{k j} \Delta g_{k j} \tilde{q}}{R T V}\right)
$$

and:

$$
\Delta g_{k j}=g_{k j}-g_{j j}
$$

In equations (7) to (9), $z$ is the coordination number set equal to $10 ; N_{G}$ is the number of groups, $v_{j}^{i}$ is the number of groups $j$ in component $i ; q_{j}$ is the number of surface segments assigned to group $j ; \theta_{k}$ is the surface fraction of group $k ; q$ is the total number of surface segments; $g_{i j}$ is the attractive energy parameter for interactions between segments $j$ and $i$; and $\alpha_{i j}$ is the corresponding non-randomness parameter.

The interactions between unlike segments are defined by equation (12):

$$
g_{j i}=k_{i j} \sqrt{g_{i i} g_{j j}}
$$

Where the symmetrical parameter $k_{i j}\left(k_{i j}=k_{j i}\right)$ is the binary interaction parameter. Both, the attractive energy $\left(g_{i j}\right)$ and the binary interaction parameter $\left(k_{i j}\right)$ have a temperature dependence described in (13) and (14) respectively:

$$
g_{i i}=g_{i i}^{*}\left\lfloor 1+g_{i i}^{\prime}\left(\frac{T}{T_{i}^{*}}-1\right)+g_{i i}^{\prime \prime} \ln \left(\frac{T}{T_{i}^{*}}\right)\right\rfloor
$$




$$
k_{i j}=k_{i j}^{*}\left[1+k_{i j}^{\prime} \ln \left(\frac{2 T}{T_{i}^{*}+T_{j}^{*}}\right)\right]
$$

Where $g_{i i}^{*}$ and $k_{i j}^{*}$ are the attractive energy and binary interaction parameters at the arbitrary, but fixed, reference temperature $T_{i}^{*}$ and $\left(T_{i}^{*}+T_{j}^{*}\right) / 2$ respectively.

\subsection{Ionic Liquid functional group}

To apply the GC-EoS it is necessary to divide the ionic liquid molecule into functional groups. Breure et al. ${ }^{27}$ showed that the anion and part of the cation, except for its alkyl chain, should be kept together in a single electroneutral group. Therefore, by adding the $\mathrm{CH}_{2}, \mathrm{CH}_{3}$ or other functional groups to the side alkyl chain, any ionic liquid of the same family can be assembled. The characteristic groups defined in Chapter 5 used in this work, [MeIm] $+\left[\mathrm{Me}_{2} \mathrm{PO}_{4}\right]^{-}$and [-MeIm] $]^{+}\left[\mathrm{Et}_{2} \mathrm{PO}_{4}\right]$; are shown in Figure 1.
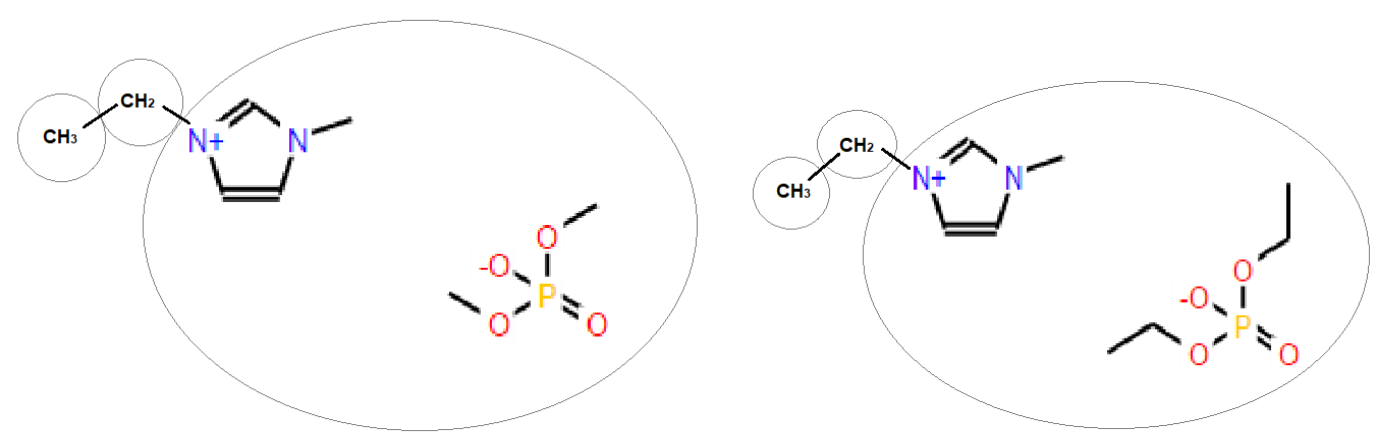

Figure 4. Group definition for [-MeIm] $]^{+}\left[\mathrm{Me}_{2} \mathrm{PO}_{4}\right]^{-}$(left) and for [-MeIm] $]^{+}\left[\mathrm{Et}_{2} \mathrm{PO}_{4}\right]^{-}$(right).

\subsection{Parametrization of the repulsive term}

The repulsive term comprises one unique characteristic parameter, which is the hardsphere diameter at critical temperature $\left(d_{c i}\right)$. Usually this parameter is derived from the pure component critical properties as with the eq. (6) or by fitting a vapor pressure data point. However, none of these data are available for the ionic liquids. In this work, $d_{c i}$ was calculated using the correlation developed by Espinosa et al. ${ }^{40}$ (see equation 14) for high molecular weight natural compounds, and applied later to ionic liquids by Breure et al. 27 and Bermejo et al. ${ }^{28}$. As shown in Equation (15), the correlation estimates $d_{c i}$ based on the normalized Van der Waals molecular volume of the compound $\left(r_{v d w}\right)$, information easy to calculate in the case of any organic compound but not available for the ionic liquids, which require a number of assumptions to attain a representative value. Later, Pereda et al. 32 
showed that the $r_{v d w}$ can be estimated by a simple linear relation with respect to the molar volume of the ionic liquid at $298 \mathrm{~K}\left(V_{298 K}\right)$.

$$
\begin{gathered}
\log \left(d_{c i}\right)=0.4152+0.4128 \log \left(r_{v d W}\right) \\
r_{v d W}=0.039 \cdot V_{298 K}\left(\mathrm{~cm}^{3} \mathrm{~mol}^{-1}\right)
\end{gathered}
$$

Table 2 summarizes the van der Waals volume and critical diameters for the ionic liquids studied in this work.

Table 2. Molecular weight ( $M w)$, molar volume ( $V$ ) at $298 \mathrm{~K}$, van der Waals volume $\left(r_{v d w}\right)$, and critical diameter $\left(d_{c}\right)$ for the ionic liquids.

\begin{tabular}{llllll}
\hline Ionic Liquid & $M w / \mathrm{g} \cdot \mathrm{mol}^{-1}$ & $V / \mathrm{cm}^{3} \cdot \mathrm{mol}^{-1}$ & Source & $r_{v d W}$ & $d_{c} / \mathrm{cm} \cdot \mathrm{mol}-1 / 3$ \\
\hline$\left[\right.$ EtMeIm] ${ }^{+}\left[\mathrm{Et}_{2} \mathrm{PO}_{4}\right]^{-}$ & 264.26 & 230.57 & 41 & 8.992 & 6.4432 \\
{$\left[\right.$ EtMeIm] ${ }^{+}\left[\mathrm{Me}_{2} \mathrm{PO}_{4}\right]$} & 194.17 & 194.10 & 42 & 7.570 & 6.0000 \\
{$[\mathrm{BuMeIm}]+\left[\mathrm{Me}_{2} \mathrm{PO}_{4}\right]$} & 264.26 & 227.43 & 43 & 8.870 & 6.4033 \\
{$\left[\mathrm{Me}_{2} \mathrm{Im}\right]+\left[\mathrm{Me}_{2} \mathrm{PO}_{4}\right]$} & 222.18 & 176.57 & 44 & 6.886 & 5.7671 \\
\hline
\end{tabular}

\subsection{Parametrization of the attractive term}

The pure group energy parameters: $g_{i i}^{*}, g_{i i}^{\prime}, g_{i i}^{\prime \prime}$, the surface area $q_{i}$, and the reference temperature $T_{i}{ }^{*}$ were obtained and displayed in the Table 3 of the Chapter 5. Up to this point, with the parameters obtained in the Chapter 5 , the ionic liquid is well described, and therefore, the only degree of freedom is the binary interaction parameters with $\mathrm{CO}_{2}$.

The Table 3 summarizes the experimental database used for the correlation and for ensuring its prediction ability.

\begin{tabular}{|c|c|c|c|c|c|c|}
\hline $\begin{array}{l}\text { Compound } \\
\text { Ionic liquid }\end{array}$ & $T(\mathrm{~K})$ & $P$ (bar) & $\begin{array}{l}\text { Data } \\
\text { uncertainty }\end{array}$ & $\begin{array}{l}\text { No exp. } \\
\text { Points }\end{array}$ & $\begin{array}{l}\text { ARD } \% \\
\left(x_{\mathrm{CO} 2}\right)\end{array}$ & Source \\
\hline$[\mathrm{EtMeIm}]^{+}\left[\mathrm{Et}_{2} \mathrm{PO}_{4}\right]^{*}$ & $313.15-350.15$ & $0.75-60.0$ & $\pm 2 \%$ & 45 & 8.9 & $\begin{array}{l}\text { This } \\
\text { work }\end{array}$ \\
\hline$[\mathrm{EtMeIm}]^{+}\left[\mathrm{Et}_{2} \mathrm{PO}_{4}\right]^{*}$ & $302.69-362.13$ & $5.34-109.48$ & $8 \%-11 \%$ & 35 & 8.4 & 25 \\
\hline$[\mathrm{EtMeIm}]^{+}\left[\mathrm{Et}_{2} \mathrm{PO}_{4}\right]^{-}$ & $313.15-333.15$ & $0.23-1.93$ & $0.7 \%-4 \%$ & 22 & 7.3 & 23 \\
\hline$\left[\mathrm{Me}_{2} \mathrm{Im}\right]+\left[\mathrm{Me}_{2} \mathrm{PO}_{4}\right]^{*}$ & $313.15-333.15$ & $0.48-1.70$ & $0.7-2 \%$ & 12 & 2.6 & 23 \\
\hline
\end{tabular}

Table 3. Database of solubility of $\mathrm{CO}_{2}$ in different ionic liquids

* Data used for the correlation 
The data from Mejía et al. 24 were not included for the correlation due to the high uncertainty of the experimental data, the authors conclude that not including them would improve the overall quality of the correlation.

\section{Results of the GC - EoS Modelling}

The pure group parameters of the IL's and the interaction parameters with the alkyl chain $\left(\mathrm{CH}_{2}\right.$ and $\left.\mathrm{CH}_{3}\right)$, are fitted and results summarized in Chapter 5 .

Table 4, 5 and 6 report the GC-EoS pure group, pure compound and binary interaction parameters, respectively. As can be seen in Table 4, the pure group parameters of the ionic liquids are the same as the fitted in Chapter 5 , while the parameters of all other groups were also taken from literature. ${ }^{45}$ This new set of parameters is able to correlate and predict all the assessed experimental data with the accuracy indicated in Table 3.

Table 4. GC-EoS pure group parameters. $T_{i}^{*}$ is the reference temperature, $q_{i}$ is the surface area of $i$ and $g^{*}, g^{\prime}$, and $g^{\prime \prime}$ are the pure group energy parameters and its temperature dependence (see equation 12 ).

\begin{tabular}{|c|c|c|c|c|c|c|}
\hline Group & $T^{*} / \mathrm{K}$ & $q$ & $g^{*} / \mathrm{atm} \cdot \mathrm{cm}^{6} \cdot \mathrm{mol}^{-2}$ & $g^{\prime}$ & $g^{\prime \prime}$ & Source \\
\hline -MeImMe $2 \mathrm{PO}_{4}$ & 600 & 4.8513 & 1154081 & -0.2941 & 0 & Chapter 5, this work \\
\hline$-\mathrm{MeImEt}_{2} \mathrm{PO}_{4}$ & 600 & 6.0116 & 1170489 & -0.1153 & 0 & Chapter 5, this work \\
\hline $\mathrm{CH}_{3}$ & 600 & 0.848 & 316910 & -0.9274 & 0 & 45 \\
\hline $\mathrm{CH}_{2}$ & 600 & 0.540 & 356080 & -0.8755 & 0 & 45 \\
\hline $\mathrm{CO}_{2}$ & 308.2 & 1.261 & 531890 & -0.578 & 0 & 45 \\
\hline
\end{tabular}

Table 5. GC-EoS pure compounds parameters. $T_{c}$ and $P_{c}$ are the critical temperature and pressure respectively taken from literature. ${ }^{46}$

\begin{tabular}{lll}
\hline Compound & $T_{c} / \mathrm{K}$ & $P_{c} /$ atm \\
\hline$[\text { EtMelm }]^{+}\left[\mathrm{Et}_{2} \mathrm{PO}_{4}\right]^{-}$ & 789.00 & 27.4855 \\
{$\left[\mathrm{Me}_{2} \mathrm{Im}\right]^{+}\left[\mathrm{Me}_{2} \mathrm{PO}_{4}\right]^{-}$} & 869.40 & 20.0345 \\
{$[\text { EtMeIm }]^{+}\left[\mathrm{Me}_{2} \mathrm{PO}_{4}\right]^{-}$} & 748.60 & 34.2000 \\
{$[\text { BuMeIm }]^{+}\left[\mathrm{Me}_{2} \mathrm{PO}_{4}\right]^{-}$} & 951.50 & 10.0000 \\
\hline
\end{tabular}


Table 6. GC-EoS binary interaction parameters correlated in this work.

\begin{tabular}{llcrrrl}
\hline Group $i$ & Group $j$ & $k_{i j}^{*}$ & $k_{i j}^{\prime}$ & $\alpha_{i j}$ & $\alpha_{j i}$ & Source \\
\hline -MeImMe2 $\mathrm{PO}_{4}$ & $\mathrm{CH}_{3}$ & 1.0169 & -0.0477 & -1.868 & -3.1969 & Chapter 5 \\
& $\mathrm{CH}_{2}$ & 1.0169 & -0.0477 & -2.3677 & -1.1145 & Chapter 5 \\
& $\mathrm{CO}_{2}$ & 1.1044 & 0 & -5.0422 & -1.6967 & This work \\
& & & & & & \\
$-\mathrm{MeImEt}_{2} \mathrm{PO}_{4}$ & $\mathrm{CH}_{3}$ & 0.999 & -0.0084 & 8.7504 & -1.8958 & Chapter 5 \\
& $\mathrm{CH}_{2}$ & 0.999 & -0.0084 & 1.3137 & -1.0597 & Chapter 5 \\
& $\mathrm{CO}_{2}$ & 1.2603 & 0 & -6.2462 & 2.4642 & This work \\
& & & & & & 45 \\
$\mathrm{CH}_{3}$ & $\mathrm{CH}_{2}$ & 1 & 0 & 0 & 0 & 45 \\
& $\mathrm{CO}_{2}$ & 0.892 & 0 & 3.369 & 3.369 & 45 \\
$\mathrm{CH}_{2}$ & & & & 3.369 & 3.369 & 45 \\
\hline
\end{tabular}

Finally, in this work the solubility of $\mathrm{CO}_{2}$, this is high-pressure equilibrium data, is modeled. Figure 4 and 5 depicts experimental solubility data of the system $\mathrm{CO}_{2}+[\text { EtMeIm] }]^{+}\left[\mathrm{Et}_{2} \mathrm{PO}_{4}\right]$ : On the other hand, in the Figure 6, the $\mathrm{CO}_{2}$ solubility in $\left[\mathrm{Me}_{2} \mathrm{Im}\right]^{+}\left[\mathrm{Me}_{2} \mathrm{PO}_{4}\right]^{-}$at low pressures is compared to the GC-EoS correlation, which shows a good agreement.

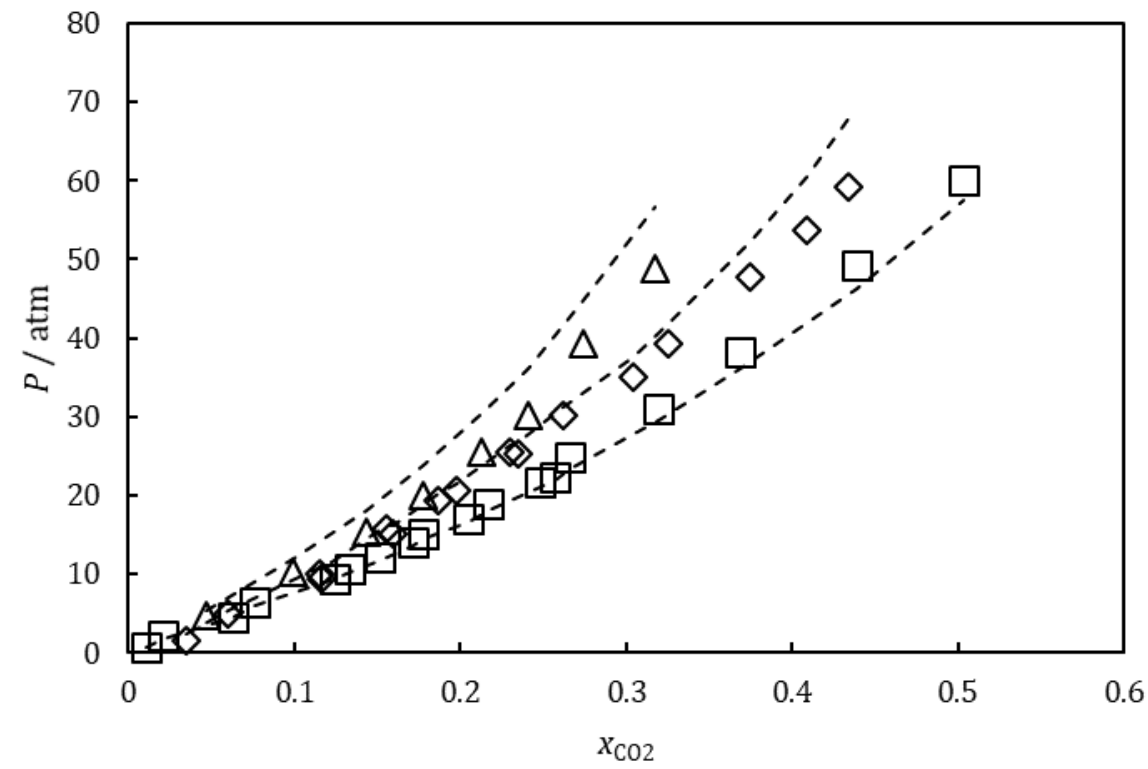

Figure 4. Solubility of $\mathrm{CO}_{2}$ in [EtMeIm] $+\left[\mathrm{Et}_{2} \mathrm{PO}_{4}\right]$ - at $313.15 \mathrm{~K}(\bigcirc) ; 333.15 \mathrm{~K}(\square)$ and 350.15 $\mathrm{K}(\diamond)$ and correlation in dashed lines. 


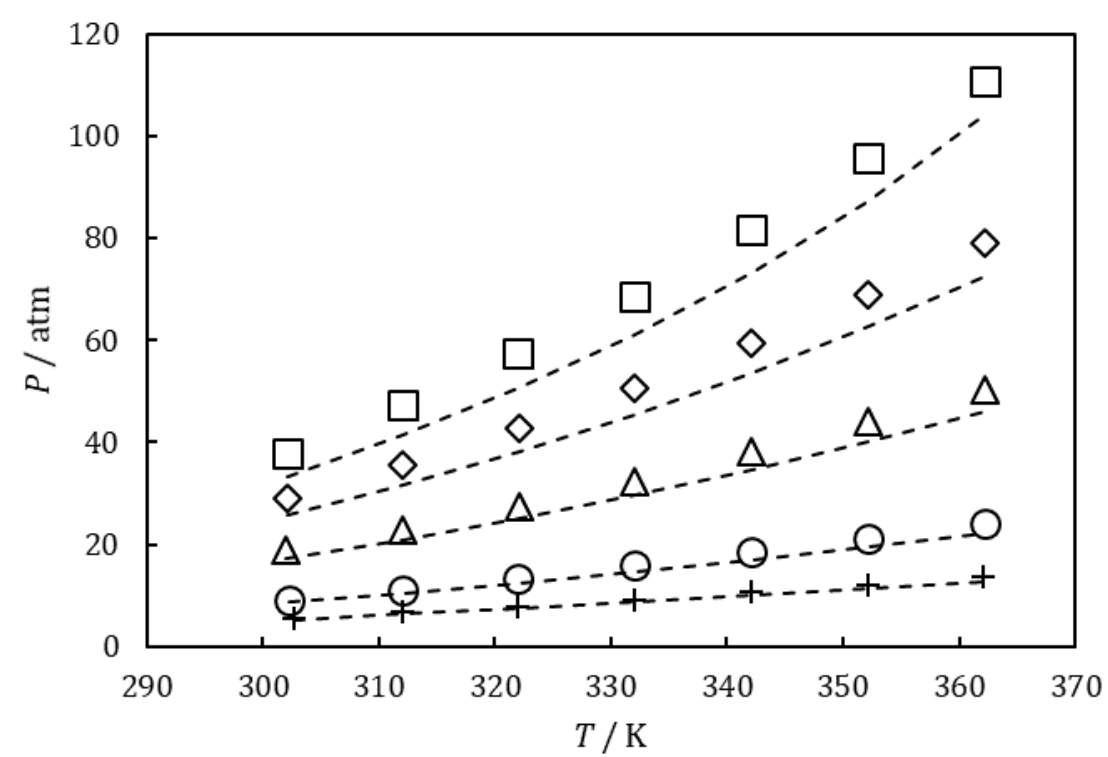

Figure 5. Experimental 25 and correlated (dashed lines) results of the system $\mathrm{CO}_{2}+$ [EtMeIm] ${ }^{+}\left[\mathrm{Et}_{2} \mathrm{PO}_{4}\right]$ - The experiments measure the bubble point of mixtures at concentrations of $x$ co2: $0.084,(+) ; 0.134,(\bigcirc) ; 0.24,(\triangle) ; 0.328,(\diamond)$ and $0.401,(\square)$;

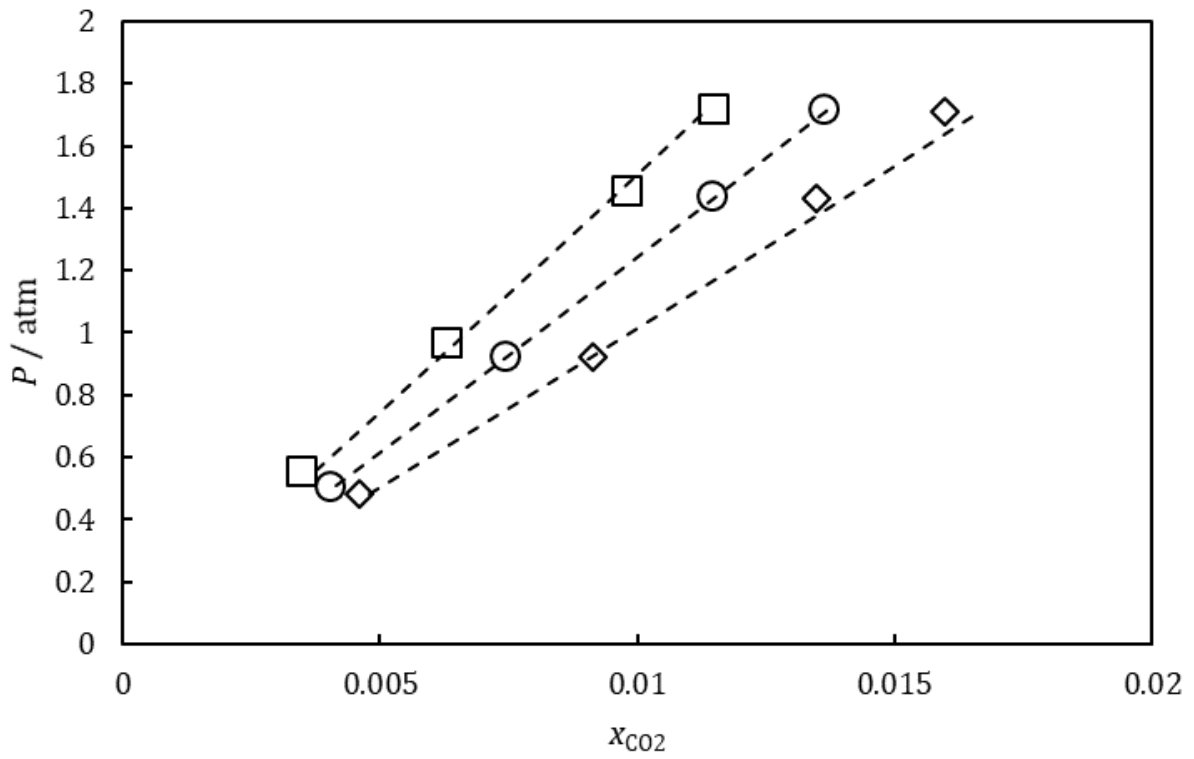

Figure 6. Experimental 23 and correlated (dashed lines) results of the system $\mathrm{CO}_{2}+\left[\mathrm{Me}_{2} \mathrm{Im}\right]^{+}$ $\left[\mathrm{Me}_{2} \mathrm{PO}_{4}\right]-$ at $313.15 \mathrm{~K}(\diamond), 323.15 \mathrm{~K}(\bigcirc)$ and $333.15 \mathrm{~K}(\square)$. 


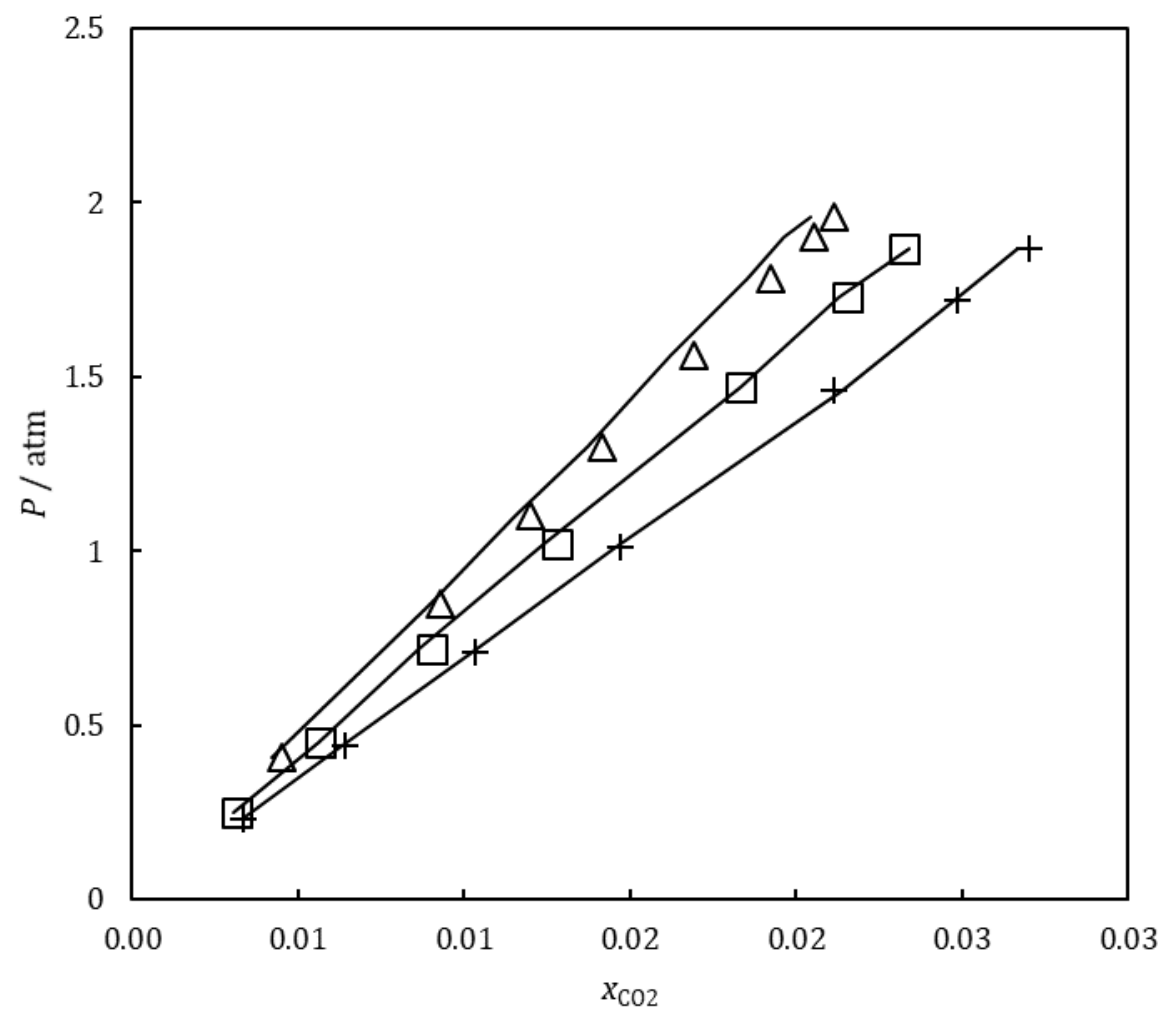

Figure 7. Experimental ${ }^{23}$ and predicted (solid lines) results of the system $\mathrm{CO}_{2}+\left[\right.$ EtMeIm] ${ }^{+}$ $\left[\mathrm{Et}_{2} \mathrm{PO}_{4}\right]$ - at $313.15 \mathrm{~K}(+), 323.15 \mathrm{~K}(\square)$ and $333.15 \mathrm{~K}(\triangle)$.

In Figure 7, the prediction of the equilibrium solubility of the system $\mathrm{CO}_{2}+[$ EtMeIm]+ $\left[\mathrm{Et}_{2} \mathrm{PO}_{4}\right]$ - is presented showing the good prediction capability of the GC-EoS with the new parameters.

Unfortunately, there are no more data available in the literature to challenge the model predictive capacity to describe the solubility of $\mathrm{CO}_{2}$ in other members of the 1-alkyl-3methylimidazolium dimethylphosphate ionic liquid family.

\section{Conclusions}

The solubility of $\mathrm{CO}_{2}$ in [EtMeIm] ${ }^{+}\left[\mathrm{Et}_{2} \mathrm{PO}_{4}\right]^{-}$has been experimentally determined for the temperatures within the range $T=[313.15,333.15,350.15] \mathrm{K}$ and pressures up to 60 bar. The solubility increases with the pressure and decreases with the temperature. The experimental data shows good agreement with the literature data.

The new experimental data, along with literature data, were used to determine the binary interaction parameters with $\mathrm{CO}_{2}$ for two new ionic liquid groups, namely, 1-alkyl-3- 
methylimidazolium dimethylphosphate and 1-alkyl-3-methylimidazolium diethylphosphate with the Group Contribution EoS. The results show that it is possible to describe the VLE with $\mathrm{CO}_{2}$ with an ARD\% $=2.6 \%$ for the 1-alkyl-3-methylimidazolium dimethylphosphate IL family and an ARD $\%=8.9 \%$ for the 1-alkyl-3-methylimidazolium diethylphosphate family.

\section{List of symbols}

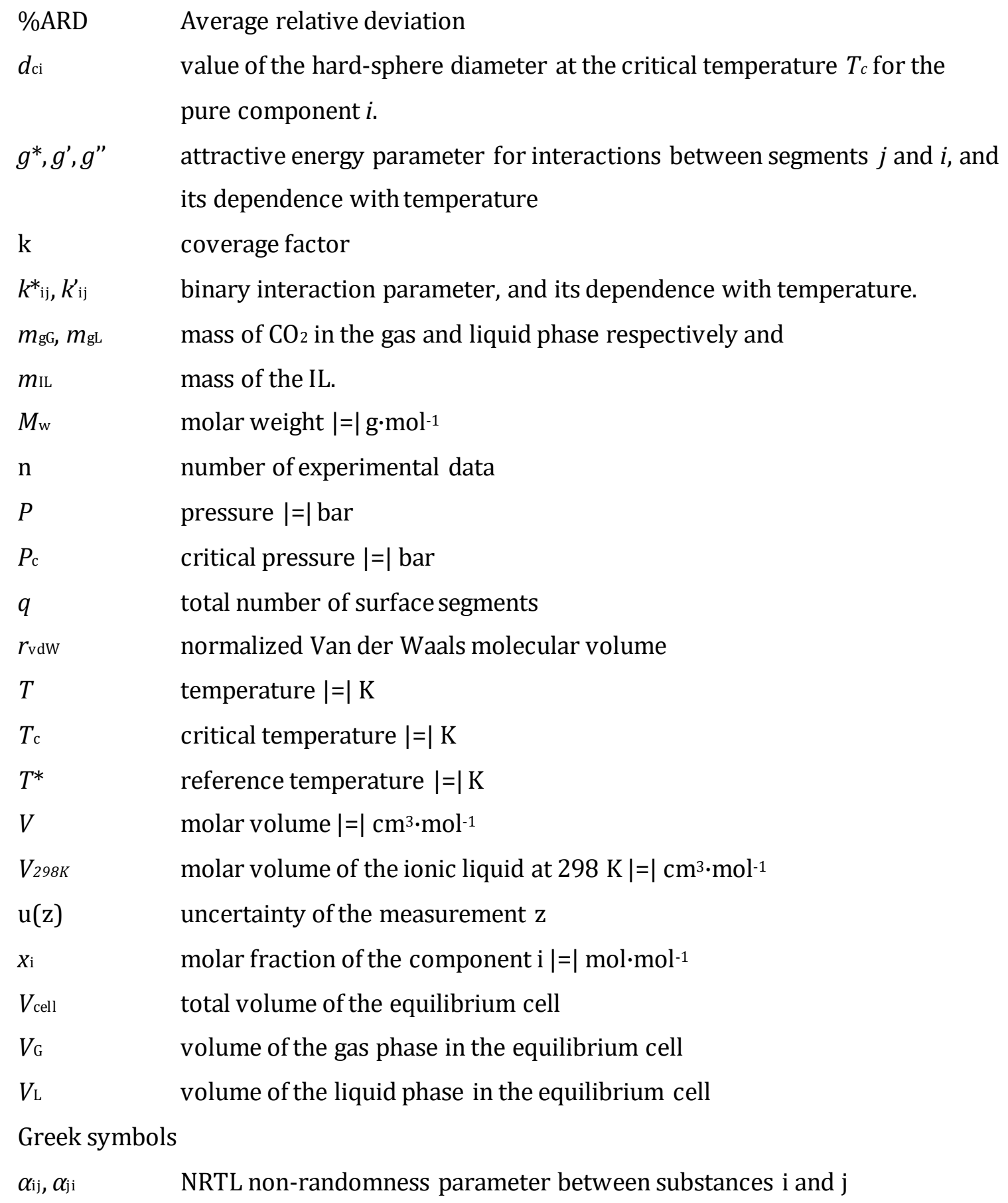




\section{Acknowledgements}

Authors thank MINECO for project ENE2014-53459-R. LP thank the Erasmus Mundus Eurica PhD student grant for the economic support. MDB thanks the Spanish Ministry of Economy and Competitiveness for the Ramón y Cajal research fellowship. 


\section{References}

(1) Raeissi, S.; Peters, C. J.J. Chem. Eng. Data 2009, 54 (2), 382-386.

(2) Shariati, A.; Peters, C. J. J. Supercrit. Fluids 2005, 34 (2 SPEC. ISS.), 171-176.

(3) Gutkowski, K. I.; Shariati, A.; Peters, C. J.J. Supercrit. Fluids 2006, 39 (2), 187-191.

(4) Blanchard, L. A.; Gu, Z.; Brennecke, J. F. J. Phys. Chem. B 2001, 105 (12), 2437-2444.

(5) Moya, C.; Alonso-Morales, N.; de Riva, J.; Morales-Collazo, O.; Brennecke, J. F.; Palomar, J. J. Phys. Chem. B. 2018, 122, 2616-2626.

(6) Raeissi, S.; Peters, C. J. Green Chem. 2009,11 (2), 185-192.

(7) Blanchard, L. a; Hancu, D. Nature 1999,399 (May), 28-29.

(8) Blanchard, L. A.; Brennecke, J. F. Ind. Eng. Chem. Res. 2001, 40 (1), 287-292.

(9) Lopes, J. M.; Sánchez, F. A.; Reartes, S. B. R.; Bermejo, M. D.; Martín, Á.; Cocero, M. J. J. Supercrit. Fluids 2016, 107, 590-604.

(10) Lopes, J. M.; Kareth, S.; Bermejo, M. D.; Martín, Á.; Weidner, E.; Cocero, M. J. J. Supercrit. Fluids 2016, 111, 91-96.

(11) Kazarian, S. G.; Sakellarios, N.; Gordon, C. M. Chemical Communications. 2002, pp 1314-1315.

(12) Scurto, A. M.; Leitner, W. Chemical communications. 2006, pp 3681-3683.

(13) Zakrzewska, M. E.; Rosatella, A. A.; Simeonov, S. P.; Afonso, C. A. M.; Najdanovic-Visak, V.; Nunes da Ponte, M. Fluid Phase Equilib. 2013,354,19-23.

(14) Liu, Z.; Wu, W.; Han, B.; Dong, Z.; Zhao, G.; Wang, J.; Jiang, T.; Yang, G. Chem. - A Eur.J. 2003, 9 (16), 3897-3903.

(15) Lopes, J.; Bermejo, M.; Martín, Á.; Cocero, M. ChemEngineering 2017, 1 (2), 10.

(16) Parra Jimenez de la, Cristina; Navarrete, Alexander; Dolores Bermejo, M.; Jose Cocero, M. Recent Pat. Eng 2012, 6 (3), 159-182.

(17) Brennecke, J. F.; Maginn, E. J. AIChEJ. 2001,47(11), 2384-2389.

(18) Lopes, J. M.; Bermejo, M. D.; Pérez, E.; Martín, Á.; Segovia Puras, J. J.; Cocero, M. J. J. Supercrit. Fluids 2017, No. September, 1-7. 
(19) Liu, Z.; Sun, X.; Hao, M.; Huang, C.; Xue, Z.; Mu, T. Carbohydr. Polym. 2015, 117, 54-62.

(20) Barber, P. S.; Griggs, C. S.; Gurau, G.; Liu, Z.; Li, S.; Li, Z.; Lu, X.; Zhang, S.; Rogers, R. D. Angew. Chemie - Int.Ed. 2013, 52 (47), 12350-12353.

(21) Iguchi, M.; Kasuya, K.; Sato, Y.; Aida, T. M.; Watanabe, M.; Smith, R. L. Cellulose 2013, $20(3), 1353-1367$.

(22) Fukaya, Y.; Hayashi, K.; Wada, M.; Ohno, H. Green Chem. 2008, 10 (1), 44-46.

(23) Palgunadi, J.; Kang, J. E.; Nguyen, D. Q.; Kim, J. H.; Min, B. K.; Lee, S. D.; Kim, H.; Kim, H. S. Thermochim. Acta 2009, 494 (1-2), 94-98.

(24) Mejía, I.; Stanley, K.; Canales, R.; Brennecke, J. F. J. Chem. Eng. Data 2013, 58 (9), 2642-2653.

(25) Ramdin, M.; Amplianitis, A.; Bazhenov, S.; Volkov, A.; Volkov, V.; Vlugt, T. J. H. H.; de Loos, T. W. Ind. Eng. Chem. Res. 2014, 53, 15427-15435.

(26) Skjold-Jørgensen, S. Ind. Eng. Chem. Res. 1988, 27 (1), 110-118.

(27) Breure, B.; Bottini, S. B.; Witkamp, G.; Peters, C. J. J. Phys. Chem. B 2007, 111 (51), 14265-14270.

(28) Bermejo, M. D.; Martin, A.; Foco, G.; Cocero, M. J.; Bottini, S. B.; Peters, C. J.J. Supercrit. Fluids 2009, 50 (2), 112-117.

(29) Martín, Á.; Méndez, D.; Bermejo, M. D. J. Chem. Thermodyn. 2010, 42 (Vl), 524-529.

(30) Bermejo, M. D.; Méndez, D.; Martín, Á. Ind. Eng. Chem. Res. 2010, 49 (10), 4966-4973.

(31) González, E. J.; Bottini, S. B.; Macedo, E. A. Fluid Phase Equilib. 2015, 387, 32-37.

(32) Pereda, S.; Raeissi, S.; Andreatta, A. E.; Bottini, S. B.; Kroon, M.; Peters, C. J. Fluid Phase Equilib. 2016, 409, 408-416.

(33) Prieto, M. G.; Sánchez, F. A.; Pereda, S. Ind. Eng. Chem. Res. 2015, 54 (49), 1241512427.

(34) Mota Martinez, M. T.; Kroon, M. C.; Peters, C. J. J. Supercrit. Fluids 2015, 101, 54-62.

(35) Gibbs, R. E.; Van Ness, H. C. Ind. Eng. Chem. Fundam. 1972, 11 (3), 410-413.

(36) Lemmon, E.W.; Span, R. J. Chem. Eng. Data 2006, 51, 785-850.

(37) Skjold-Jørgensen, S. Fluid Phase Equilib. 1984, 16 (3), 317-351. 
(38) Mansoori, G. A.; Carnahan, N. F.; Starling, K. E.; Leland, T. W. J. Chem. Phys. 1971, 54 (4), 1523-1525.

(39) Renon, H.; Pruasnitz, J. M. AIChE J. 1968, 14 (1), 116-128.

(40) Espinosa, S.; Fornari, T.; Bottini, S. B.; Brignole, E. A. J. Supercrit. Fluids 2002, 23 (2), 91-102.

(41) Cai, F.; Ibrahim, J. J.; Gao, L.; Wei, R.; Xiao, G. Fluid Phase Equilib. 2014, 382, 254-259.

(42) Freire, M. G.; Teles, A. R. R.; Rocha, M. A. A.; Schröder, B.; Neves, C. M. S. S.; Carvalho, P. J.; Evtuguin, D. V.; Santos, L. M. N. B. F.; Coutinho, J. A. P. J. Chem. Eng. Data 2011, $56(12), 4813-4822$.

(43) Gong, Y.; Shen, C.; Lu, Y.; Meng, H.; Li, C. J. Chem. Eng. Data 2012, 57, 33-39.

(44) Wang, J.; Li, C.; Shen, C.; Wang, Z. Fluid Phase Equilib. 2009, 279 (2), 87-91.

(45) Fornari, T. Fluid Phase Equilib. 2007,262 (1-2), 187-209.

(46) Valderrama, J. O.; Rojas, R. E. Ind. \{\&\} Eng. Chem. Res. 2009, 48 (14), 6890-6900. 


\section{Conclusions}


In this thesis, thermodynamic data of several ionic liquids of interest for biomass processing were determined and correlated. In particular:

- Densities, viscosities and vapor pressures of mixtures DMSO + [Amim][Cl] were determined at atmospheric pressure and densities also at high pressures up to $35 \mathrm{MPa}$ at temperatures between $293.15 \mathrm{~K}$ and $373.15 \mathrm{~K}$ and $x_{\text {DMSO }}=0,0.050 .1,0.15,0.25,0.5,0.75$, 0.9 and 1.

- It wasfound that density decreases with temperature and DMSO molar fraction and increases with pressure. It was correlated as a function of the temperature, pressure and composition of the mixture. A good fitting has been achieved with an \%ARD = $0.12 \%$. Excess molar volumes of the mixtures were calculated using experimental densities. They were found to be negative with a minimum around $x_{\mathrm{DMSO}}=0.5$

- Viscosities were found to decrease with temperature and with DMSO concentration. Correlation of viscosity was made as a function of temperature and concentration with two modifications of Grunberg and Nissan correlation, one for the whole range of concentrations and a second one for concentrations lower than 0.25 in DMSO molar fraction. The first one has an average relative deviation (ARD\%) $=6.8 \%$ and $\% \operatorname{Max}=30.7 \%$, The second one has an ARD $\%=16.3 \%$ and $\% \operatorname{Max}=45.2 \%$.

Vapor pressures of mixtures DMSO $+[\mathrm{Amim}][\mathrm{Cl}]$ were measured at $\mathrm{T}=[353.1$, 433.1] K. Positive deviations were observed at low DMSO concentrations while at high concentration the behavior approximates the Raoult's Law. The measurements were correlated with Non-Random-Two-Liquid (NRTL) model, obtaining ARD\% between 5 and $12 \%$.

- Experimental densities and viscosities of mixtures water (1) +1-ethyl-3methylimidazolium diethylphosphate and DMSO (2) + 1-ethyl-3-methylimidazolium diethylphosphate were determined in a range of temperature between $293.15 \mathrm{~K}$ and 373.15 K and molar fractions of co-solvent 0, 0.05, 0.1, 0.15, 0.25, 0.5, 0.75, 0.9 and 1. Excess molar volumes were also calculated presenting both systems negative excess molar volumes.

- Viscosities were found to decrease with temperature and co-solvent concentration. Viscosity data were correlated with modified Grunberg and Nissan correlations, achieving good results with \%AARD $=13 \%$ for the mixtures with water and \%AARD $=9.5 \%$ for the mixtures with DMSO

- Densities were found to decrease linearly with the temperature and with the cosolvent concentration. The system studied present positive deviation from the ideal behavior, which implies negative excess volume. The mixtures of ionic liquid with water are less ideal than the mixtures with DMSO, the influence of the temperature 
of both systems in the excess volume is completely reversed, while in the aqueous mixtures the absolute value of the excess volume decreases with the temperature, in the IL - DMSO mixtures increases with temperature.

-The GC-EoS table of parameters was extended to model two new families of ionic liquids, namely, 1-alkyl-3-methylimidazolium dimethylphosphate and 1-alkyl-3methylimidazolium diethylphosphate. This required the definition of two new groups, (MeImMe $\left.\mathrm{PO}_{4}\right)$ and $\left(-\mathrm{MeImEt}_{2} \mathrm{PO}_{4}\right)$, and fit their pure energy and binary interaction parameters with other functional groups: $\mathrm{CH}_{3}, \mathrm{CH}_{2}, \mathrm{ACH}, \mathrm{AC}, \mathrm{ACCH} 3, \mathrm{CH}_{2}=\mathrm{CH}$ and $\mathrm{CO}_{2}$. The results show a good correlation of the experimental data; it is possible to describe infinite dilution activity coefficient $(\gamma)$ with an ARD $\%(\gamma)$ of $4.52 \%$.

-The solubility of $\mathrm{CO}_{2}$ in $[\mathrm{EtMeIm}]+\left[\mathrm{Et}_{2} \mathrm{PO}_{4}\right]^{-}$has been experimentally determined for the temperatures within the range $T=[313.15,333.15,350.15] \mathrm{K}$ and pressures up to 60 bar. The solubility increases with the pressure and decrease with the temperature. The solubilities reached values up to 0.5 molar fraction at $313.15 \mathrm{~K}$ and $60 \mathrm{bar}$. It is possible to describe the VLE with $\mathrm{CO}_{2}$ using GC EoS with an ARD\% $=2.6 \%$ for the 1-alkyl-3methylimidazolium dimethylphosphate IL family and an ARD $\%=8.9 \%$ for the 1 -alkyl-3methylimidazolium diethylphosphate family using the new parameters determined in this work.

\section{Future work}

- Measure the density and viscosity of $\left[\right.$ EtMeIm] $\left[\mathrm{Et}_{2} \mathrm{PO}_{4}\right]$ and $[\mathrm{Amim}][\mathrm{Cl}]$ with $\mathrm{CO}_{2}$ at different pressures and temperatures.

- Measure the solubility of $\mathrm{CO}_{2}$ in $[\mathrm{Amim}][\mathrm{Cl}]$ and other ILs of interest for cellulose processing. 
Resumen

Determinación experimental y modelado de las propiedades físicas y equilibrio de fases en mezclas de líquidos iónicos disolventes de celulosa con cosolventes seleccionados 
El uso sostenible de los recursos y el aprovechamiento de nuevas fuentes de recursos hacen que haya habido un creciente interés en los líquidos iónicos y en el desarrollo de nuevas tecnologías que impliquen a los mismos. Los líquidos iónicos basados en dialquilfosfatos de imidazolio y en cloruros de imidazolio han demostrado sus capacidades de disolución de celulosa, materia prima presente en abundancia en nuestro planeta. La disolución de celulosa en un medio liquido facilita enormemente su uso como reactivo y posibilita la obtención de productos de enorme valor añadido. Esto hace posible un uso antes imposible de la celulosa como materia prima.

Los líquidos iónicos presumen de tener unas presiones de vapor extremadamente bajos por lo que pueden ser utilizados como alternativa no volátil a disolventes convencionales. Los líquidos iónicos tienen una viscosidad alta, por lo que los costes de procesado para su uso industrial aumentan, especialmente en los líquidos iónicos que disuelven celulosa, cuyas mezclas pueden presentar viscosidades considerables. Por ello es común el uso de cosolventes, como el sulfóxido de dimetilo (DMSO por sus siglas en inglés) y el $\mathrm{CO}_{2}$. Estas sustancias disminuyen la viscosidad de las mezclas conservando la capacidad de disolución de celulosa de los líquidos iónicos. Tanto los líquidos iónicos como el DMSO son altamente higroscópicos por lo que la presencia de agua es común en estas mezclas, y de ahí la importancia de la medida de la contribución del agua a las propiedades físicas como la viscosidad y la densidad.

Debido a su naturaleza, los líquidos iónicos pueden creados y modificados para cada uso específico, ya sea por combinación de los cationes y aniones o por la sustitución de las cadenas laterales de los mismos que modifican sus propiedades físico-químicas. Debido a ello, son muy numerosas las combinaciones posibles, por lo que muchos líquidos iónicos carecen de muchas mediciones de sus propiedades fundamentales en la bibliografía.

Las propiedades físicas fundamentales, como la densidad, la viscosidad y el equilibrio de fases son propiedades de gran importancia en la industria, ya que sin el conocimiento preciso de esas propiedades sería imposible el desarrollo de nuevas tecnologías que impliquen los líquidos iónicos. En este contexto, la ecuación de estado de contribución de grupos posibilita la simulación de las propiedades de equilibrio de multitud de sistemas. Por eso es de vital importancia la parametrización de nuevos grupos para que puedan ser simuladas mezclas que contengan los líquidos iónicos antes mencionados.

En esta tesis se desarrolla un estudio de las propiedades termodinámicas de los líquidos iónicos, entre las cuales se miden propiedades fundamentales como la densidad, la viscosidad, el equilibrio de fases de líquidos iónicos comunes en su uso por su capacidad de 
disolución de celulosa y además se ajustan nuevos parámetros para la ecuación de estado de contribución de grupos.

Los objetivos perseguidos en esta tesis son:

1 Determinación experimental y correlación de la densidad y viscosidad de [Amim] [Cl] y [EtMeIm] $\left[\mathrm{Et}_{2} \mathrm{PO}_{4}\right]$ con agua y DMSO como cosolventes.

2 Adaptación de la ecuación de estado de contribución de grupos para la correlación de equilibrios con líquidos iónicos de la familia de los alquilfosfatos.

3 Determinación del equilibrio $\mathrm{CO}_{2}+[\mathrm{EtMeIm}]\left[\mathrm{Et}_{2} \mathrm{PO}_{4}\right]$ a diferentes temperaturas.

En la Parte I consiste en una revisión bibliográfica del estado del arte actual de los Líquidos Iónicos. En el Capítulo 1 se describen las principales propiedades de los líquidos iónicosy su aplicabilidad como disolventes de celulosa, así como otras posibles aplicaciones. Los mecanismos de disolución y el papel que cumple el anión y el catión para ese propósito. Un detallado resumen de los líquidos iónicos y sus principales aplicaciones de las familias estudiadas en esta tesis, los cloruros y dialquilfosfatos de imidazolio. El comportamiento de los líquidos iónicos con diferentes sustancias se ha estudiado ampliamente. Estas sustancias, usadas como cosolventes y como antisolventes, están descritas en esta tesis. La relación entre el $\mathrm{CO}_{2}$ y los líquidos iónicos, sus posibilidades y efectos también está detallada.

En la Parte II de esta tesis se presenta la densidad y viscosidad de los líquidos iónicos capaces de disolver celulosa. Esta parte consta de tres capítulos.

ElCapítulo 2 trata sobre la medida de densidad, viscosidad y presión de vapor de la mezcla DMSO + [Amim $][\mathrm{Cl}]$ a presión atmosférica. La densidad disminuye con al aumentar la temperatura y la concentración de DMSO tal y como se aprecia en la Figura 1. 


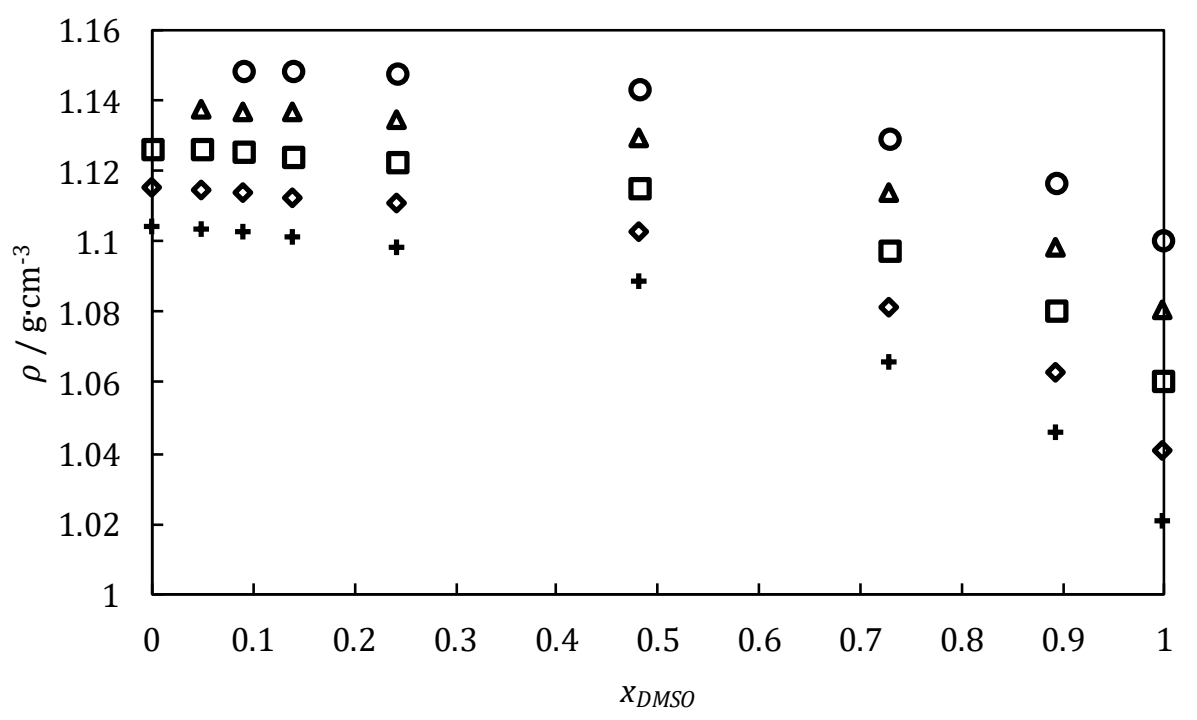

Figura 1. Densidades de mezclas binarias DMSO + [Amim $][\mathrm{Cl}]$ a presión atmosférica a temperaturas: $293.15 \mathrm{~K}(\bigcirc)$; $313.15 \mathrm{~K}(\triangle)$; $333.15 \mathrm{~K}(\square)$; $353.15 \mathrm{~K}(\diamond)$ y $373.15 \mathrm{~K}(+)$.

La viscosidad fue correlacionada con la ecuación modificada de Grunberg y Nissan. Dos correlaciones de la viscosidad fueron hechas para diferentes rangos de concentraciones. La primera para todo el rango de concentraciones y la segunda solo para concentraciones menores de 0.25 en fracción molar de DMSO. Las desviaciones en las correlaciones son el $6.8 \%$ y el $16.3 \%$ respectivamente. En la Figura 2 se representa las viscosidades medidas en todo el rango de concentraciones. Las presiones de vapor fueron correlacionadas con el modelo NRTL y los resultados de la correlación se muestran en la Figura 3. 


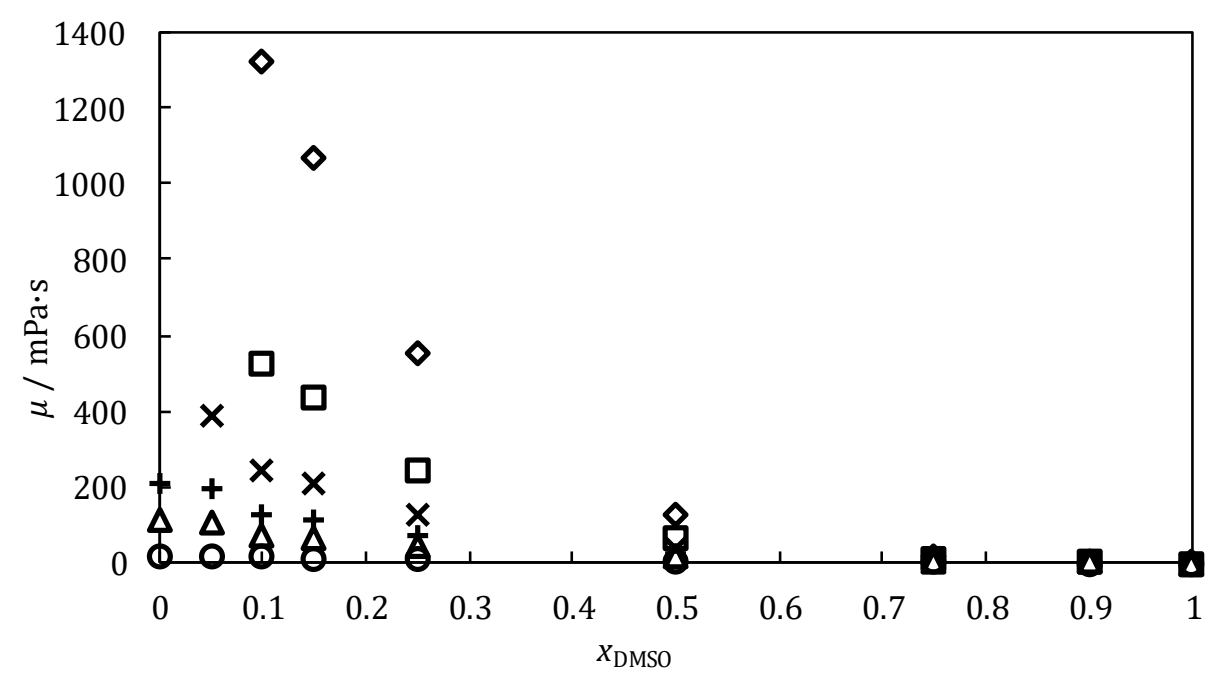

Figura 2. Viscosidades de mezcla binaria DMSO + [Amim][Cl] a presión atmosférica y 293.15 $\mathrm{K}(\diamond) ; 303.15 \mathrm{~K}(\square) ; 313.15 \mathrm{~K}(\times)$; 323.15 K $(+)$; 333.15 K $(\triangle)$ and 373.15 K $(\bigcirc)$.

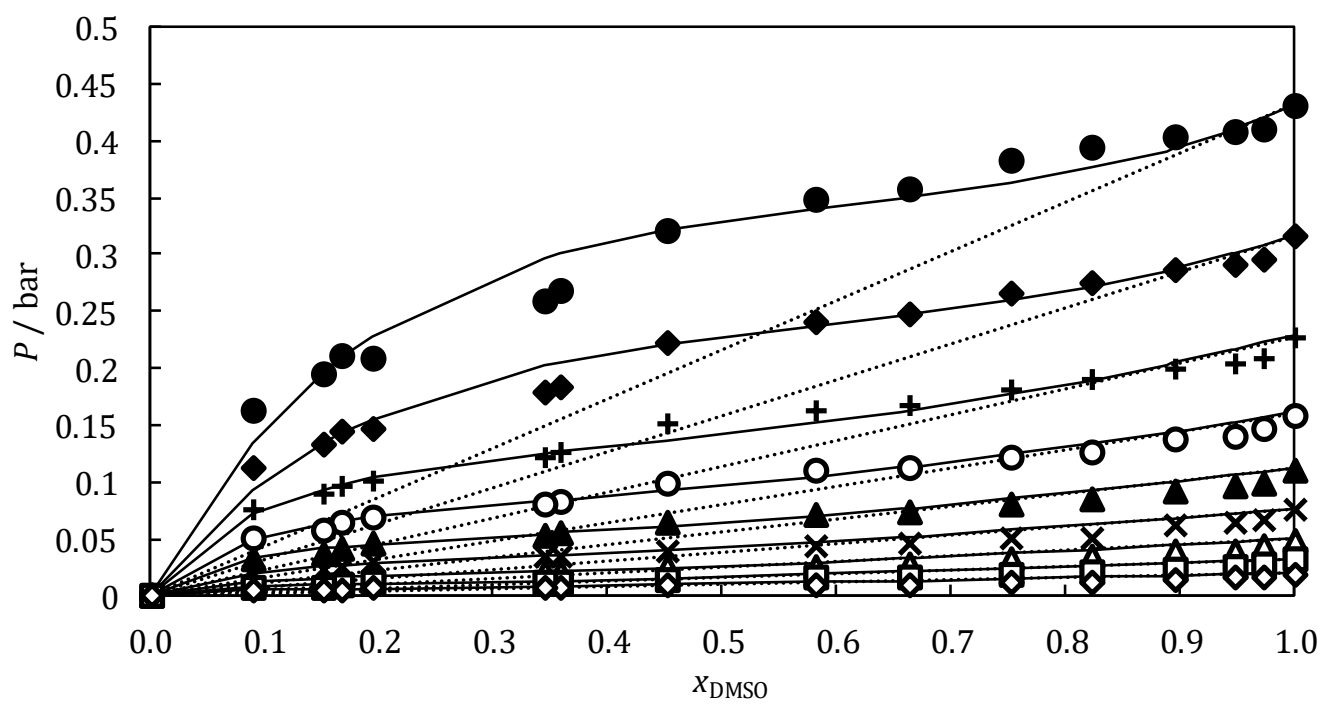

Figura 3. Presiones de vapor experimentales de la mezcla binaria DMSO + $[\mathrm{Amim}][\mathrm{Cl}] \mathrm{a}$

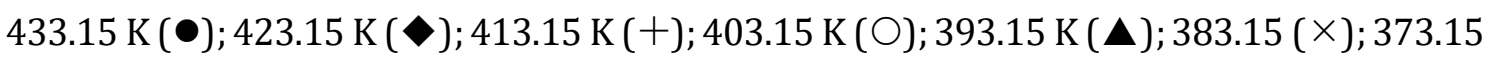
$\mathrm{K}(\triangle)$; $363.15 \mathrm{~K}(\square) ; 353.15 \mathrm{~K}(\diamond)$. Los símbolos representan los puntos experimentales, las líneas solidas representan la correlación con NRTL. Las líneas punteadas representan la predicción de la Ley de Raoult.

En el Capítulo 3 se determina de la densidad y volumen de exceso molar de DMSO y $[\mathrm{Amim}][\mathrm{Cl}]$ a alta presión. Los datos experimentales obtenidas se representan en la Figura 4. La densidad tiene una tendencia linear con la presión y la temperatura, incrementando con la concentración de líquido iónico, la presión y disminuyendo con la temperatura. El 
volumen molar de exceso es representado en función de la temperatura y a varias presiones en la Figura 5, obteniéndose un comportamiento no observado hasta entonces en los líquidos iónicos, un máximo del volumen de exceso a temperaturas cercanas a $333.15 \mathrm{~K}$, cercanas a la temperatura de fusión del líquido iónico, que es $324 \mathrm{~K}$ (según Lopes et al.). Hasta donde sabemos, este comportamiento no ha sido descrito antes por otros autores.

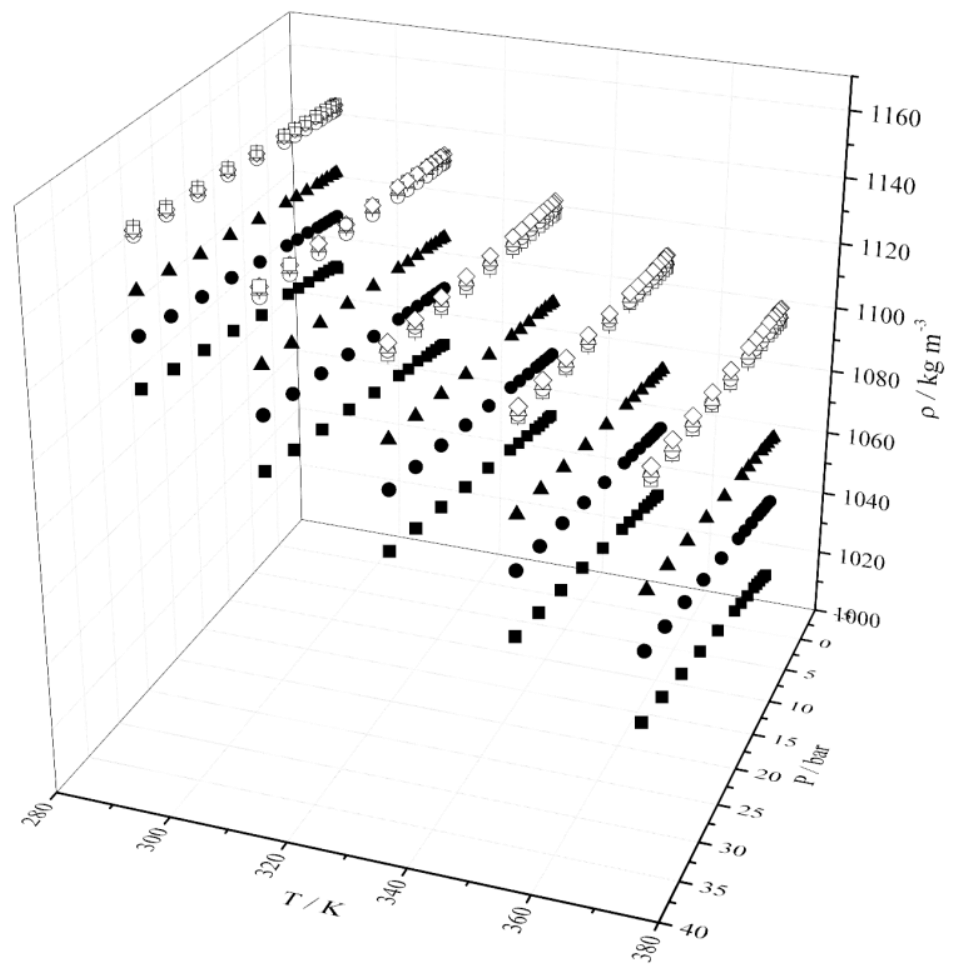

Figura 4. Representacion gráfica de las desidades del sistema DMSO + [Amim] [Cl] a las concentraciones molares $x_{\text {DMSO }}=0.999(\boldsymbol{\square}) ; 0.893(\bullet)$; $0.729(\mathbf{\Delta}) ; 0.495(\diamond) ; 0.247(+)$; $0.147(\square) ; 0.098(\bigcirc) ; 0.048(\triangle) ; 0.000(\diamond)$. 
a) $x_{\text {DMSO }}=0.241$

$T / \mathrm{K}$

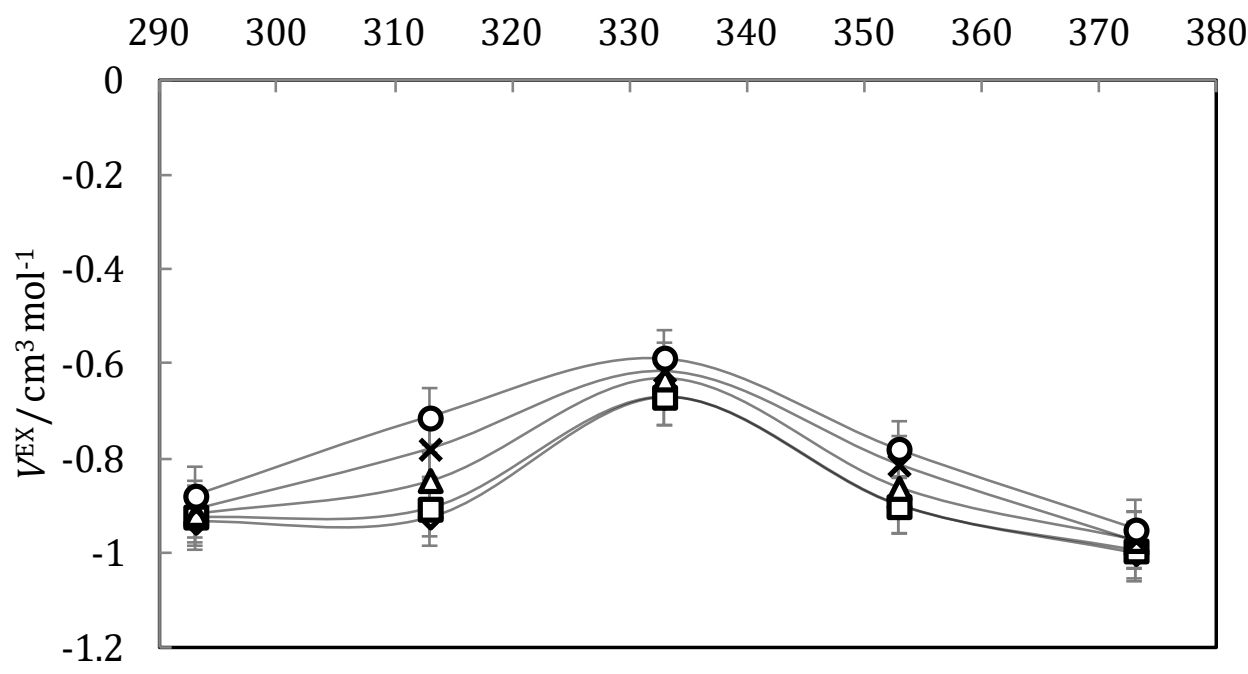

b) $X_{\text {DMSO }}=0.140$

$T / \mathrm{K}$

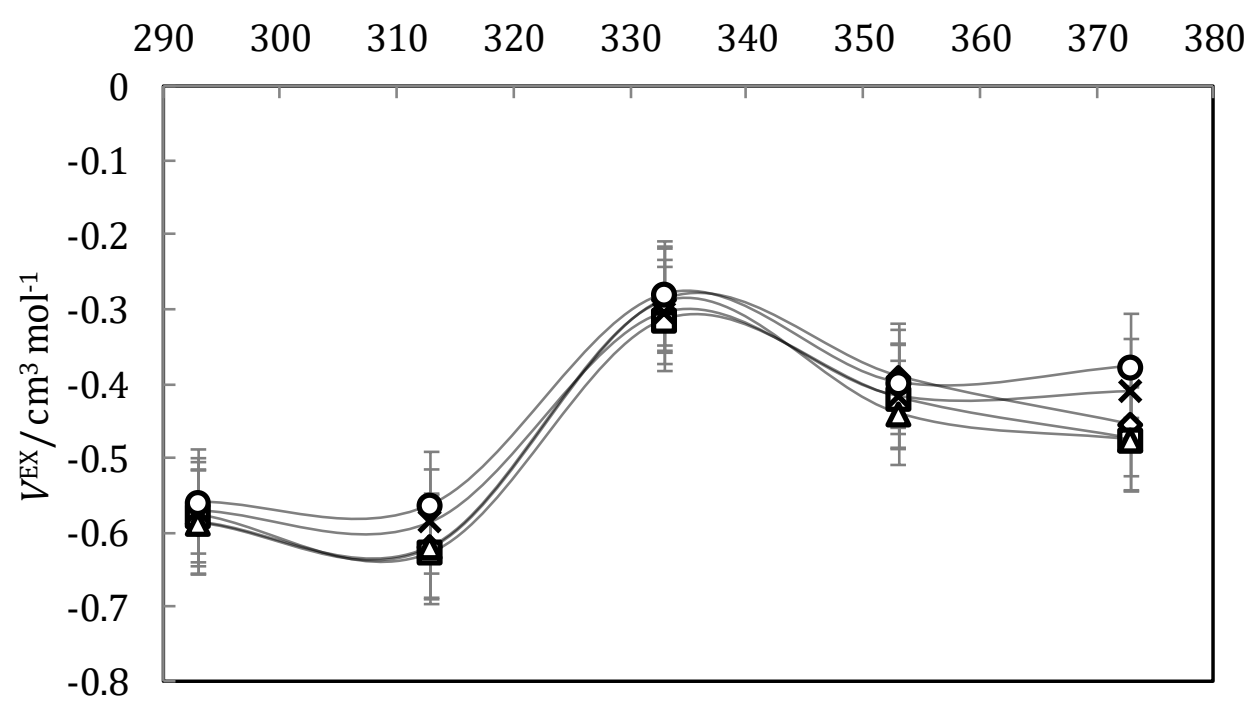

Figura 5. Influencia de la temperatura en el volumen de exceso en las mezclas a) $x_{\mathrm{DMSO}}=$ 0.241 y b) $x_{\text {DMSO }}=0.14$ a $0.1 \mathrm{MPa}(\diamond) ; 2 \mathrm{MPa}(\square) ; 6 \mathrm{MPa}(\triangle) ; 20 \mathrm{MPa}(\times)$ y $35 \mathrm{MPa}(\bigcirc)$. Las líneas son representadas como una guía de los datos.

Una hipótesis para este comportamiento es que hay dos contribuciones en el volumen de exceso, a temperaturas más bajas las moléculas están más cerca y las interacciones son más fuertes, y a temperaturas más altas hay más volumen libre "disponible" y las moléculas pueden acomodarse allí. Y, por lo tanto, a 333,15 K, en medio del rango de temperatura, las dos contribuciones tienen un efecto menor. Este mismo comportamiento puede observarse a otras concentraciones en la Figura 6. 


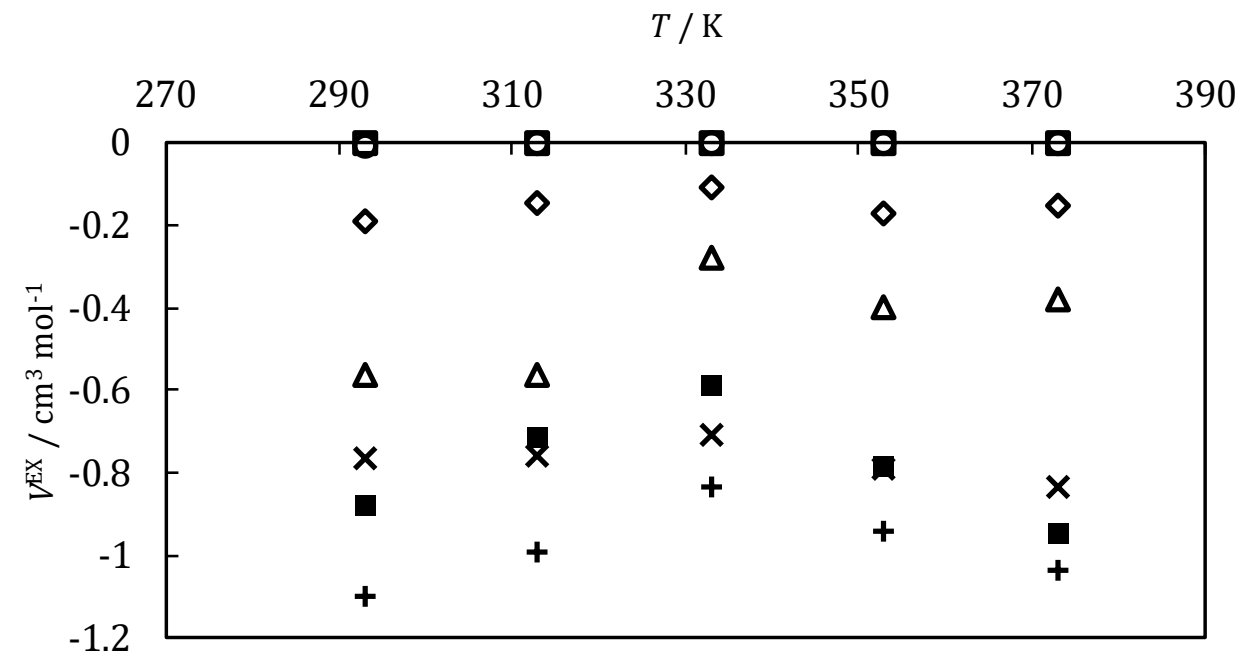

Figura 6. Volumen de exceso molar a 35 MPa у а $x_{\text {DMSO }}=0.999(\bigcirc) ; 0.728(\times) ; 0.482(+)$; $0.241(\square) ; 0.140(\Delta) ; 0.048(\diamond) ; 0.000(\square)$.

Los datos de densidad fueros correlacionados con la ecuación empírica (1)

$$
\rho=A+B \cdot P+C \cdot T
$$

Donde $A, B$ y $C$ son a su vez función de la concentración de DMSO $x_{\text {DMSO. }}$

Los resultados del ajuste se representan en la Figura 7, obteniéndose un buen ajuste con un $\%$ ARD del $0.12 \%$.

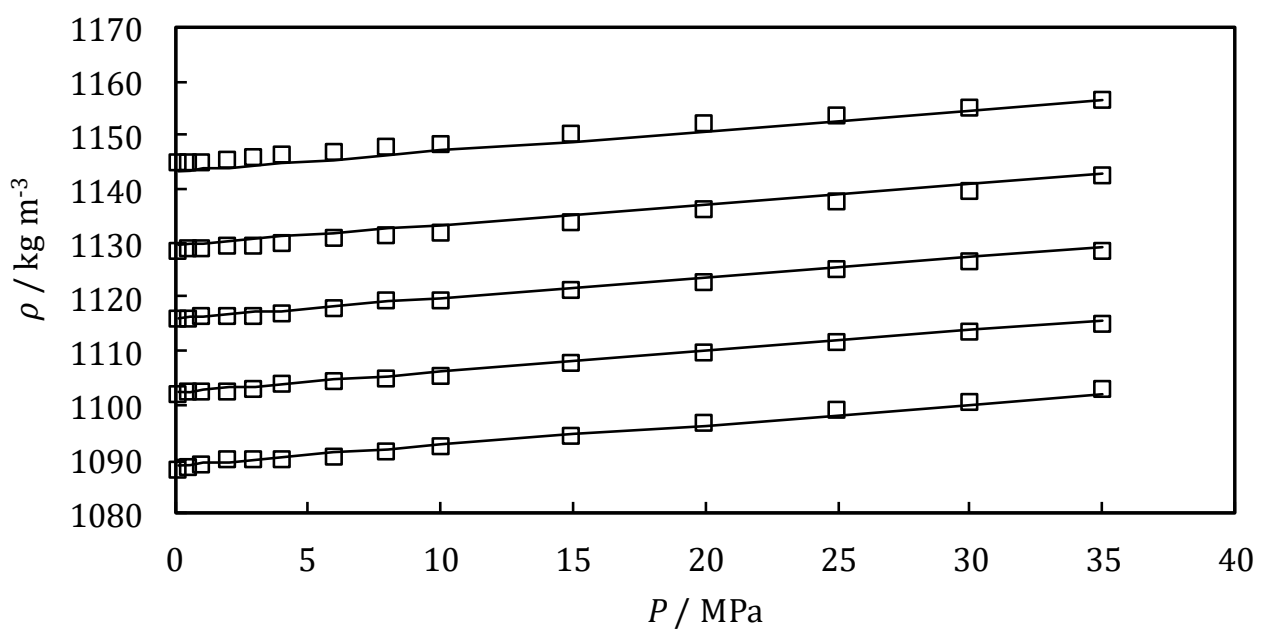

Figure 7. Comparación entre los datos experimentales y los correlacionados a diferentes temperaturas; puntos experimentales con cuadrados abiertos, puntos correlacionados con líneas sólidas. Datos para la mezcla $X_{\text {DMSO }}=0.496$. 
En el Capítulo 4 se miden las densidades y viscosidades del líquido iónico cloruro de 1-etil3-metilimidazolium dietilfosfato ([EtMeIm] $]^{+}\left[\mathrm{Et}_{2} \mathrm{PO}_{4}\right]^{-}$) en mezclas binarias con agua y dimetil sulfoxido (DMSO) a presión atmosférica y temperaturas entre 293.15 K y 373.15 K. En las Figuras 8 y 9 se pueden observar las densidades experimentales de las mezclas de $[$ EtMeIm] $]\left[\mathrm{Et}_{2} \mathrm{PO}_{4}\right]^{-}$con agua y DMSO respectivamente.

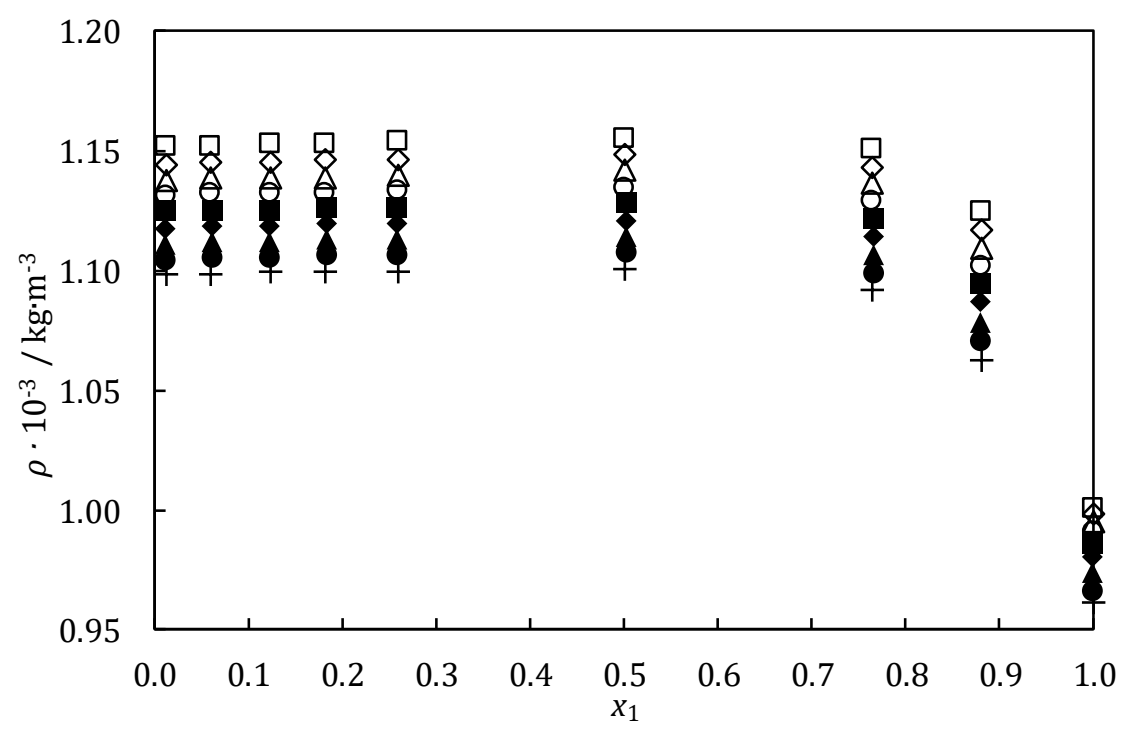

Figura 8. Densidades experimentales $\rho$ de mezclas de $\mathrm{H}_{2} \mathrm{O}(1)+\left[\mathrm{EtMeIm}+\left[\mathrm{Et}_{2} \mathrm{PO}_{4}\right]\right.$ - a 293.15

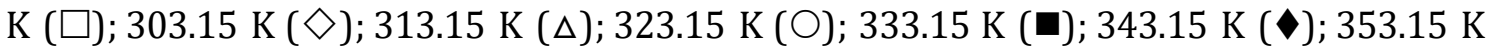
(A); $363.15 \mathrm{~K}(\bullet) ; 373.15 \mathrm{~K}(+)$, en función de la fracción molar de agua $x_{1}$.

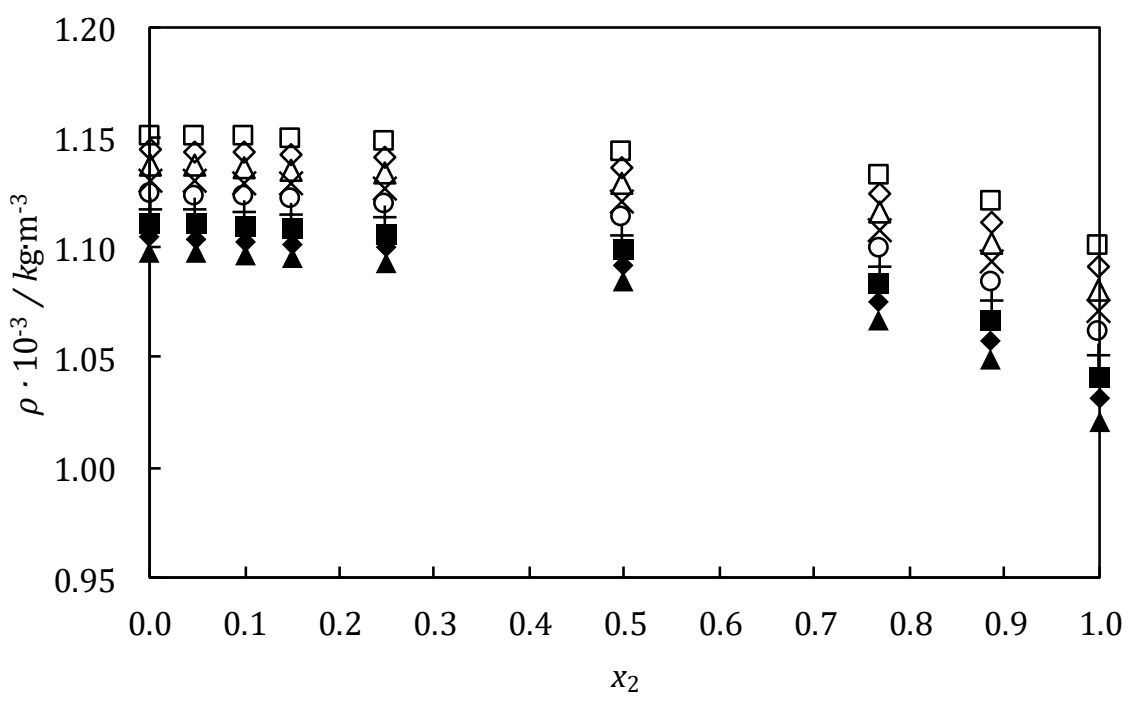

Figura 9. Densidades experimentales $\rho$ de mezclas de DMSO (2) + [EtMeIm] ${ }^{+}\left[\mathrm{Et}_{2} \mathrm{PO}_{4}\right]^{-\mathrm{a}}$ $293.15 \mathrm{~K}(\square)$; $303.15 \mathrm{~K}(\diamond) ; 313.15 \mathrm{~K}(\Delta) ; 323.15 \mathrm{~K}(\mathbf{X})$; $333.15 \mathrm{~K}(\bigcirc)$; $343.15 \mathrm{~K}(\boldsymbol{+})$; 353.15 K ( $\boldsymbol{\square})$; $363.15 \mathrm{~K}(\diamond) ; 373.15 \mathrm{~K}(\boldsymbol{\Delta})$, en función de la fracción molar de DMSO $x_{2}$. 
Los volúmenes de exceso obtenidos se representan en las Figuras 10 y 11. Como puede observarse, las mezclas de líquido iónico con agua son menos ideales.

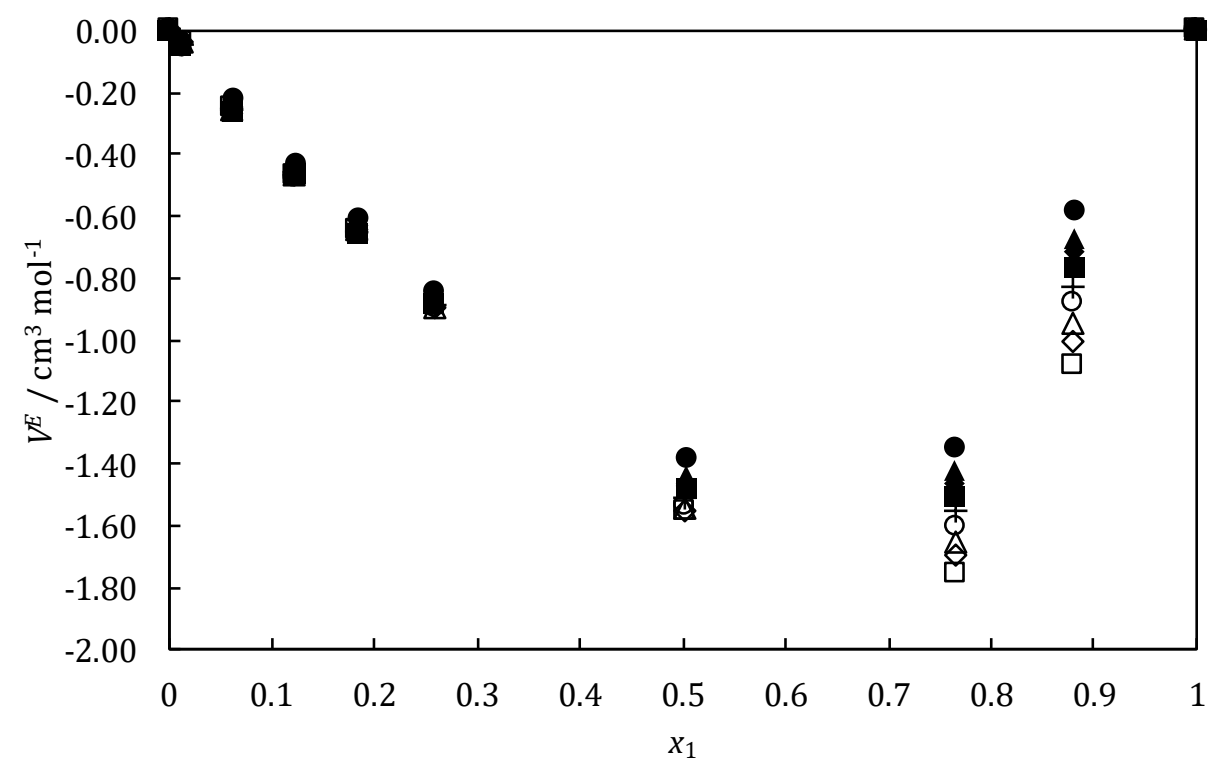

Figura 10. Volúmenes de exceso $\left(V^{E}\right)$ de mezclas de $\mathrm{H}_{2} \mathrm{O}(1)+[$ EtMeIm] $]\left[\mathrm{Et}_{2} \mathrm{PO}_{4}\right]$ - a 293.15 $\mathrm{K}(\square) ; 303.15 \mathrm{~K}(\diamond) ; 313.15 \mathrm{~K}(\Delta)$; $323.15 \mathrm{~K}(\bigcirc)$; $333.15 \mathrm{~K}(\boldsymbol{+})$; $343.15 \mathrm{~K}(\boldsymbol{\square}) ; 353.15 \mathrm{~K}$ $(\diamond) ; 363.15 \mathrm{~K}(\boldsymbol{\Delta}) ; 373.15 \mathrm{~K}(\bullet)$, en función de la fracción molar de agua $x_{1}$.

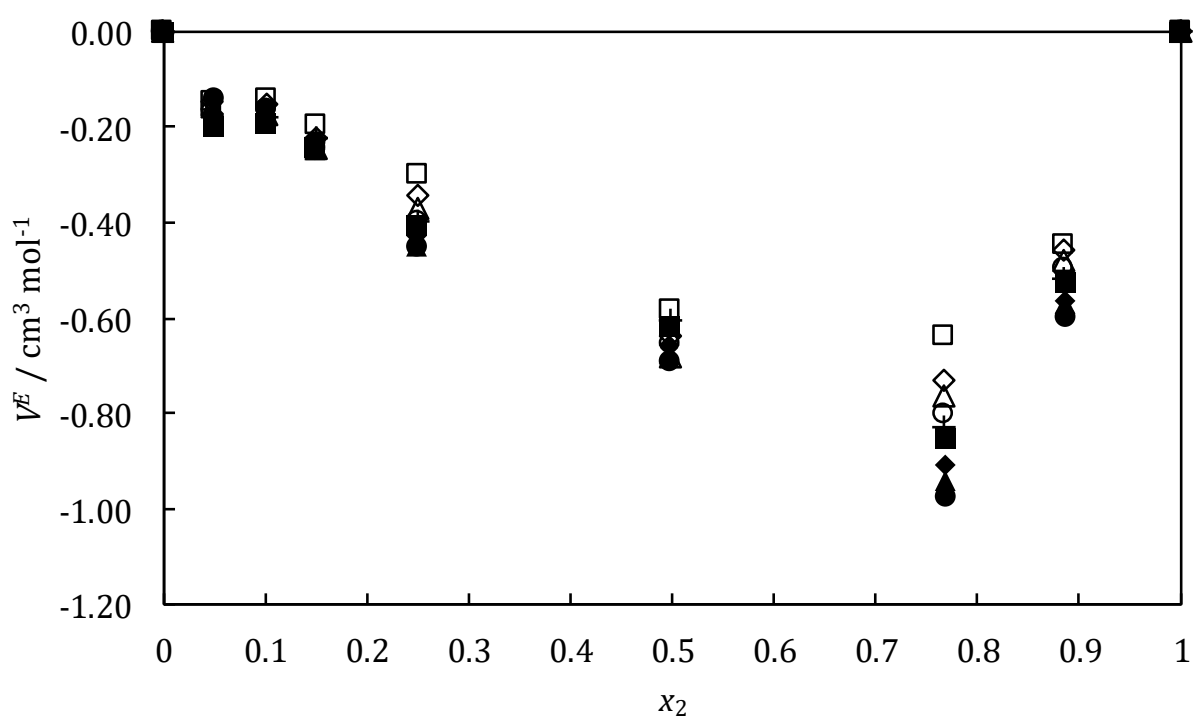

Figura 11. Volúmenes de exceso $(V E)$ de mezclas de DMSO (2) + [EtMeIm]+[Et $\left.\mathrm{PO}_{4}\right]$ - a 293.15 $\mathrm{K}(\square) ; 303.15 \mathrm{~K}(\diamond) ; 313.15 \mathrm{~K}(\Delta)$; $323.15 \mathrm{~K}(\bigcirc) ; 333.15 \mathrm{~K}(+) ; 343.15 \mathrm{~K}(\boldsymbol{\nabla}) ; 353.15 \mathrm{~K}$ $(\diamond) ; 363.15 \mathrm{~K}(\mathbf{\Delta})$; $373.15 \mathrm{~K}(\bullet)$, en función de la fracción molar de DMSO $x_{2}$. 
Sin embargo, la dependencia del volumen de exceso es diferente para ambas mezclas. En mezclas acuosas, el valor absoluto del volumen de exceso disminuye con la temperatura, en las mezclas con DMSO el valor absoluto del volumen de exceso aumenta con la temperatura. La explicación de este comportamiento puede ser que la temperatura aumenta la disponibilidad de "volumen libre" y la mezcla tiene, de esta manera, una mayor capacidad para "acomodar" moléculas DMSO en su estructura.

La viscosidad de ambas mezclas binarias se determinó con un viscosímetro Stabinger. Ylos resultados fueron ajustados con dos modificaciones de la ecuación Grunberg and Nissan. Los resultados del ajuste se muestran en las Figuras 12 y 13 obteniéndose un \%AARD de $13 \%$ y $9.5 \%$ respectivamente

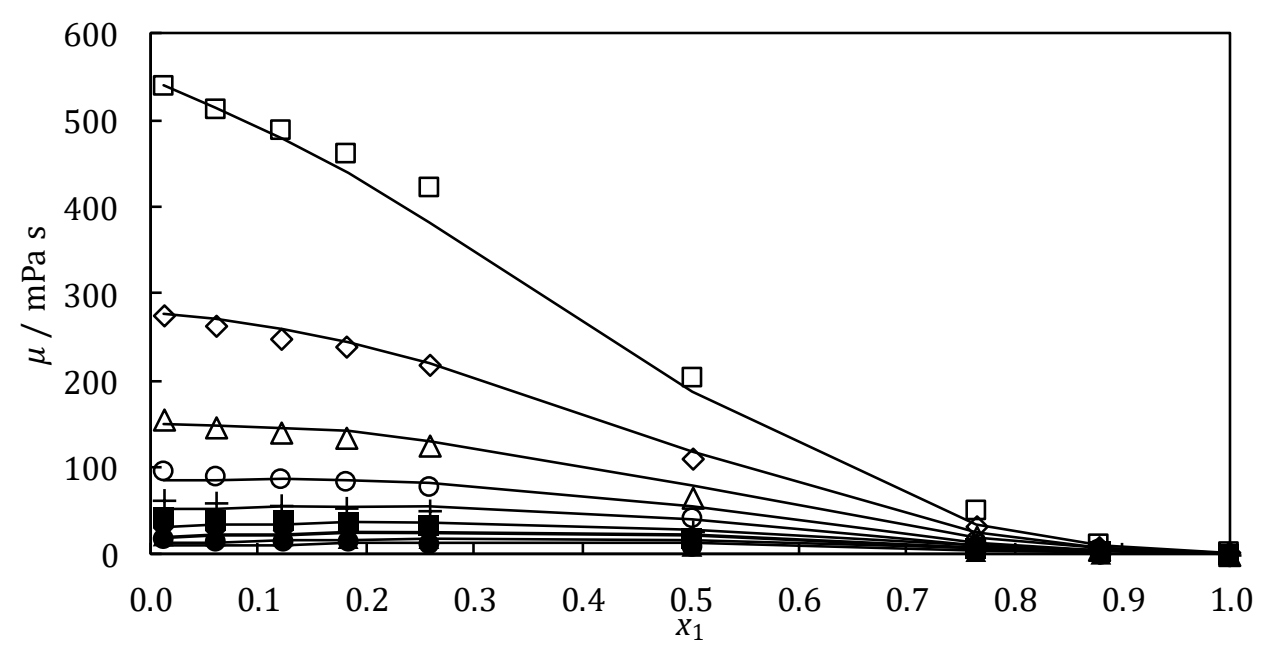

Figura 12. Viscosidad experimental $\mu$ de mezclas de $\mathrm{H}_{2} \mathrm{O}(1)+[$ EtMeIm] $]\left[\mathrm{Et}_{2} \mathrm{PO}_{4}\right]$ - a 293.15 $\mathrm{K}(\square)$; $303.15 \mathrm{~K}(\diamond) ; 313.15 \mathrm{~K}(\Delta)$; $323.15 \mathrm{~K}(\bigcirc)$; $333.15 \mathrm{~K}(+)$; $343.15 \mathrm{~K}(\mathbf{\square}) ; 353.15 \mathrm{~K}$ $(\diamond) ; 363.15 \mathrm{~K}(\mathbf{\Delta}) ; 373.15 \mathrm{~K}(\bullet)$ en función de la fracción molar de agua $x_{1}$. Las líneas sólidas representan la predicción. 


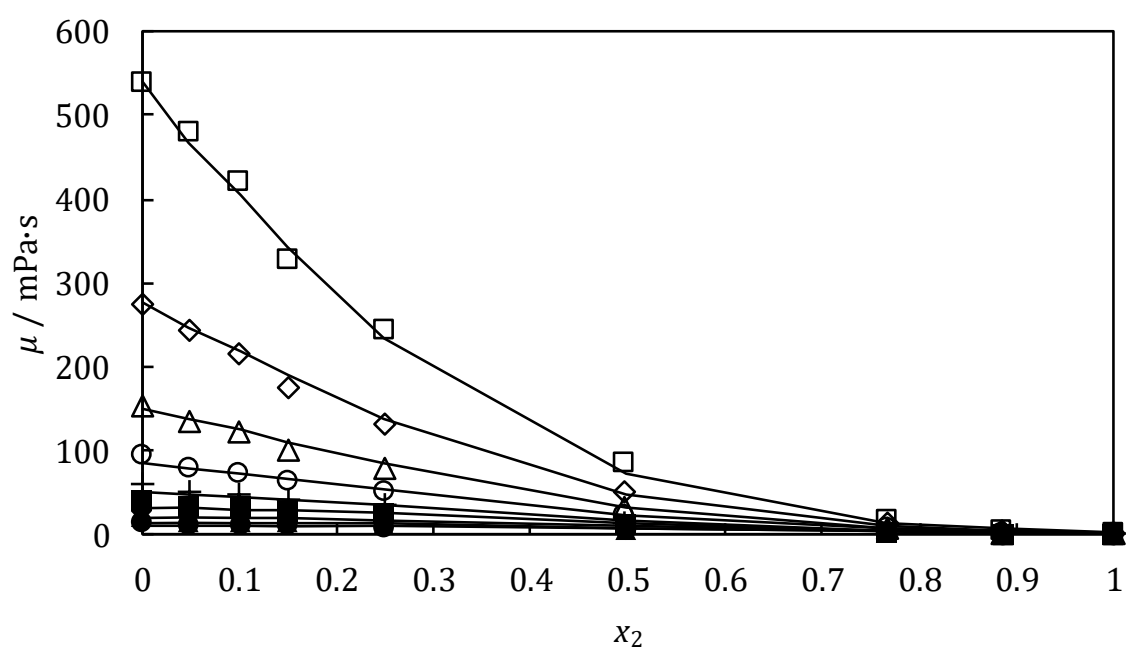

Figura 13. Viscosidad experimental $\mu$ de mezclas de DMSO (2) $+[\text { EtMeIm }]^{+}\left[\mathrm{Et}_{2} \mathrm{PO}_{4}\right]^{-}$at $293.15 \mathrm{~K}(\square)$; $303.15 \mathrm{~K}(\diamond) ; 313.15 \mathrm{~K}(\Delta)$; $323.15 \mathrm{~K}(\bigcirc)$; $333.15 \mathrm{~K}(+)$; $343.15 \mathrm{~K}(\mathbf{\square})$; 353.15 K ( $(\diamond)$; $363.15 \mathrm{~K}(\boldsymbol{\Delta})$; $373.15 \mathrm{~K}(\bullet)$ en función de la fracción molar de DMSO x2. Las líneas sólidas representan la predicción.

En la Parte III se estudia el equilibrio de fase de sistemas que contienen líquidos iónicosy $\mathrm{CO}_{2}$, así como la ampliación de la ecuación de estado de contribución de grupos (EdE-CG). En el Capítulo 5 se usan datos experimentales de la literatura para modelar dos nuevos grupos y de esta manera extender la EdE-CG. Se usaron datos de coeficientes de dilución infinita de diferentes compuestos en líquidos iónicos de las familias dimetilfosfato y dietilfosfato de 1-alquil-3-metilimidazolio, [-MeIm] $]^{+}\left[\mathrm{Me}_{2} \mathrm{PO}_{4}\right]^{-}$y $[-\mathrm{MeIm}]^{+}\left[\mathrm{Et}_{2} \mathrm{PO}_{4}\right]^{-}$ respectivamente. En este capítulo fueron estimados los parámetros de grupo puro, como los parámetros de interacción binaria con los subgrupos $\mathrm{CH}_{3}, \mathrm{CH}_{2}, \mathrm{ACH}, \mathrm{AC}, \mathrm{ACCH}, \mathrm{CH}_{2}=\mathrm{CH}$. Los resultados muestran una buena capacidad predictiva para los nuevos parámetros obtenidos.

Las Tablas 1 y 2 muestran los nuevos parámetros calculadosy los parámetros presentes en la bibliografía e igualmente usados durante la correlación. 
Tabla 1. Parámetros de grupo puro de EdE-CG. $T_{\mathrm{i}}{ }^{*}$ es la temperatura de referencia, $q_{\mathrm{i}}$ es el área superficial del grupo $i$ y $g^{*}, g^{\prime}, \mathrm{y} g^{\prime \prime}$ son los parámetros energéticos de grupo puro y su dependencia con la temperatura.

\begin{tabular}{|c|c|c|c|c|c|c|}
\hline Grupo & $T^{*} / \mathrm{K}$ & $q$ & $g^{*} / \mathrm{atm} \cdot \mathrm{cm}^{6} \cdot \mathrm{mol}^{-2}$ & $g^{\prime}$ & $g^{\prime \prime}$ & Fuente \\
\hline$-\mathrm{MeImMe}_{2} \mathrm{PO}_{4}$ & 600 & 4.8513 & 1154081 & -0.2941 & 0 & Este trabajo \\
\hline$-\mathrm{MeImEt}_{2} \mathrm{PO}_{4}$ & 600 & 6.0116 & 1170489 & -0.1153 & 0 & Este trabajo \\
\hline $\mathrm{CH}_{3}$ & 600 & 0.848 & 316910 & -0.9274 & 0 & 23 \\
\hline $\mathrm{CH}_{2}$ & 600 & 0.540 & 356080 & -0.8755 & 0 & 23 \\
\hline $\mathrm{ACH}$ & 600 & 0.400 & 723210 & -0.606 & 0 & 23 \\
\hline $\mathrm{AC}$ & 600 & 0.285 & 723210 & -0.606 & 0 & 23 \\
\hline $\mathrm{ACCH}_{3}$ & 600 & 0.968 & 506290 & -0.8013 & 0 & 23 \\
\hline $\mathrm{CH}_{2}=\mathrm{CH}$ & 600 & 1.176 & 337980 & -0.6764 & 0 & 23 \\
\hline
\end{tabular}

Tabla 2. Parámetros de interacción binaria de EdE-CG correlacionados en este trabajo.

\begin{tabular}{|c|c|c|c|c|c|c|}
\hline Grupo $i$ & Grupo $j$ & $k_{i j}^{*}$ & $k_{i j}^{\prime}$ & $\alpha_{i j}$ & $\alpha_{j i}$ & Fuente \\
\hline \multirow[t]{6}{*}{$-\mathrm{MeImMe}_{2} \mathrm{PO}_{4}$} & $\mathrm{CH}_{3}$ & 1.0169 & -0.0477 & -1.868 & -3.1969 & Este trabajo \\
\hline & $\mathrm{CH}_{2}$ & 1.0169 & -0.0477 & -2.3677 & -1.1145 & Este trabajo \\
\hline & $\mathrm{ACH}$ & 0.9144 & 0.0939 & 0 & 0 & Este trabajo \\
\hline & $\mathrm{AC}$ & 0.9822 & -0.0761 & 4.0314 & -12.0482 & Este trabajo \\
\hline & $\mathrm{ACCH}_{3}$ & 0.8826 & 0.0618 & 12.8818 & -0.767 & Este trabajo \\
\hline & $\mathrm{CH}_{2}=\mathrm{CH}-$ & 1.0076 & 0.0894 & -2.0427 & -1.6513 & Este trabajo \\
\hline \multirow[t]{4}{*}{$-\mathrm{MeImEt}_{2} \mathrm{PO}_{4}$} & $\mathrm{CH}_{3}$ & 0.999 & -0.0084 & 8.7504 & -1.8958 & Este trabajo \\
\hline & $\mathrm{CH}_{2}$ & 0.999 & -0.0084 & 1.3137 & -1.0597 & Este trabajo \\
\hline & $\mathrm{ACH}$ & 0.9677 & 0.0614 & 0 & 0 & Este trabajo \\
\hline & $\mathrm{ACCH}_{3}$ & 0.9822 & 0.0563 & 1.5544 & -0.8988 & Este trabajo \\
\hline \multirow{5}{*}{$\mathrm{CH}_{3}$} & $\mathrm{CH}_{2}$ & 1 & 0 & 0 & 0 & 23 \\
\hline & $\mathrm{ACH}$ & 1.041 & 0.094 & 0.391 & 0.391 & 23 \\
\hline & $\mathrm{AC}$ & 1.041 & 0.094 & 0.391 & 0.391 & 23 \\
\hline & $\mathrm{ACCH}_{3}$ & 0.975 & 0 & 0 & 0 & 23 \\
\hline & $\mathrm{CH}_{2}=\mathrm{CH}-$ & 1 & 0 & 0 & 0 & 23 \\
\hline \multirow[t]{4}{*}{$\mathrm{CH}_{2}$} & $\mathrm{ACH}$ & 1.041 & 0.094 & 0.391 & 0.391 & 23 \\
\hline & $\mathrm{AC}$ & 1.041 & 0.094 & 0.391 & 0.391 & 23 \\
\hline & $\mathrm{ACCH}_{3}$ & 0.975 & 0 & 0 & 0 & 23 \\
\hline & $\mathrm{CH}_{2}=\mathrm{CH}-$ & 1 & 0 & 0 & 0 & 23 \\
\hline \multirow[t]{3}{*}{$\mathrm{ACH}$} & $\mathrm{AC}$ & 1 & 0 & 0 & 0 & 23 \\
\hline & $\mathrm{ACCH}_{3}$ & 1.007 & 0 & 0 & 0 & 23 \\
\hline & $\mathrm{CH}_{2}=\mathrm{CH}-$ & 0.984 & 0 & 0 & 0 & 23 \\
\hline \multirow[t]{2}{*}{$\mathrm{AC}$} & $\mathrm{ACCH}_{3}$ & 1.007 & 0 & 0 & 0 & 23 \\
\hline & $\mathrm{CH}_{2}=\mathrm{CH}-$ & 0.984 & 0 & 0 & 0 & 23 \\
\hline $\mathrm{ACCH}_{3}$ & $\mathrm{CH}_{2}=\mathrm{CH}-$ & 1.034 & 0 & 0 & 0 & 23 \\
\hline
\end{tabular}




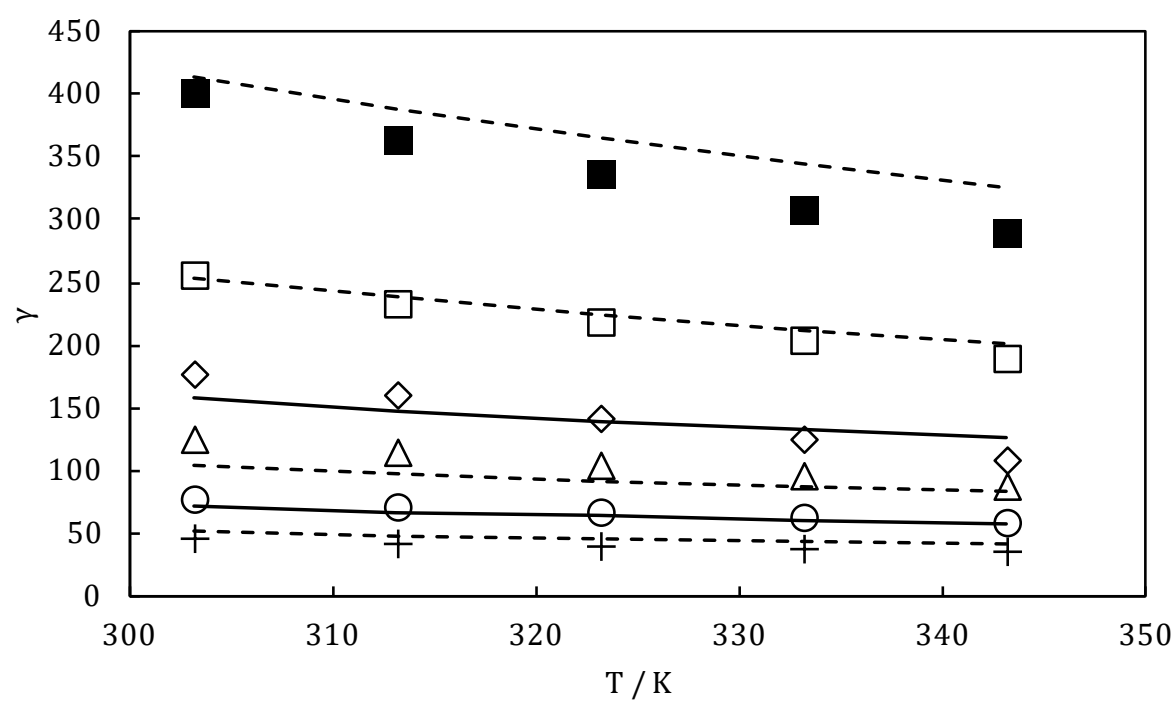

Figura 14. Coeficientes de actividad a dilución infinita $(\gamma)$ en [EtMeIm]+ $\left[\mathrm{Et}_{2} \mathrm{PO}_{4}\right]^{-}$en función de la temperatura $(T)$ de diferentes hidrocarbonos: Decano $(\boldsymbol{\square})$; Nonano $(\square)$; Octano $(\diamond)$; Heptano $(\triangle)$; Hexano $(\bigcirc)$ and Pentano $(+)$. Líneas punteadas representan la correlación y las líneas sólidas representan la predicción de la EdE-CG.

Por último, en el Capítulo 6 se mide la solubilidad del $\mathrm{CO}_{2}$ en el líquido iónico dietilfosfato de 1-etil-3-metilimidazolio a $313.15 \mathrm{~K}, 333.15 \mathrm{~K}$ y $353.15 \mathrm{~K}$ hasta presiones de 60 bar. Los datos obtenidos, mostrados en la Figura 15, junto más datos de equilibrio de la bibliografía, sirvieron para extender la EdE-CG con los parámetros de interacción binaria de los grupos definidos en el capítulo anterior con $\mathrm{CO}_{2}$. En la Tabla 3 se muestran los parámetros obtenidos en la correlación. A presiones y temperaturas moderadas los datos de solubilidad obtenidos se ajustan bien a los datos de otros autores. La EdE-CG puede correlacionar los datos obtenidos de solubilidad con un \%ARD = 8.9\%. 


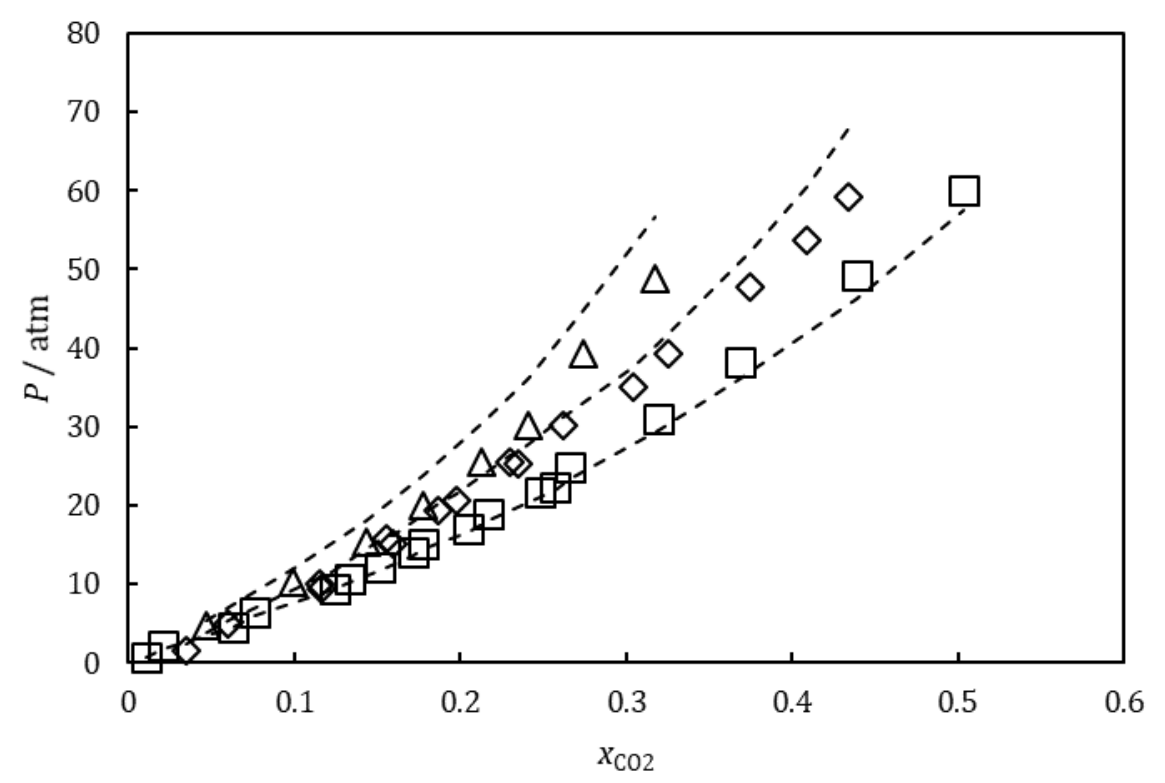

Figura 15. Solubilidad de $\mathrm{CO}_{2}$ en [EtMeIm] $\left[\mathrm{Et}_{2} \mathrm{PO}_{4}\right]$ - a $313.15 \mathrm{~K}(\mathrm{O}) ; 333.15 \mathrm{~K}(\square)$ y 353.15 $\mathrm{K}(\diamond)$ y la correlación de la EdE-CG en líneas punteadas.

Tabla 3. Parámetros de interacción binaria de EdE-CG correlacionados en este trabajo.

\begin{tabular}{llclrrl}
\hline Grupo $i$ & Grupo $j$ & \multicolumn{1}{c}{$k_{i j}^{*}$} & \multicolumn{1}{c}{$k_{i j}^{\prime}$} & $\alpha_{i j}$ & $\alpha_{j i}$ & Fuente \\
\hline$-\mathrm{MeImMe}_{2} \mathrm{PO}_{4}$ & $\mathrm{CH}_{3}$ & 1.0169 & -0.0477 & -1.868 & -3.1969 & Capítulo 5 \\
& $\mathrm{CH}_{2}$ & 1.0169 & -0.0477 & -2.3677 & -1.1145 & Capítulo 5 \\
& $\mathrm{CO}_{2}$ & 1.1044 & 0 & -5.0422 & -1.6967 & Este trabajo \\
$-\mathrm{MeImEt}_{2} \mathrm{PO}_{4}$ & $\mathrm{CH}_{3}$ & 0.999 & -0.0084 & 8.7504 & -1.8958 & Capítulo 5 \\
& $\mathrm{CH}_{2}$ & 0.999 & -0.0084 & 1.3137 & -1.0597 & Capítulo 5 \\
& $\mathrm{CO}_{2}$ & 1.2603 & 0 & -6.2462 & 2.4642 & Este trabajo \\
& & & & & & 46 \\
$\mathrm{CH}_{3}$ & $\mathrm{CH}_{2}$ & 1 & 0 & 0 & 0 & 46 \\
& $\mathrm{CO}_{2}$ & 0.892 & 0 & 3.369 & 3.369 & 46 \\
$\mathrm{CH}_{2}$ & $\mathrm{CO}_{2}$ & 0.814 & 0 & 3.369 & 3.369 & 46 \\
\hline
\end{tabular}




\section{Conclusiones}

En esta tesis se determinaron y correlacionaron los datos termodinámicos de varios líquidos iónicos de interés para el procesamiento de biomasa. En particular:

- Las densidades, viscosidades y presiones de vapor de las mezclas DMSO + [Amim] $[\mathrm{Cl}]$ se determinaron a presión atmosférica y densidades también a altas presiones de hasta 35 MPa a temperaturas entre $293.15 \mathrm{~K}$ y $373.15 \mathrm{~K}$ у $X_{\text {DMSO }}=0,0.05,0.1,0.15,0.25,0.5,0.75,0.9$ y 1.

- Se encontró que la densidad disminuye con la temperatura y la fracción molar DMSO y aumenta con la presión. Se correlacionó en función de la temperatura, presión y composición de la mezcla. Se consiguió un buen ajuste con un \%ARD $=0.12 \%$. Los volúmenes molares de exceso de las mezclas se calcularon utilizando densidades experimentales. Se encontró que eran negativos con un mínimo de alrededor de $x_{\text {DMSO }}=0.5$.

- Se encontró que las viscosidades disminuyen con la temperatura y con la concentración de DMSO. La correlación de la viscosidad se realizó en función de la temperatura y la concentración con dos modificaciones de la correlación de Grunberg y Nissan, una para todo el rango de concentraciones y otra para concentraciones inferiores a 0.25 en la fracción molar DMSO. El primero tiene una desviación relativa promedio $(\mathrm{ARD} \%)=6.8 \%$ y $\% \mathrm{Max}=30.7 \%$ y el segundo tiene una $\mathrm{ARD} \%=16.3 \%$ y $\% \operatorname{Max}=45.2 \%$.

Las presiones de vapor de las mezclas DMSO $+[\mathrm{Amim}][\mathrm{Cl}]$ se midieron a $\mathrm{T}=[353.1$, 433.1] K. Se observaron desviaciones positivas a bajas concentraciones de DMSO mientras que a altas concentraciones el comportamiento se aproxima a la Ley de Raoult. Las mediciones se correlacionaron con el modelo NRTL (Non-Random-TwoLiquid), obteniendo un ARD\% entre 5 y $12 \%$.

- Se determinaron las densidades y viscosidades experimentales de las mezclas agua + dietilfosfato de 1-etil-3-metilimidazolium y DMSO + dietilfosfato de 1-etil-3-metilimidazolio en un rango de temperaturas comprendido entre $293.15 \mathrm{~K}$ y $373.15 \mathrm{~K}$ y fracciones molares del co-disolvente $0,0.05,0.1,0.15,0.25,0.5,0.75,0.9$ y 1 . Los volúmenes molares de exceso también se calcularon presentando ambos sistemas valores negativos.

- Se encontró que las viscosidades disminuyen con la temperatura y la concentración de disolventes. Los datos de viscosidad se correlacionaron con las correlaciones modificadas de Grunberg y Nissan, obteniendo buenos resultados con \%AARD = 13 $\%$ para las mezclas con agua y \%AARD $=9.5 \%$ para las mezclas con DMSO. 
- Se encontró que las densidades disminuyen linealmente con la temperatura y con la concentración del co-disolvente. El sistema estudiado presenta una desviación positiva del comportamiento ideal, lo que implica un volumen de exceso negativo. Las mezclas de líquido iónico con agua son menos ideales que las mezclas con DMSO. La influencia de la temperatura de ambos sistemas en el volumen de exceso es completamente inversa, en las mezclas acuosas el valor absoluto del volumen de exceso disminuye con la temperatura, mientras que en las mezclas con DMSO el volumen de exceso aumenta con la temperatura.

- La tabla de parámetros del EdE-CG se amplió para modelar dos nuevas familias de líquidos iónicos, a saber, el dimetilfosfato de 1-alquil-3-metilimidazolio y el dietilfosfato de 1-alquil3-metilimidazolio. Esto requirió la definición de dos nuevos grupos, [-MeIm]-[ $\left.\mathrm{Me}_{2} \mathrm{PO}_{4}\right]^{+}$y [MeIm]-[Et $\left.\mathrm{PO}_{4}\right]^{+}$, y el ajuste de sus parámetros de energía pura e interacción binaria con otros grupos funcionales: $\mathrm{CH}_{3}, \mathrm{CH}_{2}, \mathrm{ACH}, \mathrm{AC}, \mathrm{ACCH}_{3}, \mathrm{CH}_{2}=\mathrm{CH}$ y $\mathrm{CO}_{2}$. Los resultados muestran una buena correlación de los datos experimentales; es posible describir los coeficientes de actividad de dilución infinita $(\gamma)$ con un ARD\% $(\gamma)$ de 4.52\%.

- La solubilidad del $\mathrm{CO}_{2}$ en[EtMeIm] $+\left[\mathrm{Et}_{2} \mathrm{PO}_{4}\right]^{-}$ha sido determinada experimentalmente para las temperaturas dentro del rango $\mathrm{T}=[313.15,333.15,350.15]$. $\mathrm{K}$ y presiones de hasta 60 bar. La solubilidad aumenta con la presión y disminuye con la temperatura. Las solubilidades alcanzaron valores de hasta 0.5 fracción molar a $313.15 \mathrm{~K}$ y 60 bar. Es posible describir el VLE con $\mathrm{CO}_{2}$ usando EdE-CG con un ARD\% $=2.6 \%$ para la familia del dimetilfosfato de 1-alquil-3-metilimidazolio IL y un ARD\% $=8.9 \%$ para la familia del dietilfosfato de 1-alquil-3-metilimidazolio utilizando los nuevos parámetros determinados en este trabajo. 


\section{About the author:}

Laura de Pablo was born in Valladolid, Spain, the August 30th of 1989. She studied Chemical Engineering in the University of Valladolid, between October 2012 and August 2013 she got an Erasmus scholarship to carry out the final project in the Bayreuth University, Germany. From July 2014 and June 2015 Laura has been working as a R\&D Project Manager in Proyectos Ingeniería y Gestión S.A. (PROINGESA) in Valladolid. At the same time, from September 2014 to August 2015, she coursed the Master Degree in Fluid Thermodynamics Engineering in the University of Valladolid.

In November 2015 Laura started her Ph.D. in the High-Pressure Processes Group. During the Ph.D. Laura completed its research work at with PLAPIQUI (CONICET) in Argentina under the supervision of Dr. Selva Pereda.

\section{List of publications}

Rodríguez-Rojo, S.; de Pablo, L.; Martín, A.; Cocero, M. J. Solubility of Bisphenol A in Supercritical Carbon Dioxide. J. Chem. Eng. Data 2011, 56 (10), 3910-3913.

de Pablo Nisa, L.; Segovia, J. J.; Martín, Á.; Martín, M. C.; Bermejo, M. D. Determination of Density and Excess Molar Volume of Dimethyl Sulfoxide + 1-Allyl-3-Methylimidazolium Chloride Mixtures at High Pressure. J. Supercrit. Fluids 2017, 130, 76-83.

de Pablo, L.; Segovia Puras, J. J.; Martín, C.; Bermejo, M. D. Determination of Density and Viscosity of Binary Mixtures of Water and Dimethyl Sulfoxide with 1-Ethyl-3Methylimidazolium Diethylphosphate $[\mathrm{EtMeIm}]+\left[\mathrm{Et}_{2} \mathrm{PO}_{4}\right]-$ at Atmospheric Pressure. J. Chem. Eng. Data 2018, 63 (4), 1053-1064.

de Pablo, L.; Segovia, J. J.; Martín, A.; Martín, M. C.; Bermejo, M. D. Determination of Density, Viscosity and Vapor Pressures of Mixtures of Dimethyl Sulfoxide + 1-Allyl-3Methylimidazolium Chloride at Atmospheric Pressure. J. Chem. Thermodyn. 2018. (In press)

\section{Presentations:}

De Pablo, L., Cantera, P.D., Pereda, S., Segovia, J.J., Martín, A., Martín M.C., Bermejo MD, Influence of co-solvents in the physical properties of Ionic Liquids" Poster in 10 $0^{\text {th }}$ World Congress of Chemical Engineering - WCCE 2017, Barcelona, 1st-5th October 2017.

De Pablo, L., Sánchez, F.A., Bermejo, M.D., Pereda, S., Ionic Liquids, application and measurement. Modeling with GC EoS, Invited Oral Communication in the Chemistry 
Department, College of Natural and Computational Sciences, Addis Ababa University, Ethiopia.

De Pablo, L., Sánchez, F.A., Bermejo, M.D., Pereda, S., Líquidos iónicos: Aplicaciones, medida y Modelado con la GC-EoS, oral presentation in Investigadoras de la UVa en la Aventura de la Ciencia y de la Tecnología, Valladolid, 2nd March 2018. 


\title{
Agradecimientos
}

En primer lugar, quiero agradecer a mis tutoras, las profesoras Dra. Ma Dolores Bermejo y Dra. Selva Pereda por todo lo que aprendí, por vuestra confianza y ánimos.

También a los profesores Dra. Mํㅡㄹ José Cocero y Dr. Ángel Martín y al grupo de investigación TERMOCAL Dr. José Juán Segovia, Dra. Maㅡ Carmen Martín, Dr. César Chamorro, Dra. Rosa María Villamañán y Dr. Miguel Ángel Villamañán por vuestra ayuda, consejos y motivación admirable. En especial quiero agradecer a Dr. Ángel Gómez por toda la ayuda brindada.

A mis amigos y compañeros de laboratorio, los de acá y los de allá, por vuestros consejos, amistad y compañía. Tuve el gran placer y el honor de trabajar con personas de admirable talento y dedicación. Muchas gracias a todos.

A mi familia y amigos que siempre estuvisteis a mi lado en este camino.

\author{
Doctora en Ingeniería \\ quién me lo iba a decir \\ que lo más importante \\ fueron las personas \\ a las que conocí
}

